Issued by Sandia National Laboratories, operated for the United States Department of Energy by Sandia Corporation.

NOTICE: This report was prepared as an account of work sponsored by an agency of the United States Government. Neither the United States Government, nor any agency thereof, nor any of their employees, nor any of their contractors, subcontractors, or their employees, make any warranty, express or implied, or assume any legal liability or responsibility for the accuracy, completeness, or usefulness of any information, apparatus, product, or process disclosed, or represent that its use would not infringe privately owned rights. Reference herein to any specific commercial product, process, or service by trade name, trademark, manufacturer, or otherwise, does not necessarily constitute or imply its endorsement, recommendation, or favoring by the United States Government, any agency thereof, or any of their contractors or subcontractors. The views and opinions expressed herein do not necessarily state or reflect those of the United States Government, any agency thereof, or any of their contractors.

Printed in the United States of America. This report has been reproduced directly from the best available copy.

Available to DOE and DOE contractors from

U.S. Department of Energy

Office of Scientific and Technical Information

P.O. Box 62

Oak Ridge, TN 37831

Telephone: (865)576-8401

Facsimile: (865)576-5728

E-Mail: reports@adonis.osti.gov

Online ordering: http://www.doe.gov/bridge

Available to the public from

U.S. Department of Commerce

National Technical Information Service

5285 Port Royal Rd

Springfield, VA 22161

Telephone: (800)553-6847

Facsimile: (703)605-6900

E-Mail: orders@ntis.fedworld.gov

Online order: http://www.ntis.gov/ordering.htm

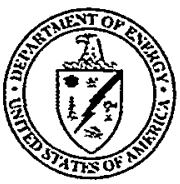




\section{DISCLAIMER}

Portions of this document may be illegible in electronic image products. Images are produced from the best available original document. 
SAND2000-2679

Unlimited Release

Printed November 2000

\title{
Mechanical Properties of Cold Gas-Dynamic Spray Nickel
}

\author{
Merlin K. Decker \\ Advanced \& Exploratory Systems Department \\ Sandia National Laboratories \\ P.O. Box 5800 \\ Albuquerque, NM 87185-0481 \\ Dr. Hy D. Tran and Dr. Yu-Lin Shen \\ University of New Mexico \\ Department of Mechanical Engineering \\ Mechanical Engineering Building \\ Albuquerque, NM 87131
}

\begin{abstract}
The Cold Gas-Dynamic Spray Method (CGSM) is a technique to produce freestanding structures or coatings from powder feedstocks, on metallic, polymeric, or ceramic substrates, through the use of high particle velocities achieved by the control of gas dynamics in a converging-diverging nozzle. The freestanding structures and coatings are formed by the energetic impact of particles, whereby inter-particle bonding is governed by deformation of the particles. This investigation attempts to understand the mechanical properties of CGSM freestanding structures. Imaging and testing techniques include metallographic imaging, ultrasonic, indentation, hardness, tension, and compression.

Characterization of these freestanding structures is subjective since the final product of any thermal spray process produces a material unlike any other material formed by conventional techniques. Specifically, this investigation is to determine the mechanical characteristics of nickel, which are well characterized in bulk material forms. Experimentation and imaging techniques to characterize the freestanding structures are (1) metallographic imaging for examination; (2) ultrasonic testing to estimate the elastic
\end{abstract}


constants and ultrasonic imaging to check for consistency; (3) indentation testing to estimate the type of residual stress; (4) hardness testing to estimate the ultimate strength; and (5) tension and compression testing to estimate strength properties. In addition, finite element modeling simulations of one and two particle impact were performed.

The metallographic imaging showed that as-sprayed nickel has slightly more voids than the heat-treated structures. Ultrasonic testing of the as-sprayed nickel showed nominal shear moduli, Poisson's ratios, and Young's moduli close to typical values of bulk nickel, yet showing anisotropy. After the heat treatment, the material was nearly isotropic. Ultrasonic imaging showed the heat-treated nickel was much more consistent. Indentation testing proved the residual stress of as-sprayed nickel was in compression. Hardness testing showed the as-sprayed nickel was much harder than the heat-treated, sprayed nickel, therefore having greater ultimate strength. Tensile tests of as-sprayed nickel showed little plastic behavior. Heat treatment gives much more ductility without compromising ultimate strength. Compression tests indicate as-sprayed nickel has high yield strength but low ductility. After heat treatment, yield strength dropped but ductility increased. Finite element modeling indicates the material will have residual stresses.

\section{Keywords}

Thermal Spray, Cold Spray, Cold Gas-Dynamic Spray, LIGA, Electroplating, Coating, Metallographic Imaging, Mechanical Properties, Mechanical Testing, Ultrasonic Testing, Acoustic Testing, Indentation Testing, Sharp Indentation Testing, Nanoindentation Testing, Residual Stress, Hardness Testing, Tension Testing, Compression Testing, Finite Element Model, Nickel

\section{Acknowledgements}

I heartily acknowledge Dr. Hy Tran, my advisor and thesis chair, for continuing to encourage me through the years. His encouragement will remain with me as I continue my career. I also would like to thank my committee members, Dr. Yu-Lin Shen and Dr. John Wood, for their valuable recommendations pertaining to this study and assistance in my professional development. To Kent Meeks, my manager at Sandia National Laboratories, for his continued support and funding to pursue this research. To Ray Cote, Rich Neiser, and Mark Smith, for the use of the Thermal Spray Research Laboratory, I thank you. Also, many thanks go to Henry Apodaca for his machining skills and Gary Gallegos for his heat treatment assistance. Finally, I wish to acknowledge George Blann, John Gieske, Adam Harris, Alice Kilgo, Mark Rodriguez, David Schmale, and Gary Zender for their support and assistance with the material testing and imaging. 


\section{Table of Contents}

List of Figures......................................................................................................... vii

List of Tables ....................................................................................................... ix

List of Symbols....................................................................................................... xi

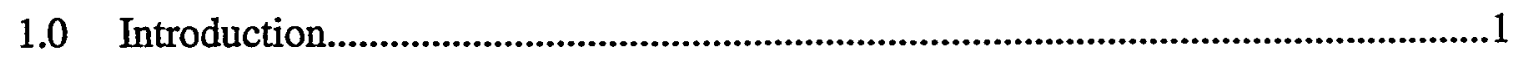

2.0 Background Art .....................................................................................................

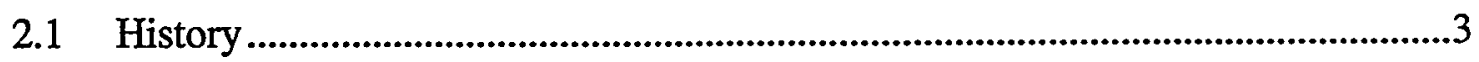

2.2 Numerical Modeling and Simulations..............................................................5

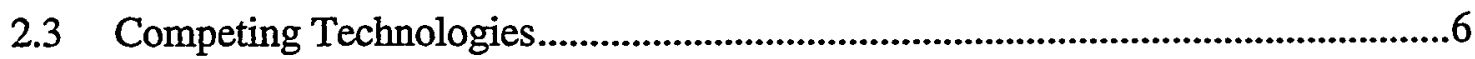

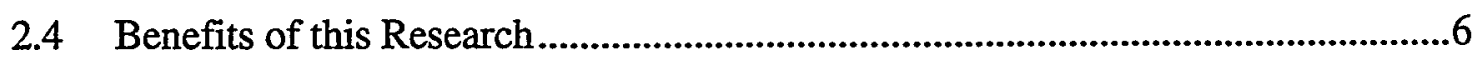

3.0 CGSM Experimentation, Parameters, and Post Processing........................................ 8

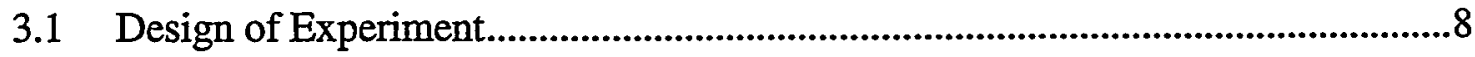

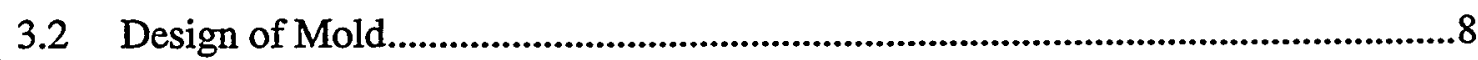

3.3 Cold Gas-Dynamic Spray ..................................................................................10

3.4 Post Cold Gas-Dynamic Spray Processing ..............................................................12

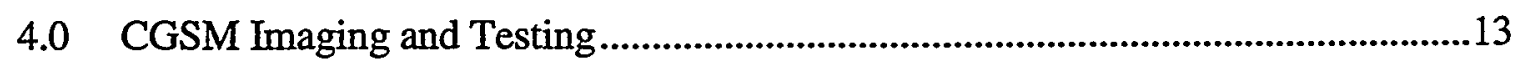

4.1 Microstructure Investigations...........................................................................13

4.1.1 X-Ray Diffraction .......................................................................................13

4.1.2 Metallographic Imaging............................................................................15

4.2 Ultrasonic Testing ....................................................................................19

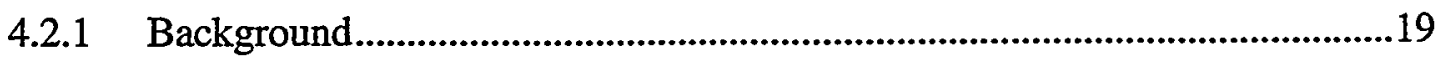

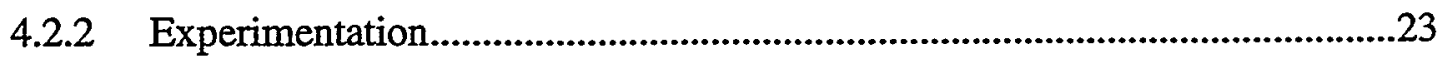

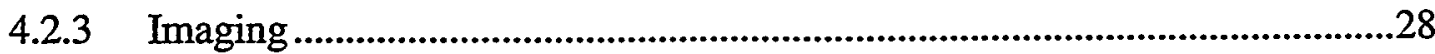

4.3 Sharp Indentation Testing .................................................................................30

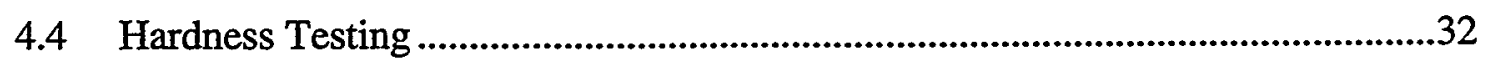

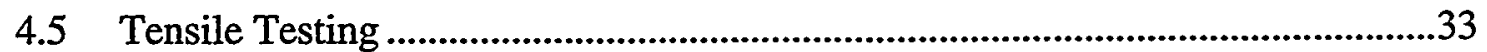

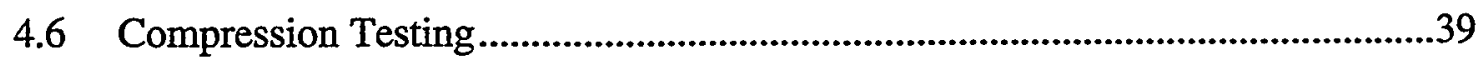

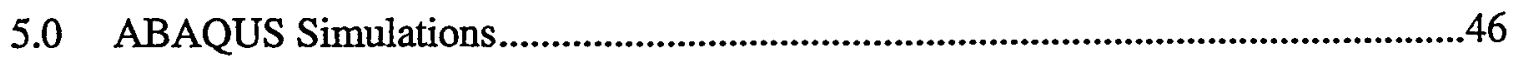

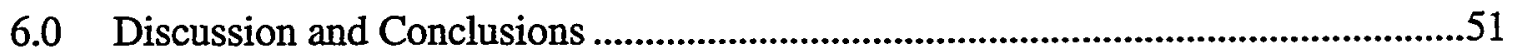

7.0 Looking Forward ...................................................................................................53 


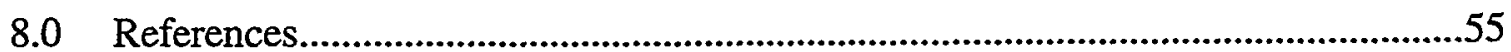

9.0 Appendix A, Deposition Rates .......................................................................58

10.0 Appendix B, Speed of Sound...........................................................................60

11.0 Appendix C, Uncertainty Analysis of Elastic Constants ...........................................61

11.1 Model of Aluminum as an Example....................................................................67

12.0 Appendix D, ABAQUS Input Files ....................................................................70

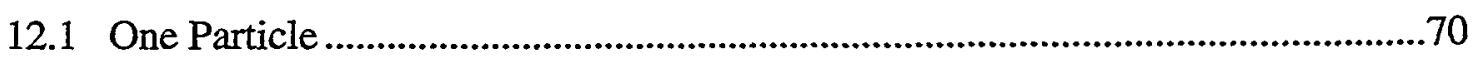

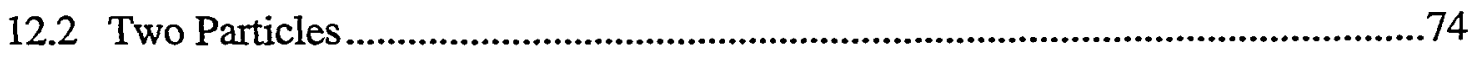

13.0 Appendix E, ABAQUS Status Files ...................................................................79

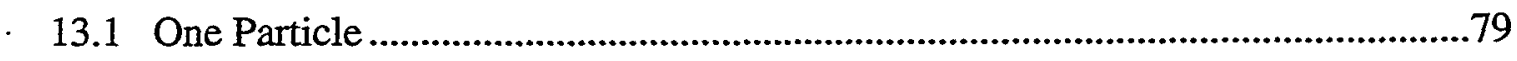

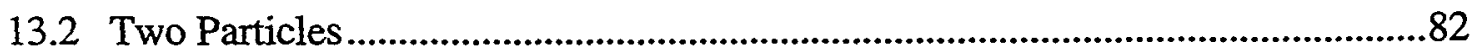

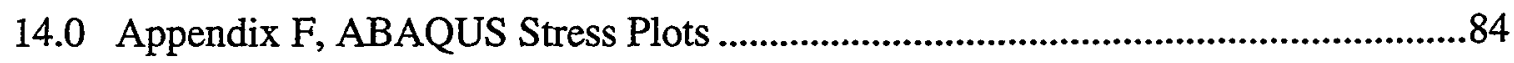

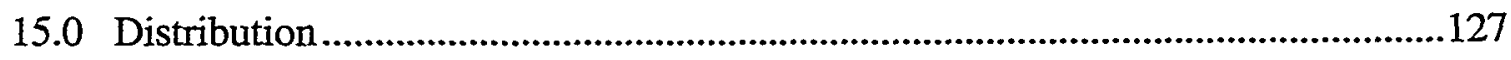




\section{List of Figures}

Figure 1, Equipment schematic of the Cold Gas-Dynamic Spray Method.........................4

Figure 2, Schematic of the one-dimensional cold gas-dynamic spray experiment............8

Figure 3, Design of mold for cold gas-dynamic spray nickel, drawn in inches.................9

Figure 4, Sample mold for cold gas-dynamic spray nickel..............................................10

Figure 5, Equipment setup to cold gas-dynamic spray nickel into a copper mold (top). Close-up view of copper mold as it is being filled with nickel (bottom)........11

Figure 6, Theta-two-theta scan of the cold gas-dynamic spray nickel in the as-sprayed condition.

Figure 7, Theta-two-theta scan of the cold gas-dynamic spray nickel in the heat-treated condition.

Figure 8, Top view micrographs of the nickel grain structure. The left column shows the as-sprayed condition, while the right column shows the heat-treated condition. Magnifications are 100x, 500x, and 1000x

Figure 9, Side view micrographs of the nickel grain structure. The left column shows the as-sprayed condition, while the right column shows the heat-treated condition. Magnifications are $20 x$ and $100 x$

Figure 10, Side view micrographs of the nickel grain structure. The left column shows the as-sprayed condition, while the right column shows the heat-treated condition. Magnifications are $500 \times$ and $1000 \times$.

Figure 11, Ultrasonic, signal amplitude images of the cold gas-dynamic spray nickel in the as-sprayed (left) and heat-treated (right) conditions.

Figure 12, Ultrasonic, pulse-echo time images of the cold gas-dynamic spray nickel in the as-sprayed (left) and heat-treated (right) conditions.

Figure 13, Actual indentation load vs. displacement of loading and unloading for cold gas-dynamic spray nickel in the as-sprayed and heat-treated conditions.

Figure 14, Modeled indentation load vs. displacement of loading and unloading for cold gas-dynamic spray nickel in the as-sprayed and heat-treated conditions. ........31

Figure 15, Details of tensile specimen, drawn in $\mathrm{mm}$. 
Figure 16, Tension test, engineering stress vs. engineering strain for cold gas-dynamic spray nickel in the as-sprayed condition. .35

Figure 17, Tension test, engineering stress vs. engineering strain for cold gas-dynamic spray nickel in the as-sprayed condition. .35

Figure 18, Tension test, engineering stress vs. engineering strain for cold gas-dynamic spray nickel in the heat-treated condition.

Figure 19, Tension test, engineering stress vs. engineering strain for cold gas-dynamic spray nickel in the heat-treated condition. 37

Figure 20, SEM images of the fracture area of the as-sprayed, tension test specimen 4 .

Figure 21, SEM images of the fracture area of the heat-treated, tension test specimen 8 .

Figure 22, Details of compression specimen, drawn in $\mathrm{mm}$.

Figure 23, Compression test, engineering stress vs. engineering strain for cold gas-dynamic spray nickel in the as-sprayed condition.

Figure 24, Compression test, engineering stress vs. engineering strain for cold gas-dynamic spray nickel in the heat-treated condition.

Figure 25, SEM images of the fracture area of the as-sprayed, compression test specimen 4 .

Figure 26, SEM image of the buckle in the heat-treated, compression test specimen $8 . . .45$

Figure 27, Two-dimensional ABAQUS mesh representing a single nickel particle and an existing nickel coating. 46

Figure 28, Two-dimensional ABAQUS mesh representing two nickel particles and an existing nickel coating.

Figure 29, Three SEM images of the "bowl" shaped phenomena represented in the ABAQUS simulations.

Figure 30, Kinetic energy vs. time for the ABAQUS impact simulations........................50

Figures 31 - 72, Forty-two ABAQUS stress plots at various simulation times. .85 


\section{List of Tables}

Table 1, Cold Gas-Dynamic Spray parameters used to deposit nickel. .10

Table 2, Measured mass, size, and time-of-flight velocities with tolerances for cold gas-dynamic spray nickel in the as-sprayed and heat-treated conditions.

Table 3, Calculations of density and wave velocities with uncertainties for as-sprayed nickel.

Table 4, Calculations of density and wave velocities with uncertainties for heat-treated, sprayed nickel.

Table 5, Elastic stiffness constants and uncertainties for as-sprayed nickel. .26

Table 6, Elastic stiffness constants and uncertainties for heat-treated, sprayed nickel...27

Table 7, Calculation of shear moduli, Poisson's ratios, and Young's moduli with bounds for as-sprayed nickel and published values for bulk nickel.

Table 8, Calculation of shear moduli, Poisson's ratios, and Young's moduli with bounds for heat-treated, sprayed nickel and published values for nickel

Table 9, Data obtained from Rockwell A hardness testing for cold gas-dynamic spray nickel in the as-sprayed and heat-treated conditions.

Table 10, Statistical analysis results of Rockwell A hardness testing for cold gas-dynamic spray nickel in the as-sprayed and heat-treated conditions. 33

Table 11, Young's modulus, yield strength, ultimate strength, and fracture strain, for cold gas-dynamic spray nickel in the as-sprayed condition, including typical values for bulk nickel and electroplated nickel.

Table 12, Young's modulus, yield strength, ultimate strength, and fracture strain, for cold gas-dynamic spray nickel in the heat-treated condition, including typical values for bulk nickel and electroplated nickel.

Table 13, Young's modulus, yield strength, ultimate strength, and fracture strain, for cold gas-dynamic spray nickel in the as-sprayed condition, including typical values for bulk nickel and electroplated nickel.

Table 14, Young's modulus, yield strength, maximum strength, and maximum strain, for cold gas-dynamic spray nickel in the heat-treated condition, including typical values for bulk nickel and electroplated nickel. 
Table 15, Young's modulus and yield strength compared between testing methods for cold gas-dynamic spray nickel in the as-sprayed condition, including typical values for bulk nickel and electroplated nickel...

Table 16, Young's modulus and yield strength compared between testing methods for cold gas-dynamic spray nickel in the heat-treated condition, including typical values for bulk nickel and electroplated nickel.

Table 17, Estimates of mass, size, and time-of-flight measurements with tolerances for aluminum.

Table 18, Estimates of density and wave velocities with uncertainties for aluminum. ....68

Table 19, Estimates of elastic stiffness constants and uncertainties for aluminum. .68

Table 20, Estimates of shear moduli, Poisson's ratios, and Young's moduli with bounds and the published values for aluminum .69 


\section{List of Symbols}

\begin{tabular}{ll}
$A$ & Area \\
$C$ & Elastic Constant \\
$c$ & Speed of Sound \\
$E$ & Young's Modulus \\
$\varepsilon_{f}$ & Fracture Strain \\
$\varepsilon_{f}^{*}$ & Strain at End of Test \\
$\mathfrak{I}$ & Faraday's Constant \\
$G$ & Shear Modulus \\
$h$ & Displacement \\
$I$ & Moment of Inertia \\
$J$ & Current Density \\
$k$ & Specific Heat Ratio \\
$m$ & Mass \\
$\dot{m}$ & Mass Feed Rate \\
$\eta$ & Efficiency \\
$V$ & Poisson's Ratio \\
$P$ & Load \\
$P_{c r}$ & Critical Load \\
$R$ & Gas Constant \\
$R^{2}$ & Correlation Coefficient \\
$\rho$ & Density \\
$s$ & Structure Thickness \\
$\sigma_{f}$ & Fracture Strength \\
$\sigma_{u}$ & Ultimate Strength \\
$\sigma_{u}^{*}$ & Strength at End of Test \\
$\sigma_{y}$ & Yield Strength \\
$T$ & Electroplating Thickness \\
$t_{p}$ & Plating Time \\
$t_{L}$ & Longitudinal Time-of-Flight \\
$t_{T}$ & Transverse Time-of-Flight \\
$\tau$ & Temperature \\
$U$ & Uncertainty \\
$V_{L}$ & Longitudinal Wave Velocity \\
$V_{L 45^{\circ}}$ & Longitudinal Wave Velocity in $45^{\circ}$ Plane \\
$V_{T}$ & Transverse Wave Velocity \\
& \\
\hline & \\
\hline &
\end{tabular}




\subsection{Introduction}

The objective of this investigation is to characterize nickel deposited by the Cold GasDynamic Spray Method (CGSM). The particular application of the nickel members deposited using the CGSM is in compression. It is necessary that the compression strength of the nickel members exceed the strength characteristics of bulk and electroplated nickel.

A potential, future application for the CGSM is as an alternative material deposition process to fabricate LIGA hardware from metals that cannot be deposited by an electroplating process. LIGA is an acronym derived from the German words for lithography, electroplating, and molding-Lithographie, Galvanoformung, and Abformung. The LIGA fabrication process is an additive process in which material is deposited, typically by electroplating, into a precision mold of polymethyl methacrylate (PMMA) realized through deep X-ray lithography [1].

Currently, the materials that can be readily deposited using the electroplating process are copper, nickel, permalloy ( $80 \% \mathrm{Ni}$ and $20 \% \mathrm{Fe}$ ), and gold. Developing alternatives to electroplating would allow designers the choice of using other materials, including ceramics and nonmetals, when designing freestanding mechanical structures. To best understand the properties of the CGSM and how its properties compare to the electroplating method, nickel was the baseline material chosen for this investigation.

In the CGSM, a supersonic jet of compressed gas is used to accelerate near-roomtemperature powder particles, typically 1 to 50 microns in diameter, and velocities in the range of 300 to $1200 \mathrm{~m} / \mathrm{s}$ [2]. Under proper conditions, when a solid powder particle impacts a solid surface, its kinetic energy is sufficient to cause plastic deformation and consolidation of the arriving particle with the underlying material, by a process thought to be analogous to explosive welding [3]. Because cold spray is a near-room-temperature, solid-state process, potential advantages of its use include eliminating cool-down induced stresses in the finished part and the possibility of avoiding undesirable phases, oxidation, and grain growth during the deposition process.

This investigation attempts to gain a thorough understanding of the material properties of CGSM freestanding structures. Testing techniques to investigate the material properties of these freestanding structures are ultrasonic, sharp indentation, hardness, tension, and compression testing. The characterization of freestanding structures produced by the CGSM is subjective since the final product of any thermal spray process produces a material unlike any other processing technique. Specifically, this investigation attempts to determine some of the mechanical characteristics of cold gas-dynamic spray nickel, which has an excellent knowledge base in traditional material forms. The experimentation and imaging techniques to characterize the freestanding structures are (1) Metallographic imaging to visually examine the coating; (2) Ultrasonic testing to estimate the elastic stiffness constants and ultrasonic imaging to visually examine the consistency of the freestanding structures; (3) Sharp indentation testing to predict the type, or sign, of residual stresses; (4) Hardness testing to estimate the ultimate strength of 
the material; and (5) Tension and compression testing to estimate yield and ultimate strength properties of the material. With all of these testing methods, varying results may be obtained for the same material property. This is intended to check testing, material and specimen consistency where possible.

In addition to investigating the material properties of CGSM freestanding structures, two ABAQUS finite element models were developed to simulate the deformation behavior of the nickel particles. One model simulates a single particle impacting an existing nickel coating, while the second model simulates two particles impacting an existing nickel surface. However, these models cannot simulate kinetic energy being converted to heat when there is extreme plastic deformation. It is believed that when the kinetic energy is converted to heat, a sintering process takes place, thereby fusing with the surrounding nickel coating.

Overall, this research attempts to investigate some material properties of cold gasdynamic spray nickel to determine if this deposition process can be produce freestanding, nickel members whose strength characteristics exceed that of bulk and electroplated nickel. Techniques to understand the mechanical properties of freestanding structures produced with the CGSM will be done through metallographic imaging and mechanical testing. Testing methods include ultrasonic, sharp indentation, hardness, tension, and compression testing. Finally, finite element models will be used to estimate the residual stresses in a freestanding, nickel structure. Each of these testing and modeling methods give a unique perspective to the material properties of nickel structures produced by the CGSM.

The experimental results indicate that nickel structures produced by the CGSM are best suited for high compression environments. Nickel tested in the as-sprayed condition exhibits high compressive strength properties, $300 \%$ more yield strength in compression than in tension. A stress relieving, heat treatment process will improve the ductility, but reduce the yield strength of nickel. However, the yield strength, determined from tension testing, is $30 \%$ weaker than electroplated nickel in tension. Therefore, the best use of the structures produced by the CGSM is in compression. 


\subsection{Background Art}

The Background Art is divided into several areas. First, the history of the Cold GasDynamic Spray Method (CGSM) is discussed from the time of the original United States patent. Once a patent was obtained, investigations were performed to determine what materials could be sprayed using the CGSM. Materials such as metals, alloys, and ceramics sprayed successfully using the CGSM. Then basic characterization and modeling of the CGSM, as well as some limited material property investigations were performed. Technologies that could potentially compete with the CGSM are discussed. The final discussion is about the contributions of this research to the CGSM.

\section{$2.1 \quad$ History}

Thermal spray coating processes may be broadly classified into two areas. The first process is where the feedstock material is molten by its introduction into an intense heated region, such as by flame, plasma, or arc prior to propulsion onto a substrate. The other process exploits high particle velocities, shorter transit times, and overall lower temperatures of the particle, called the Cold Gas-Dynamic Spray Method [4]. The latter process will be used to produce the nickel freestanding structures whose material properties will be investigated with this research.

The CGSM has been under development in Russia since the early 1990's by A.P. Alkhimov, A.N. Papyrin and their coworkers. United States Patent, 5,302,414, "GasDynamic Spraying Method for Applying a Coating," was awarded to A.P. Alkhimov on April 12, 1994 [5]. The CGSM for applying a coating to a substrate starts with a metal, alloy, polymer, or mechanical mixture of the particle, having a physical size from 1 to 50 microns in diameter. These particles are introduced into a gas stream and this mixture forms a supersonic jet having a temperature below the fusing temperature of the powder

material and a velocity ranging from 300 to $1200 \mathrm{~m} / \mathrm{s}$. This jet is then directed at a substrate of metal, alloy, or dielectric, creating a coating with these particles. A schematic of the equipment to produce this coating is shown in Figure 1. 


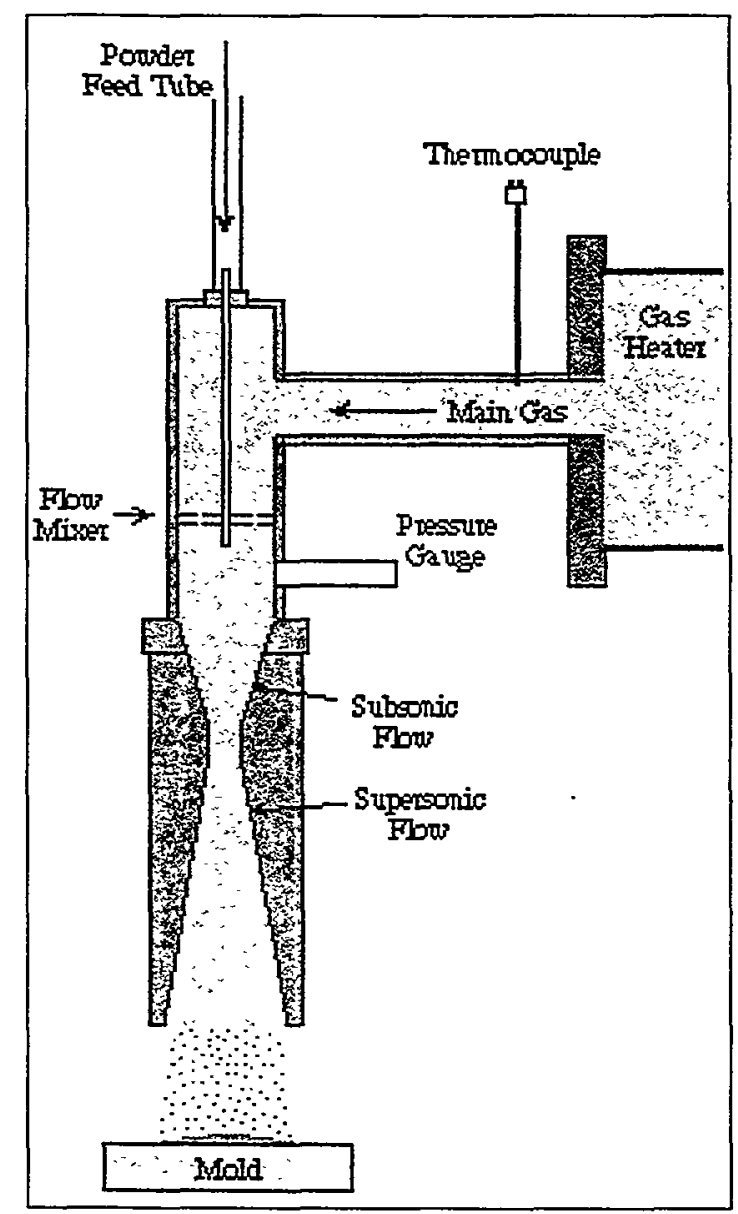

Figure 1, Equipment schematic of the Cold Gas-Dynamic Spray Method.

Early experiments of the CGSM studied the effect of particle velocity when forming coatings. One parameter that influenced the exit velocity was the type of gas used. When air was used, it would exit the nozzle at a velocity of $560 \mathrm{~m} / \mathrm{s}$, while helium would exit at a velocity of $1400 \mathrm{~m} / \mathrm{s}$. Realizing that particle velocity could be adjusted significantly, the hardness and porosity of an aluminum coating could be tailored to a certain extent. Additional metals and alloys that have been investigated to produce coatings include copper, nickel, cobalt, vanadium, iron, zinc, and titanium as well as mixtures of metal powders with various hard ceramic powder materials [6].

Once it was demonstrated that certain materials could be sprayed using the CGSM, characterization of the coatings has been performed in several areas. Porosity and particle deformation of a single layer of aluminum on steel have been investigated. Results showed particle deformation to range from $15 \%$ to $60 \%$. The middle portion of the coating had a uniform deformation of $30 \%$. The porosity of the aluminum coating proved to vary from $3 \%$ to $13 \%$. However, no parameter combination could give a coating without pores [7]. The microstructure and residual stress of copper on copper and steel on aluminum have also been investigated. Coatings produced from the copper 
powder tended to be brittle and much harder than commercially pure copper in wrought form. The residual stress in this coating was found to be uniform and compressive. Coatings produced from the steel powder indicated that the microhardness was significantly greater than that of cold-rolled plain carbon steel. The residual stress state for a coated aluminum substrate showed through-thickness variation extending to a highly compressive state near the interface with the substrate, and a net tensile residual stress in the substrate material at the junction [8]. Another study of two copper powders has also been investigated. The first type of copper powder was produced by a direct reduction process, while the other powder was produced by an inert gas atomization process. Scanning electron microscopy (SEM) photos showed that the powder particles produced by direct reduction had highly convoluted surfaces, while the gas-atomized particles are generally more spherical. Material properties investigated for the two types of copper powder include microhardness, Young's modulus, and through-coating residual stress distribution. An annealing study was also performed for both copper powders. In the direct reduction copper compacts, oxide limited the ability of the structure to adopt an equiaxed grain structure after an annealing process. The gas-atomized copper compacts showed grain growth uninhibited by oxide particles in the structure [9].

\subsection{Numerical Modeling and Simulations}

Numerical modeling, analysis, and experimentation to investigate the CGSM has been very limited, but much more work has been done to investigate the plasma spray method. A model was developed to predict residual stress in plasma sprayed coatings. This model accounts for the primary and secondary cooling processes. The three mechanisms considered are shrinkage of the spray particles after solidification; deformation of the deposit during spraying; and deformation of the deposit after spraying [10].

A finite element model was developed using ABAQUS to predict the residual stress profile through a plasma sprayed coating after being deposited. This model consisted of two parts. First, the temperature through the specimen during the spray process was calculated with a one-dimensional heat conduction model. Second, the calculated temperature history was used to compute the thermal stress generated during the build up of the coating. This modeling effort was supported experimentally with residual stress measurements. The residual stress profiles were measured using the modified layer removal method $[11,12]$.

Numerical analysis and experimental measurements of the flattening degree of plasma sprayed molybdenum and zirconia droplets deposited on different substrate materials have been studied. This investigation focused on the rate of solidification, the wetting angle on droplet spreading, the effects of droplet size and velocity, and effects from substrate temperature and thermal contact resistance [13].

Another study focused on obtaining Young's modulus and Poisson's ratio for thermal spray coatings. A cantilever beam method for evaluating these mechanical properties is

developed. A thermal spray coating is applied to a beam of known dimensions. Then 
two strain gages are applied to the coated surface and two strain gages are applied on the opposite substrate side. A force is applied at the end of the beam through calibrated weights. The strain is then measured and this data is used to determine Young's modulus and Poisson's ratio. A three-dimensional finite element analysis was used to verify this cantilever beam method and a sensitivity analysis was also performed using the experimental parameters. Coatings studied include tungsten carbide/cobalt, zirconia, nickel aluminum, and stainless steel [14].

Overall, interesting studies and investigations have been completed. From the early 1990's, when the CGSM was developed, demonstrations were performed regarding what materials could be effectively deposited using the CGSM. A discovery was made that when certain deposition parameters were manipulated, porosity could be controlled to a certain degree. Yet, the final quality of the coating can only be as good as the quality of the powder being fed into the hopper. Residual stress modeling of the plasma spray method was done by overlaying a temperature distribution determined by a conduction model, then residual stresses from the heat interaction of the particle and its surrounding. Modeling and experimentation of the flattening degree of molybdenum and zirconia droplets was studied. A cantilever beam method was used to determine Young's modulus and Poisson's ratio of several coating materials. Yet, no mechanical characterization of nickel deposited with the CGSM was performed.

\subsection{Competing Technologies}

Competing technologies for the CGSM may include hot isostatic pressing (HIPing) and microforming by metal jet. A manufacturing process in powder metallurgy is HIPing. This densification of metal and ceramic powders involves compaction and sintering, but in spite of the existence of pressure-sintering models, it is believed that there is no systematic way of predicting the tensile strength of a HIPed material that is ductile at room temperature. Some predictive equations for tensile strength are found in literature, but these are believed to be oversimplified and result in large deviations between experimental and predicted results. Therefore, an attempt has been made to correlate the relative tensile strength and relative density of HIPed 304 stainless steel powder by taking into account the stress concentration effect from the pores [15].

Another microprocess forms three-dimensional microstructures by a metal jet. This technique utilizes molten metal that is jetted onto a plate to form an image. Similar to the CGSM, this process has the potential to form structures of metal, ceramic, or plastic. Unlike the CGSM, microforming by metal jet potentially can form a three-dimensional structure [16].

\subsection{Benefits of this Research}

The objective of this investigation is to characterize nickel deposited by the CGSM. The particular application of the nickel members deposited using the CGSM is in 
compression, where the compressive strength of the nickel members must exceed the strength characteristics of bulk and electroplated nickel. This research will prove that the CGSM will produce a freestanding structure that will meet and exceed this requirement.

A potential application for the CGSM is to fabricate LIGA hardware from materials that cannot be electroplated. If the CGSM could be used as an intermediate step to fabricate LIGA hardware then a significantly larger material selection would be available for designers and engineers to choose from when designing mechanical systems. In addition to having an increased material base, the deposition time could be greatly reduced. The material deposition rate of cold gas-dynamic spray nickel is $108 \mu \mathrm{m} / \mathrm{min}$, while the material deposition rate for electroplating nickel is $0.82 \mu \mathrm{m} / \mathrm{min}$, see Appendix A for details. Therefore, this research will provide insight to the mechanical properties of cold gas-dynamic spray nickel and prove that the compressive strength properties will exceed the compressive strength properties of electroplated nickel and bulk nickel. 


\subsection{CGSM Experimentation, Parameters, and Post Processing}

This section discusses the design of experiment for the Cold Gas-Dynamic Spray Method (CGSM), the material to be deposited, and the testing to be performed on the material. A copper mold was designed to deposit enough cold gas-dynamic spray material to perform all the imaging and testing described. The parameters for the CGSM are recorded for completeness. Finally, all post-spray machining and heat treatment processes for the cold gas-dynamic spray material are explained.

\subsection{Design of Experiment}

One material was investigated, nickel. Reasons for choosing nickel are that nickel has an excellent knowledge base in bulk forms and nickel can be electroplated using the LIGA manufacturing method. Cold gas-dynamic spray nickel was tested in two conditions; the first condition was in an as-sprayed condition and other condition was in a heat-treated condition. The purpose of the heat treatment will be to relieve the stresses in nickel. The testing and imaging performed for the two material conditions were metallographic imaging, ultrasonic testing and imaging, hardness testing, sharp indentation testing, tension testing, and compression testing. The design of experiment to investigate CGSM material properties is shown in Figure 2.

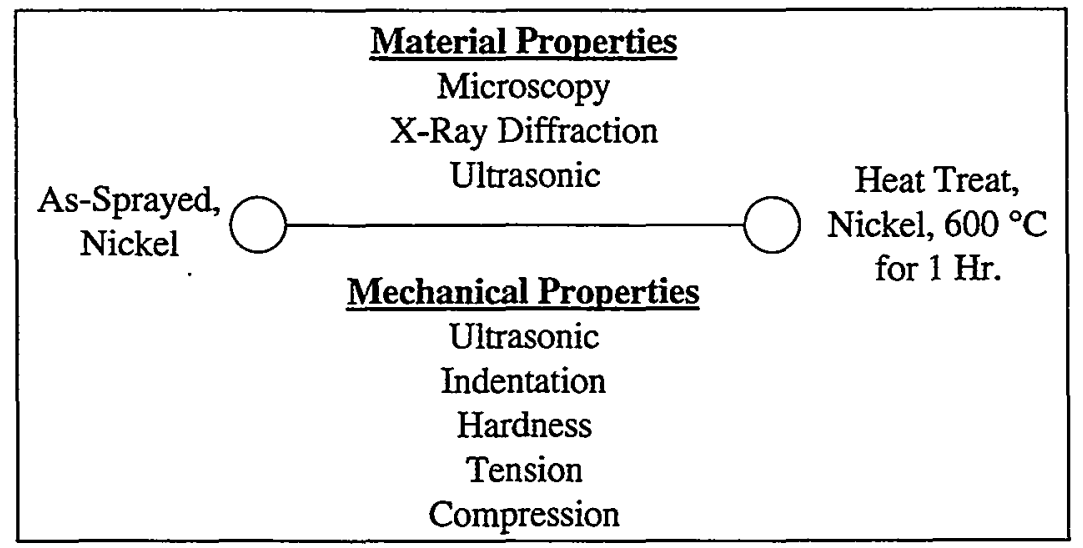

Figure 2, Schematic of the one-dimensional cold gas-dynamic spray experiment.

\subsection{Design of Mold}

For several reasons, copper was the material chosen for the mold. Copper is able to withstand the high particle velocity as well as the heat that may be generated from the high velocities of the deposited material. Also, it is desirable for the mold to be made of a material that could be electroplated using the LIGA process. Additionally, once the cold gas-dynamic spray material is deposited, the mold must be able to be etched away to release the material within the mold. Copper met these requirements due to its 
compatibility with the LIGA fabrication process and its ability to be easily etched with a chemical etch solution without effecting the deposited material.

The copper mold used for this experiment was machined conventionally and a sketch is shown in Figure 3. This mold has four large rectangular pockets to be used for the metallographic imaging, ultrasonic testing, sharp indentation testing, hardness testing, tension testing, and compression testing. The five small rectangular pockets will be used for metallographic imaging and ultrasonic testing and imaging. After nickel is deposited into the copper mold, the mold will be separated into two pieces. One piece of the nickel-filled mold will be heat-treated while the other piece will remain in an as-sprayed condition. A photograph of a similar copper mold is shown in Figure 4.
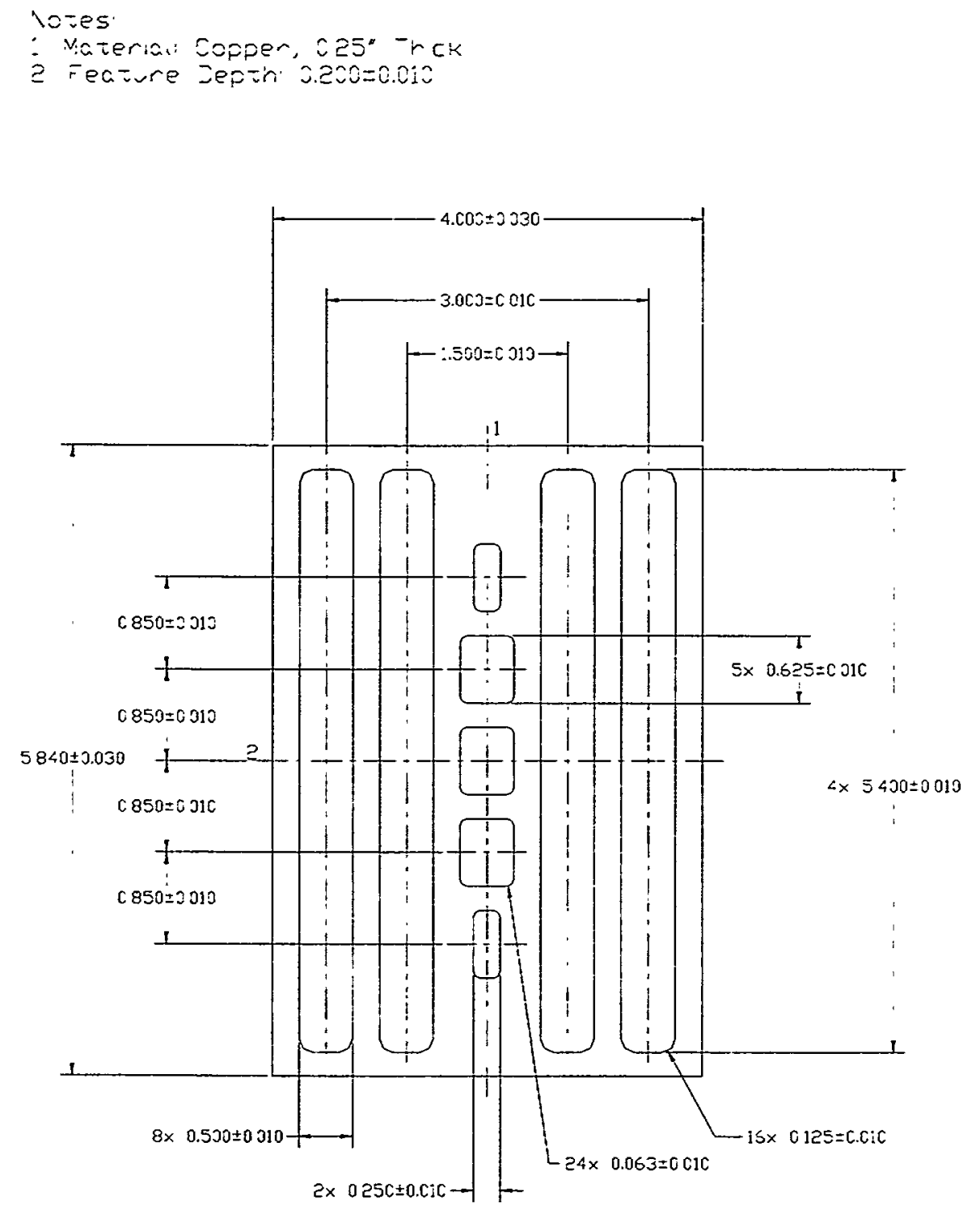

Figure 3, Design of mold for cold gas-dynamic spray nickel, drawn in inches. 


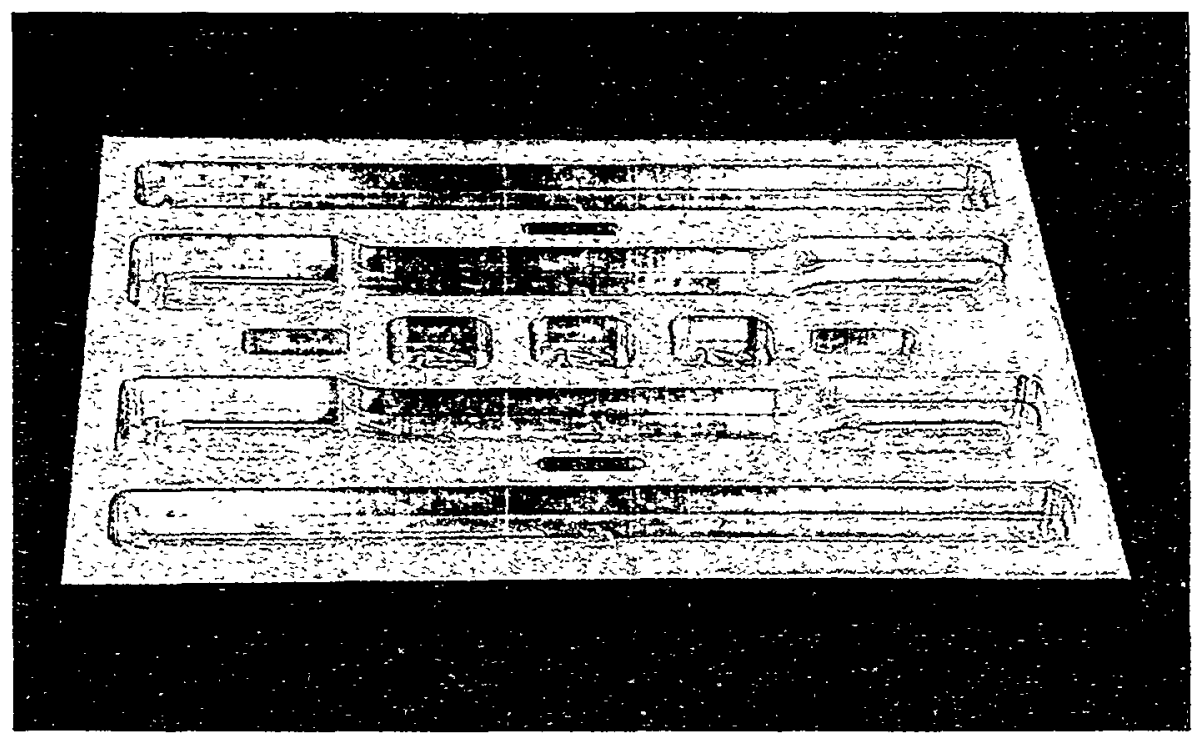

Figure 4, Sample mold for cold gas-dynamic spray nickel.

\subsection{Cold Gas-Dynamic Spray}

The cold gas-dynamic spray parameters are documented and the equipment setup is shown in this section. Before any material was deposited into the copper mold, it was cleaned with sulfuric acid $\left(5 \% \mathrm{H}_{2} \mathrm{SO}_{4}\right)$ to remove the copper oxide on the mold and to eliminate any possible unknown reactions between the copper mold and the nickel being deposited. Although there was no effort to influence the cold gas-dynamic spray parameters, they were recorded. The cold gas-dynamic spray parameters that were used to spray the nickel powder are shown in Table 1.

Table 1, Cold Gas-Dynamic Spray parameters used to deposit nickel.

\begin{tabular}{|c|c|}
\hline Parameter & Value \\
\hline Powder Type & Nickel \\
\hline Powder Size & $14 \pm 9 \mu \mathrm{m}$ \\
\hline Gas Type & Helium \\
\hline Main Gas Pressure & $300 \mathrm{psi}$ \\
\hline Heater Temperature & $325^{\circ} \mathrm{C}$ \\
\hline Powder Gas, Delta P & $10 \mathrm{psi}$ \\
\hline Powder Hopper Angular Velocity & $5 \mathrm{pm}$ \\
\hline Nozzle Type & Rectangular \\
\hline Traverse Distance & $12.25 \mathrm{in}$ \\
\hline Step Distance & $0.14 \mathrm{in}$ \\
\hline Nozzle Velocity & $1 \mathrm{in} / \mathrm{sec}$ \\
\hline
\end{tabular}


In addition to the parameters recorded in Table 1 , the helium and nickel particles exited the nozzle at a velocity of $879 \pm 78 \mathrm{~m} / \mathrm{s}$. This velocity was determined experimentally. The helium and nickel particles are travelling at supersonic velocities in air, see Appendix B for details.

The upper photograph in Figure 5 shows the cold gas-dynamic spray equipment. The large cylinder near the bottom of the frame is the gas heater. To the left of the gas heater is the powder feed tube. At the end of the powder feed tube is the converging-diverging nozzle. Near the lower left portion of the photograph, under the converging-diverging nozzle, is the copper mold that is being filled with nickel. The lower photograph in Figure 5 shows a close-up view of the copper mold as it is being filled with nickel.
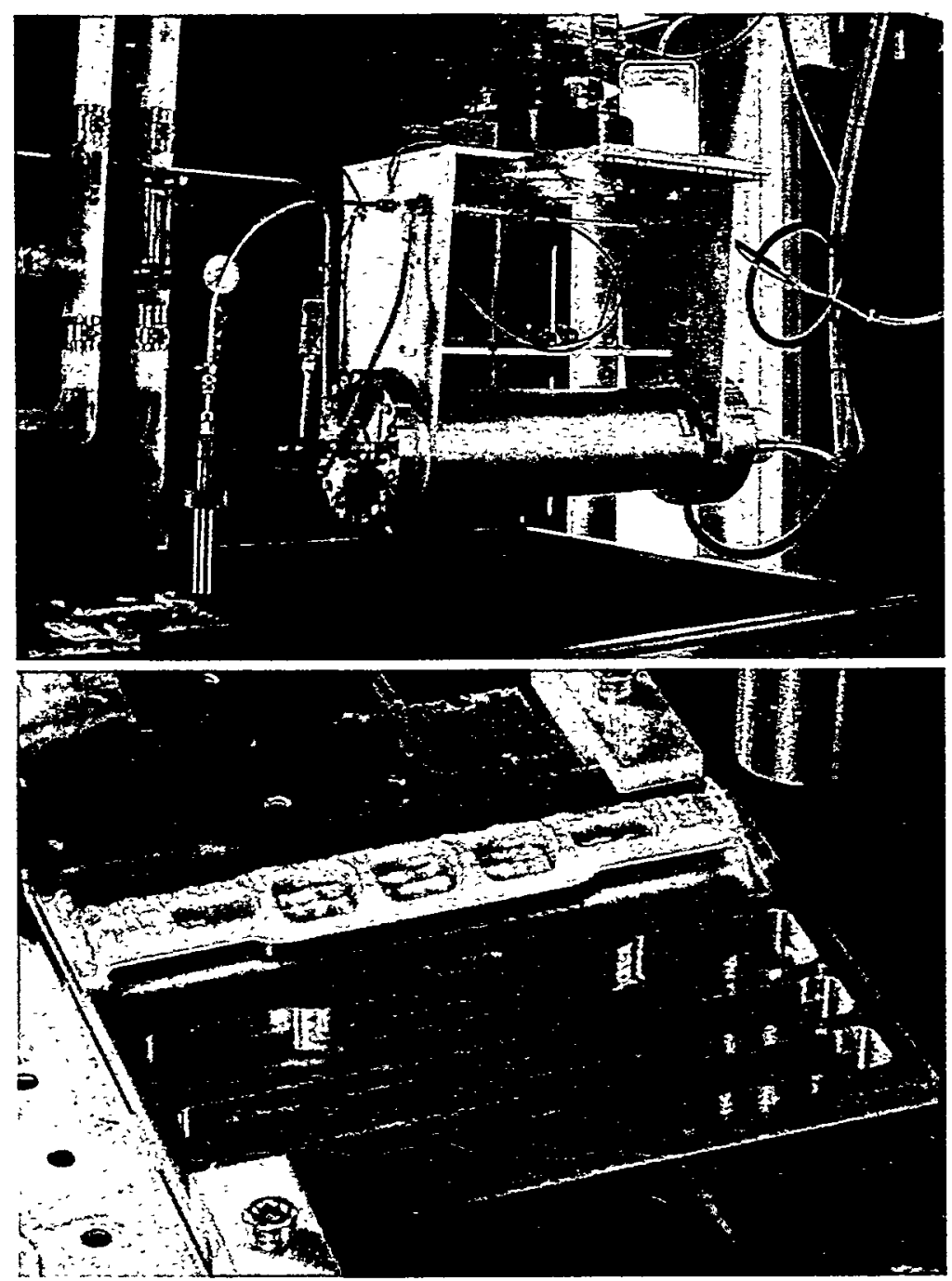

Figure 5, Equipment setup to cold gas-dynamic spray nickel into a copper mold (top). Close-up view of copper mold as it is being filled with nickel (bottom). 


\subsection{Post Cold Gas-Dynamic Spray Processing}

After the copper mold is filled with nickel, the excess nickel was machined from the copper mold. The mold was then separated, and half of the copper mold was heattreated. As the nickel is deposited into the copper mold, it forms a coating that is irregular in thickness. In other words, there is a significant difference between the minimum and maximum height of the nickel coating. To eliminate the ridges in the nickel coating, the top surface of the coating was machined with an end-mill. After the milling procedure, the copper mold was then cut with a band saw to separate the portion of the nickel-filled mold that will be heat-treated. The purpose of the heat treatment was to relieve the stresses in the nickel-filled mold. To do this, the nickel-filled mold was heated to $600^{\circ} \mathrm{C}\left(1112^{\circ} \mathrm{F}\right)$ for a period of one hour [17] in an inert argon atmosphere. Additional machining, grinding, and polishing was performed as specific testing and imaging required. 


\subsection{CGSM Imaging and Testing}

Several types of testing and imaging methods have been performed on the nickel coating that was deposited using the CGSM. Metallographic imaging and $\mathrm{x}$-ray diffraction scanning were performed on the cold gas-dynamic sprayed nickel specimens to get an understanding of the structure. Ultrasonic testing was performed to determine the elastic stiffness constants. From the elastic stiffness constants, Young's moduli, shear moduli, and Poisson's ratios can be directly determined. Ultrasonic imaging was also performed to determine the consistency or imperfections within the nickel specimens. Indentation testing was performed to determine the type of residual stress within the as-sprayed nickel specimen. Hardness testing was performed to estimate the ultimate strength of the nickel specimens. Finally, tensile and compression testing was performed to experimentally determine strength properties of the cold gas-dynamic spray nickel and to see how the heat treatment process effected the material properties. These testing and imaging techniques are described in the following sections.

\subsection{Microstructure Investigations}

The CGSM nickel specimens used for the $\mathrm{x}$-ray diffraction and metallographic imaging were mounted and prepared at Buehler Ltd. using an innovative processing technique. The nickel specimens were mounted in an Epoxicure ${ }^{\mathrm{TM}}$ epoxy where a vacuum was drawn to remove all the open pores within the epoxy. The initial polishing procedure started with a SiC, 240 grit abrasive for 40 seconds at a pressure of 5 pounds, rotating at a speed of $250 \mathrm{rpm}$. The second polish was with a $9 \mu \mathrm{m}$ abrasive for 4 minutes at a pressure of 5 pounds, rotating at a speed of $150 \mathrm{rpm}$. Finally, a $3 \mu \mathrm{m}$ polish was performed for 3 minutes at a pressure of 6 pounds, rotating at a speed of $120 \mathrm{rpm}$. To expose the microstructure, a solution of 1 part nitric acid and 4 parts hydrochloric acid was swabbed on the nickel surface for $10-15$ seconds. Then the specimens were rinsed in warm water. This etching process revealed the grains and their boundaries in the nickel specimens.

\subsubsection{X-Ray Diffraction}

Theta-two-theta, $x$-ray diffraction scans were performed on the as-sprayed nickel and heat-treated nickel samples. Figures 6 and 7 show the results of the scans for the respective samples. The full width, half-maximum value at the 44.5 degree peak for the as-sprayed nickel was 0.174 degrees in the theta-two-theta scan. Typical instrumental broadening for the Siemens D500 X-Ray Diffractometer is 0.078 degrees. This would indicate that the as-sprayed nickel is crystalline, but defects are present with poorly defined grain boundaries, which will contribute to the peak broadening, as seen here. The full width, half-maximum value for the cold gas-dynamic spray nickel in the heattreated condition was found to be 0.088 degrees. This peak narrowing indicates that the heat-treated nickel is also crystalline, but with a fewer number of defects and better grain boundary definition. 


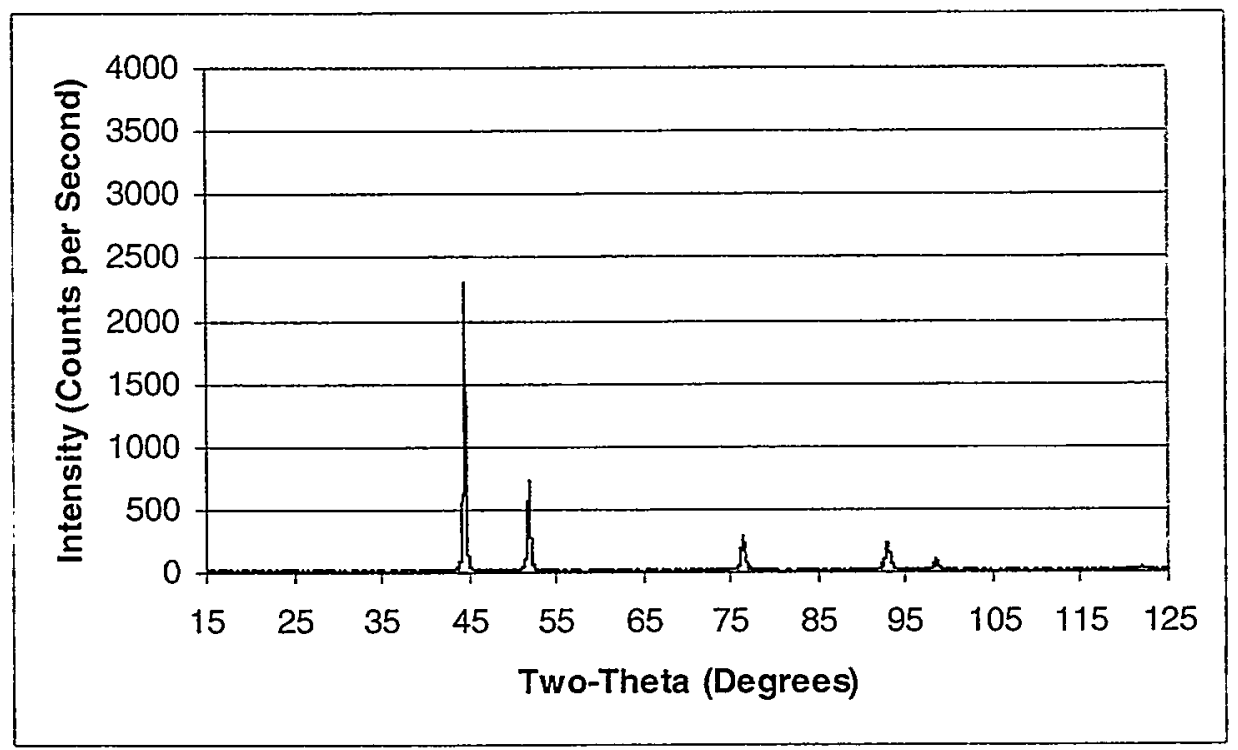

Figure 6, Theta-two-theta scan of the cold gas-dynamic spray nickel in the as-sprayed condition.

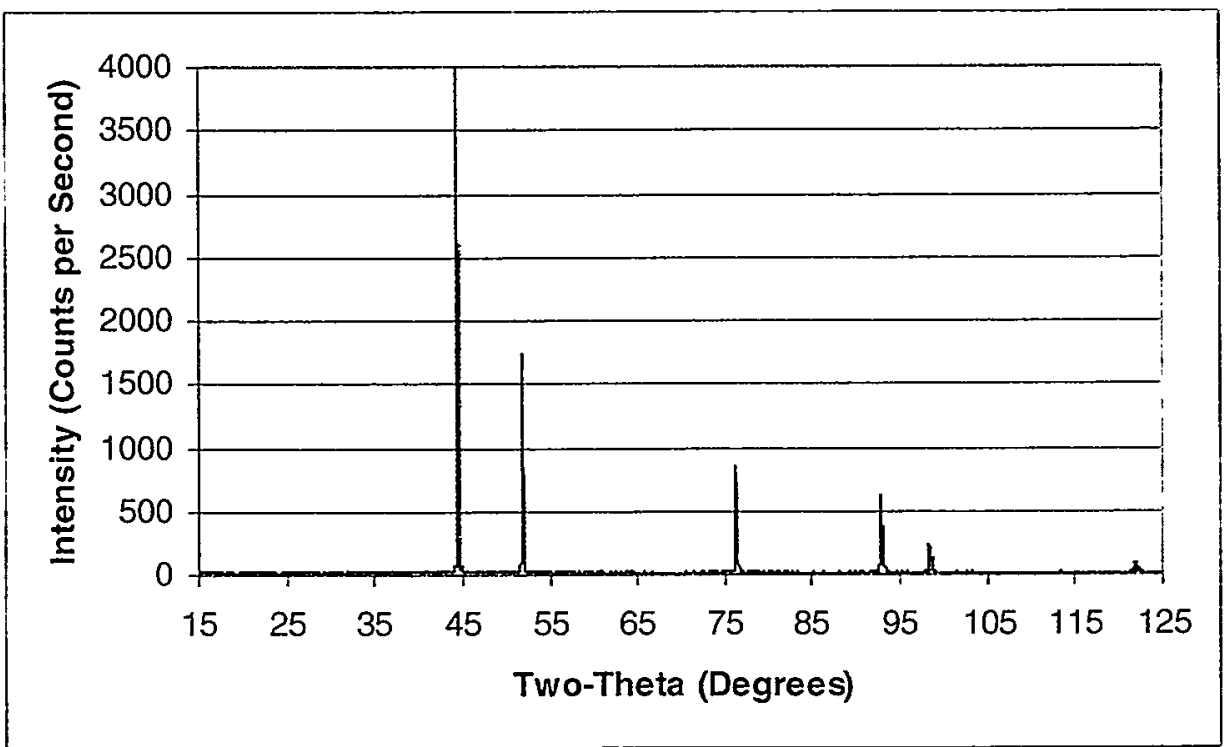

Figure 7, Theta-two-theta scan of the cold gas-dynamic spray nickel in the heat-treated condition. 


\subsubsection{Metallographic Imaging}

Photo microscopy was performed with a Reichert MeF4A microscope and a BetterLight, Model 6000 insert. Figure 8 shows the microstructure from the top view, of the assprayed nickel and heat-treated cold gas-dynamic spray nickel. The top view is the direction the nickel particles were deposited. The magnifications of the images are 100x for the first row, 500x for the second row, and 1000× for the last row. Figures 9 and 10 show the microstructure from the side view. The side view will show the profile of the cold gas-dynamic spray nickel. The magnifications of the images in are $20 \times$ for the first row and $100 \times$ for the second row in Figure 9. Magnifications in Figure 10 are 500× for the first row, and $1000 \times$ for the second row.

The first row of metallographic images shown in Figure 8, the sprayed nickel in the heattreated condition (right column) appears to have fewer voids, or pores, than in the assprayed nickel (left column). As the magnification increases, in the second and third row of images, it appears that the grains are better formed. The stress relieving heat treatment process appears to have caused the nickel to recrystallize. Several factors that promote recrystallization are (1) prior deformation, (2) temperature, (3) time, (4) initial grain size, (5) composition, and (6) the amount of recovery prior to the start of recrystallization [29]. Only a minimum amount of deformation is needed to cause recrystallization. If the amount of deformation is large, a lower temperature will cause recrystallization. Since the cold gas-dynamic spray nickel particles deform upon impact, there will be a significant amount of deformation to promote recrystallization. Though the recrystallization temperature is not a fixed temperature in the sense of a melting temperature, the recrystallization temperature also decreases as the purity of the metal increases. The composition of the nickel powder used for the CGSM is $99.5 \%$ pure. Therefore, it would very reasonable to conclude that a stress relief heat treatment of $600^{\circ} \mathrm{C}$ for one hour caused the nickel with high internal stresses to recrystallize. Furthermore, if the residual stresses are in compression, when heated, the nickel will seek a relaxed state by expanding to fill in the voids, causing the voids to be smaller and fewer in number, as seen between the as-sprayed and heat-treated cold gas-dynamic spray nickel.

The first row of metallographic images shown in Figure 9, show the profile of the nickel coating in the copper mold. The left column is the as-sprayed nickel, while the right column in the heat-treated nickel. There are definite visible layers of nickel as the coating was deposited. The magnification is increased in the second row, the overall porosity can be seen in the two samples. The images in Figure 10 are from the same specimens, but at higher at higher magnifications. The wavy and splash like features could indicate that the grain boundaries seen from the top view of the as-sprayed specimen are particle or splat boundaries. Now that both sets of images can be compared, the stress relieving heat treatment process appears to have caused the nickel to recrystallize. 

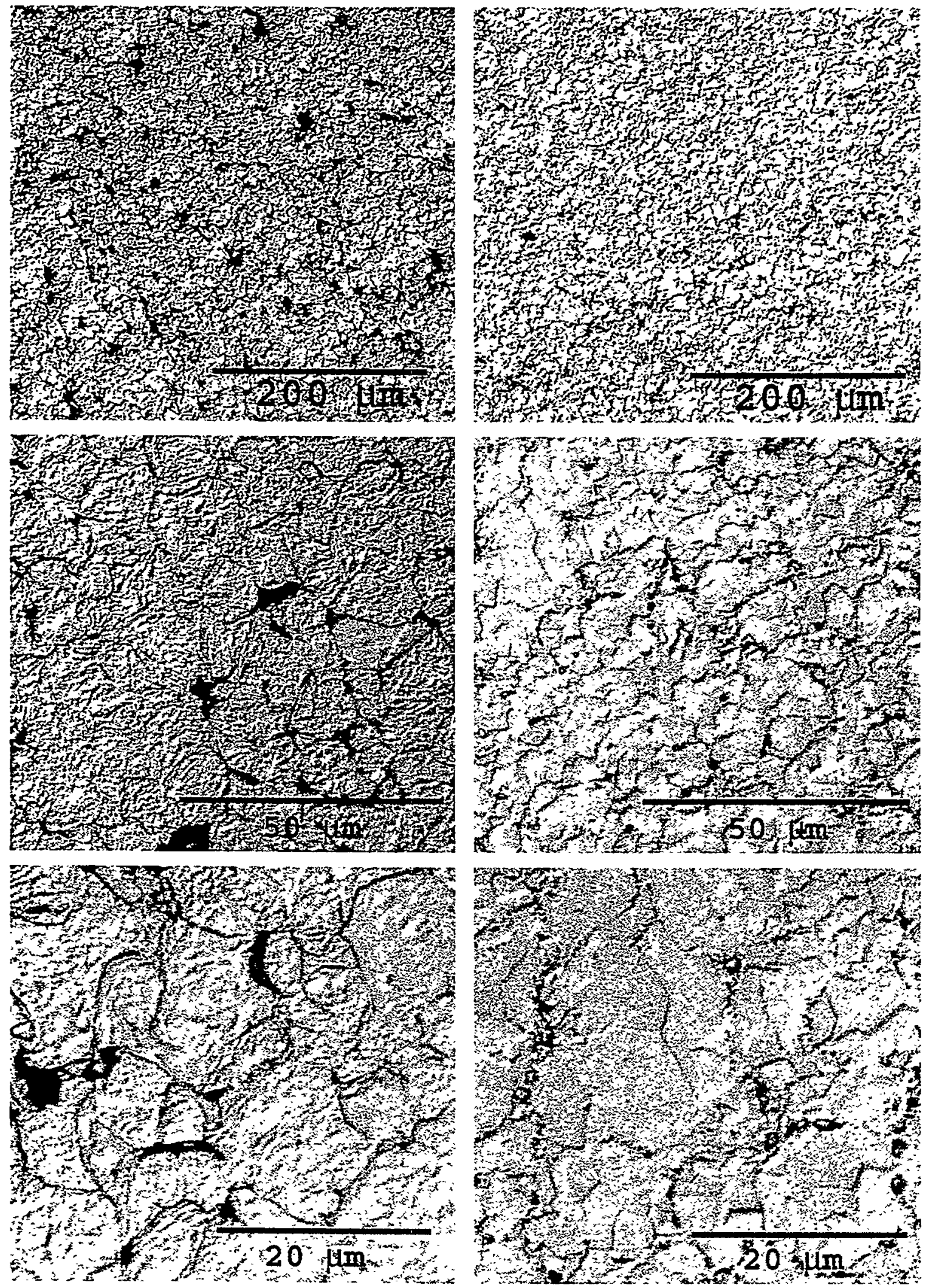

Figure 8, Top view micrographs of the nickel grain structure. The left column shows the as-sprayed condition, while the right column shows the heat-treated condition.

Magnifications are $100 \times, 500 \times$, and $1000 \times$. 

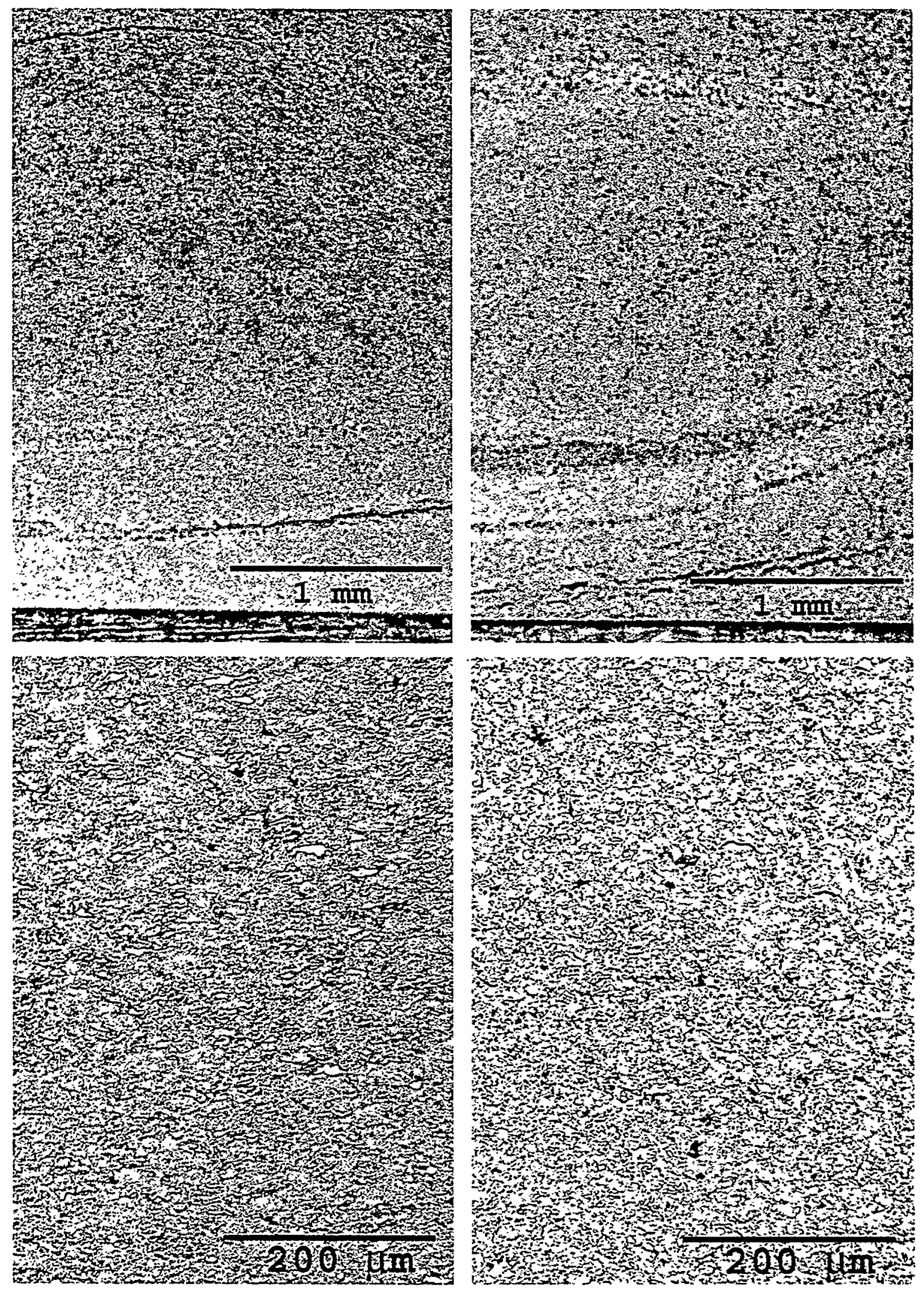

Figure 9, Side view micrographs of the nickel grain structure. The left column shows the as-sprayed condition, while the right column shows the heat-treated condition.

Magnifications are 20x and 100x. 

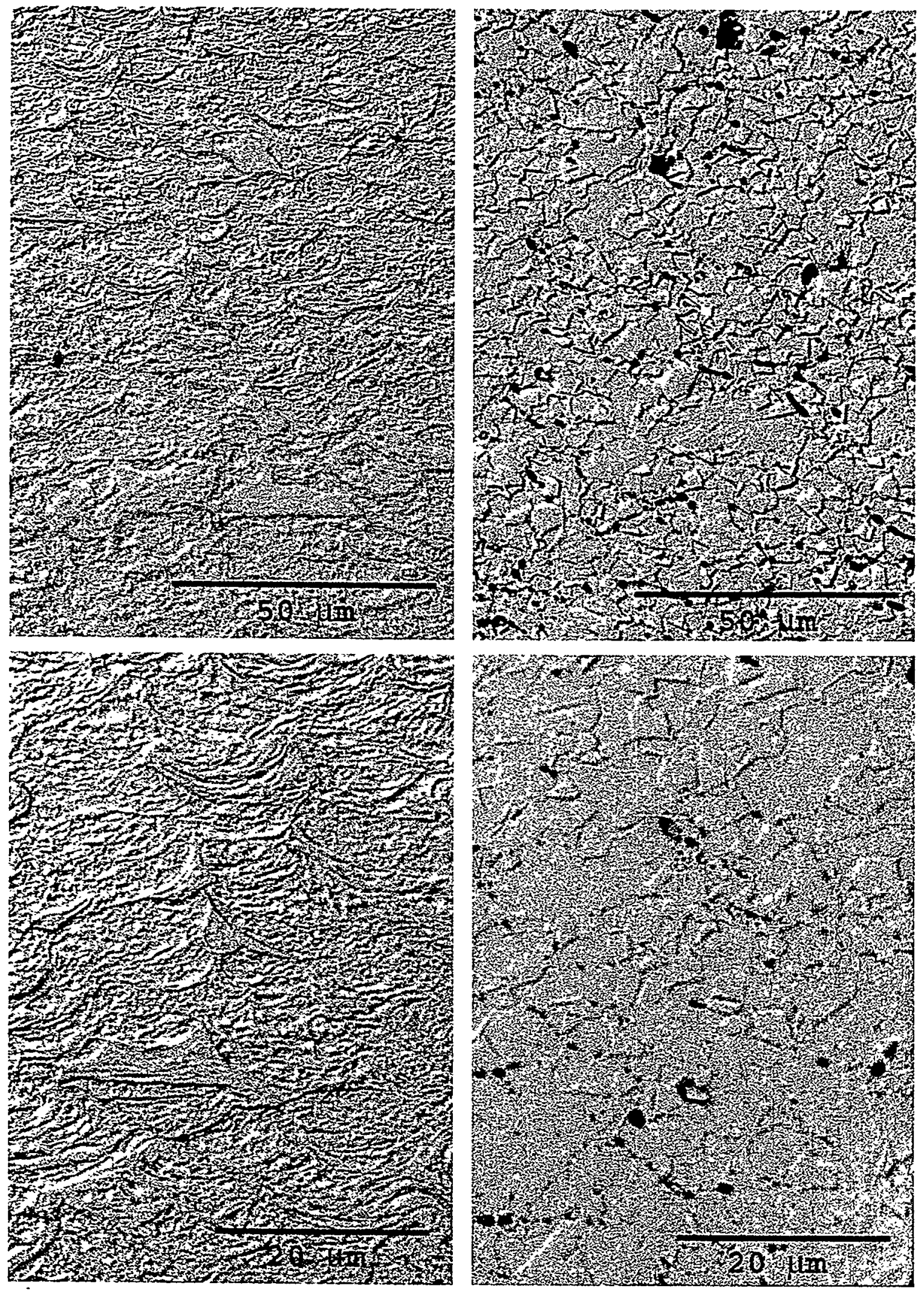

Figure 10, Side view micrographs of the nickel grain structure. The left column shows the as-sprayed condition, while the right column shows the heat-treated condition. Magnifications are 500 $\times$ and 1000x. 


\subsection{Ultrasonic Testing}

The ultrasonic testing section is divided into three sub-sections titled Background, Experimentation, and Imaging. The Background sub-section will develop the equations necessary to determine shear moduli, Poisson's ratios, and Young's moduli. The Experimentation sub-section will actually determine shear moduli, Poisson's ratios, and Young's moduli values for the cold gas-dynamic spray nickel in both as-sprayed and heat-treated conditions. Finally, the Imaging sub-section will present ultrasonic images of cold gas-dynamic spray nickel in the as-sprayed and heat-treated conditions.

\subsubsection{Background}

Sound travels by the vibration of the atoms and molecules present, traveling with a velocity that depends on the mechanical properties of the material. Imperfections, inclusions, and pores in the material can cause the sound waves to be scattered, resulting in echoes and a general dampening of the sound wave. This nondestructive test is carried out using ultrasonic waves of frequency above $20 \mathrm{kHz}$. The velocity of the waves varies, depending on the medium, from 300 to $6000 \mathrm{~m} / \mathrm{s}$. The range of frequencies used in ultrasonic testing are from 0.1 to $25 \mathrm{MHz}$ with wavelengths from 1 to $10 \mathrm{~mm}$ [18].

All of the independent elastic stiffness constants for transversely isotropic, or tetragonal, materials may be determined experimentally by ultrasonic-wave propagation techniques. The ultrasonic technique offers a means of nondestructively measuring the moduli of fabricated structures. The elastic stiffness constants resolved ultrasonically are comparable to those determined through mechanical tests, provided the ultrasonic wavelengths used are much larger than the dimensions of the constituent material phases and smaller than the dimensions of the specimen. The complete matrix of independent elastic constants may be found by measuring the ultrasonic wave velocity in the symmetry directions of the material. The engineering constants such as the shear moduli, Poisson's ratios, and Young's moduli may then be determined from the measured independent elastic stiffness constants. If a transversely isotropic, or tetragonal, symmetry is present, the calculations can be simplified by using the Wigner-Seitz approximation as shown below [19].

The basic measurements to be determined for use with the ultrasonic method are the physical measurements of the specimen $(s)$ and the time-of-flight $(t)$ for each of the waves. Once these measurements are determined, the elastic stiffness constants can be determined using the following method.

The longitudinal wave velocities $\left(V_{L}\right)$, and transverse wave velocities $\left(V_{T}\right)$ are determined as shown in Equations 4.1 - 4.6.

$$
V_{L 1}=\frac{s_{1}}{t_{L 1}}
$$




$$
\begin{aligned}
& V_{L 2}=\frac{s_{2}}{t_{L 2}} \\
& V_{L 3}=\frac{s_{3}}{t_{L 3}} \\
& V_{T 23}=\frac{s_{2}}{t_{T 3}} \\
& V_{T 13}=\frac{s_{1}}{t_{T 3}} \\
& V_{T 12}=\frac{s_{1}}{t_{T 2}}
\end{aligned}
$$

The longitudinal wave velocities in the $45^{\circ}$ plane $\left(V_{L 45^{\circ}}\right)$ are approximated with the following equations. It was necessary to approximate these values since the actual measurement would require grinding two parallel surfaces, at a $45^{\circ}$ angle, between the two described planes. Obtaining one of these measurements would prohibit obtaining values for the remaining surfaces. Therefore, an averaging approximation will be used as shown in Equations 4.7 - 4.9.

$$
\begin{aligned}
& V_{L 45^{\circ}, 23}=\frac{V_{L 2}+V_{L 3}}{2} \\
& V_{L 45^{\circ}, 13}=\frac{V_{L 1}+V_{L 3}}{2} \\
& V_{L 45^{\circ}, 12}=\frac{V_{L 1}+V_{L 2}}{2}
\end{aligned}
$$

Now that the longitudinal wave velocities $\left(V_{L}\right)$, and transverse wave velocities $\left(V_{T}\right)$ are known in each of the directions, the elastic stiffness coefficients can be computed. Assuming the material is transversely isotropic, or tetragonal, it will have six unique elastic coefficients [20]. The reason for this assumption is based on physical considerations of the CGSM. As the particle impacts the substrate, it will flatten, causing the material identical properties in the 1 and 2 directions, but different properties in the 3 direction. Using matrix notation, the indices are replaced as indicated: $11 \rightarrow 1,22 \rightarrow 2$, $33 \rightarrow 3,23 \rightarrow 4,13 \rightarrow 5$, and $12 \rightarrow 6$. Therefore, the elastic coefficient matrix for a transversely isotropic, or tetragonal, material will be as shown in Equation 4.10. 


$$
C=\left[\begin{array}{lllllll}
C_{11} & C_{12} & C_{13} & & & \\
C_{12} & C_{11} & C_{13} & & & \\
C_{13} & C_{13} & C_{33} & & & \\
& & & C_{44} & & \\
& & & & C_{44} & \\
& & & & & C_{66}
\end{array}\right]
$$

The elastic stiffness coefficients can be determined from Equations $4.11-4.16$.

$$
\begin{aligned}
& C_{11}=\rho V_{L 1}^{2} \\
& C_{33}=\rho V_{L 3}^{2} \\
& C_{44}=\rho V_{T 23}^{2} \\
& C_{66}=\rho V_{T 12}^{2} \\
& C_{12}=C_{11}-2 C_{66} \\
& C_{13}=\frac{1}{2} \sqrt{\left[4 \rho V_{L 45^{\circ}, 13}^{2}-C_{11}-C_{33}-2 C_{44}\right]^{2}-\left[C_{11}-C_{33}\right]^{2}}-C_{44}
\end{aligned}
$$

The values of these elastic stiffness constants have uncertainties associated with them [21]. The uncertainty of the elastic stiffness constants will arise from measurement error associated with density and the wave velocity measurements. Density will have measurement error from the mass and volume of the specimen, while wave velocity measurements will have errors from the specimen thickness and time-of-flight of the wave.

The uncertainties of the elastic stiffness constants are given by Eqs. $4.17-4.22$. For a complete analysis of the uncertainty for the elastic stiffness constants, see Appendix C.

$$
\begin{aligned}
& U_{C_{11}}=C_{11} \sqrt{\left(\frac{U_{m}}{m}\right)^{2}+5\left(\frac{U_{s_{1}}}{s_{1}}\right)^{2}+\left(\frac{U_{s_{2}}}{s_{2}}\right)^{2}+\left(\frac{U_{s_{3}}}{s_{3}}\right)^{2}+4\left(\frac{U_{t_{L 1}}}{t_{L 1}}\right)^{2}} \\
& U_{C_{33}}=C_{33} \sqrt{\left(\frac{U_{m}}{m}\right)^{2}+\left(\frac{U_{s_{1}}}{s_{1}}\right)^{2}+\left(\frac{U_{s_{2}}}{s_{2}}\right)^{2}+5\left(\frac{U_{s_{3}}}{s_{3}}\right)^{2}+4\left(\frac{U_{t_{L 3}}}{t_{L 3}}\right)^{2}}
\end{aligned}
$$




$$
\begin{aligned}
& U_{C_{44}}=C_{44} \sqrt{\left(\frac{U_{m}}{m}\right)^{2}+\left(\frac{U_{s_{1}}}{s_{1}}\right)^{2}+5\left(\frac{U_{s_{2}}}{s_{2}}\right)^{2}+\left(\frac{U_{s_{3}}}{s_{3}}\right)^{2}+4\left(\frac{U_{t_{T 3}}}{t_{T 3}}\right)^{2}} \\
& U_{C_{66}}=C_{66} \sqrt{\left(\frac{U_{m}}{m}\right)^{2}+5\left(\frac{U_{s_{1}}}{s_{1}}\right)^{2}+\left(\frac{U_{s_{2}}}{s_{2}}\right)^{2}+\left(\frac{U_{s_{3}}}{s_{3}}\right)^{2}+4\left(\frac{U_{t_{T 2}}}{t_{T 2}}\right)^{2}} \\
& U_{C_{12}}=\sqrt{U_{C_{11}}^{2}+4 U_{C_{65}}^{2}}
\end{aligned}
$$$$
U_{C_{13}}=\sqrt{\left(\frac{2 V_{L 45^{\circ}, 13}^{2}\left(4 \rho V_{L 45^{\circ}, 13}^{2}-C_{11}-C_{33}-2 C_{44}\right)}{\sqrt{\left(4 \rho V_{L 45^{\circ}, 13}^{2}-C_{11}-C_{33}-2 C_{44}\right)^{2}-\left(C_{11}-C_{33}\right)^{2}}}\right)^{2}} U_{\rho}^{2}
$$

$$
+\left(\frac{4 V_{L 45^{\circ}, 13}\left(4 \rho V_{L 45^{\circ}, 13}^{2}-C_{11}-C_{33}-2 C_{44}\right)}{\sqrt{\left(4 \rho V_{L 45^{\circ}, 13}^{2}-C_{11}-C_{33}-2 C_{44}\right)^{2}-\left(C_{11}-C_{33}\right)^{2}}}\right)^{2} U_{V_{L 45^{\circ}, 13}}^{2}
$$

$$
+\left(\frac{-2 \rho V_{L 45^{\circ}, 13}^{2}+C_{33}+C_{44}}{\sqrt{\left(4 \rho V_{L 45^{\circ}, 13}^{2}-C_{11}-C_{33}-2 C_{44}\right)^{2}-\left(C_{11}-C_{33}\right)^{2}}}\right)^{2} U_{C_{11}}^{2}
$$

$$
+\left(\frac{-2 \rho V_{L 45^{\circ}, 13}^{2}+C_{11}+C_{44}}{\sqrt{\left(4 \rho V_{L 45^{\circ}, 13}^{2}-C_{11}-C_{33}-2 C_{44}\right)^{2}-\left(C_{11}-C_{33}\right)^{2}}}\right)^{2} U_{C_{33}^{2}}^{2}
$$

$$
+\left(\frac{-4 \rho V_{L 45^{\circ}, 13}^{2}+C_{11}+C_{33}+2 C_{44}}{\sqrt{\left(4 \rho V_{L 45^{\circ}, 13}^{2}-C_{11}-C_{33}-2 C_{44}\right)^{2}-\left(C_{11}-C_{33}\right)^{2}}}-1\right)^{2} U_{C_{44}}^{2}
$$

(Eq. 4.22).

After the elastic constants are computed, shear moduli $(G)$, Poisson's ratios $(v)$, and Young's moduli $(E)$ can be calculated using the following relationships shown in Equations 4.23-4.30.

$$
\begin{aligned}
& G_{23}=C_{44} \\
& G_{13}=G_{23}
\end{aligned}
$$




$$
\begin{aligned}
& G_{12}=C_{66} \\
& v_{12}=\frac{C_{13}^{2}-C_{12} C_{33}}{C_{13}^{2}-C_{11} C_{33}} \\
& v_{13}=\frac{C_{12} C_{13}-C_{11} C_{13}}{C_{13}^{2}-C_{11} C_{33}} \\
& E_{1}=C_{11}-v_{13} C_{13}-v_{12} C_{12} \\
& E_{2}=E_{1} \\
& E_{3}=C_{33}-2 v_{31} C_{13}
\end{aligned}
$$

Now that shear moduli, Poisson's ratios, and Young's moduli are known nominally, the upper and lower bounds must be determined. Adding or subtracting the uncertainty associated with the elastic stiffness constants to the actual elastic stiffness constant to maximize or minimize the values of the shear moduli, Poisson's ratios, and Young's moduli is the technique that was used. This is how the upper and lower bounds for these properties were determined. The upper bound for $G_{23}$ and $E_{3}$ are shown in Equations 4.31 and 4.32 respectively.

$$
\begin{aligned}
& G_{23}=C_{44}+U_{C_{44}} \\
& E_{3}=\left(C_{33}+U_{C_{33}}\right)-2\left(\text { lower bound of } v_{31}\right)\left(C_{13}-U_{C_{13}}\right)
\end{aligned}
$$

This is the method that was used to determining the upper and lower bounds for each of the material properties described by Equations 4.23 - 4.30. It wasn't obvious how to determine the bounds for Poisson's ratios, so every possible combination of minimizing and maximizing each variable will be tested to obtain an overall maximum and minimum value for the material property.

\subsubsection{Experimentation}

The equipment setup used to perform the pulse-echo (PE) and the through-transmission (TT) measurements was a $5052 \mathrm{PR}$ pulser/receiver, $5 \mathrm{MHz}$ longitudinal and shear transducers, 7603 oscilloscope, 8013A LeCroy Digitizer, and a LabView software program that was used to capture the digitized signal for time measurements. Two specimens of cold gas-dynamic spray nickel, one as-sprayed and one heat-treated 
specimen, were tested using the ultrasonic method. Both nickel specimens were ground and polished, using a jig, until the edges were flat and parallel within 0.0005 inches.

First, the mass, physical dimensions, and time-of-flight measurements are recorded and there tolerances determined. Second, the density and the wave velocities are calculated. Third, the elastic constants are determined. Finally, the shear moduli $(G)$, Poisson's ratios $(v)$, and Young's moduli $(E)$ are computed. The values measured for the mass, physical dimensions, and time-of-flight velocities, with their tolerances for cold gasdynamic spray nickel in the as-sprayed and heat-treated conditions are shown in Table 2.

Table 2, Measured mass, size, and time-of-flight velocities with tolerances for cold gas-dynamic spray nickel in the as-sprayed and heat-treated conditions.

\begin{tabular}{|c|c|c|c|}
\hline Feature & As-Sprayed & Heat-Treated & Tolerance \\
\hline Mass $(\mathrm{m})$ & $6.583 \mathrm{e}-3 \mathrm{~kg}$ & $5.925 \mathrm{e}-3 \mathrm{~kg}$ & $0.05 \mathrm{e}-3 \mathrm{~kg}$ \\
\hline Dimension $\left(\mathrm{s}_{1}\right)$ & $15.1 \mathrm{e}-3 \mathrm{~m}$ & $14.3 \mathrm{e}-3 \mathrm{~m}$ & $12.7 \mathrm{e}-6 \mathrm{~m}$ \\
\hline Dimension $\left(\mathrm{s}_{2}\right)$ & $12.2 \mathrm{e}-3 \mathrm{~m}$ & $11.7 \mathrm{e}-3 \mathrm{~m}$ & $12.7 \mathrm{e}-6 \mathrm{~m}$ \\
\hline Dimension $\left(\mathrm{s}_{3}\right)$ & $4.25 \mathrm{e}-3 \mathrm{~m}$ & $4.22 \mathrm{e}-3 \mathrm{~m}$ & $12.7 \mathrm{e}-6 \mathrm{~m}$ \\
\hline Longitudinal Time-of-Flight, TT $\left(\mathrm{t}_{\mathrm{L} 1}\right)$ & $2.695 \mathrm{e}-6 \mathrm{~s}$ & $2.590 \mathrm{e}-6 \mathrm{~s}$ & $0.025 \mathrm{e}-6 \mathrm{~s}$ \\
\hline Longitudinal Time-of-Flight, TT $\left(\mathrm{t}_{\mathrm{L} 2}\right)$ & $2.195 \mathrm{e}-6 \mathrm{~s}$ & $2.120 \mathrm{e}-6 \mathrm{~s}$ & $0.025 \mathrm{e}-6 \mathrm{~s}$ \\
\hline Longitudinal Time-of-Flight, PE $\left(\mathrm{t}_{\mathrm{T} 3}\right)$ & $0.8100 \mathrm{e}-6 \mathrm{~s}$ & $0.7742 \mathrm{e}-6 \mathrm{~s}$ & $0.010 \mathrm{e}-6 \mathrm{~s}$ \\
\hline Transverse Time-of-Flight, TT $\left(\mathrm{t}_{\mathrm{T} 12}\right)$ & $5.055 \mathrm{e}-6 \mathrm{~s}$ & $4.885 \mathrm{e}-6 \mathrm{~s}$ & $0.025 \mathrm{e}-6 \mathrm{~s}$ \\
\hline Transverse Time-of-Flight, TT $\left(\mathrm{t}_{\mathrm{T} 13}\right)$ & $5.140 \mathrm{e}-6 \mathrm{~s}$ & $4.935 \mathrm{e}-6 \mathrm{~s}$ & $0.025 \mathrm{e}-6 \mathrm{~s}$ \\
\hline Transverse Time-of-Flight, TT $\left(\mathrm{t}_{\mathrm{T} 21}\right)$ & $4.085 \mathrm{e}-6 \mathrm{~s}$ & $4.010 \mathrm{e}-6 \mathrm{~s}$ & $0.025 \mathrm{e}-6 \mathrm{~s}$ \\
\hline Transverse Time-of-Flight, TT $\left(\mathrm{t}_{\mathrm{T} 23}\right)$ & $4.250 \mathrm{e}-6 \mathrm{~s}$ & $4.070 \mathrm{e}-6 \mathrm{~s}$ & $0.025 \mathrm{e}-6 \mathrm{~s}$ \\
\hline Transverse Time-of-Flight, PE $\left(\mathrm{t}_{\mathrm{T} 31}\right)$ & $1.478 \mathrm{e}-6 \mathrm{~s}$ & $1.454 \mathrm{e}-6 \mathrm{~s}$ & $0.010 \mathrm{e}-6 \mathrm{~s}$ \\
\hline Transverse Time-of-Flight, PE $\left(\mathrm{t}_{\mathrm{T} 32}\right)$ & $1.478 \mathrm{e}-6 \mathrm{~s}$ & $1.464 \mathrm{e}-6 \mathrm{~s}$ & $0.010 \mathrm{e}-6 \mathrm{~s}$ \\
\hline
\end{tabular}

Once the basic measurements are determined, density and velocity measurements can be calculated. The density and wave velocity results with their uncertainties are shown in Table 3 for as-sprayed nickel and Table 4 for heat-treated nickel. Recall, the longitudinal wave velocities in the $45^{\circ}$ plane $\left(V_{L 45^{\circ}}\right)$ are approximations. It was necessary to approximate these values since the actual measurement would require grinding two parallel surfaces, at a $45^{\circ}$ angle, between the two described planes. Obtaining one of these measurements would prohibit obtaining values for the remaining surfaces. Therefore, an averaging approximation will be used as shown in Equations 4.7 -4.9. 
Table 3, Calculations of density and wave velocities with uncertainties for as-sprayed nickel.

\begin{tabular}{|c|c|c|}
\hline Feature & Result & Uncertainty \\
\hline Density $(\rho)$ & $8.401 \mathrm{e}+3 \mathrm{~kg} / \mathrm{m}^{3}$ & $0.069 \mathrm{e}+3 \mathrm{~kg} / \mathrm{m}^{3}$ \\
\hline Longitudinal Wave Velocity $\left(\mathrm{V}_{\mathrm{L} 1}\right)$ & $5.599 \mathrm{e}+3 \mathrm{~m} / \mathrm{s}$ & $0.052 \mathrm{e}+3 \mathrm{~m} / \mathrm{s}$ \\
\hline Longitudinal Wave Velocity $\left(\mathrm{V}_{\mathrm{L} 2}\right)$ & $5.560 \mathrm{e}+3 \mathrm{~m} / \mathrm{s}$ & $0.064 \mathrm{e}+3 \mathrm{~m} / \mathrm{s}$ \\
\hline Longitudinal Wave Velocity $\left(\mathrm{V}_{\mathrm{L} 3}\right)$ & $5.252 \mathrm{e}+3 \mathrm{~m} / \mathrm{s}$ & $0.067 \mathrm{e}+3 \mathrm{~m} / \mathrm{s}$ \\
\hline Longitudinal Wave Velocity $\left(\mathrm{V}_{\mathrm{L} 45^{\circ}, 23}\right)$ & $5.406 \mathrm{e}+3 \mathrm{~m} / \mathrm{s}$ & $0.046 \mathrm{e}+3 \mathrm{~m} / \mathrm{s}$ \\
\hline Longitudinal Wave Velocity $\left(\mathrm{V}_{\mathrm{L} 45^{\circ}, 13}\right)$ & $5.426 \mathrm{e}+3 \mathrm{~m} / \mathrm{s}$ & $0.042 \mathrm{e}+3 \mathrm{~m} / \mathrm{s}$ \\
\hline Longitudinal Wave Velocity $\left(\mathrm{V}_{\mathrm{L} 45^{\circ}, 12}\right)$ & $5.580 \mathrm{e}+3 \mathrm{~m} / \mathrm{s}$ & $0.041 \mathrm{e}+3 \mathrm{~m} / \mathrm{s}$ \\
\hline Transverse Wave Velocity $\left(\mathrm{V}_{\mathrm{T} 12}\right)$ & $2.985 \mathrm{e}+3 \mathrm{~m} / \mathrm{s}$ & $0.015 \mathrm{e}+3 \mathrm{~m} / \mathrm{s}$ \\
\hline Transverse Wave Velocity $\left(\mathrm{V}_{\mathrm{T} 13}\right)$ & $2.936 \mathrm{e}+3 \mathrm{~m} / \mathrm{s}$ & $0.015 \mathrm{e}+3 \mathrm{~m} / \mathrm{s}$ \\
\hline Transverse Wave Velocity $\left(\mathrm{V}_{\mathrm{T} 21}\right)$ & $2.988 \mathrm{e}+3 \mathrm{~m} / \mathrm{s}$ & $0.019 \mathrm{e}+3 \mathrm{~m} / \mathrm{s}$ \\
\hline Transverse Wave Velocity $\left(\mathrm{V}_{\mathrm{T} 23}\right)$ & $2.872 \mathrm{e}+3 \mathrm{~m} / \mathrm{s}$ & $0.017 \mathrm{e}+3 \mathrm{~m} / \mathrm{s}$ \\
\hline Transverse Wave Velocity $\left(\mathrm{V}_{\mathrm{T} 13}\right)$ & $2.878 \mathrm{e}+3 \mathrm{~m} / \mathrm{s}$ & $0.021 \mathrm{e}+3 \mathrm{~m} / \mathrm{s}$ \\
\hline Transverse Wave Velocity $\left(\mathrm{V}_{\mathrm{T} 32}\right)$ & $2.878 \mathrm{e}+3 \mathrm{~m} / \mathrm{s}$ & $0.021 \mathrm{e}+3 \mathrm{~m} / \mathrm{s}$ \\
\hline
\end{tabular}


Table 4, Calculations of density and wave velocities with uncertainties for heat-treated, sprayed nickel.

\begin{tabular}{|c|c|c|}
\hline Feature & Result & Uncertainty \\
\hline Density $(\rho)$ & $8.422 \mathrm{e}+3 \mathrm{~kg} / \mathrm{m}^{3}$ & $0.076 \mathrm{e}+3 \mathrm{~kg} / \mathrm{m}^{3}$ \\
\hline Longitudinal Wave Velocity $\left(\mathrm{V}_{\mathrm{L} 1}\right)$ & $5.517 \mathrm{e}+3 \mathrm{~m} / \mathrm{s}$ & $0.053 \mathrm{e}+3 \mathrm{~m} / \mathrm{s}$ \\
\hline Longitudinal Wave Velocity $\left(\mathrm{V}_{\mathrm{L} 2}\right)$ & $5.508 \mathrm{e}+3 \mathrm{~m} / \mathrm{s}$ & $0.065 \mathrm{e}+3 \mathrm{~m} / \mathrm{s}$ \\
\hline Longitudinal Wave Velocity $\left(\mathrm{V}_{\mathrm{L} 3}\right)$ & $5.446 \mathrm{e}+3 \mathrm{~m} / \mathrm{s}$ & $0.072 \mathrm{e}+3 \mathrm{~m} / \mathrm{s}$ \\
\hline Longitudinal Wave Velocity $\left(\mathrm{V}_{\mathrm{L} 45^{\circ}, 23}\right)$ & $5.477 \mathrm{e}+3 \mathrm{~m} / \mathrm{s}$ & $0.049 \mathrm{e}+3 \mathrm{~m} / \mathrm{s}$ \\
\hline Longitudinal Wave Velocity $\left(\mathrm{V}_{\mathrm{L} 45^{\circ}, 13}\right)$ & $5.482 \mathrm{e}+3 \mathrm{~m} / \mathrm{s}$ & $0.045 \mathrm{e}+3 \mathrm{~m} / \mathrm{s}$ \\
\hline Longitudinal Wave Velocity $\left(\mathrm{V}_{\mathrm{L} 45^{\circ}, 12}\right)$ & $5.513 \mathrm{e}+3 \mathrm{~m} / \mathrm{s}$ & $0.042 \mathrm{e}+3 \mathrm{~m} / \mathrm{s}$ \\
\hline Transverse Wave Velocity $\left(\mathrm{V}_{\mathrm{T} 12}\right)$ & $2.925 \mathrm{e}+3 \mathrm{~m} / \mathrm{s}$ & $0.015 \mathrm{e}+3 \mathrm{~m} / \mathrm{s}$ \\
\hline Transverse Wave Velocity $\left(\mathrm{V}_{\mathrm{T} 13}\right)$ & $2.896 \mathrm{e}+3 \mathrm{~m} / \mathrm{s}$ & $0.015 \mathrm{e}+3 \mathrm{~m} / \mathrm{s}$ \\
\hline Transverse Wave Velocity $\left(\mathrm{V}_{\mathrm{T} 21}\right)$ & $2.912 \mathrm{e}+3 \mathrm{~m} / \mathrm{s}$ & $0.018 \mathrm{e}+3 \mathrm{~m} / \mathrm{s}$ \\
\hline Transverse Wave Velocity $\left(\mathrm{V}_{\mathrm{T} 23}\right)$ & $2.869 \mathrm{e}+3 \mathrm{~m} / \mathrm{s}$ & $0.018 \mathrm{e}+3 \mathrm{~m} / \mathrm{s}$ \\
\hline Transverse Wave Velocity $\left(\mathrm{V}_{\mathrm{T} 31}\right)$ & $2.899 \mathrm{e}+3 \mathrm{~m} / \mathrm{s}$ & $0.022 \mathrm{e}+3 \mathrm{~m} / \mathrm{s}$ \\
\hline Transverse Wave Velocity $\left(\mathrm{V}_{\mathrm{T} 32}\right)$ & $2.879 \mathrm{e}+3 \mathrm{~m} / \mathrm{s}$ & $0.022 \mathrm{e}+3 \mathrm{~m} / \mathrm{s}$ \\
\hline
\end{tabular}

After the density and wave velocities are determined, the elastic constants can be calculated. The elastic stiffness constants with their uncertainties are shown for assprayed nickel in Table 5 and heat-treated nickel in Table 6 . The published values for the elastic stiffness constants are for a nickel monocrystal at ambient temperature [22].

Table 5, Elastic stiffness constants and uncertainties for as-sprayed nickel.

\begin{tabular}{|c|c|c|c|}
\hline Elastic Constant & Value & Uncertainty & Bulk Nickel \\
\hline $\mathrm{C}_{11}$ & $263.4 \mathrm{GPa}$ & $5.4 \mathrm{GPa}$ & $246.5 \mathrm{GPa}$ \\
\hline $\mathrm{C}_{33}$ & $231.8 \mathrm{GPa}$ & $6.2 \mathrm{GPa}$ & $246.5 \mathrm{GPa}$ \\
\hline $\mathrm{C}_{44}$ & $69.6 \mathrm{GPa}$ & $1.1 \mathrm{GPa}$ & $124.7 \mathrm{GPa}$ \\
\hline $\mathrm{C}_{66}$ & $75.0 \mathrm{GPa}$ & $1.1 \mathrm{GPa}$ & $124.7 \mathrm{GPa}$ \\
\hline $\mathrm{C}_{12}$ & $113.4 \mathrm{GPa}$ & $5.8 \mathrm{GPa}$ & $147.3 \mathrm{GPa}$ \\
\hline $\mathrm{C}_{13}$ & $107.2 \mathrm{GPa}$ & $6.2 \mathrm{GPa}$ & $147.3 \mathrm{GPa}$ \\
\hline
\end{tabular}


Table 6, Elastic stiffness constants and uncertainties for heat-treated, sprayed nickel.

\begin{tabular}{|c|c|c|c|}
\hline Elastic Constant & Value & Uncertainty & Bulk Nickel \\
\hline $\mathrm{C}_{11}$ & $256.4 \mathrm{GPa}$ & $5.5 \mathrm{GPa}$ & $246.5 \mathrm{GPa}$ \\
\hline $\mathrm{C}_{33}$ & $249.8 \mathrm{GPa}$ & $7.0 \mathrm{GPa}$ & $246.5 \mathrm{GPa}$ \\
\hline $\mathrm{C}_{44}$ & $69.8 \mathrm{GPa}$ & $1.2 \mathrm{GPa}$ & $124.7 \mathrm{GPa}$ \\
\hline $\mathrm{C}_{66}$ & $71.4 \mathrm{GPa}$ & $1.1 \mathrm{GPa}$ & $124.7 \mathrm{GPa}$ \\
\hline $\mathrm{C}_{12}$ & $113.6 \mathrm{GPa}$ & $5.9 \mathrm{GPa}$ & $147.3 \mathrm{GPa}$ \\
\hline $\mathrm{C}_{13}$ & $113.4 \mathrm{GPa}$ & $6.8 \mathrm{GPa}$ & $147.3 \mathrm{GPa}$ \\
\hline
\end{tabular}

Finally, once the elastic stiffness constants and their uncertainties are known, shear moduli $(G)$, Poisson's ratios $(v)$, and Young's moduli $(E)$, including their upper and lower bounds, can be determined. The results of these calculations, including the published values for nickel at ambient temperature [17], are shown in Table 7 for assprayed nickel and Table 8 for heat-treated nickel.

Table 7, Calculation of shear moduli, Poisson's ratios, and Young's moduli with bounds for as-sprayed nickel and published values for bulk nickel.

\begin{tabular}{|c|c|c|c|c|}
\hline $\begin{array}{c}\text { Mechanical } \\
\text { Property }\end{array}$ & $\begin{array}{c}\text { Lower } \\
\text { Bound }\end{array}$ & $\begin{array}{c}\text { Nominal } \\
\text { Value }\end{array}$ & $\begin{array}{c}\text { Upper } \\
\text { Bound }\end{array}$ & $\begin{array}{c}\text { Bulk } \\
\text { Nickel }\end{array}$ \\
\hline $\mathrm{G}_{23}$ & $68.5 \mathrm{GPa}$ & $69.6 \mathrm{GPa}$ & $70.7 \mathrm{GPa}$ & $70 \mathrm{GPa}$ \\
\hline $\mathrm{G}_{13}$ & $68.5 \mathrm{GPa}$ & $69.6 \mathrm{GPa}$ & $70.7 \mathrm{GPa}$ & $70 \mathrm{GPa}$ \\
\hline $\mathrm{G}_{12}$ & $73.9 \mathrm{GPa}$ & $75.0 \mathrm{GPa}$ & $76.1 \mathrm{GPa}$ & $70 \mathrm{GPa}$ \\
\hline$v_{12}$ & 0.239 & 0.299 & 0.355 & 0.31 \\
\hline$v_{13}$ & 0.274 & 0.324 & 0.382 & 0.31 \\
\hline $\mathrm{E}_{1}$ & $172.3 \mathrm{GPa}$ & $194.8 \mathrm{GPa}$ & $215.4 \mathrm{GPa}$ & $207 \mathrm{GPa}$ \\
\hline $\mathrm{E}_{2}$ & $172.3 \mathrm{GPa}$ & $194.8 \mathrm{GPa}$ & $215.4 \mathrm{GPa}$ & $207 \mathrm{GPa}$ \\
\hline $\mathrm{E}_{3}$ & $155.3 \mathrm{GPa}$ & $170.8 \mathrm{GPa}$ & $185.4 \mathrm{GPa}$ & $207 \mathrm{GPa}$ \\
\hline
\end{tabular}


Table 8, Calculation of shear moduli, Poisson's ratios, and Young's moduli with bounds for heat-treated, sprayed nickel and published values for nickel.

\begin{tabular}{|c|c|c|c|c|}
\hline $\begin{array}{c}\text { Mechanical } \\
\text { Property }\end{array}$ & $\begin{array}{c}\text { Lower } \\
\text { Bound }\end{array}$ & $\begin{array}{c}\text { Nominal } \\
\text { Value }\end{array}$ & $\begin{array}{c}\text { Upper } \\
\text { Bound }\end{array}$ & $\begin{array}{c}\text { Bulk } \\
\text { Nickel }\end{array}$ \\
\hline $\mathrm{G}_{23}$ & $68.7 \mathrm{GPa}$ & $69.8 \mathrm{GPa}$ & $71.0 \mathrm{GPa}$ & $70 \mathrm{GPa}$ \\
\hline $\mathrm{G}_{13}$ & $68.7 \mathrm{GPa}$ & $69.8 \mathrm{GPa}$ & $71.0 \mathrm{GPa}$ & $70 \mathrm{GPa}$ \\
\hline $\mathrm{G}_{12}$ & $70.3 \mathrm{GPa}$ & $71.4 \mathrm{GPa}$ & $72.5 \mathrm{GPa}$ & $70 \mathrm{GPa}$ \\
\hline$v_{12}$ & 0.238 & 0.303 & 0.364 & 0.31 \\
\hline$v_{13}$ & 0.264 & 0.316 & 0.377 & 0.31 \\
\hline $\mathrm{E}_{1}$ & $162.1 \mathrm{GPa}$ & $186.1 \mathrm{GPa}$ & $208.1 \mathrm{GPa}$ & $207 \mathrm{GPa}$ \\
\hline $\mathrm{E}_{2}$ & $162.1 \mathrm{GPa}$ & $186.1 \mathrm{GPa}$ & $208.1 \mathrm{GPa}$ & $207 \mathrm{GPa}$ \\
\hline $\mathrm{E}_{3}$ & $162.2 \mathrm{GPa}$ & $180.3 \mathrm{GPa}$ & $197.2 \mathrm{GPa}$ & $207 \mathrm{GPa}$ \\
\hline
\end{tabular}

The nominal shear moduli value, $G_{23}$, for cold gas-dynamic spray nickel in the assprayed condition closely matches a typical value for bulk nickel, while $G_{12}$ has a larger value that the typical value for bulk nickel. Similarly, for Poisson's ratios, $v_{12}$ and $v_{13}$, the nominal value for $v_{12}$ is less than the value for bulk nickel, while $v_{13}$ is greater than the value for bulk nickel. Young's moduli are all less than the typical values for bulk nickel but, $E_{1}$ is greater than $E_{3}$. When the cold gas-dynamic spray nickel is heattreated, the measured values for shear moduli, Poisson's ratios, and Young's moduli have less of a difference than the measured values for the as-sprayed material. This would indicate that the heat treatment process is relieving nearly all of the internal stresses, allowing the material to become more isotropic, or have similar material properties in all directions.

\subsubsection{Imaging}

Ultrasonic imaging can be used to gain an understanding of the consistency within any given material. Imperfections, inclusions, and pores in a material can cause weak, slow signals. These ultrasonic images, taken through the thickness of the cold gas-dynamic nickel specimens, were created using a pulse-echo method. The step size was 0.005 inches with a wave frequency of $25 \mathrm{MHz}$.

Figure 11 shows the signal amplitude of the cold gas-dynamic spray nickel in the assprayed (left) and heat-treated (right) conditions. The specimen in the as-sprayed condition appears to have only a very small region where the amplitude of the signal is at 


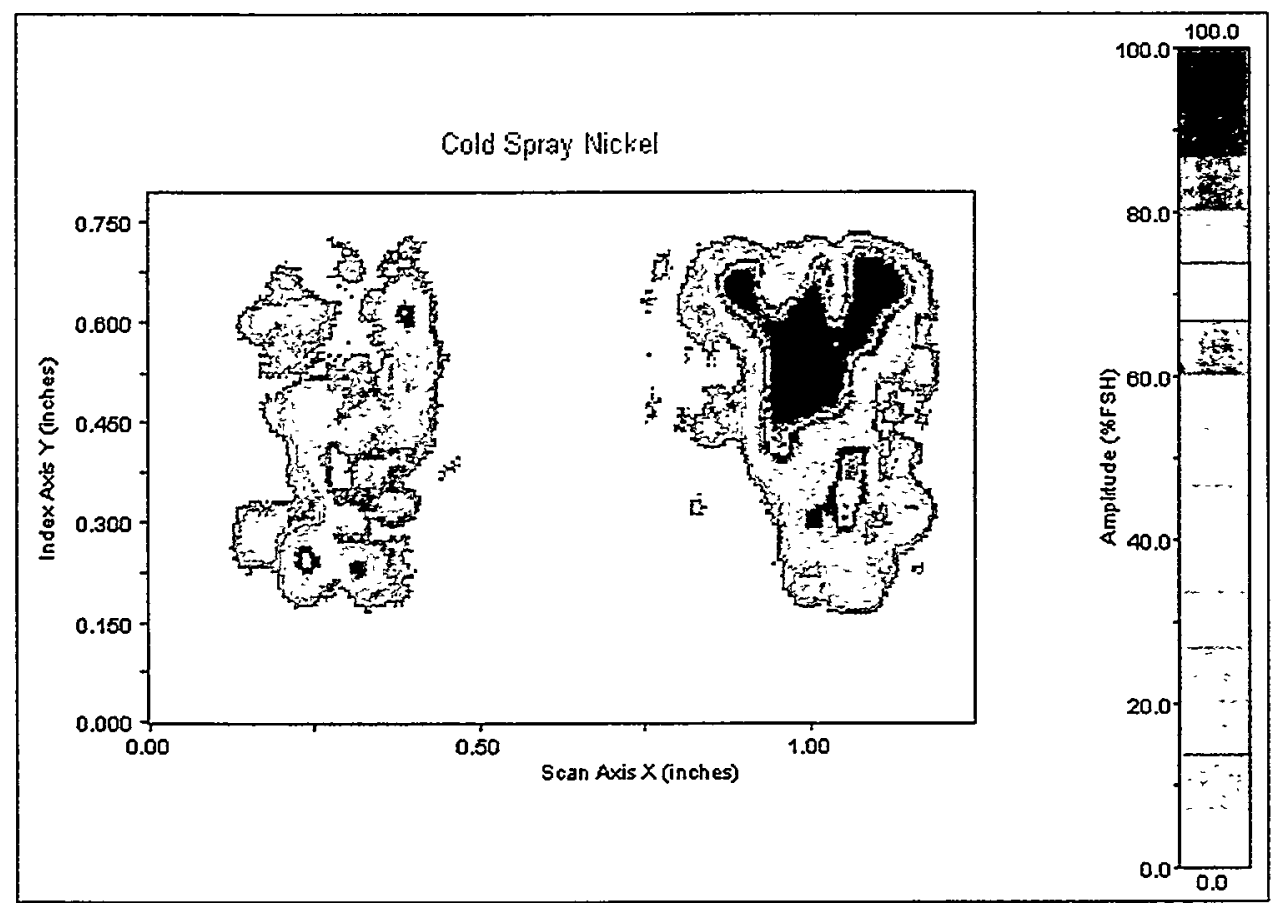

Figure 11, Ultrasonic, signal amplitude images of the cold gas-dynamic spray nickel in the as-sprayed (left) and heat-treated (right) conditions.

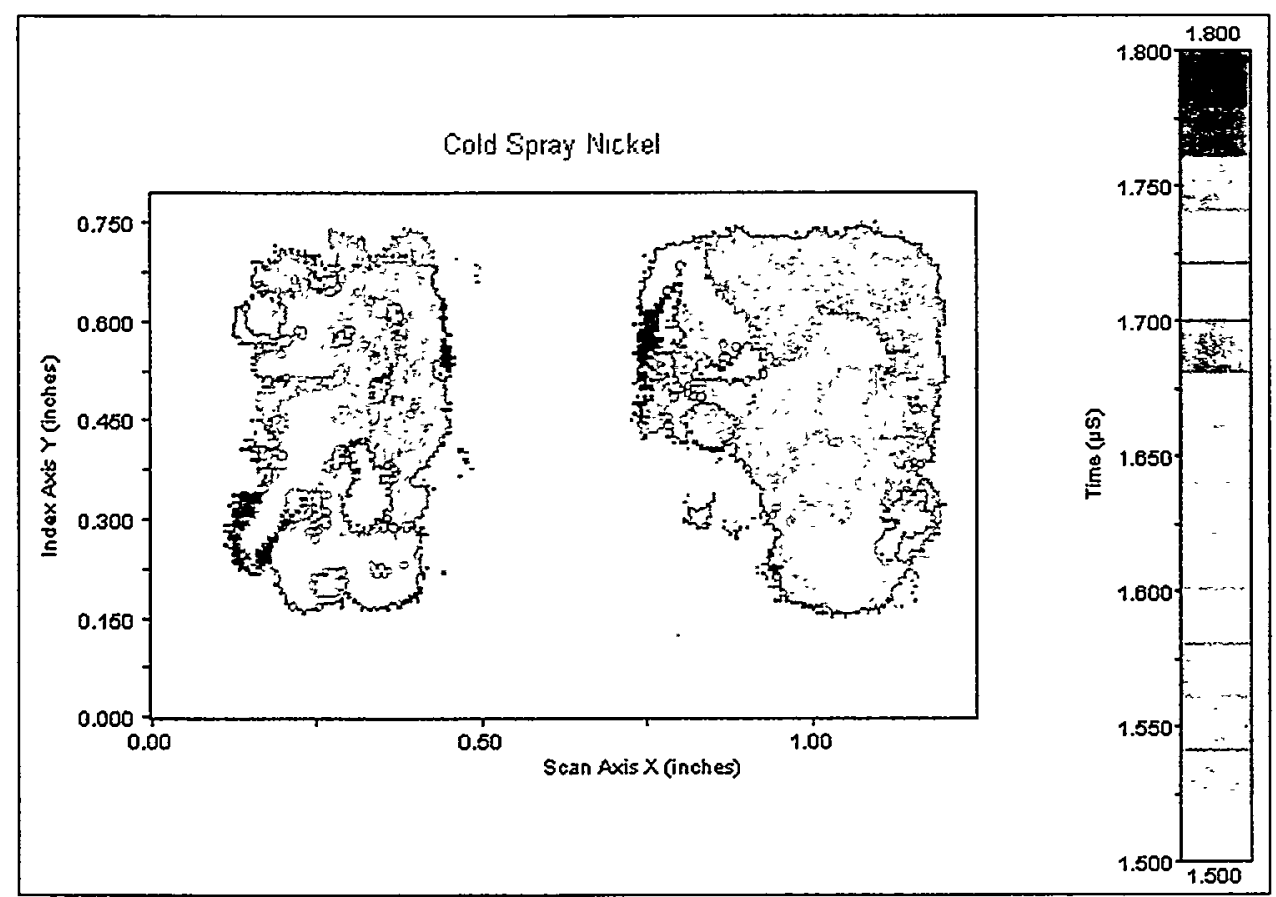

Figure 12, Ultrasonic, pulse-echo time images of the cold gas-dynamic spray nickel in the as-sprayed (left) and heat-treated (right) conditions. 
$75 \%$, with a large portion of the specimen showing an amplitude less than 50\%. This indicates that the cold gas-dynamic spray nickel in the as-spray condition has poor material consistency. There are many imperfections, inclusions, or pores in the material preventing a strong signal. The specimen in the heat-treated condition shows a relatively large region where a strong signal passes through the material. In this region, the material consistency is near perfect.

Figure 12 shows the round trip, time-of-flight of the wave for same cold gas-dynamic spray, nickel specimens. Again, the cold gas-dynamic spray nickel in the as-sprayed condition shows a wide range of times for the round trip time-of-flight. Generally, it appears as though the round trip time-of-flight is approximately $1.64 \mu \mathrm{s}$, indicating a longitudinal time-of-flight of $0.82 \mu \mathrm{s}$, which compares closely to $0.8100 \mu \mathrm{s}$ as shown in Table 2. The specimen in the heat-treated condition shows large areas of similar times. The largest portion of this specimen, with the best time, indicates a round trip time-offlight of $1.57 \mu \mathrm{s}$. The longitudinal time-of-flight would be $0.78 \mu \mathrm{s}$, which also compares closely to $0.7742 \mu$ s as shown in Table 2 .

Overall, the cold gas-dynamic spray nickel in the as-sprayed condition shows relatively low amplitude signals with a large variation for the flight times. This would indicate that the material contains imperfections, inclusions, or pores that would prohibit faster flight times with higher amplitudes. The cold gas-dynamic spray nickel in the heat-treated condition has a region where the amplitude of the signal is the strongest. Also in the same region, the flight time is the shortest, indicating a lack of imperfections, inclusions, and pores. The heat treatment process appears to have removed many of these imperfections, inclusions, and pores within the material.

\subsection{Sharp Indentation Testing}

Sharp indentation testing is also known as nanoindentation testing. It combines continuous recording of loads and displacements while regulating the loading rate and velocity. This test was originally designed to determine the material characteristics of thin coatings. The test also generates data that are meaningful in determining properties from the load-depth curve. In the test, operator error and bias are eliminated, and results yield more information than hardness numbers. A wide range of indenters can be used, such as Vickers, Knoop, Berkovich, Meyer, Brinell, and Rockwell [23].

For this experiment a NanoIndentor XP system was used with a Berkovich indenter. The cold gas-dynamic spray nickel in the as-sprayed and heat-treated conditions were polished using $\mathrm{SiC}$ grit paper. The final polish was done with 1200 grit $\mathrm{SiC}$ paper. The indentation testing was performed at a constant strain rate of $0.05 \mathrm{~s}^{-1}$, to a depth of $2000 \mathrm{~nm}$. A total of ten indents per specimen were performed and the data sets were then averaged to produce a single set of loading and unloading data for each specimen. The experimental results for the cold gas-dynamic spray nickel in the as-sprayed and heattreated conditions are shown in Figure 13. 


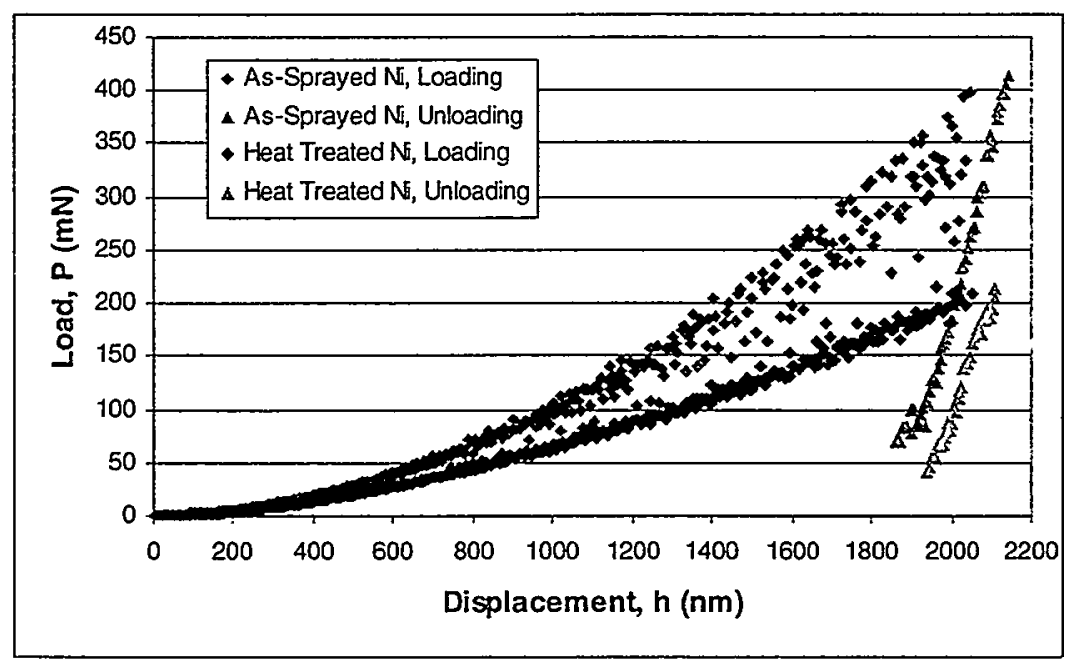

Figure 13, Actual indentation load vs. displacement of loading and unloading for cold gas-dynamic spray nickel in the as-sprayed and heat-treated conditions.

$$
\begin{array}{ll}
P=3.706 \times 10^{-4} h^{1.804} & R^{2}=0.9977 \\
P=1.550 h-2910 & R^{2}=0.9939 \\
P=5.830 \times 10^{-4} h^{1.679} & R^{2}=0.9993 \\
P=1.049 h-2003 & R^{2}=0.9826
\end{array}
$$

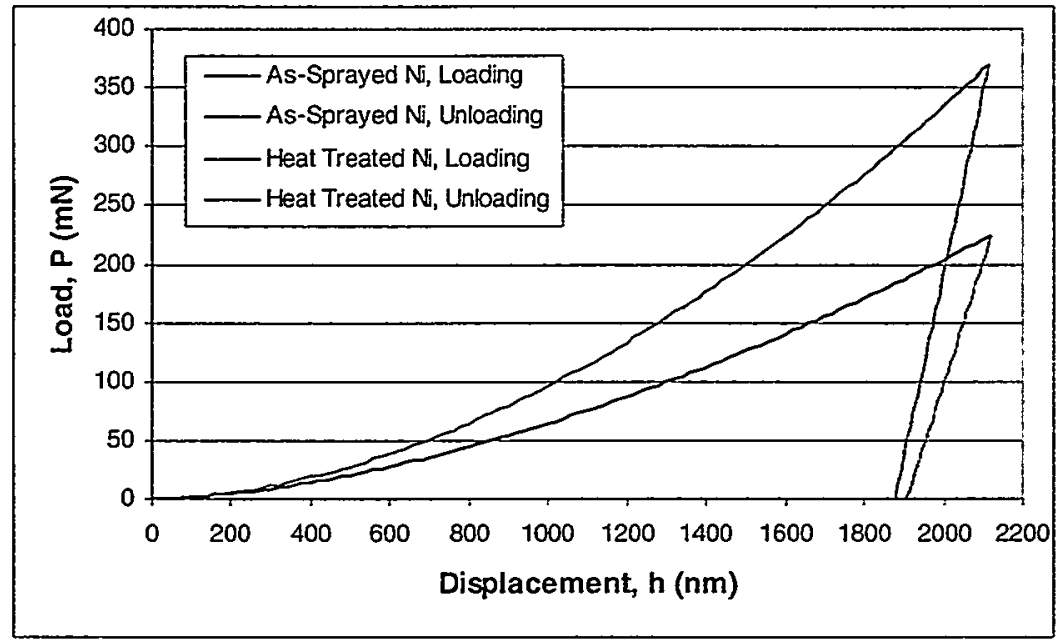

Figure 14, Modeled indentation load vs. displacement of loading and unloading for cold gas-dynamic spray nickel in the as-sprayed and heat-treated conditions. 
Curve fits were determined for the two portions of each load-displacement curve. The equations, including the correlation coefficients, for the loading and unloading portions of the cold gas-dynamic spray nickel in the as-sprayed condition are represented with Equations $4.33-4.34$ respectively. The equations for the loading and unloading portions of the cold gas-dynamic spray nickel in the heat-treated condition are represented with Equations $4.35-4.36$ respectively. The data produced from these models are shown in Figure 14.

Once the quantitative indentation load-displacement curves have been obtained for both loading and unloading of the stress free material and the material with residual stresses, the following determination can be made [24]. The sign of the residual stress can be determined. The curve for the cold gas-dynamic spray nickel in the heat-treated condition is below the curve for the cold gas-dynamic spray nickel in the as-sprayed condition. This indicates that the residual stresses in the as-sprayed nickel are compressive, or negative in sign.

Unfortunately, a quantitative assessment of the residual stress cannot be determined using the method outlined by S. Suresh and A.E. Giannakopoulos [24]. The reason is that the stresses are not an equal-biaxial state of residual stresses. As the nanoindenter travels, it encounters varying stress states, which are not equal-biaxial. Therefore, only a qualitative assessment of the type of residual stresses can be determined.

\subsection{Hardness Testing}

The Rockwell hardness test is a commonly used method for determining hardness for several reasons. It is a simple test to perform. A Rockwell hardness test can determine the hardness a wide range of metals and alloys. The entire test operation only takes 5 to 10 seconds to complete. Finally, readings can be taken from a digital display [23]. The Rockwell hardness test consists of measuring the additional depth to which the indenter is forced by a heavy load beyond the depth of a previously applied light load. This testing method causes the indenter to break through slight surface roughness and crush foreign particles, therefore allowing a much more accurate test. The light load is applied first, and then the heavy load is applied. After the heavy load is removed, the Rockwell hardness number is displayed on the digital readout.

For this experiment a Wilson Series 2000, Model 2000 TB was used on the Rockwell A scale. Two specimens of cold gas-dynamic spray nickel were tested; one in the assprayed condition and other in the heat-treated condition. Both nickel specimens were tested after being ground and polished. The data obtained from the Rockwell A hardness experiment are shown in Table 9. Five readings were taken in the 1 and 2-directions and five readings were taken in the 3-direction. The 3-direction is the direction of the particle deposition. Table 10 shows the average and standard deviation analysis for each direction. Since the individual sets are not unique for the same process parameters, average and standard deviation for the combined directions are shown at the bottom of the table. 
Table 9, Data obtained from Rockwell A hardness testing for cold gas-dynamic spray nickel in the as-sprayed and heat-treated conditions.

\begin{tabular}{|c|c|c|c|}
\hline \multicolumn{2}{|c|}{ As-Sprayed } & \multicolumn{2}{c|}{ Heat-Treated } \\
\hline 1 \& 2-Directions & 3-Direction & 1 \& 2-Directions & 3-Direction \\
\hline 62.1 & 63.7 & 38.7 & 39.6 \\
\hline 58.7 & 67.6 & 41.9 & 33.5 \\
\hline 58.5 & 62.2 & 41.7 & 37.6 \\
\hline 63.2 & 62.6 & 41.6 & 36.1 \\
\hline 64.0 & 58.9 & 38.3 & 37.4 \\
\hline
\end{tabular}

Table 10, Statistical analysis results of Rockwell A hardness testing for cold gas-dynamic spray nickel in the as-sprayed and heat-treated conditions.

\begin{tabular}{|c|c|c|c|}
\hline \multicolumn{2}{|c|}{ As-Sprayed } & \multicolumn{2}{c|}{ Heat-Treated } \\
\hline 1 \& 2-Directions & 3-Direction & 1 \& 2-Directions & 3-Direction \\
\hline Average $=61.3$ & Average $=63.0$ & Average $=40.4$ & Average $=36.8$ \\
\hline Std. Dev. $=2.6$ & Std. Dev. $=3.1$ & Std. Dev. $=1.8$ & Std. Dev. $=2.2$ \\
\hline \multicolumn{2}{|c|}{ Average $=62.2$} & \multicolumn{2}{c|}{ Average $=38.6$} \\
\hline \multicolumn{2}{|c|}{ Std. Dev. $=2.8$} & \multicolumn{2}{c|}{ Std. Dev. $=2.7$} \\
\hline
\end{tabular}

A Rockwell A hardness number of 62.2 corresponds to a Brinell hardness number of 245 , which indicates an ultimate strength between 807 and $876 \mathrm{MPa}$. A Rockwell A hardness number of 38.6 corresponds to a Brinell hardness number of 104, which indicates an ultimate strength between 338 and $400 \mathrm{MPa}[23,27]$. Overall, this test shows the cold gas-dynamic spray nickel in the as-sprayed condition is more than twice as hard, on the Brinell scale, and has more than twice the ultimate strength of the cold gas-dynamic spray nickel in the heat-treated condition. A tradeoff has occurred between strength and ductility. When specimens are heat-treated, the hardness decreases, thus, reducing the ultimate strength of the cold gas-dynamic spray nickel.

\subsection{Tensile Testing}

There are several reasons for tensile testing. The results of a tensile test can be used in selecting materials for engineering applications. Tensile properties are measured when new materials or processes are developed. Then these properties can be compared to other materials and processes. Also, tensile properties are used to predict the behavior of a material under forms of loading other than uniaxial tension. The strength of a material may be a primary concern. The strength may be measured in terms of the stress 
necessary to cause plastic deformation, or the maximum stress the material can withstand. Low ductility in a tensile test often accompanies low resistance to fracture under loading. Elastic properties can also be measured by ultrasonic techniques and tend to give more accurate measurements.

The force measurement system in the tensile-testing machine will employ strain-gage load cells. The strain gages will undergo electrical resistance changes when there is mechanical deformation. The tensile-testing equipment uses a load cell connected to a bridge circuit to measure small changes in resistance, and therefore, changes in the applied load. The circuit is excited with a signal generated by the load cell amplifier. An applied force causes the strain-gage bridge circuit to be unbalanced. This signal is returned to the amplifier and converted into an output signal that is proportional to the applied force. This applied force is then captured and stored on a computer [25].

The tensile specimens were placed in a mounting jig and inserted into a load cell. Then load cell was then zeroed, and the screws of mounting jig were tightened [26]. A laser beam was then centered on the tabs of the tensile specimen to measure the strain. The test cycle for the tensile specimens was to first ramp up to $0.06 \mathrm{~mm}$, under stroke control, at a stroke rate of $0.006 \mathrm{~mm} / \mathrm{s}$. Then the control method was switched to force control and ramped down to $10 \mathrm{~N}$ at a rate of $10 \mathrm{~N} / \mathrm{s}$. Finally, the control method was switched back to stroke control and ramped up to failure at a stroke rate of $0.006 \mathrm{~mm} / \mathrm{s}$. This test sequence generated a strain rate of approximately $0.001 \mathrm{~s}^{-1}$. Figure 15 shows the details of the tensile test specimen, drawn in $\mathrm{mm}$. The applied force will be in the 1-direction until fracture. The information obtained from the engineering stress-strain curves will be Young's modulus $\left(E_{1}\right)$, yield strength $\left(\sigma_{y}\right)$, ultimate strength $\left(\sigma_{u}\right)$ and fracture $\operatorname{strain}\left(\varepsilon_{f}\right)$.

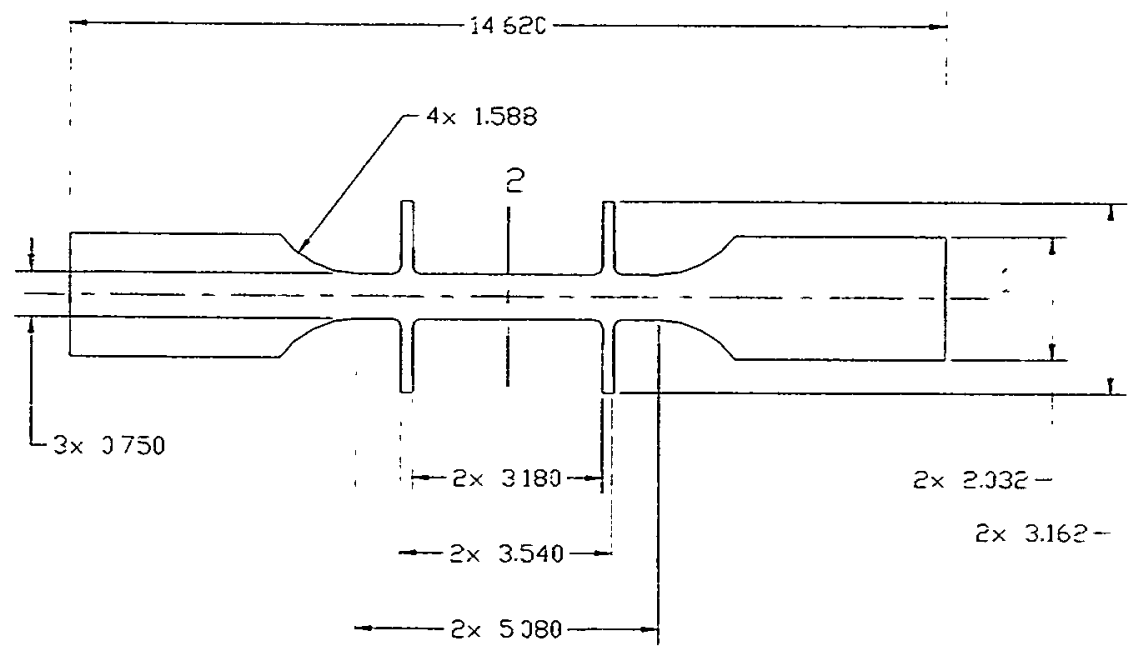

Figure 15, Details of tensile specimen, drawn in $\mathbf{m m}$. 


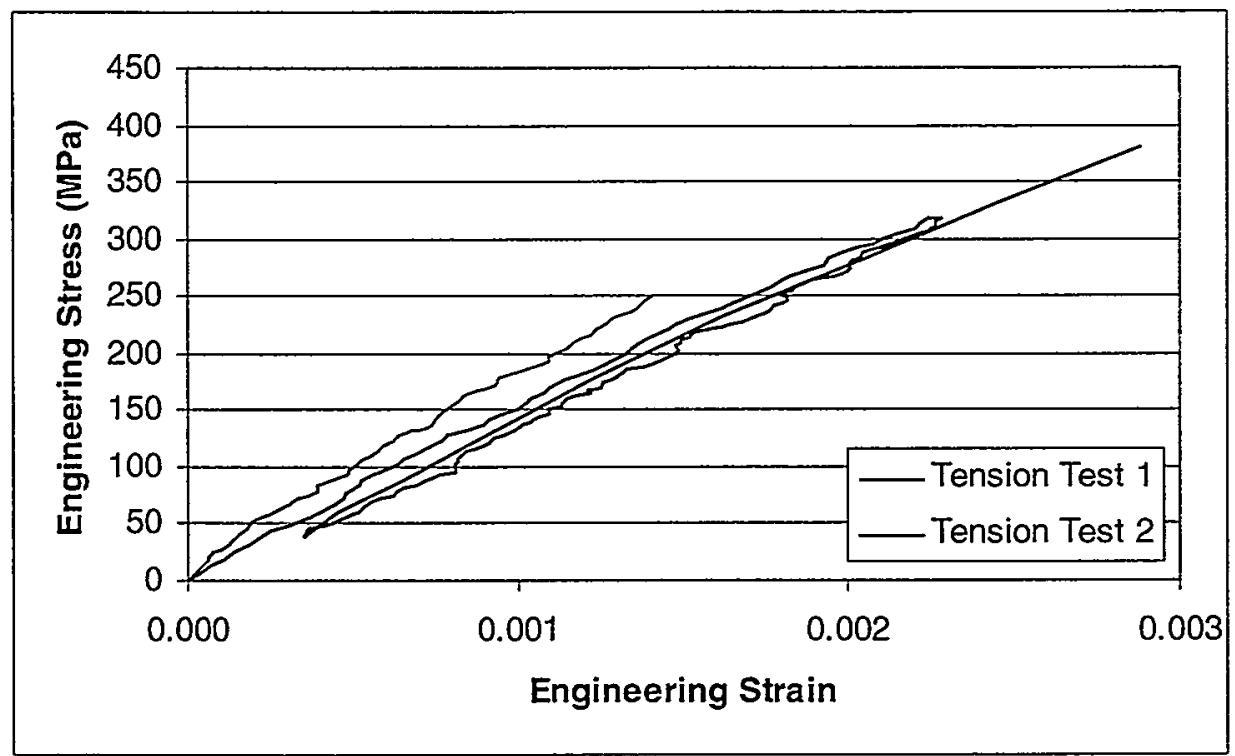

Figure 16, Tension test, engineering stress vs. engineering strain for cold gas-dynamic spray nickel in the as-sprayed condition.

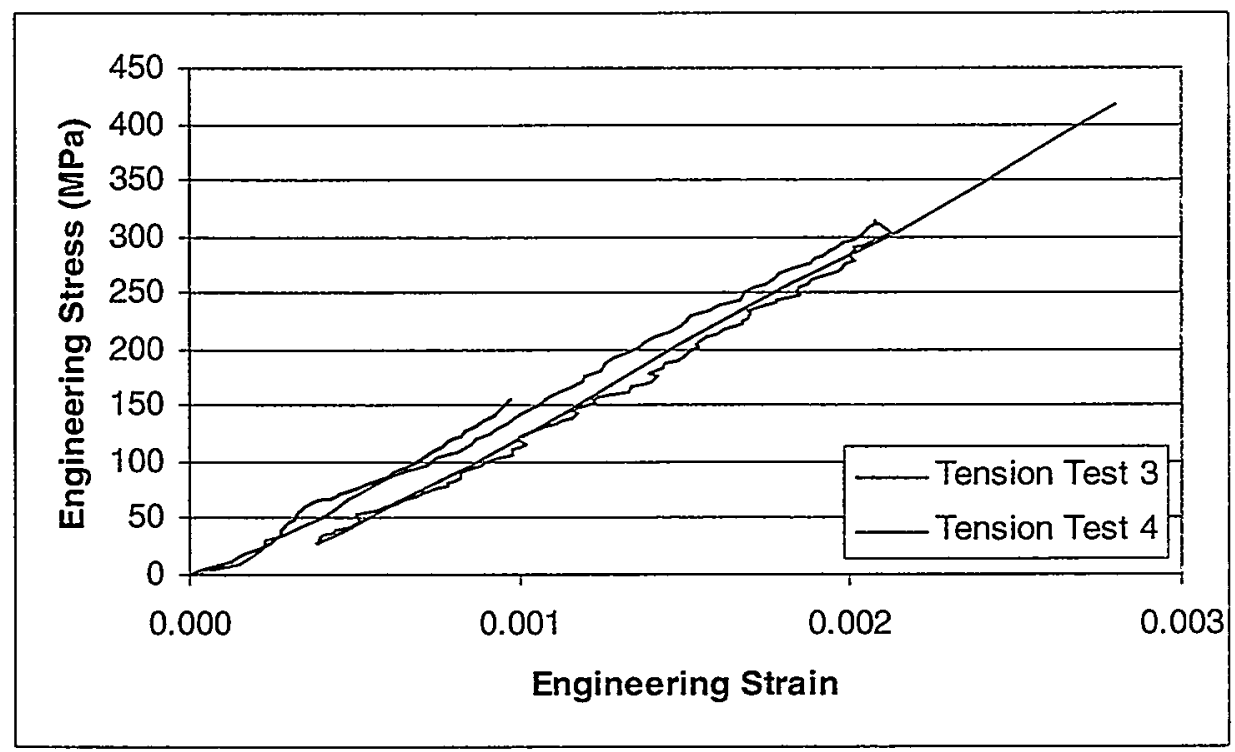

Figure 17, Tension test, engineering stress vs. engineering strain for cold gas-dynamic spray nickel in the as-sprayed condition.

Figures 16 and 17 show the engineering stress vs. engineering strain of four tensile specimens that were tested in the as-sprayed condition. Table 11 shows the Young's modulus $\left(E_{1}\right)$, yield strength $\left(\sigma_{y}\right)$, ultimate strength $\left(\sigma_{u}\right)$, and fracture strain $\left(\varepsilon_{f}\right)$ for these four nickel, tensile specimens. Also shown in this table are the typical values for 
these material properties of bulk nickel at ambient temperature [17] and electroplated nickel at a current density of $40 \mathrm{~mA} / \mathrm{cm}^{2}$ [1]. Since these as-sprayed tensile specimens display significant brittle behavior, the yield strength will be assumed to be equal to the ultimate strength.

Table 11, Young's modulus, yield strength, ultimate strength, and fracture strain, for cold gas-dynamic spray nickel in the as-sprayed condition, including typical values for bulk nickel and electroplated nickel.

\begin{tabular}{|c|c|c|c|c|}
\hline & $\begin{array}{c}\text { Young's } \\
\text { Modulus } \\
\left(E_{1}\right)\end{array}$ & $\begin{array}{c}\text { Yield } \\
\text { Strength } \\
\left(\sigma_{y}\right)\end{array}$ & $\begin{array}{c}\text { Ultimate } \\
\text { Strength } \\
\left(\sigma_{u}\right)\end{array}$ & $\begin{array}{c}\text { Fracture } \\
\text { Strain } \\
\left(\varepsilon_{f}\right)\end{array}$ \\
\hline Tension Test 1 & $165 \mathrm{GPa}$ & $251 \mathrm{MPa}$ & $251 \mathrm{MPa}$ & 0.00000 \\
Tension Test 2 & $153 \mathrm{GPa}$ & $374 \mathrm{MPa}$ & $374 \mathrm{MPa}$ & 0.00047 \\
Tension Test 3 & $160 \mathrm{GPa}$ & $419 \mathrm{MPa}$ & $419 \mathrm{MPa}$ & 0.00001 \\
Tension Test 4 & $155 \mathrm{GPa}$ & $156 \mathrm{MPa}$ & $156 \mathrm{MPa}$ & 0.00024 \\
\hline Average Value & $158 \mathrm{GPa}$ & $300 \mathrm{MPa}$ & $300 \mathrm{MPa}$ & 0.00018 \\
Standard Deviation & $6 \mathrm{GPa}$ & $119 \mathrm{MPa}$ & $119 \mathrm{MPa}$ & 0.00022 \\
\hline Bulk Nickel & $207 \mathrm{GPa}$ & $59 \mathrm{MPa}$ & $317 \mathrm{MPa}$ & 0.30 \\
\hline Electroplated Nickel & $155 \pm 11 \mathrm{GPa}$ & $305 \pm 12 \mathrm{MPa}$ & $562 \pm 9 \mathrm{MPa}$ & $0.124 \pm 0.005$ \\
\hline
\end{tabular}

Figures 18 and 19 show engineering stress vs. engineering strain of four tensile specimens that were tested in a heat-treated condition. Table 12 shows Young's modulus $\left(E_{1}\right)$, yield strength $\left(\sigma_{y}\right)$, ultimate strength $\left(\sigma_{u}\right)$, and fracture strain $\left(\varepsilon_{f}\right)$ for these four nickel, tensile specimens. Also shown in this table are the typical values for these material properties of bulk nickel at ambient temperature [17] and electroplated nickel at a current density of $40 \mathrm{~mA} / \mathrm{cm}^{2}$ [1]. Since these heat-treated tensile specimens displayed increased ductility and plasticity, yield strength will be determined using a $0.2 \%$ offset. 


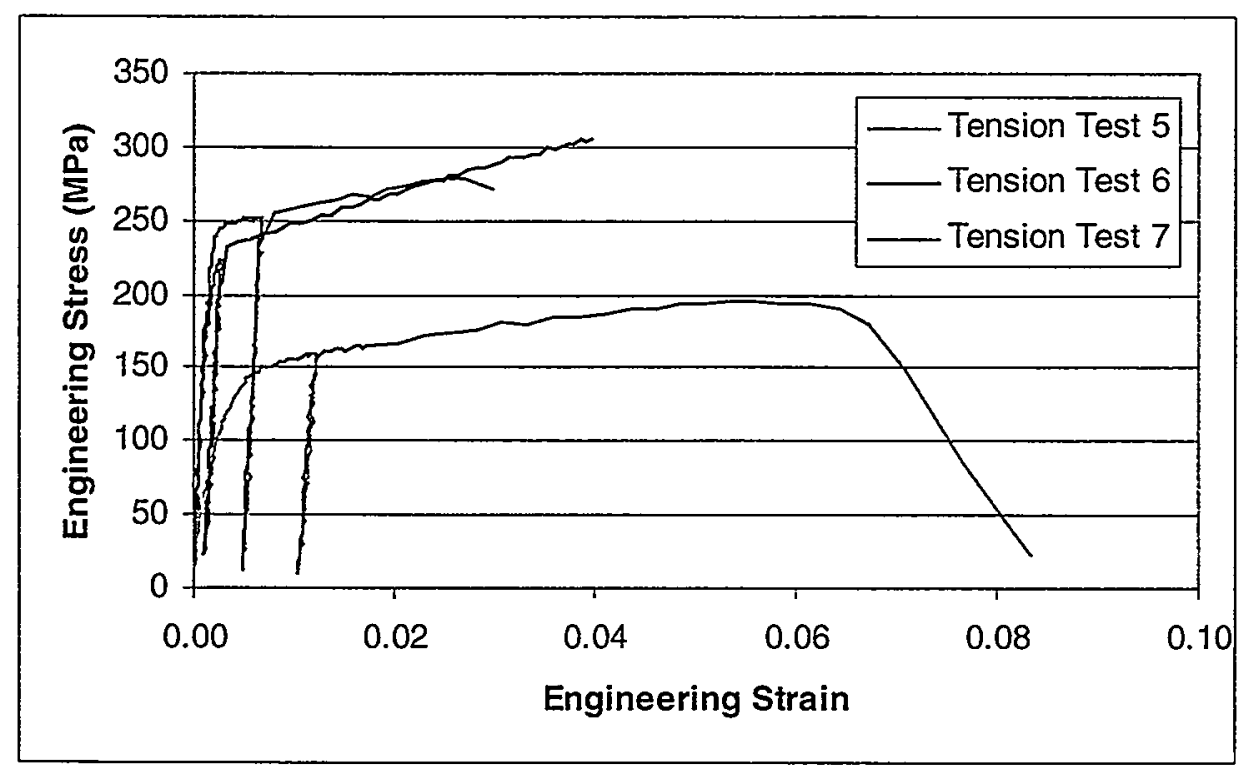

Figure 18, Tension test, engineering stress vs. engineering strain for cold gas-dynamic spray nickel in the heat-treated condition.

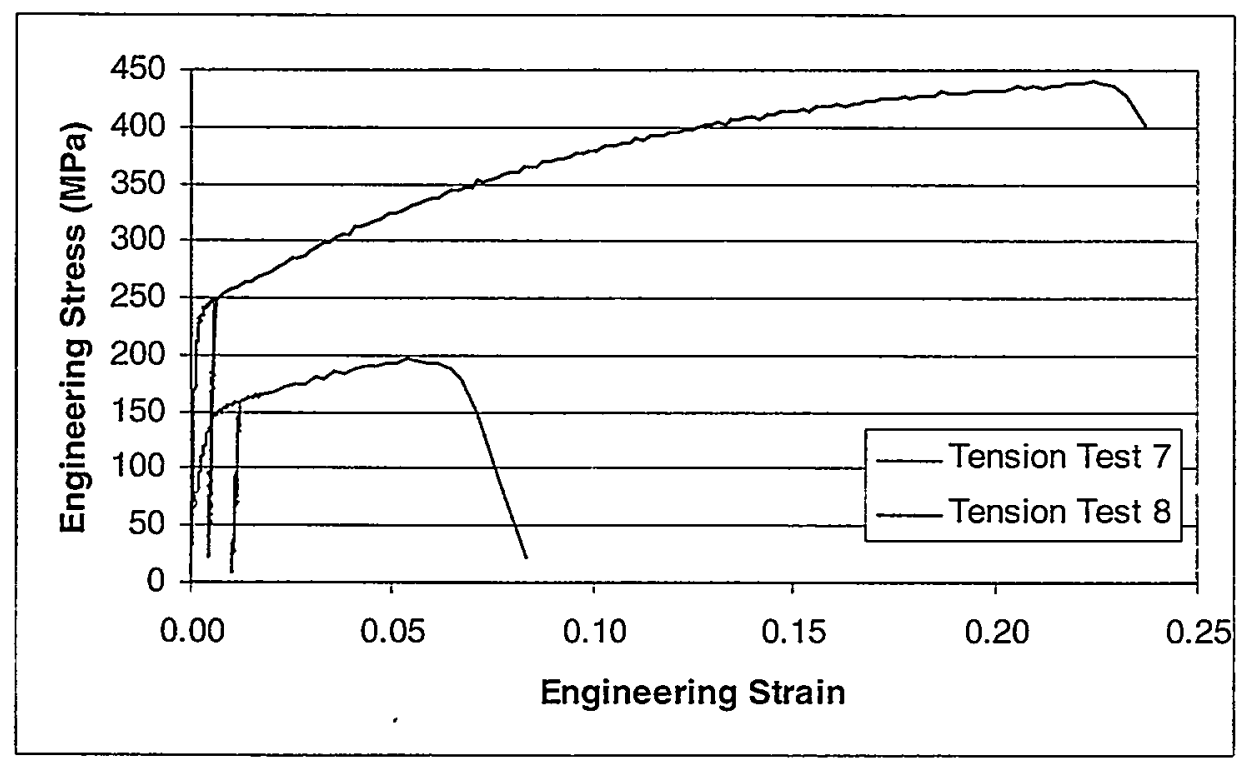

Figure 19, Tension test, engineering stress vs. engineering strain for cold gas-dynamic spray nickel in the heat-treated condition. 
Table 12, Young's modulus, yield strength, ultimate strength, and

fracture strain, for cold gas-dynamic spray nickel in the heat-treated condition, including typical values for bulk nickel and electroplated nickel.

\begin{tabular}{|c|c|c|c|c|}
\hline & $\begin{array}{c}\text { Young's } \\
\text { Modulus } \\
\left(E_{1}\right)\end{array}$ & $\begin{array}{c}\text { Yield } \\
\text { Strength } \\
\left(\sigma_{y}\right)\end{array}$ & $\begin{array}{c}\text { Ultimate } \\
\text { Strength } \\
\left(\sigma_{u}\right)\end{array}$ & $\begin{array}{c}\text { Fracture } \\
\text { Strain } \\
\left(\varepsilon_{f}\right)\end{array}$ \\
\hline Tension Test 5 & $133 \mathrm{GPa}$ & $248 \mathrm{MPa}$ & $278 \mathrm{MPa}$ & 0.0278 \\
Tension Test 6 & $126 \mathrm{GPa}$ & $231 \mathrm{MPa}$ & $305 \mathrm{MPa}$ & 0.0372 \\
Tension Test 7 & $84 \mathrm{GPa}$ & $122 \mathrm{MPa}$ & $196 \mathrm{MPa}$ & 0.0831 \\
Tension Test 8 & $159 \mathrm{GPa}$ & $229 \mathrm{MPa}$ & $439 \mathrm{MPa}$ & 0.2343 \\
\hline Average Value & $125 \mathrm{GPa}$ & $207 \mathrm{MPa}$ & $304 \mathrm{MPa}$ & 0.0956 \\
Standard Deviation & $31 \mathrm{GPa}$ & $57 \mathrm{MPa}$ & $101 \mathrm{MPa}$ & 0.0956 \\
\hline Bulk Nickel & $207 \mathrm{GPa}$ & $59 \mathrm{MPa}$ & $317 \mathrm{MPa}$ & 0.30 \\
\hline Electroplated Nickel & $155 \pm 11 \mathrm{GPa}$ & $305 \pm 12 \mathrm{MPa}$ & $562 \pm 9 \mathrm{MPa}$ & $0.124 \pm 0.005$ \\
\hline
\end{tabular}

Tension testing of the cold gas-dynamic spray nickel in the as-sprayed condition reveals that the specimens exhibit no plastic behavior. Young's modulus and yield strength are nearly identical to those values of electroplated nickel. The as-sprayed nickel displays only $53 \%$ of the ultimate strength of electroplated nickel. Tension testing of the cold gasdynamic spray nickel in the heat-treated condition reveals that the specimens do exhibit plastic behavior. Young's modulus of the nickel in the heat-treated condition is similar to that of electroplated nickel. The yield strength of the heat-treated, sprayed nickel is $68 \%$ of electroplated nickel and the ultimate strength of the heat-treated, sprayed nickel is 54\% of electroplated nickel. Since the material characteristics of the cold gas-dynamic spray nickel are generally less than those of electroplated nickel, the only compelling reason to use the CGSM would be for a material that cannot be electroplated. Then the designer must accept there will be no ductility when the material is not heat-treated.

Scanning Electron Microscope (SEM) images were taken of the fractured surface for both of the as-sprayed and heated tensile specimens. Figure 20 shows the fractured area of Tension Test Specimen 4, which is the as-sprayed tensile specimen. The SEM image on the left is an overall view of the cross-sectional area, while the SEM image on the right is a larger magnification. These images show the brittle fracture surface. The higher magnification image appears to reveal a partial inter-granular failure. Figure 21 shows the fracture area of Tension Test Specimen 8, which is the heat-treated tensile specimen. The SEM image on the left is an overall view, while the SEM image on the right is at a larger magnification. These images reveal a ductile fracture surface. This is because of the large number of dimples in the fracture surface. When dimples are present in a fracture surface, this could indicate that the fracture mechanism is ductile tearing. 

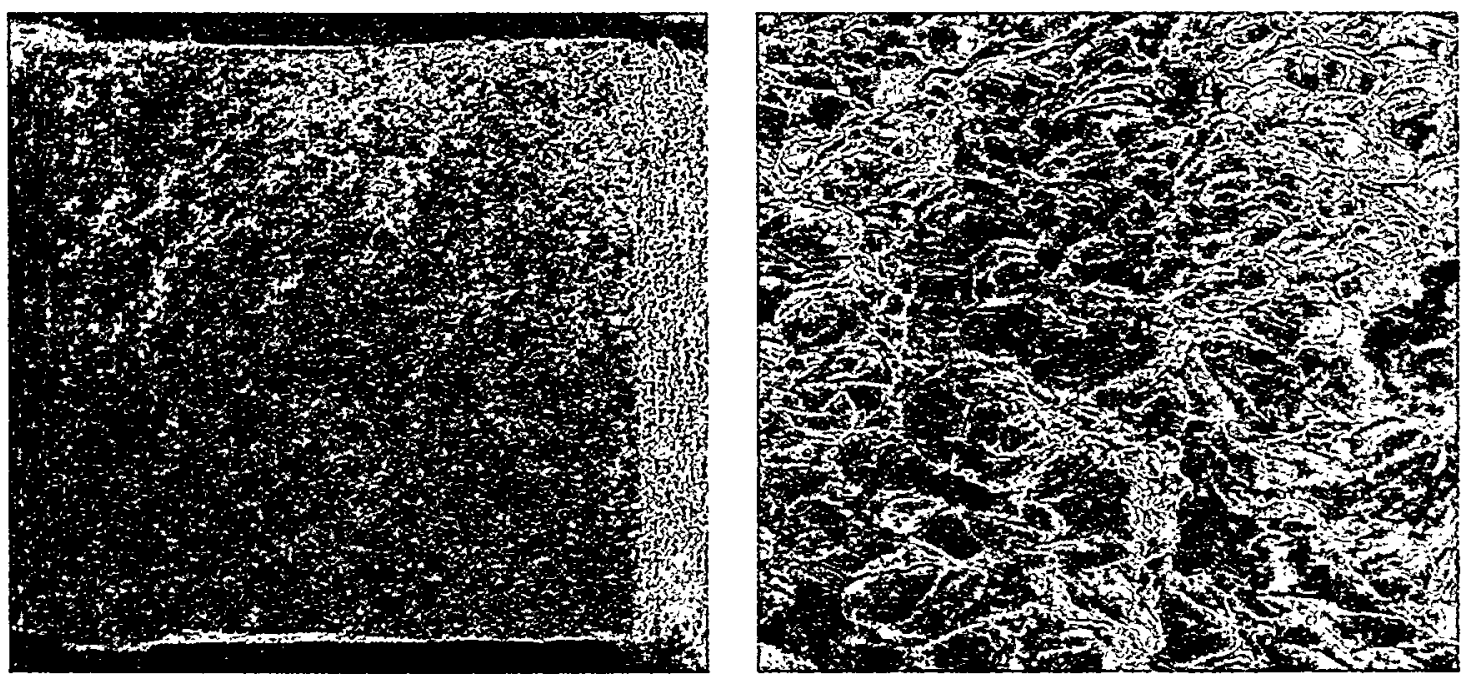

Figure 20, SEM images of the fracture area of the as-sprayed, tension test specimen 4.
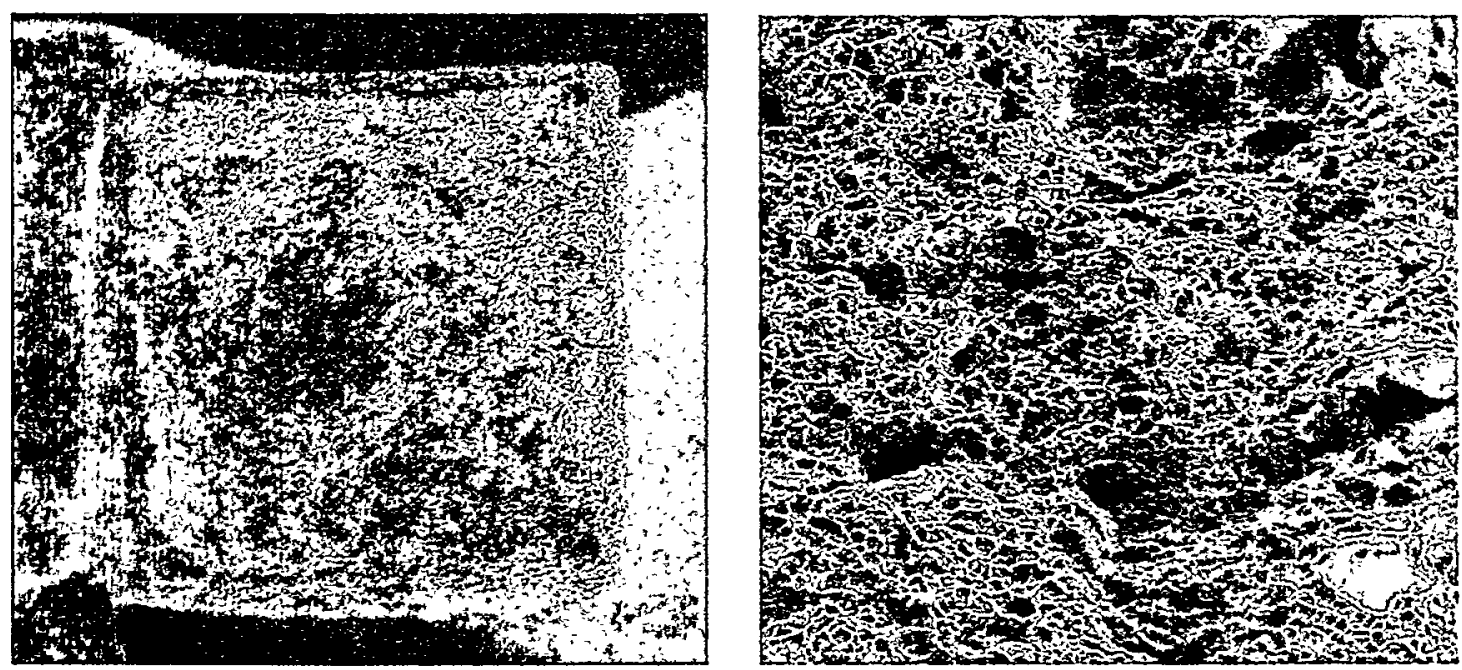

Figure 21, SEM images of the fracture area of the heat-treated, tension test specimen 8.

\subsection{Compression Testing}

There are several reason for compression testing. The results of a compression test can also be used to select materials for engineering application. In addition, the strength of a material can be measured in terms of the stress necessary to cause plastic deformation. Estimates of the residual stress in a material can also be determined when the compression curve is compared to the tensile curve.

The method for compression testing was similar to the tensile testing method. The compression specimens were placed in a mounting jig and inserted into a load cell. Then load cell was then zeroed, and the screws of mounting jig were tightened [26]. A laser beam was then centered on the tabs of the compression specimen to measure the strain. 
The test sequence for the compression specimens was to ramp to buckling, failure or an approximate strain of $10 \%$, under stroke control, at a stroke rate of $0.003 \mathrm{~mm} / \mathrm{s}$. The strain rate at which the compression specimens were tested was approximately $0.001 \mathrm{~s}^{-1}$. Figure 22 shows the details of the compression test specimen, drawn in mm. The applied force will be in the 1-direction until fracture. The information obtained from the engineering stress-strain curves will be Young's modulus $\left(E_{1}\right)$, yield strength $\left(\sigma_{y}\right)$, ultimate strength $\left(\sigma_{u}\right)$ and fracture strain $\left(\varepsilon_{f}\right)$.

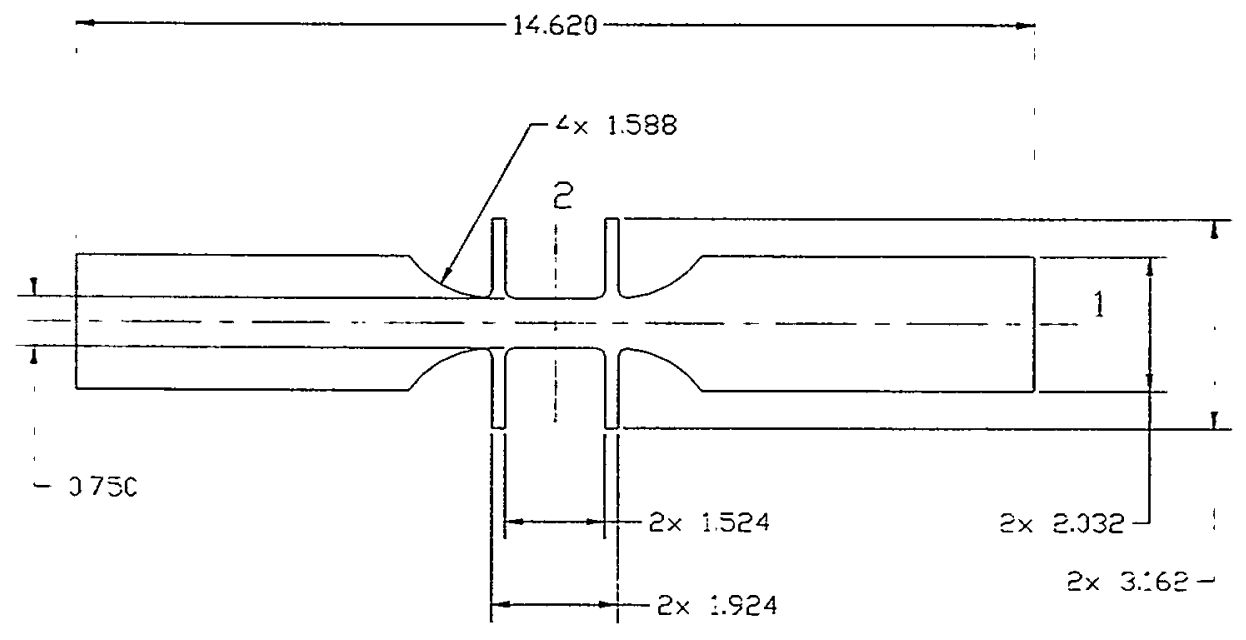

Figure 22, Details of compression specimen, drawn in mm.

To verify the compression specimen will not fail in buckling before yielding, the following calculations have been completed. The critical buckling load is determined by Equations 4.36 and 4.37 .

$$
\begin{gathered}
P_{c r}=\frac{\pi^{2} E I}{s_{1}^{2}} \\
I=\frac{s_{2}^{3} s_{3}}{12}
\end{gathered}
$$

where $E=150 \times 10^{9} \mathrm{~Pa} \quad s_{1}=0.003 \mathrm{~m} \quad s_{2}=0.00075 \mathrm{~m} \quad s_{3}=0.0075 \mathrm{~m}$

Solving, $P_{c r}=4,300 \mathrm{~N}$.

The critical load, $P_{c r}$, must not cause the stress in the specimen to exceed the proportional limit in the nickel. The actual load to cause failure in the specimen is given by Equation 4.38 . 


$$
P=\sigma_{y} s_{2} s_{3}
$$

where $\sigma_{y}=200 \times 10^{6} \mathrm{~Pa}$

Solving, $P=113 N$.

Since $P<P_{c r}$, the specimen should not buckle before exceeding the proportional limit of the nickel. Young's modulus used in this calculation was determined from the ultrasonic testing, and the yield strength is an estimate based on BondArc $^{\circledR}(95 \% \mathrm{Ni} 5 \% \mathrm{Al})$ deposited using the twin-wire arc, thermal spray method [28]. Therefore, the gage design of the compression specimen is acceptable.

Figure 23 shows the engineering stress vs. engineering strain of four compression specimens that were tested in the as-sprayed condition. These compression specimens were tested to buckling or failure. Table 13 shows the Young's modulus $\left(E_{1}\right)$, yield strength $\left(\sigma_{y}\right)$, ultimate strength $\left(\sigma_{u}\right)$, and fracture strain $\left(\varepsilon_{f}\right)$ for these four nickel, compression specimens. Also shown in this table are the typical values for these material properties of bulk nickel at ambient temperature [17] and electroplated nickel at a current density of $40 \mathrm{~mA} / \mathrm{cm}^{2}$ [1]. Since these as-sprayed compression specimens displayed slight ductility and plasticity behavior, the yield strength will be determined using a $0.2 \%$ offset. 


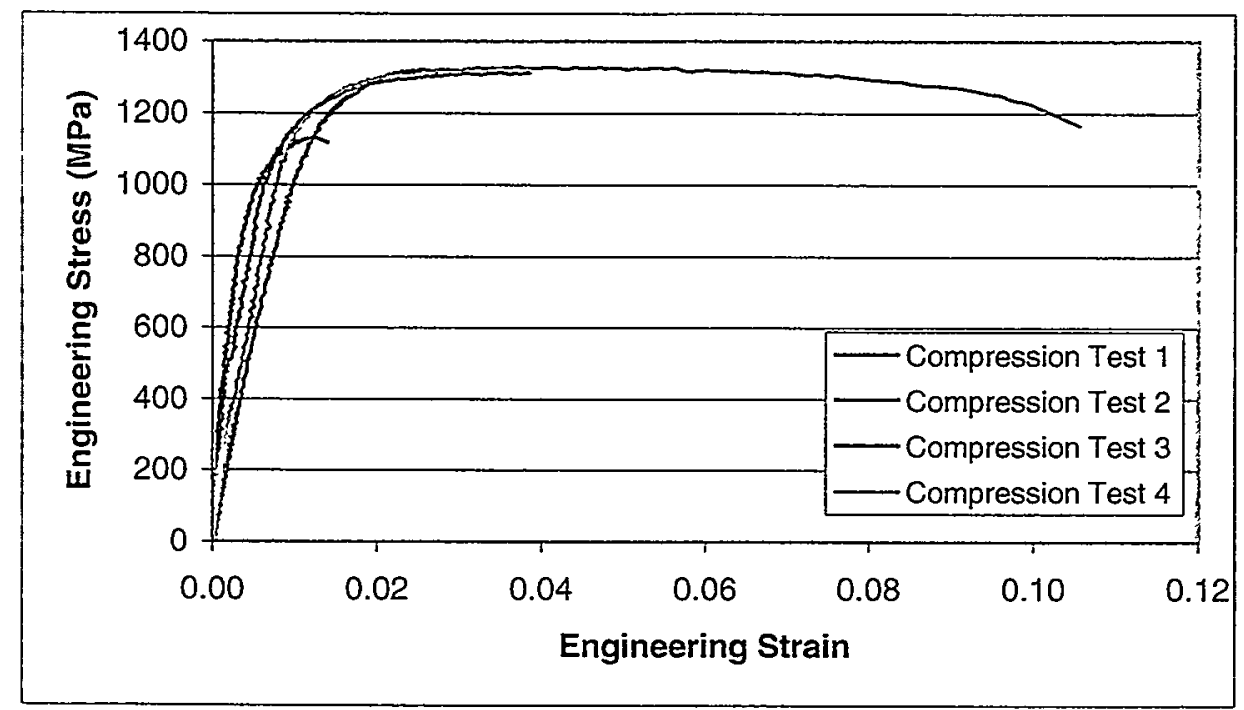

Figure 23, Compression test, engineering stress vs. engineering strain for cold gas-dynamic spray nickel in the as-sprayed condition.

Table 13, Young's modulus, yield strength, ultimate strength, and fracture strain, for cold gas-dynamic spray nickel in the as-sprayed condition, including typical values for bulk nickel and electroplated nickel.

\begin{tabular}{|c|c|c|c|c|}
\hline & $\begin{array}{c}\text { Young's } \\
\text { Modulus } \\
\left(E_{1}\right)\end{array}$ & $\begin{array}{c}\text { Yield } \\
\text { Strength } \\
\left(\sigma_{y}\right)\end{array}$ & $\begin{array}{c}\text { Ultimate } \\
\text { Strength } \\
\left(\sigma_{u}\right)\end{array}$ & $\begin{array}{c}\text { Fracture } \\
\text { Strain } \\
\left(\varepsilon_{f}\right)\end{array}$ \\
\hline Compression Test 1 & $228 \mathrm{GPa}$ & $1005 \mathrm{MPa}$ & $1312 \mathrm{MPa}$ & 0.0328 \\
Compression Test 2 & $249 \mathrm{GPa}$ & $1018 \mathrm{MPa}$ & $1128 \mathrm{MPa}$ & 0.0085 \\
Compression Test 3 & $121 \mathrm{GPa}$ & $1071 \mathrm{MPa}$ & $1318 \mathrm{MPa}$ & 0.0163 \\
Compression Test 4 & $194 \mathrm{GPa}$ & $839 \mathrm{MPa}$ & $1328 \mathrm{MPa}$ & 0.0953 \\
\hline Average Value & $198 \mathrm{GPa}$ & $983 \mathrm{MPa}$ & $1271 \mathrm{MPa}$ & 0.0382 \\
Standard Deviation & $56 \mathrm{GPa}$ & $100 \mathrm{MPa}$ & $96 \mathrm{MPa}$ & 0.0394 \\
\hline Bulk Nickel & $207 \mathrm{GPa}$ & $59 \mathrm{MPa}$ & $317 \mathrm{MPa}$ & 0.30 \\
\hline Electroplated Nickel & $155 \pm 11 \mathrm{GPa}$ & $305 \pm 12 \mathrm{MPa}$ & $562 \pm 9 \mathrm{MPa}$ & $0.124 \pm 0.005$ \\
\hline
\end{tabular}

Figure 24 shows the engineering stress vs. engineering strain of four compression specimens that were tested in the heat-treated condition. These compression specimens were tested to an approximate strain of $10 \%$. Table 14 shows Young's modulus $\left(E_{1}\right)$; yield strength $\left(\sigma_{y}\right)$; strength $\left(\sigma_{u}^{*}\right)$, which is the strength at the end of the test; and strain 
$\left(\varepsilon_{f}^{*}\right)$, which is the strain at the end of the test, for these four compression specimens. Also shown in this table are the typical values for these material properties of bulk nickel at ambient temperature [17] and electroplated nickel at a current density of $40 \mathrm{~mA} / \mathrm{cm}^{2}$ [1]. Since these heat-treated compression specimens displayed significant ductility and plasticity behavior, the yield strength was determined using a $0.2 \%$ offset.

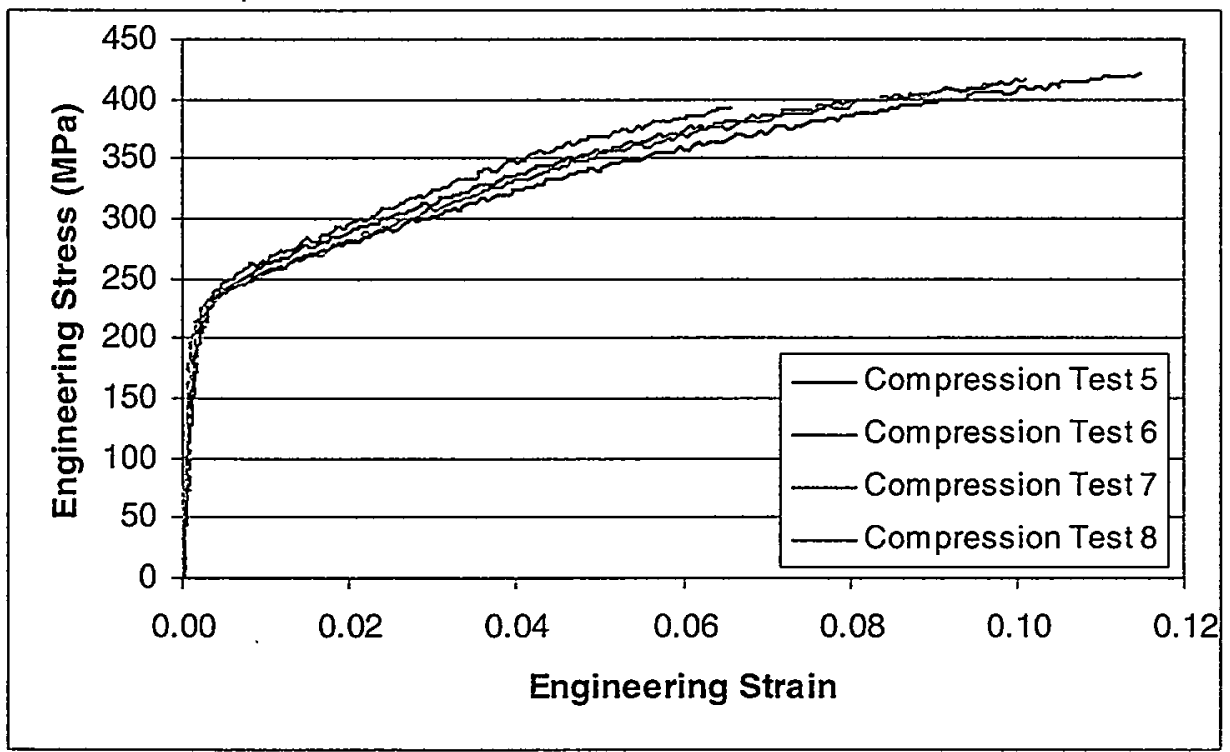

Figure 24, Compression test, engineering stress vs. engineering strain for cold gas-dynamic spray nickel in the heat-treated condition.

Table 14, Young's modulus, yield strength, maximum strength, and maximum strain, for cold gas-dynamic spray nickel in the heat-treated condition, including typical values for bulk nickel and electroplated nickel.

\begin{tabular}{|c|c|c|c|c|}
\hline & $\begin{array}{c}\text { Young's } \\
\text { Modulus } \\
\left(E_{1}\right)\end{array}$ & $\begin{array}{c}\text { Yield } \\
\text { Strength } \\
\left(\sigma_{y}\right)\end{array}$ & $\begin{array}{c}\text { Ultimate } \\
\text { Strength } \\
\left(\sigma_{u}^{*}\right)\end{array}$ & $\begin{array}{c}\text { Fracture } \\
\text { Strain } \\
\left(\varepsilon_{f}^{*}\right)\end{array}$ \\
\hline Compression Test 5 & $147 \mathrm{GPa}$ & $233 \mathrm{MPa}$ & $393 \mathrm{MPa}$ & 0.0632 \\
Compression Test 6 & $121 \mathrm{GPa}$ & $231 \mathrm{MPa}$ & $412 \mathrm{MPa}$ & 0.0946 \\
Compression Test 7 & $202 \mathrm{GPa}$ & $231 \mathrm{MPa}$ & $422 \mathrm{MPa}$ & 0.1127 \\
Compression Test 8 & $166 \mathrm{GPa}$ & $229 \mathrm{MPa}$ & $418 \mathrm{MPa}$ & 0.0985 \\
\hline Average Value & $159 \mathrm{GPa}$ & $231 \mathrm{MPa}$ & $411 \mathrm{MPa}$ & 0.0923 \\
Standard Deviation & $34 \mathrm{GPa}$ & $2 \mathrm{MPa}$ & $13 \mathrm{MPa}$ & 0.0209 \\
\hline Bulk Nickel & $207 \mathrm{GPa}$ & $59 \mathrm{MPa}$ & $317 \mathrm{MPa}$ & 0.30 \\
\hline Electroplated Nickel & $155 \pm 11 \mathrm{GPa}$ & $305 \pm 12 \mathrm{MPa}$ & $562 \pm 9 \mathrm{MPa}$ & $0.124 \pm 0.005$ \\
\hline
\end{tabular}


Compression testing of the nickel in the as-sprayed condition reveals that the specimens exhibit a high yield and ultimate strength. When large numbers of dislocations are present in a material, a high value for the yield stress will be observed, as seen in these compression tests. The behavior that is seen in compression test 4 can be attributed to the use of the energy in the experiment. The energy is being used to crush the voids in the material. Young's modulus is nearly identical to that of electroplated nickel. The yield strength of the as-sprayed nickel is $322 \%$ greater than that of electroplated nickel and the ultimate strength is $226 \%$ greater than that of electroplated nickel. Compression testing of the cold gas-dynamic spray nickel in the heat-treated condition reveals that the specimens exhibit plastic behavior. Young's modulus of the nickel in the heat-treated condition is similar to that of electroplated nickel. The yield strength of the heat-treated, sprayed nickel is $76 \%$ of electroplated nickel and the ultimate strength of the heat-treated, sprayed nickel is approximately $73 \%$ of electroplated nickel. Since the compression strength of the cold gas-dynamic spray nickel is significantly greater than that of any other form of nickel, the compelling reason to use the CGSM is for structural members that will be used in compression.

SEM images were also taken of the fractured surface for both of the as-sprayed and heated compression specimens. Figure 25 shows the fractured area of Compression Test Specimen 4, which is the as-sprayed compression specimen. The SEM image on the left is an overall view of the cross-sectional area, while the SEM image on the right is a larger magnification. These images also show the brittle fracture surface which appear to be similar to the fracture surface of the tensile specimen, but slightly flatter. The higher magnification image reveals to show fewer voids which is an indication that these voids were crushed while undergoing the compression testing. Figure 26 shows Compression Test Specimen 8 after the compression test. This specimen failed by buckling. Once buckling occurs, the data will become suspect since the distance between the tabs on the compression specimen will change at a different rate than the gage section of the specimen. Therefore, the tabulated ultimate strength $\left(\sigma_{u}^{*}\right)$, and fracture strain $\left(\varepsilon_{f}^{*}\right)$ are the actual values that the equipment measured, but the validity of these results may be questionable. 

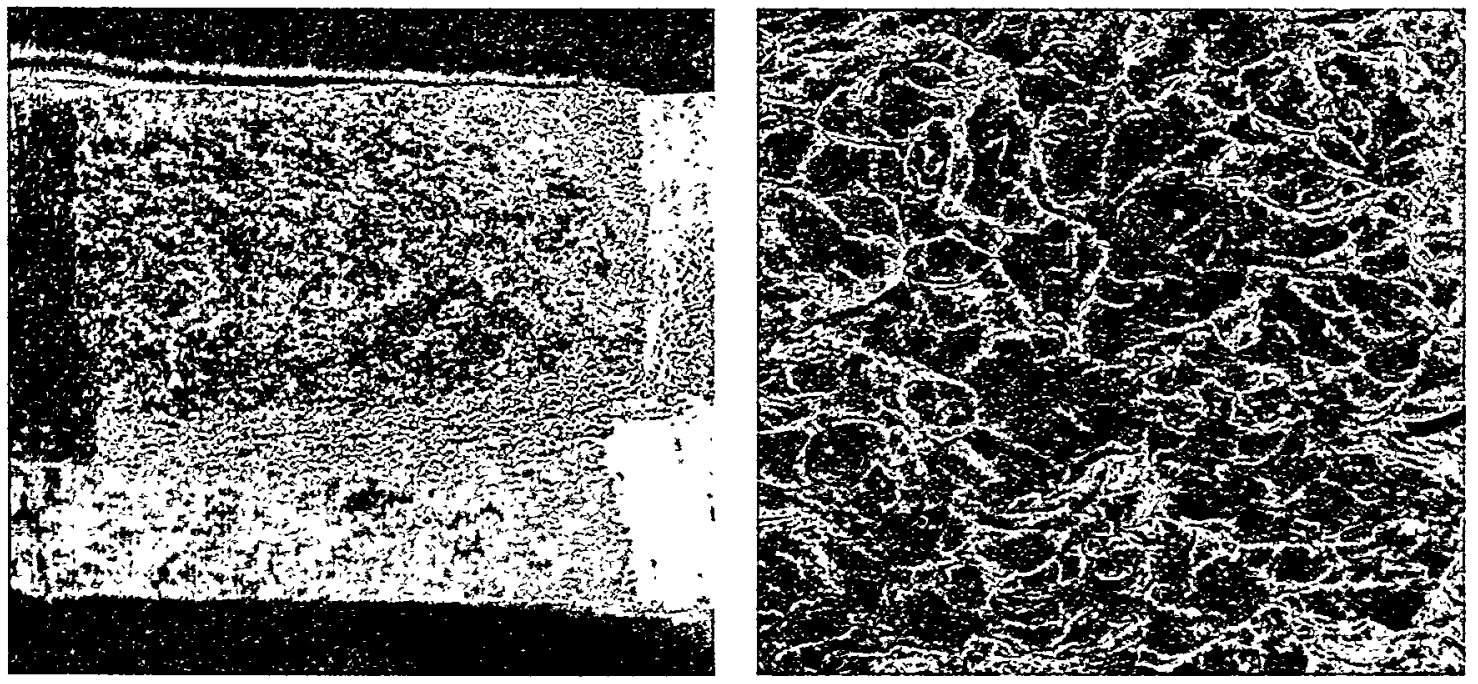

Figure 25, SEM images of the fracture area of the as-sprayed, compression test specimen 4.
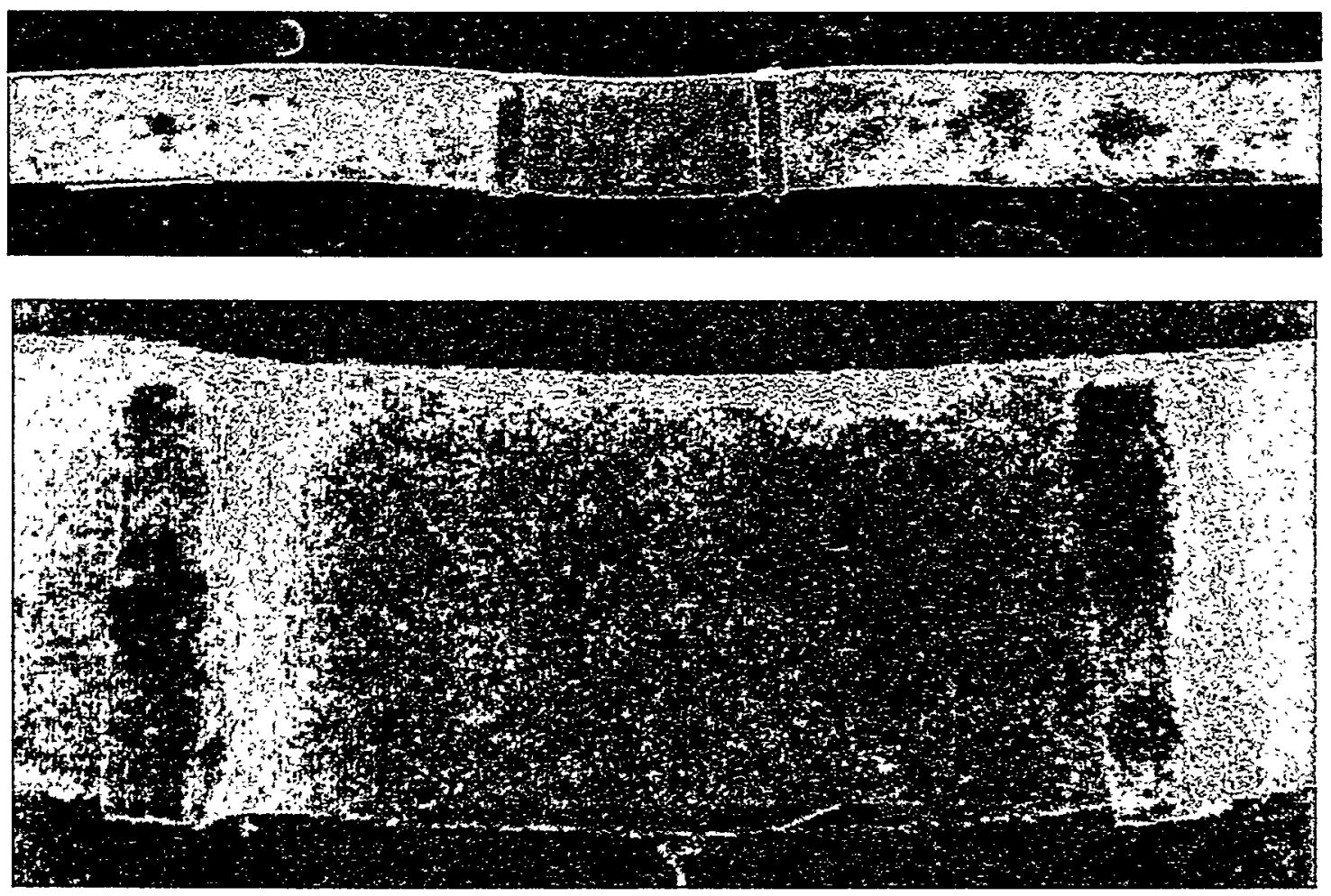

Figure 26, SEM image of the buckle in the heat-treated, compression test specimen 8 . 


\subsection{ABAQUS Simulations}

Two ABAQUS simulations were developed to model the particle impact behavior of the cold gas-dynamic spray method. The first model simulates a single nickel particle impacting an existing nickel surface. The second model simulates two nickel particles impacting an existing nickel surface. ABAQUS is a dimensionless software package. If consistent units are used when defining geometry, boundary conditions, and material properties, the results will also be in consistent units. For these simulations, SI units were used. Therefore, the computed stresses are in Pascals. The ABAQUS input files for this simulation are shown in Appendix D; the ABAQUS status files are shown in Appendix $\mathrm{E}$, and the stress plots at various times are shown in Appendix F.

The nickel particles are at a specified velocity as they impact an existing coating of nickel. Symmetry in the simulation was assumed to be at the centerline of the nickel particles and the centerline of the existing coating. The nickel particles are $40 \mu \mathrm{m}$ in diameter and have an initial velocity of $500 \mathrm{~m} / \mathrm{s}$. These nickel particles also have an imposed boundary condition at the centerline, the nodes are not allowed to move in the horizontal direction. The existing nickel coating is $42 \mu \mathrm{m}$ thick. This coating also has imposed boundary conditions. The nodes at the centerline are fixed in the horizontal direction. Additionally, the nodes at the back surface of the coating are fixed in the vertical direction. A value of 0.4 was used for the friction coefficient between the nickel particle and the existing coating. The finite element type for the particle and coating is a 4-node bilinear axisymmetric quadrilateral, reduced integration, with hourglass control. Orientation and mesh of the single nickel particle and the existing coating is shown in Figure 27. Orientation and mesh of two nickel particles and the existing coating are shown in Figure 28. The nodes with fixed boundary conditions are indicated with red arrows.

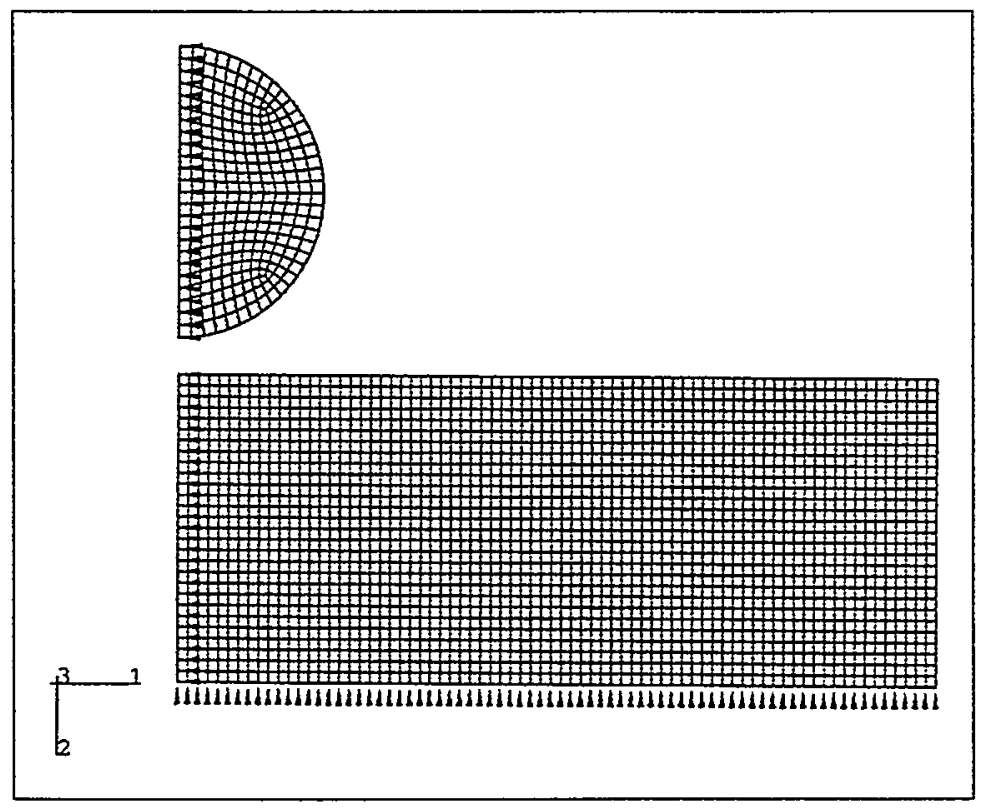

Figure 27, Two-dimensional ABAQUS mesh representing a single nickel particle and an existing nickel coating. 


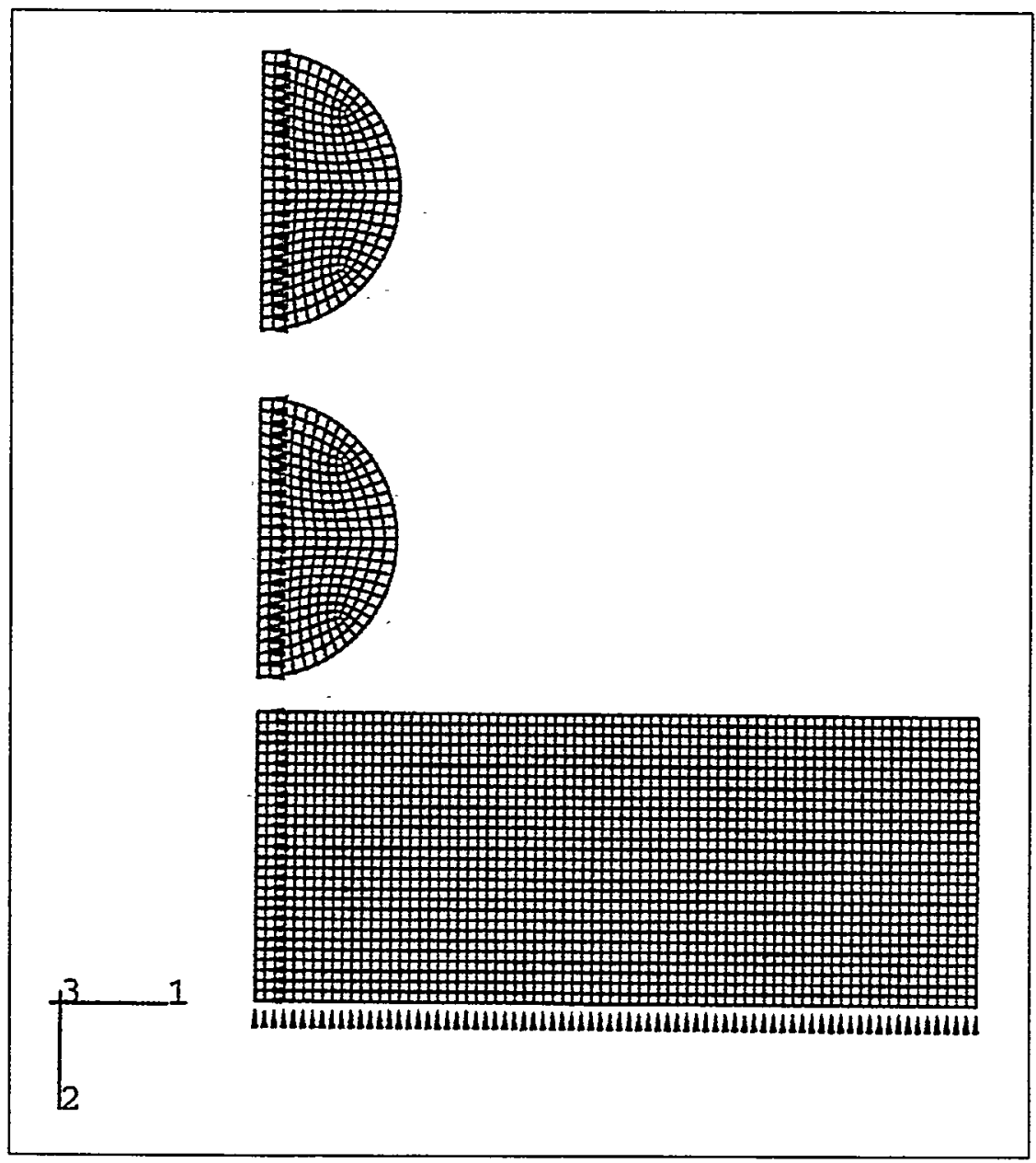

Figure 28, Two-dimensional ABAQUS mesh representing two nickel particles and an existing nickel coating.

Stress plots at various times are shown in Appendix F for both simulations. These plots reveal that it may be difficult to estimate the residual stresses since there are so few nickel particles in the simulations. When this extreme deformation in the nickel particles occur, it is believed that a portion of the energy causing this extreme plastic deformation is converted to heat. In fact, there may be an extremely high temperature at the local impact area, for a very short period of time. Thus, when a nickel particle impacts an existing coating, heat is generated, causing fusion to occur, thus relieving some of the stresses in the coating.

Similarities in the particle deformation behavior shown in the stress plots in Appendix $F$ can be also seen in the micrographs shown in Figures $8-10$. The left column of Figure 8 shows the top view of the splat boundaries of the cold gas-dynamic spray nickel in the assprayed condition. Some of the splat boundaries are nearly circular as the predictive models indicate. The left column of Figure 10 shows the side view of the nickel particles after the impact. In many places this "bowl" shaped deformation phenomena can be 
seen. This "bowl" shaped deformation shown in the micrographs is also similar to the deformation shown in the predictive models. Additional "bowl shaped features can be seen in Figure 29.

Convergence was verified by plotting the kinetic energy in the model as a function of time. The kinetic energy for the single particle model started near $40,000 \mu \mathrm{N}-\mathrm{mm}$ and reached a minimum value of $4 \mu \mathrm{N}$-mm during the $0.5 \mathrm{e}-6$ second period. The kinetic energy for the two particle model started near $80,000 \mu \mathrm{N}-\mathrm{mm}$ and reached a minimum value of $20 \mu \mathrm{N}-\mathrm{mm}$ during the $0.5 \mathrm{e}-6$ second period. The kinetic energy dropped significantly during the initial 0.2e-6 second interval, and with the damped oscillation over the remaining time period, a steady state solution was reached. Figure 30 shows the kinetic energy vs. time for the finite element impact simulations. 

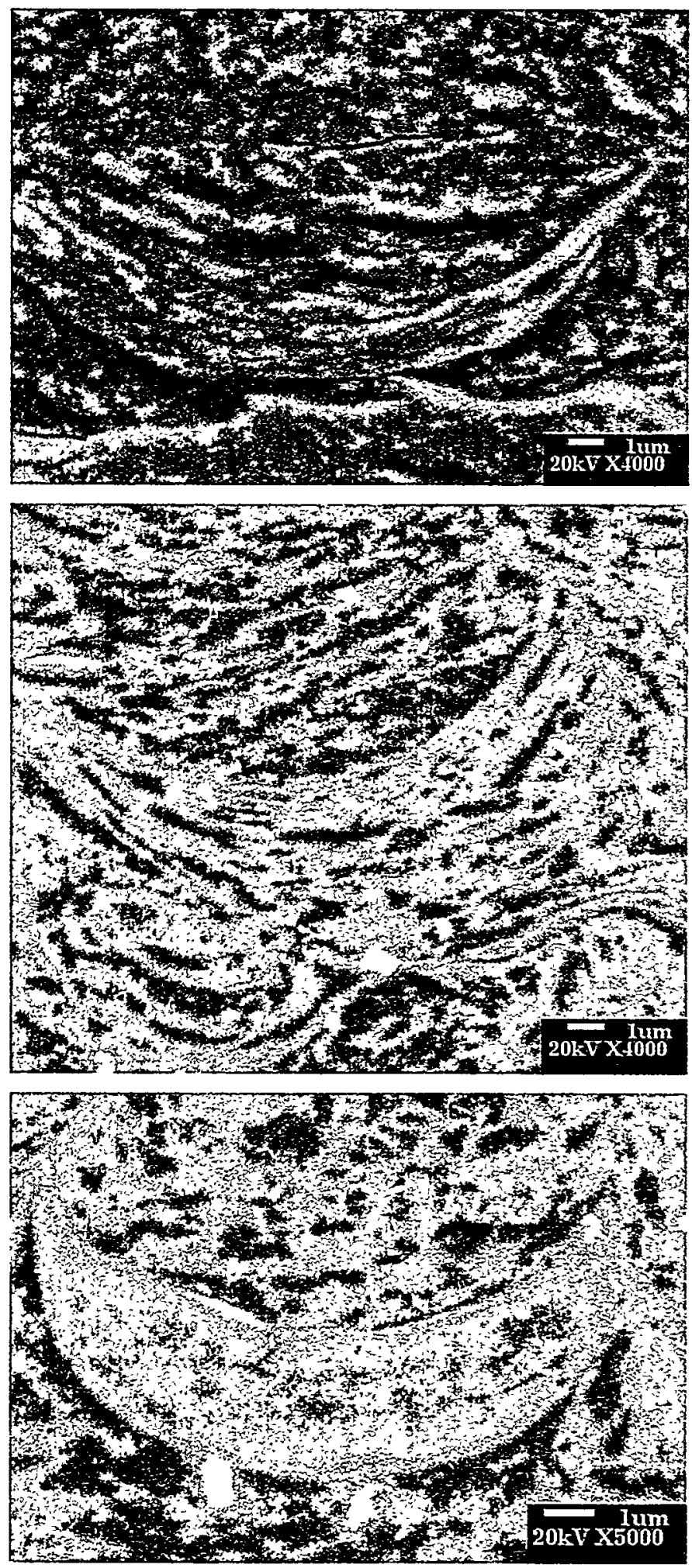

Figure 29, Three SEM images of the "bowl" shaped phenomena represented in the ABAQUS simulations. 


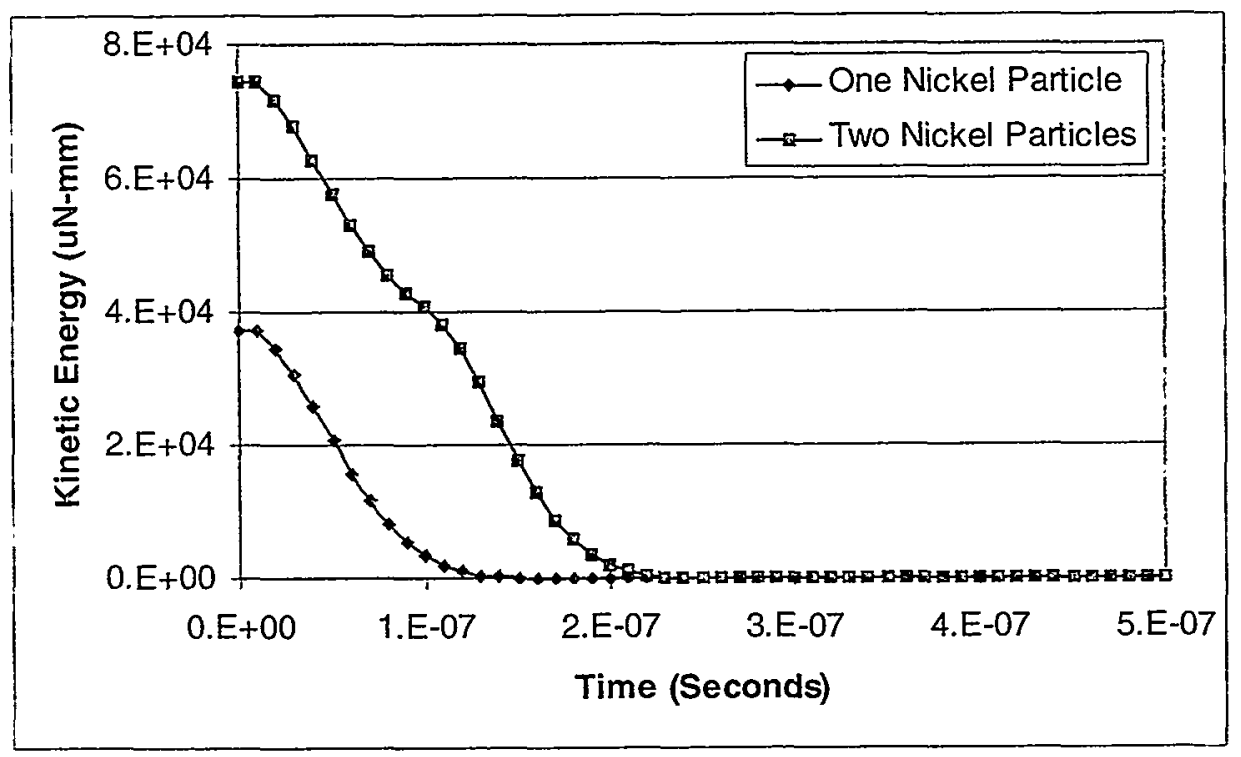

Figure 30, Kinetic energy vs. time for the ABAQUS impact simulations.

Consideration was given regarding the use of ANSYS to model the particle behavior of this problem. Unfortunately, the ANSYS package that was available through the university did not have the capability of a built in explicit solver to solve this type of model. ABAQUS/Explicit easily solves nonlinear, transient dynamic problems. The benefits of having an explicit solver is that it provides a nonlinear, transient, dynamic analysis of the solids using explicit time integration. In addition, the contact capabilities and the application of boundary conditions were quite simple to program for this model. The actual computational time for the two particle simulation to run on a SUN workstation over the 0.5 e- 6 second interval was 15 minutes. 


\subsection{Discussion and Conclusions}

Results of Young's modulus and yield strength are compared between ultrasonic, hardness, tension, and compression tests where applicable. Young's modulus and yield strength results of the different experiments for the cold gas-dynamic nickel in the assprayed condition are shown in Table 15. The modulus results obtained by the ultrasonic and compression testing give similar results, which are close to typical values for bulk nickel, while the modulus and yield strength results obtained from the tension testing give comparable results to that of electroplated nickel. When the yield strength was determined using hardness and compression methods, the results were similar, while the yield strength determined by tensile testing closely matches the yield strength of the electroplated nickel.

Table 15, Young's modulus and yield strength compared between testing methods for cold gas-dynamic spray nickel in the as-sprayed condition, including typical values for bulk nickel and electroplated nickel.

\begin{tabular}{|c|c|c|}
\hline & $\begin{array}{c}\text { Young's Modulus } \\
\left(E_{1}\right)\end{array}$ & $\begin{array}{c}\text { Yield Strength } \\
\left(\sigma_{y}\right)\end{array}$ \\
\hline Ultrasonic Testing & $196.5 \pm 18.5 \mathrm{GPa}$ & N/A \\
Hardness Testing & $\mathrm{N} / \mathrm{A}$ & $842 \pm 34 \mathrm{MPa}$ \\
Tension Testing & $158 \pm 6 \mathrm{GPa}$ & $300 \pm 119 \mathrm{MPa}$ \\
Compression Testing & $198 \pm 56 \mathrm{GPa}$ & $983 \pm 100 \mathrm{MPa}$ \\
\hline Bulk Nickel & $207 \mathrm{GPa}$ & $59 \mathrm{MPa}$ \\
\hline Electroplated Nickel & $155 \pm 11 \mathrm{GPa}$ & $305 \pm 12 \mathrm{MPa}$ \\
(Tension) & & \\
\hline
\end{tabular}

Again, results of Young's modulus and yield strength are compared between ultrasonic, hardness, tension, and compression tests where applicable. Young's modulus and yield strength results of the different experiments for the cold gas-dynamic nickel in the heattreated condition are shown in Table 16. The modulus results obtained by the ultrasonic testing give results that are comparable to typical values for bulk nickel. The modulus results obtained from the tension and compression testing give similar results to that of electroplated nickel. The yield strength determined from the tension and compression tests fall short of the strength of electroplated nickel, but exceed the typical values of bulk nickel. The yield strength determined from the hardness testing give results comparable to that of electroplated nickel. 
Table 16, Young's modulus and yield strength compared between testing methods for cold gas-dynamic spray nickel in the heat-treated condition, including typical values for bulk nickel and electroplated nickel.

\begin{tabular}{|c|c|c|}
\hline & $\begin{array}{c}\text { Young's Modulus } \\
\left(E_{1}\right)\end{array}$ & $\begin{array}{c}\text { Yield Strength } \\
\left(\sigma_{y}\right)\end{array}$ \\
\hline Ultrasonic Testing & $188 \pm 20 \mathrm{GPa}$ & N/A \\
Hardness Testing & $\mathrm{N} / \mathrm{A}$ & $369 \pm 31 \mathrm{MPa}$ \\
Tension Testing & $125 \pm 31 \mathrm{GPa}$ & $207 \pm 57 \mathrm{MPa}$ \\
Compression Testing & $159 \pm 34 \mathrm{GPa}$ & $231 \pm 2 \mathrm{MPa}$ \\
\hline Bulk Nickel & $207 \mathrm{GPa}$ & $59 \mathrm{MPa}$ \\
\hline $\begin{array}{c}\text { Electroplated Nickel } \\
\text { (Tension) }\end{array}$ & $155 \pm 11 \mathrm{GPa}$ & $305 \pm 12 \mathrm{MPa}$ \\
\hline
\end{tabular}

The ABAQUS finite element simulations show that the deformation behavior can be modeled. Results from the ABAQUS finite element simulations indicate residual stresses will remain in the material as particles are deposited. After the cold gas-dynamic spray nickel was heat-treated, only negligible residual stresses would remain in the material.

Recall the objective of this investigation is to characterize nickel deposited by the CGSM. The particular application of the nickel members deposited using the CGSM is in compression and the compression yield strength of the nickel members exceed the yield strength characteristics of bulk and electroplated nickel. Experimental results indicate this requirement was achieved. The compressive yield strength of cold gas-dynamic spray nickel is $983 \pm 100 \mathrm{MPa}$, which is well above $305 \pm 12 \mathrm{MPa}$ for electroplated nickel with a current density of $40 \mathrm{~mA} / \mathrm{cm}^{2}$, and $59 \mathrm{MPa}$ for bulk nickel. 


\subsection{Looking Forward}

Before looking forward, if there were an opportunity to redo this experiment, there would be several things to reconsider. The first item to consider would be to cold gas-dynamic spray nickel onto a plain sheet of copper without any machined features in the copper. This would eliminate all preliminary machining costs. Since all tension and compression specimens were electro-discharge machined (EDMed) from the copper mold, eliminating slotted features in the copper mold would allow for tension and compression specimens to be EDMed in the 2-direction. This would allow for an experimental determination of Young's modulus in the 2-direction, proving that the moduli are the same in both directions. Another consideration would be to increase the gage width of the tension and compression specimens from 0.75 to $1.00 \mathrm{~mm}$. Making this change may allow for easier EDMing of these specimens; thus rejecting fewer specimens and potentially obtaining consistent data.

An additional investigation might include a method to study the minimum feature size the CGSM could produce. Variables may include particle size, type of material, and the aspect ratio of a mold feature. The size of a particle would definitely be a limitation to a minimum feature size. The type of material may also present a limitation depending upon the amount of plastic deformation that it could undergo. Finally, the aspect ratio may also pose a limitation. If a feature is too deep and narrow, a particle may not have enough energy to adhere to the bottom surface of the mold.

Present uses for the CGSM include coating surfaces exposed to high heat, corrosion, and wear environments. Examples include the inside surface of engine cylinder walls, the external surface of structural components in motion, and turbine blades used in power plants and jet engines. Each of these items benefit from coating the surface of critical areas to improve the resistance to heat, corrosion, and wear. Also, these applications take advantage of the high compression characteristics of the material deposited by the CGSM.

This deposition process may lend itself to additional applications. One application may be to utilize the CGSM to produce simple, freestanding, three-dimensional components. Additional processing steps to make these types components may include a masking or sacrificial layering technique. These sacrificial layers may prevent the material from being deposited in specific locations, then that layer would be removed creating a component with features in the third dimension. Another application for the CGSM would be to create metal matrix composite structures. For example, use a ceramic as a reinforcement material in a metal matrix. The CGSM could also be used to create highly porous materials. A mixture of copper and nickel could be deposited using the CGSM, then with a copper etch, the copper could be removed, creating a highly porous material. Unfortunately, trapped copper will remain in the material. Also the CGSM could be used to repair damaged or cracked glass. Finally, another application would be to use the CGSM to fabricate LIGA hardware from metals that cannot be deposited by an electroplating process. The LIGA fabrication process is an additive process in which material is deposited, typically by electroplating, into a precision mold of polymethyl 
methacrylate (PMMA) realized through deep X-ray lithography. Currently, the materials that can be readily deposited using the electroplating process are copper, nickel, permalloy ( $80 \% \mathrm{Ni}$ and $20 \% \mathrm{Fe}$ ), and gold. Developing alternatives to electroplating would allow designers the choice of using other materials, including ceramics and nonmetals, when designing freestanding mechanical structures. 


\subsection{References}

1. T.R. Christenson, T.E. Buchheit, D.T. Schmale, and R.J. Bourcier, Mechanical and Metallographic Characterization of LIGA Fabricated Nickel and 80\% NI-20\% Fe Permalloy, SAND98-0906C, Sandia National Laboratories, Albuquerque, NM, April 1998.

2. M.F. Smith and R.A. Neiser, Cold Spray Direct Fabrication-High Rate, Solid State Material Consolidation, Proc. Symposium V, Materials Research Soc., Fall 1998. Mtg., Boston, MA, November 30-December 4, 1998.

3. H. El-Sobky, Explosive Welding, Forming and Compaction, Edited by T.Z. Blazynski, Applied Science Publishers, London, 1983.

4. R.C. McCune, A.N. Papyrin, J.N. Hall, W.L. Riggs II, P.H. Zajchowski, An Exploration of the Cold-Dynamic Spray Method for Several Materials Systems, Proceedings of the $8^{\text {th }}$ National Thermal Spray Conference, Houston, Texas, September 11-15, 1995.

5. A.P. Alkhimov, A.N. Papyrin, V.F. Kosarev, N.I. Nesterovich, and M.M. Shushpanov, Gas-Dynamic Spraying Method for Applying a Coating, United States Patent 5,302,414, April 12, 1994.

6. A.P. Alkhimov, V.F. Kosarev, A.N. Papyrin, A Method of 'Cold' Gas-Dynamic Deposition, Sov. Phys. Dokl., vol. 35(12), December 1990, p. 1047-1049.

7. A.O. Tokarev, Structure of Aluminum Powder Coatings Prepared by Cold GasDynamic Spraying, Metal Science and Heat Treatment, vol. 38(3-4), 1996, p 136-9.

8. R.C. McCune, W.T. Donlon, E.L. Cartwright, A.N. Papyrin, E.F. Rybicki, and J.R. Shadley, Characterization of Copper and Steel Coatings Made by the Cold GasDynamic Spray Method, Thermal Spray: Practical Solutions for Engineering Problems, 1996, p. 397-403.

9. R.C. McCune, W.T. Donlon, O.O. Popoola, and E.L. Cartwright, Characterization of Copper Layers Produced by Cold Gas-Dynamic Spraying, Journal of Thermal Spray Technology, vol. 9(1), March 2000, p. 73-82.

10. S. Takeuchi, M. Ito, and K. Takeda, Modelling of Residual Stress in Plasma-Sprayed Coatings: Effect of Substrate Temperature, Surface and Coatings Technology, vol. 43/44, 1990, p. 426-435.

11. P. Bengtsson and C. Persson, Modelled and Measured Residual Stresses in Plasma Sprayed Thermal Barrier Coatings, Surface and Coatings Technology, vol. 92, 1997, p. 78-86.

12. D.J. Greving, E.F. Rybicki, and J.R. Shadley, Through-Thickness Residual Stress Evaluations for Several Industrial Thermal Spray Coatings Using a Modified LayerRemoval Method, Journal of Thermal Spray Technology, vol. 3(4), 1994, p. 379-388. 
13. Y.P Wan, H. Zhang, X.Y. Jiang, S. Sampath, and V. Prasad, Role of Solidification, Substrate Temperature and Reynolds Number on Droplet Spreading in Thermal Spray Deposition: Measurements and Modeling, Proceedings of $33^{\text {rd }}$ National Heat Transfer Conference August 15-17, 1999.

14. E.F. Rybicki, J.R. Shadley, Y. Xiong, and D.J. Greving, A Cantilever Beam Method for Evaluating Young's Modulus and Poisson's Ratio of Thermal Spray Coatings, Journal of Thermal Spray Technology, vol. 4(4), 1995, p 377-383.

15. W. Kim and J.G. Byrne, A Model for the Mechanical Properties of Hot Isostatically Pressed Rapidly Solidified Stainless Steel Powder, The International Journal of Powder Metallurgy, vol. 31(3), 1995, p. 247-256.

16. K. Yamaguchi and K. Sakai, Three-Dimensional Microforming by Metal Jet, Proceedings of the $14^{\text {th }}$ Annual Meeting of the American Society for Precision Engineering, October 31-November 5, 1999, p. 53-56.

17. J.R. Davis, Metals Handbook, Desk Edition, Second Edition, ASM International, Materials Park, Ohio, December 1998, p 118 and 1044-6.

18. L. Cartz, Nondestructive Testing, ASM International, Materials Park, Ohio, February 1996, p 81-125.

19. J.H. Gieske and R.E. Allred, Elastic Constants of B-AI Composites by Ultrasonic Velocity Measurements, Experimental Mechanics, vol. 14, No. 3, April 1974, p. 158-165.

20. A.P. Boresi and K.P. Chong, Elasticity in Engineering Mechanics, Second Edition, John Wiley \& Sons, Inc., New York, 2000, p. 235-9.

21. H.W. Coleman and W.G. Steele, Experimentation and Uncertainty Analysis for Engineers, John Wiley \& Sons, Inc., New York, 1999, p. 47-80.

22. M.A. Meyers and K.K. Chawla, Mechanical Behavior of Materials, Prentice-Hall Inc., New Jersey, 1999, p. 91-2.

23. H. Chandler, Hardness Testing, Second Edition, ASM International, Materials Park, Ohio, December 1999, p 27-49, 86-7, and 143-5.

24. S. Suresh and A.E. Giannakopoulos, A New Method for Estimating Residual Stresses by Instrumented Sharp Indentation, Scripta Materialia, vol. 36(3), 1997, p. 283-290.

25. P. Han, Tensile Testing, ASM International, Materials Park, Ohio, February 1999, p 1-33.

26. D.T. Schmale, R.J. Bourcier, T.E. Buchheit, Description of a Micro-Mechanical Testing System, SAND97-1608. Sandia National Laboratories, Albuquerque, NM, July 1997.

27. E. Oberg, F.D. Jones, H.L. Horton, Machinery's Handbook, 23 Edition, Industrial Press Inc., New York, 1989, p. 511.

28. M.K. Decker and M.F. Smith, Thermal Spray and Cold Spray Analysis of Density, Porosity, and Tensile Specimens for Use with LIGA Applications, SAND2000-0339. Sandia National Laboratories, Albuquerque, NM, February 2000. 
29. G.E. Dieter, Mechanical Metallurgy, Third Edition, McGraw-Hill, New York, 1986, p. 233-5.

30. F.A. Lowenheim, Electroplating, McGraw-Hill, New York, 1978, p. 8-26. 


\subsection{Appendix A, Deposition Rates}

Calculations for the deposition rates of electroplated nickel and deposition rate for cold gas-dynamic spray nickel.

The time to electroplate nickel is determined using the following technique [30]. This calculation assumes $100 \%$ efficiency.

$$
\begin{aligned}
& A=12.9 \mathrm{~cm}^{2} \\
& T=0.1 \mathrm{~cm} \\
& J=40 \mathrm{~mA} / \mathrm{cm}^{2} \\
& \rho=8.90 \mathrm{~g} / \mathrm{cm}^{3} \\
& m=58.69 \mathrm{~g} / \mathrm{mol} \\
& \Im=96,500 \mathrm{~A} \cdot \mathrm{s} / \mathrm{mol} \\
& \eta=1
\end{aligned}
$$

$$
t_{p}=\frac{T \times \rho \times \mathfrak{I}}{m \times J \times \eta}
$$

$$
t_{p}=\frac{0.1 \mathrm{~cm} \times 8.90 \frac{\mathrm{g}}{\mathrm{cm}^{3}} \times 96,500 \frac{\mathrm{A} \cdot \mathrm{s}}{\mathrm{mol}}}{\frac{58.69}{2} \frac{\mathrm{g}}{\mathrm{mol}} \times 0.04 \frac{\mathrm{A}}{\mathrm{cm}^{2}} \times 1}=73,200 \mathrm{~s}=1220 \mathrm{~min}=20.3 \mathrm{hours}
$$

Deposition Rate $=\frac{1000 \mu \mathrm{m}}{1220 \mathrm{~min}}=0.82 \frac{\mu \mathrm{m}}{\mathrm{min}}$ 
The time to deposit cold gas-dynamic nickel is determined using the following technique. This calculation assumes the nozzle is on the mold $25 \%$ of the time.

$$
\begin{aligned}
& A=12.9 \mathrm{~cm}^{2} \\
& T=0.1 \mathrm{~cm} \\
& \rho=8.90 \mathrm{~g} / \mathrm{cm}^{3} \\
& \dot{m}=5 \frac{\mathrm{g}}{\min } \\
& \eta=0.25
\end{aligned}
$$

$$
t_{p}=\frac{T \times A \times \rho}{\dot{m} \times \eta}
$$

$$
t_{p}=\frac{0.1 \mathrm{~cm} \times 12.9 \mathrm{~cm}^{2} \times 8.90 \frac{\mathrm{g}}{\mathrm{cm}^{3}}}{5 \frac{\mathrm{g}}{\min } \times 0.25}=9.2 \mathrm{~min}
$$

$$
\text { Deposition Rate }=\frac{1000 \mu m}{9.2 \mathrm{~min}}=108 \frac{\mu m}{\min }
$$




\subsection{Appendix B, Speed of Sound}

The speed of sound in air can be determined by Equation 10.1. Air is assumed to be an ideal gas. The result is shown in Equation 10.2.

$$
\begin{aligned}
& c=\sqrt{k R \tau} \\
& k_{\text {air }}=1.400 \quad R_{\text {air }}=286.9 \frac{\mathrm{J}}{\mathrm{kgK}} \quad \tau_{\text {air }}=298 \mathrm{~K} . \\
& c_{\text {air }}=346 \frac{\mathrm{m}}{\mathrm{s}}
\end{aligned}
$$

Recall, the helium and nickel particles exited the nozzle at a velocity of $879 \pm 78 \mathrm{~m} / \mathrm{s}$. This calculation shows that the velocity of the helium and nickel particle mixture are exceeding the speed of sound in air, or travelling at supersonic velocities.

The speed of sound in helium is also shown. The result is given by Equation 10.3.

$$
\begin{aligned}
& k_{\text {helium }}=1.667 \quad R_{\text {helium }}=2077 \frac{\mathrm{J}}{\mathrm{kg} \mathrm{K}} \quad \tau_{\text {helium }}=598 \mathrm{~K} \\
& c_{\text {helium }}=1439 \frac{\mathrm{m}}{\mathrm{s}}
\end{aligned}
$$




\subsection{Appendix C, Uncertainty Analysis of Elastic Constants}

A thorough, general uncertainty analysis [21] of the six elastic constants will be developed in this appendix. The general form of $\mathrm{C}_{11}, \mathrm{C}_{33}, \mathrm{C}_{44}$, and $\mathrm{C}_{66}$ are shown by Equation 11.1. The general wave velocity is shown in Equation 11.2. Finally, the equation for density is given by Equation 11.3.

$$
\begin{aligned}
& C=\rho V^{2} \\
& V=\frac{s}{t} \\
& \rho=\frac{m}{s_{1} \cdot s_{2} \cdot s_{3}}
\end{aligned}
$$

Starting with Equation 11.1, the general uncertainty analysis expression becomes:

$$
\begin{aligned}
& \left(\frac{U_{C}}{C}\right)^{2}=\left(\frac{\rho}{C} \frac{\partial C}{\partial \rho}\right)^{2}\left(\frac{U_{\rho}}{\rho}\right)^{2}+\left(\frac{V}{C} \frac{\partial C}{\partial V}\right)^{2}\left(\frac{U_{V}}{V}\right)^{2} \\
& \left(\frac{\rho}{C} \frac{\partial C}{\partial \rho}\right)=\frac{\rho}{C} \cdot V^{2}=1 \\
& \left(\frac{V}{C} \frac{\partial C}{\partial V}\right)=\frac{V}{C} \cdot 2 \rho V=2 \\
& \left(\frac{U_{C}}{C}\right)^{2}=\left(\frac{U_{\rho}}{\rho}\right)^{2}+4\left(\frac{U_{V}}{V}\right)^{2}
\end{aligned}
$$




$$
\begin{aligned}
& \left(\frac{U_{\rho}}{\rho}\right)^{2}=\left(\frac{m}{\rho} \frac{\partial \rho}{\partial m}\right)^{2}\left(\frac{U_{m}}{m}\right)^{2}+\left(\frac{s_{1}}{s_{1} \cdot s_{2} \cdot s_{3}} \frac{\partial\left(s_{1} \cdot s_{2} \cdot s_{3}\right)}{\partial s_{1}}\right)^{2}\left(\frac{U_{s_{1}}}{s_{1}}\right) \\
& \quad+\left(\frac{s_{2}}{s_{1} \cdot s_{2} \cdot s_{3}} \frac{\partial\left(s_{1} \cdot s_{2} \cdot s_{3}\right)}{\partial s_{2}}\right)^{2}\left(\frac{U_{s_{2}}}{s_{2}}\right)+\left(\frac{s_{3}}{s_{1} \cdot s_{2} \cdot s_{3}} \frac{\partial\left(s_{1} \cdot s_{2} \cdot s_{3}\right)}{\partial s_{3}}\right)^{2}\left(\frac{U_{s_{3}}}{s_{3}}\right)^{2^{2}}
\end{aligned}
$$

(Eq. 11.8)

$$
\begin{gathered}
\left(\frac{m}{\rho} \frac{\partial \rho}{\partial m}\right)=\frac{m}{\rho} \cdot \frac{1}{s_{1} \cdot s_{2} \cdot s_{3}}=1 \\
\left(\frac{s_{1}}{s_{1} \cdot s_{2} \cdot s_{3}} \frac{\partial\left(s_{1} \cdot s_{2} \cdot s_{3}\right)}{\partial s_{1}}\right)=\frac{s_{1}}{s_{1} \cdot s_{2} \cdot s_{3}} \cdot s_{2} \cdot s_{3}=1 \\
\left(\frac{s_{2}}{s_{1} \cdot s_{2} \cdot s_{3}} \frac{\partial\left(s_{1} \cdot s_{2} \cdot s_{3}\right)}{\partial s_{2}}\right)=\frac{s_{2}}{s_{1} \cdot s_{2} \cdot s_{3}} \cdot s_{1} \cdot s_{3}=1 \\
\left(\frac{s_{3}}{s_{1} \cdot s_{2} \cdot s_{3}} \frac{\partial\left(s_{1} \cdot s_{2} \cdot s_{3}\right)}{\partial s_{3}}\right)=\frac{s_{3}}{s_{1} \cdot s_{2} \cdot s_{3}} \cdot s_{1} \cdot s_{2}=1 \\
\left(\frac{U_{V}}{\rho}\right)^{2}=\left(\frac{U_{m}}{m}\right)^{2}+\left(\frac{U_{s_{1}}}{s_{1}}\right)^{2}+\left(\frac{U_{s_{2}}}{s_{2}}\right)^{2}+\left(\frac{U_{s_{3}}}{s_{3}}\right)^{2} \\
\left(\frac{U_{V}}{V}\right)^{2}=\left(\frac{s}{V} \frac{\partial V}{\partial s}\right)^{2}\left(\frac{U_{s}}{s}\right)^{2}+\left(\frac{t}{V} \frac{\partial V}{\partial t}\right)^{2}\left(\frac{U_{t}}{t}\right)^{2} \\
\left(\frac{s}{V} \frac{\partial \rho}{\partial s}\right)=\frac{s}{V} \cdot \frac{1}{t}=1 \\
\left(\frac{s}{t^{2}}\right)^{2}=-1
\end{gathered}
$$


Substituting Equations 11.13 and. 11.17 into Equation 11.7, the general uncertainty analysis expression is represented with Equation 11.18.

$$
\left(\frac{U_{C}}{C}\right)^{2}=\left(\frac{U_{m}}{m}\right)^{2}+\left(\frac{U_{s_{1}}}{s_{1}}\right)^{2}+\left(\frac{U_{s_{2}}}{s_{2}}\right)^{2}+\left(\frac{U_{s_{3}}}{s_{3}}\right)^{2}+4\left(\frac{U_{s}}{s}\right)^{2}+4\left(\frac{U_{t}}{t}\right)^{2}
$$

Finally, Equation 11.19 is the general uncertainty solution.

$$
U_{C}=C \sqrt{\left(\frac{U_{m}}{m}\right)^{2}+\left(\frac{U_{s_{1}}}{s_{1}}\right)^{2}+\left(\frac{U_{s_{2}}}{s_{2}}\right)^{2}+\left(\frac{U_{s_{3}}}{s_{3}}\right)^{2}+4\left(\frac{U_{s}}{s}\right)^{2}+4\left(\frac{U_{t}}{t}\right)^{2}}
$$

Now that the general equation for the uncertainty is developed, the specific relations can be readily determined as shown in the Equations $4.17-4.20$.

$$
\begin{aligned}
& U_{C_{11}}=C_{11} \sqrt{\left(\frac{U_{m}}{m}\right)^{2}+5\left(\frac{U_{s_{1}}}{s_{1}}\right)^{2}+\left(\frac{U_{s_{2}}}{s_{2}}\right)^{2}+\left(\frac{U_{s_{3}}}{s_{3}}\right)^{2}+4\left(\frac{U_{t_{L 1}}}{t_{L 1}}\right)^{2}} \\
& U_{C_{33}}=C_{33} \sqrt{\left(\frac{U_{m}}{m}\right)^{2}+\left(\frac{U_{s_{1}}}{s_{1}}\right)^{2}+\left(\frac{U_{s_{2}}}{s_{2}}\right)^{2}+5\left(\frac{U_{s_{3}}}{s_{3}}\right)^{2}+4\left(\frac{U_{t_{L 3}}}{t_{L 3}}\right)^{2}} \\
& U_{C_{44}}=C_{44} \sqrt{\left(\frac{U_{m}}{m}\right)^{2}+\left(\frac{U_{s_{1}}}{s_{1}}\right)^{2}+5\left(\frac{U_{s_{2}}}{s_{2}}\right)^{2}+\left(\frac{U_{s_{3}}}{s_{3}}\right)^{2}+4\left(\frac{U_{t_{T 3}}}{t_{T 3}}\right)^{2}} \\
& U_{C_{66}}=C_{66} \sqrt{\left(\frac{U_{m}}{m}\right)^{2}+5\left(\frac{U_{s_{1}}}{s_{1}}\right)^{2}+\left(\frac{U_{s_{2}}}{s_{2}}\right)^{2}+\left(\frac{U_{s_{3}}}{s_{3}}\right)^{2}+4\left(\frac{U_{t_{t 2}}}{t_{T 2}}\right)^{2}}
\end{aligned}
$$

The uncertainty for $C_{12}$ is computed as shown. The solution is shown in Equation 4.21.

$$
\begin{aligned}
& C_{12}=C_{11}-2 C_{66} \\
& U_{C_{12}}^{2}=\left(\frac{\partial C_{12}}{\partial C_{11}}\right)^{2} U_{C_{11}}^{2}+\left(\frac{\partial C_{12}}{\partial C_{66}}\right)^{2} U_{C_{65}}^{2} \\
& \left(\frac{\partial C_{12}}{\partial C_{11}}\right)=1
\end{aligned}
$$




$$
\begin{gathered}
\left(\frac{\partial C_{12}}{\partial C_{66}}\right)=-2 \\
U_{C_{12}}^{2}=U_{C_{11}}^{2}+4 U_{C_{66}}^{2} \\
U_{C_{12}}=\sqrt{U_{C_{11}}^{2}+4 U_{C_{66}}^{2}}
\end{gathered}
$$

Similarly, the uncertainty for $\mathrm{C}_{13}$, is determined using the following method. The solution is shown in Equation 4.22.

$$
\begin{aligned}
& C_{13}=\frac{1}{2} \sqrt{\left[4 \rho V_{L 45^{\circ}, 13}^{2}-C_{11}-C_{33}-2 C_{44}\right]^{2}-\left[C_{11}-C_{33}\right]^{2}}-C_{44} \\
& U_{C_{13}}^{2}=\left(\frac{\partial C_{13}}{\partial \rho}\right)^{2} U_{\rho}^{2}+\left(\frac{\partial C_{13}}{\partial V_{L 45^{\circ}, 13}}\right)^{2} U_{V_{L 45^{\circ}, 13}^{2}}^{2} \\
& +\left(\frac{\partial C_{13}}{\partial C_{11}}\right)^{2} U_{C_{11}}^{2}+\left(\frac{\partial C_{13}}{\partial C_{33}}\right)^{2} U_{C_{33}}^{2}+\left(\frac{\partial C_{13}}{\partial C_{44}}\right)^{2} U_{C_{44}}^{2} \\
& \left(\frac{\partial C_{13}}{\partial \rho}\right)=\frac{2 V_{L 45^{\circ}, 13}^{2}\left(4 \rho V_{L 45^{\circ}, 13}^{2}-C_{11}-C_{33}-2 C_{44}\right)}{\sqrt{\left(4 \rho V_{L 45^{\circ}, 13}^{2}-C_{11}-C_{33}-2 C_{44}\right)^{2}-\left(C_{11}-C_{33}\right)^{2}}} \\
& \left(\frac{\partial C_{13}}{\partial V_{L 45^{\circ}, 13}}\right)=\frac{4 V_{L 45^{\circ}, 13}\left(4 \rho V_{L 45^{\circ}, 13}^{2}-C_{11}-C_{33}-2 C_{44}\right)}{\sqrt{\left(4 \rho V_{L 45^{\circ}, 13}^{2}-C_{11}-C_{33}-2 C_{44}\right)^{2}-\left(C_{11}-C_{33}\right)^{2}}} \\
& \left(\frac{\partial C_{13}}{\partial C_{11}}\right)=\frac{-2 \rho V_{L 45^{\circ}, 13}^{2}+C_{33}+C_{44}}{\sqrt{\left(4 \rho V_{L 45^{\circ}, 13}^{2}-C_{11}-C_{33}-2 C_{44}\right)^{2}-\left(C_{11}-C_{33}\right)^{2}}} \\
& \left(\frac{\partial C_{13}}{\partial C_{33}}\right)=\frac{-2 \rho V_{L 45^{\circ}, 13}^{2}+C_{11}+C_{44}}{\sqrt{\left(4 \rho V_{L 45^{\circ}, 13}^{2}-C_{11}-C_{33}-2 C_{44}\right)^{2}-\left(C_{11}-C_{33}\right)^{2}}} \\
& \left(\frac{\partial C_{13}}{\partial C_{44}}\right)=\frac{-4 \rho V_{L 45^{\circ}, 13}^{2}+C_{11}+C_{33}+2 C_{44}}{\sqrt{\left(4 \rho V_{L 45^{\circ}, 13}^{2}-C_{11}-C_{33}-2 C_{44}\right)^{2}-\left(C_{11}-C_{33}\right)^{2}}}-1
\end{aligned}
$$




$$
\begin{aligned}
U_{C_{13}}^{2} & =\left(\frac{2 V_{L 45^{\circ}, 13}^{2}\left(4 \rho V_{L 45^{\circ}, 13}^{2}-C_{11}-C_{33}-2 C_{44}\right)}{\sqrt{\left(4 \rho V_{L 45^{\circ}, 13}^{2}-C_{11}-C_{33}-2 C_{44}\right)^{2}-\left(C_{11}-C_{33}\right)^{2}}}\right)^{2} U_{\rho}^{2} \\
& +\left(\frac{4 V_{L 45^{\circ}, 13}\left(4 \rho V_{L 45^{\circ}, 13}^{2}-C_{11}-C_{33}-2 C_{44}\right)}{\sqrt{\left(4 \rho V_{L 45^{\circ}, 13}^{2}-C_{11}-C_{33}-2 C_{44}\right)^{2}-\left(C_{11}-C_{33}\right)^{2}}}\right)^{2} U_{V_{L 45,13}}^{2} \\
& +\left(\frac{-2 \rho V_{L 45^{\circ}, 13}^{2}+C_{33}+C_{44}}{\sqrt{\left(4 \rho V_{L 45^{\circ}, 13}^{2}-C_{11}-C_{33}-2 C_{44}\right)^{2}-\left(C_{11}-C_{33}\right)^{2}}}\right)^{2} U_{C_{11}}^{2} \\
& +\left(\frac{-2 \rho V_{L 45^{\circ}, 13}^{2}+C_{11}+C_{44}}{\sqrt{\left(4 \rho V_{L 45^{\circ}, 13}^{2}-C_{11}-C_{33}-2 C_{44}\right)^{2}-\left(C_{11}-C_{33}\right)^{2}}}\right)^{2} U_{C_{33}}^{2} \\
& +\left(\frac{-4 \rho V_{L 45^{\circ}, 13}^{2}+C_{11}+C_{33}+2 C_{44}}{\sqrt{\left(4 \rho V_{L 45^{\circ}, 13}^{2}-C_{11}-C_{33}-2 C_{44}\right)^{2}-\left(C_{11}-C_{33}\right)^{2}}}-1\right)^{2} U_{C_{44}}^{2}
\end{aligned}
$$




$$
\begin{aligned}
& U_{C_{13}}=\sqrt{\left(\frac{2 V_{L 45^{\circ}, 13}^{2}\left(4 \rho V_{L 45^{\circ}, 13}^{2}-C_{11}-C_{33}-2 C_{44}\right)}{\sqrt{\left(4 \rho V_{L 45^{\circ}, 13}^{2}-C_{11}-C_{33}-2 C_{44}\right)^{2}-\left(C_{11}-C_{33}\right)^{2}}}\right)^{2}} U_{\rho}^{2} \\
& +\left(\frac{4 V_{L 45^{\circ}, 13}\left(4 \rho V_{L 45^{\circ}, 13}^{2}-C_{11}-C_{33}-2 C_{44}\right)}{\sqrt{\left(4 \rho V_{L 45^{\circ}, 13}^{2}-C_{11}-C_{33}-2 C_{44}\right)^{2}-\left(C_{11}-C_{33}\right)^{2}}}\right)^{2} U_{V_{245^{\circ}, 13}^{2}}^{2} \\
& +\left(\frac{-2 \rho V_{L 45^{\circ}, 13}^{2}+C_{33}+C_{44}}{\sqrt{\left(4 \rho V_{L 45^{\circ}, 13}^{2}-C_{11}-C_{33}-2 C_{44}\right)^{2}-\left(C_{11}-C_{33}\right)^{2}}}\right)^{2} U_{C_{11}}^{2} \\
& +\left(\frac{-2 \rho V_{L 45^{\circ}, 13}^{2}+C_{11}+C_{44}}{\sqrt{\left(4 \rho V_{L 45^{\circ}, 13}^{2}-C_{11}-C_{33}-2 C_{44}\right)^{2}-\left(C_{11}-C_{33}\right)^{2}}}\right)^{2} U_{C_{33}}^{2} \\
& +\left(\frac{-4 \rho V_{L 45^{\circ}, 13}^{2}+C_{11}+C_{33}+2 C_{44}}{\sqrt{\left(4 \rho V_{L 45^{\circ}, 13}^{2}-C_{11}-C_{33}-2 C_{44}\right)^{2}-\left(C_{11}-C_{33}\right)^{2}}}-1\right)^{2} U_{C_{44}}^{2}
\end{aligned}
$$




\subsection{Model of Aluminum as an Example}

A fictitious cube of bulk aluminum is modeled using the ultrasonic method as an example. First the basic measurements are taken and their tolerances determined. Second, the density and the wave velocities are calculated. Third, the elastic constants are determined. Finally, the shear moduli $(G)$, Poisson's ratios $(v)$, and Young's moduli $(E)$ are computed. Estimates of the mass, physical dimensions, and time-offlight measurements with their tolerances are shown in Table 17.

Table 17, Estimates of mass, size, and time-of-flight measurements with tolerances for aluminum.

\begin{tabular}{|c|c|c|}
\hline Feature & Value & Tolerance \\
\hline Mass $(\mathrm{m})$ & $5.528 \mathrm{e}-3 \mathrm{~kg}$ & $0.05 \mathrm{e}-3 \mathrm{~kg}$ \\
\hline Dimension $\left(\mathrm{s}_{1}\right)$ & $12.7 \mathrm{e}-3 \mathrm{~m}$ & $12.7 \mathrm{e}-6 \mathrm{~m}$ \\
\hline Dimension $\left(\mathrm{s}_{2}\right)$ & $12.7 \mathrm{e}-3 \mathrm{~m}$ & $12.7 \mathrm{e}-6 \mathrm{~m}$ \\
\hline Dimension $\left(\mathrm{s}_{3}\right)$ & $12.7 \mathrm{e}-3 \mathrm{~m}$ & $12.7 \mathrm{e}-6 \mathrm{~m}$ \\
\hline Longitudinal Time-of-Flight, TT $\left(\mathrm{t}_{\mathrm{L} 1}\right)$ & $2.000 \mathrm{e}-6 \mathrm{~s}$ & $0.025 \mathrm{e}-6 \mathrm{~s}$ \\
\hline Longitudinal Time-of-Flight, TT $\left(\mathrm{t}_{\mathrm{L} 2}\right)$ & $2.000 \mathrm{e}-6 \mathrm{~s}$ & $0.025 \mathrm{e}-6 \mathrm{~s}$ \\
\hline Longitudinal Time-of-Flight, PE $\left(\mathrm{t}_{\mathrm{L} 3}\right)$ & $2.000 \mathrm{e}-6 \mathrm{~s}$ & $0.010 \mathrm{e}-6 \mathrm{~s}$ \\
\hline Transverse Time-of-Flight, TT $\left(\mathrm{t}_{\mathrm{T} 12}\right)$ & $4.000 \mathrm{e}-6 \mathrm{~s}$ & $0.025 \mathrm{e}-6 \mathrm{~s}$ \\
\hline Transverse Time-of-Flight, TT $\left(\mathrm{t}_{\mathrm{T} 13}\right)$ & $4.000 \mathrm{e}-6 \mathrm{~s}$ & $0.025 \mathrm{e}-6 \mathrm{~s}$ \\
\hline Transverse Time-of-Flight, TT $\left(\mathrm{t}_{\mathrm{T} 21}\right)$ & $4.000 \mathrm{e}-6 \mathrm{~s}$ & $0.025 \mathrm{e}-6 \mathrm{~s}$ \\
\hline Transverse Time-of-Flight, TT $\left(\mathrm{t}_{\mathrm{T} 23}\right)$ & $4.000 \mathrm{e}-6 \mathrm{~s}$ & $0.025 \mathrm{e}-6 \mathrm{~s}$ \\
\hline Transverse Time-of-Flight, PE $\left(\mathrm{t}_{\mathrm{T} 31}\right)$ & $4.000 \mathrm{e}-6 \mathrm{~s}$ & $0.010 \mathrm{e}-6 \mathrm{~s}$ \\
\hline Transverse Time-of-Flight, PE $\left(\mathrm{t}_{\mathrm{T} 32}\right)$ & $4.000 \mathrm{e}-6 \mathrm{~s}$ & $0.010 \mathrm{e}-6 \mathrm{~s}$ \\
\hline
\end{tabular}

Once the basic measurements are determined, density and velocity measurements can be calculated. The density and wave velocity results with their uncertainties are shown in Table 18. 
Table 18, Estimates of density and wave velocities with uncertainties for aluminum.

\begin{tabular}{|c|c|c|}
\hline Feature & Result & Uncertainty \\
\hline Density $(\rho)$ & $2.699 \mathrm{e}+3 \mathrm{~kg} / \mathrm{m}^{3}$ & $0.025 \mathrm{e}+3 \mathrm{~kg} / \mathrm{m}^{3}$ \\
\hline Longitudinal Wave Velocity $\left(\mathrm{V}_{\mathrm{L} 1}\right)$ & $6.350 \mathrm{e}+3 \mathrm{~m} / \mathrm{s}$ & $0.080 \mathrm{e}+3 \mathrm{~m} / \mathrm{s}$ \\
\hline Longitudinal Wave Velocity $\left(\mathrm{V}_{\mathrm{L} 2}\right)$ & $6.350 \mathrm{e}+3 \mathrm{~m} / \mathrm{s}$ & $0.080 \mathrm{e}+3 \mathrm{~m} / \mathrm{s}$ \\
\hline Longitudinal Wave Velocity $\left(\mathrm{V}_{\mathrm{L} 3}\right)$ & $6.350 \mathrm{e}+3 \mathrm{~m} / \mathrm{s}$ & $0.032 \mathrm{e}+3 \mathrm{~m} / \mathrm{s}$ \\
\hline Longitudinal Wave Velocity $\left(\mathrm{V}_{\mathrm{L} 45^{\circ}, 23}\right)$ & $6.350 \mathrm{e}+3 \mathrm{~m} / \mathrm{s}$ & $0.043 \mathrm{e}+3 \mathrm{~m} / \mathrm{s}$ \\
\hline Longitudinal Wave Velocity $\left(\mathrm{V}_{\mathrm{L} 45^{\circ}, 13}\right)$ & $6.350 \mathrm{e}+3 \mathrm{~m} / \mathrm{s}$ & $0.043 \mathrm{e}+3 \mathrm{~m} / \mathrm{s}$ \\
\hline Longitudinal Wave Velocity $\left(\mathrm{V}_{\mathrm{L} 45^{\circ}, 12}\right)$ & $6.350 \mathrm{e}+3 \mathrm{~m} / \mathrm{s}$ & $0.056 \mathrm{e}+3 \mathrm{~m} / \mathrm{s}$ \\
\hline Transverse Wave Velocity $\left(\mathrm{V}_{\mathrm{T} 12}\right)$ & $3.175 \mathrm{e}+3 \mathrm{~m} / \mathrm{s}$ & $0.020 \mathrm{e}+3 \mathrm{~m} / \mathrm{s}$ \\
\hline Transverse Wave Velocity $\left(\mathrm{V}_{\mathrm{T} 13}\right)$ & $3.175 \mathrm{e}+3 \mathrm{~m} / \mathrm{s}$ & $0.020 \mathrm{e}+3 \mathrm{~m} / \mathrm{s}$ \\
\hline Transverse Wave Velocity $\left(\mathrm{V}_{\mathrm{T} 21}\right)$ & $3.175 \mathrm{e}+3 \mathrm{~m} / \mathrm{s}$ & $0.020 \mathrm{e}+3 \mathrm{~m} / \mathrm{s}$ \\
\hline Transverse Wave Velocity $\left(\mathrm{V}_{\mathrm{T} 23}\right)$ & $3.175 \mathrm{e}+3 \mathrm{~m} / \mathrm{s}$ & $0.020 \mathrm{e}+3 \mathrm{~m} / \mathrm{s}$ \\
\hline Transverse Wave Velocity $\left(\mathrm{V}_{\mathrm{T} 31}\right)$ & $3.175 \mathrm{e}+3 \mathrm{~m} / \mathrm{s}$ & $0.009 \mathrm{e}+3 \mathrm{~m} / \mathrm{s}$ \\
\hline Transverse Wave Velocity $\left(\mathrm{V}_{\mathrm{T} 32}\right)$ & $3.175 \mathrm{e}+3 \mathrm{~m} / \mathrm{s}$ & $0.009 \mathrm{e}+3 \mathrm{~m} / \mathrm{s}$ \\
\hline
\end{tabular}

After the density and wave velocities are determined, the elastic constants can be calculated. The elastic stiffness constants with their uncertainties are shown for aluminum in Table 19. The published values for the elastic stiffness constants are for an aluminum monocrystal at ambient temperature [22].

Table 19, Estimates of elastic stiffness constants and uncertainties for aluminum.

\begin{tabular}{|c|c|c|c|}
\hline Elastic Constant & Value & Uncertainty & Bulk Value \\
\hline $\mathrm{C}_{11}$ & $108.8 \mathrm{GPa}$ & $2.9 \mathrm{GPa}$ & $108.2 \mathrm{GPa}$ \\
\hline $\mathrm{C}_{33}$ & $108.8 \mathrm{GPa}$ & $1.5 \mathrm{GPa}$ & $108.2 \mathrm{GPa}$ \\
\hline $\mathrm{C}_{44}$ & $27.2 \mathrm{GPa}$ & $0.3 \mathrm{GPa}$ & $28.5 \mathrm{GPa}$ \\
\hline $\mathrm{C}_{66}$ & $27.2 \mathrm{GPa}$ & $0.4 \mathrm{GPa}$ & $28.5 \mathrm{GPa}$ \\
\hline $\mathrm{C}_{12}$ & $54.4 \mathrm{GPa}$ & $3.0 \mathrm{GPa}$ & $61.3 \mathrm{GPa}$ \\
\hline $\mathrm{C}_{13}$ & $54.4 \mathrm{GPa}$ & $2.7 \mathrm{GPa}$ & $61.3 \mathrm{GPa}$ \\
\hline
\end{tabular}

Finally, once the elastic constants are known, shear moduli $(G)$, Poisson's ratios $(v)$, and Young's moduli $(E)$ can be calculated. These nominal values with the upper and 
lower bounds and the published values for polycrystalline aluminum [22] are shown in Table 20.

Table 20, Estimates of shear moduli, Poisson's ratios, and Young's moduli with bounds and the published values for aluminum.

\begin{tabular}{|c|c|c|c|c|}
\hline $\begin{array}{c}\text { Mechanical } \\
\text { Property }\end{array}$ & $\begin{array}{c}\text { Lower } \\
\text { Bound }\end{array}$ & $\begin{array}{c}\text { Nominal } \\
\text { Value }\end{array}$ & $\begin{array}{c}\text { Upper } \\
\text { Bound }\end{array}$ & $\begin{array}{c}\text { Bulk } \\
\text { Value }\end{array}$ \\
\hline $\mathrm{G}_{23}$ & $26.9 \mathrm{GPa}$ & $27.2 \mathrm{GPa}$ & $27.5 \mathrm{GPa}$ & $26.1 \mathrm{GPa}$ \\
\hline $\mathrm{G}_{13}$ & $26.9 \mathrm{GPa}$ & $27.2 \mathrm{GPa}$ & $27.5 \mathrm{GPa}$ & $26.1 \mathrm{GPa}$ \\
\hline $\mathrm{G}_{12}$ & $26.8 \mathrm{GPa}$ & $27.2 \mathrm{GPa}$ & $27.6 \mathrm{GPa}$ & $26.1 \mathrm{GPa}$ \\
\hline$v_{12}$ & 0.259 & 0.333 & 0.406 & 0.345 \\
\hline$v_{13}$ & 0.279 & 0.333 & 0.394 & 0.345 \\
\hline $\mathrm{E}_{1}$ & $60.1 \mathrm{GPa}$ & $72.6 \mathrm{GPa}$ & $84.0 \mathrm{GPa}$ & $70.3 \mathrm{GPa}$ \\
\hline $\mathrm{E}_{2}$ & $60.1 \mathrm{GPa}$ & $72.6 \mathrm{GPa}$ & $84.0 \mathrm{GPa}$ & $70.3 \mathrm{GPa}$ \\
\hline $\mathrm{E}_{3}$ & $65.9 \mathrm{GPa}$ & $72.6 \mathrm{GPa}$ & $78.6 \mathrm{GPa}$ & $70.3 \mathrm{GPa}$ \\
\hline
\end{tabular}




\subsection{Appendix D, ABAQUS Input Files}

Two ABAQUS simulations were developed. The first simulation shows a single nickel particle impacting an existing nickel coating. The second simulation shows two nickel particles impacting and existing nickel coating. Symmetry in both simulations was assumed to be at the centerline of the particle(s) and the centerline of the existing coating. This assumption greatly reduced the computer time. The nickel particle is $40 \mu \mathrm{m}$ in diameter and has an initial velocity of $500 \mathrm{~m} / \mathrm{s}$. This nickel particle also has an imposed boundary condition at the centerline, the nodes are not allowed to move in the horizontal direction. The existing nickel coating is $42 \mu \mathrm{m}$ thick. This coating also has imposed boundary conditions. The nodes at the centerline are fixed in the horizontal direction. Additionally, the nodes representing the back surface of the coating are fixed in the vertical direction. The finite element type for the particle and coating is a 4-node bilinear axisymmetric quadrilateral, reduced integration, with hourglass control.

\subsection{One Particle}

This ABAQUS input file defines the single nickel particle model.

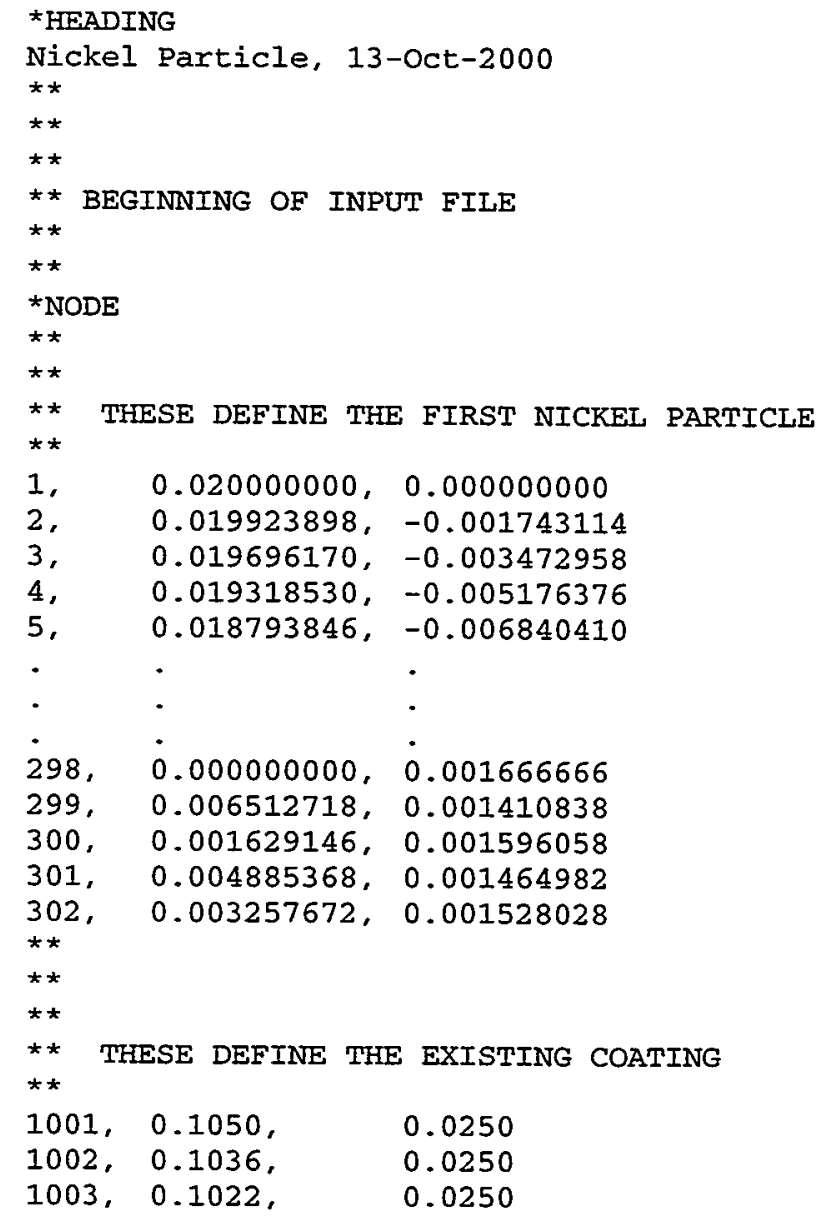




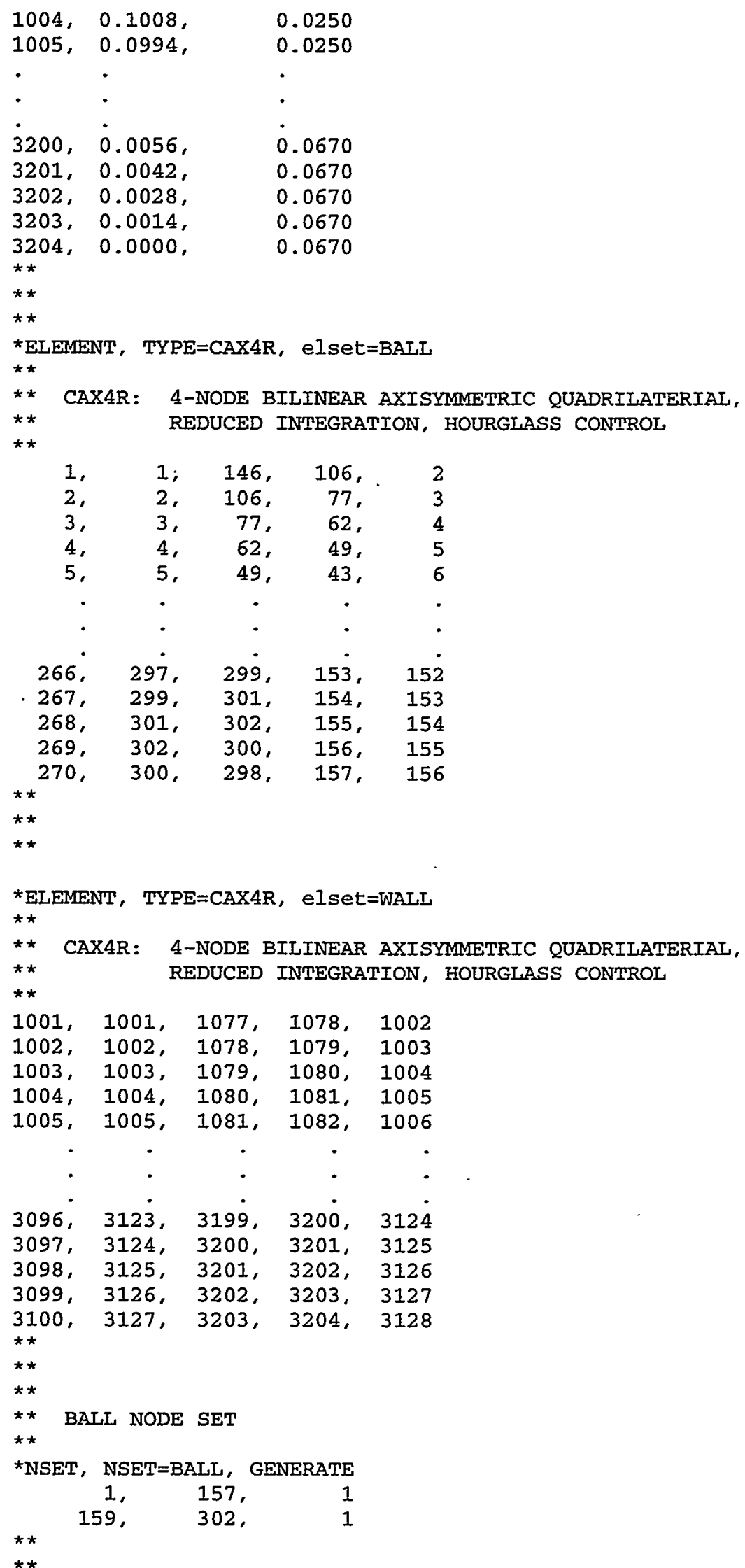




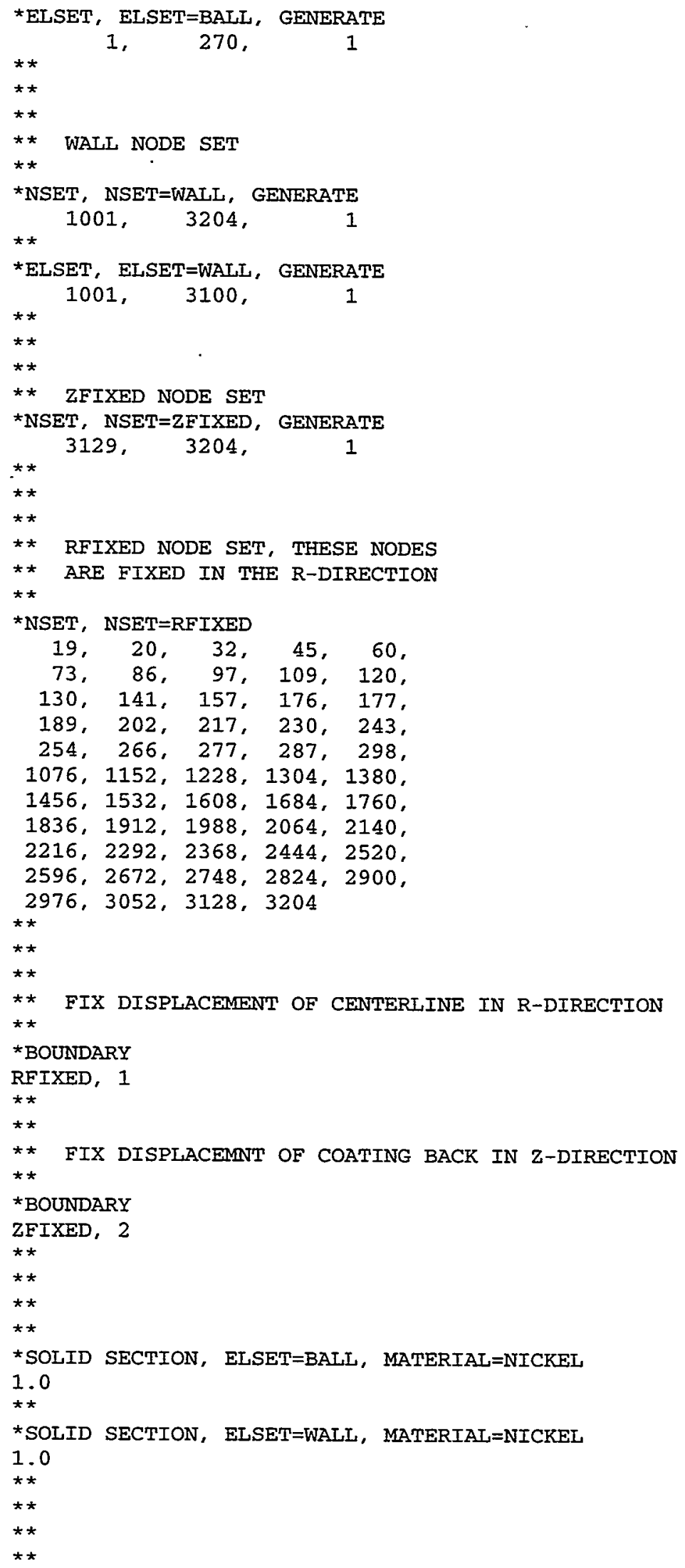




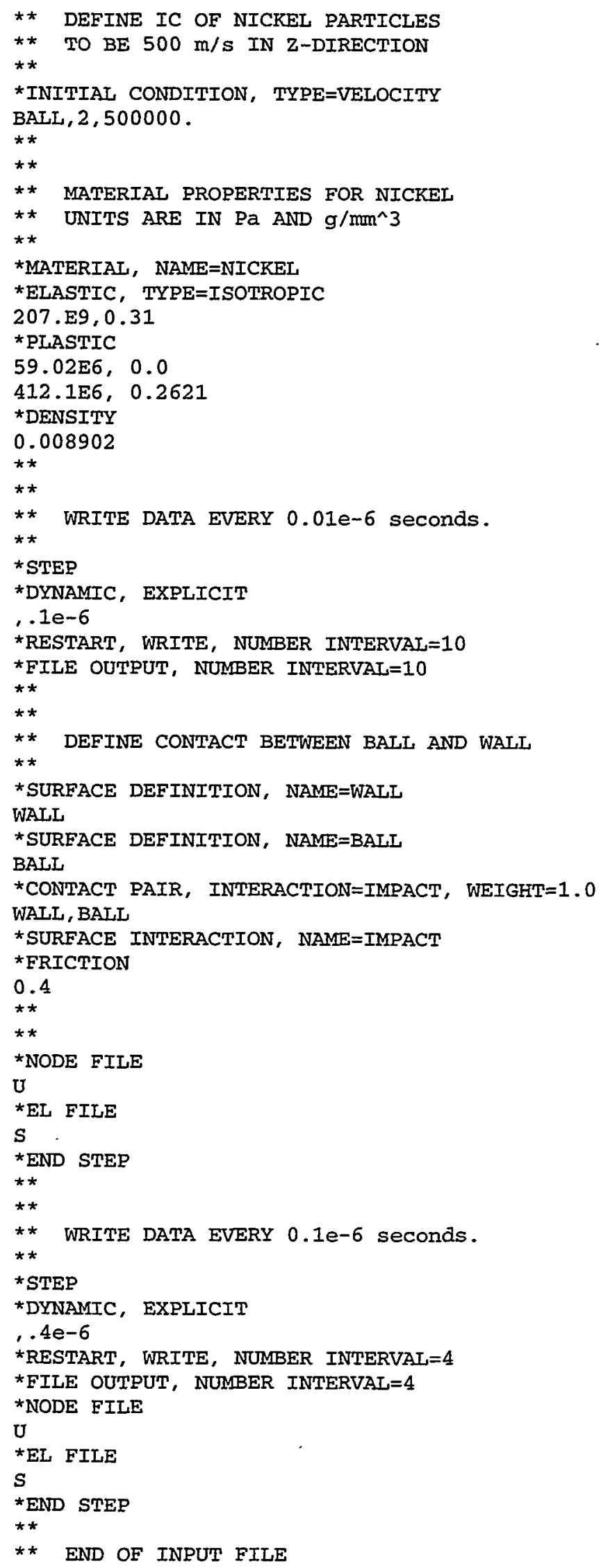




\subsection{Two Particles}

This ABAQUS input file defines the two nickel particle model.

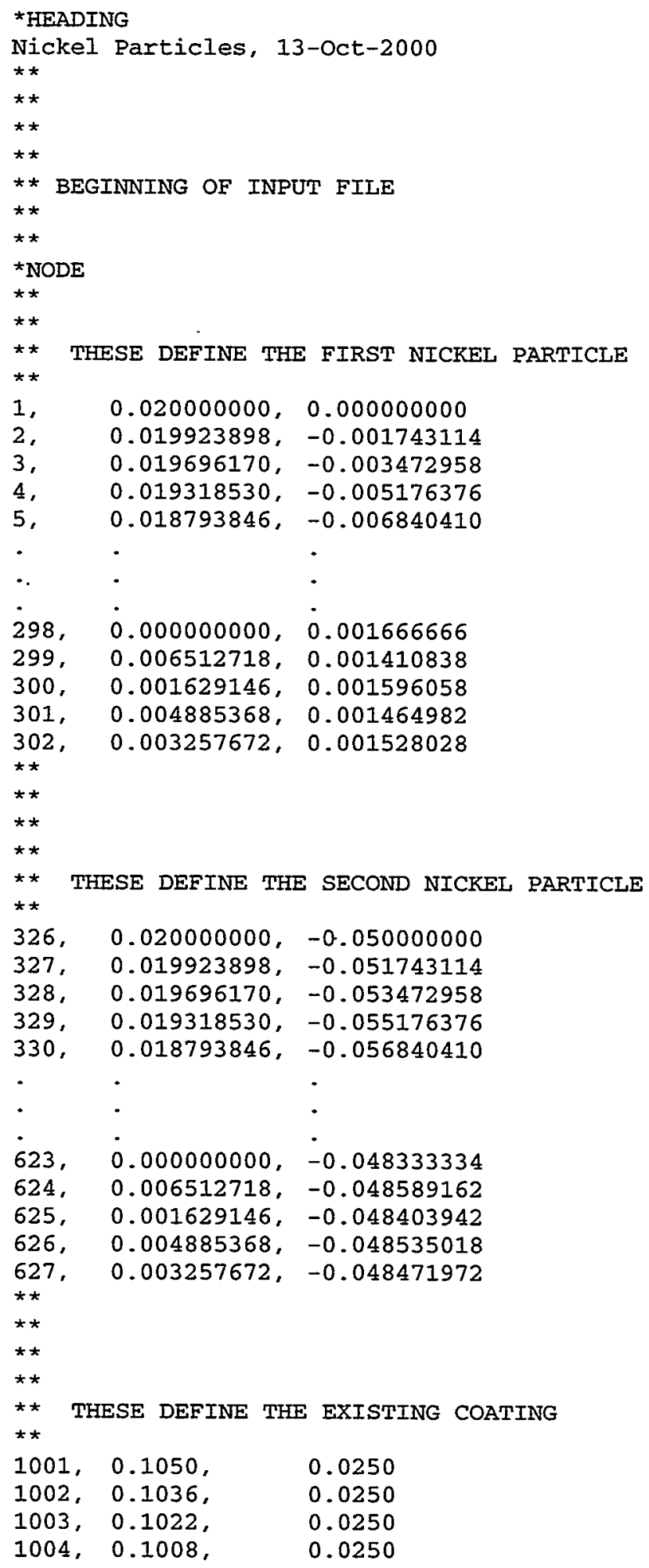




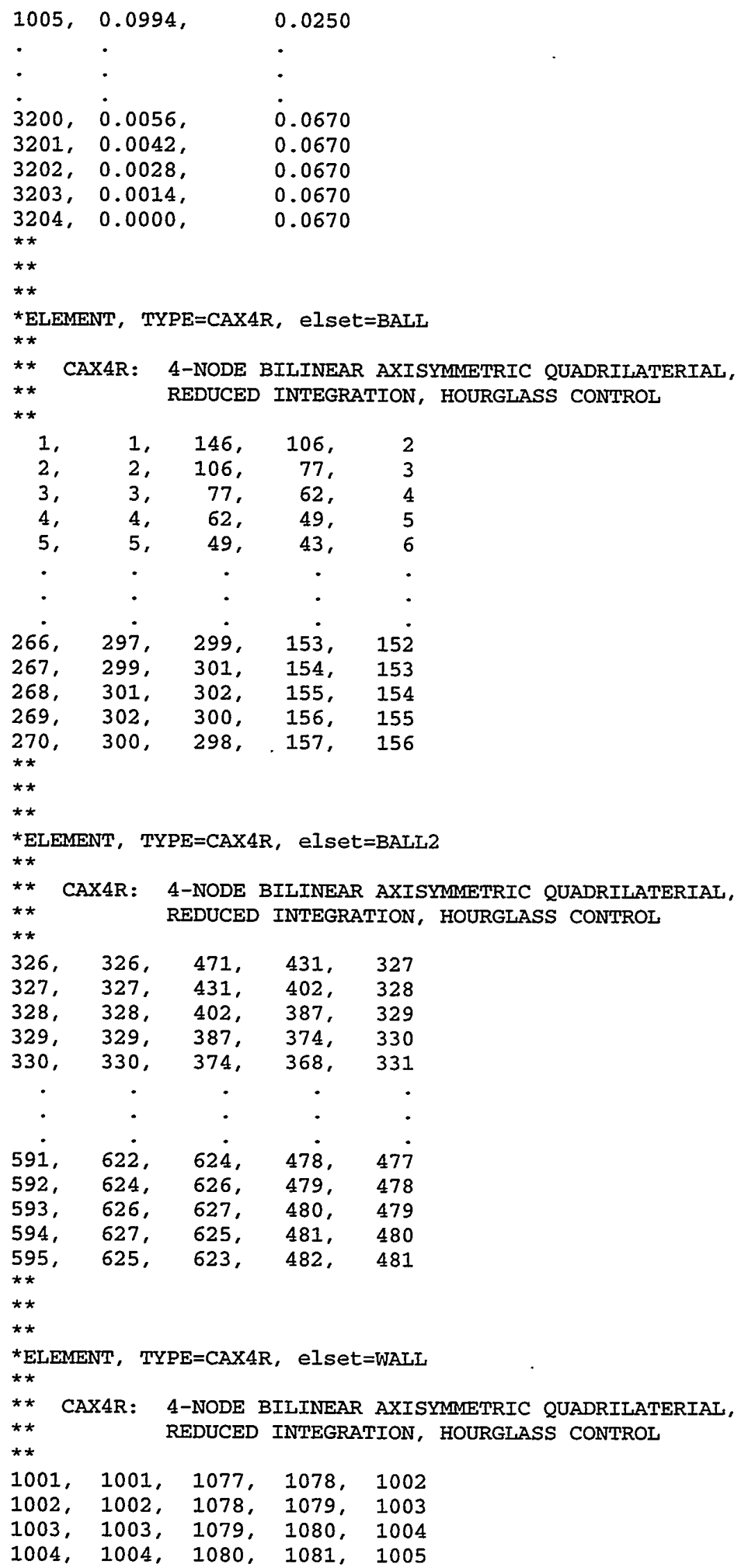




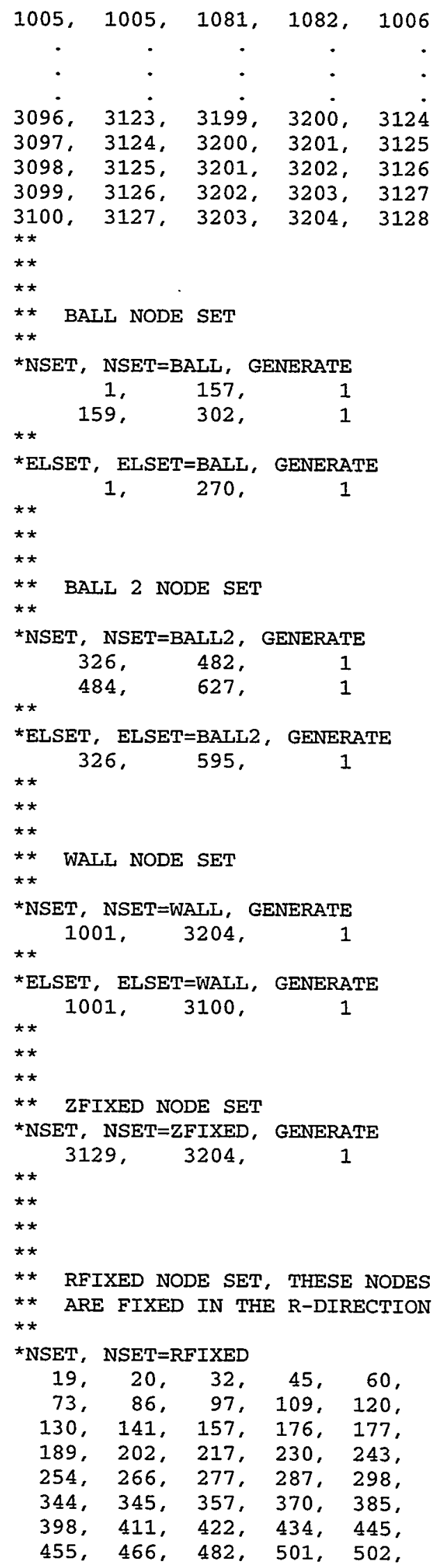




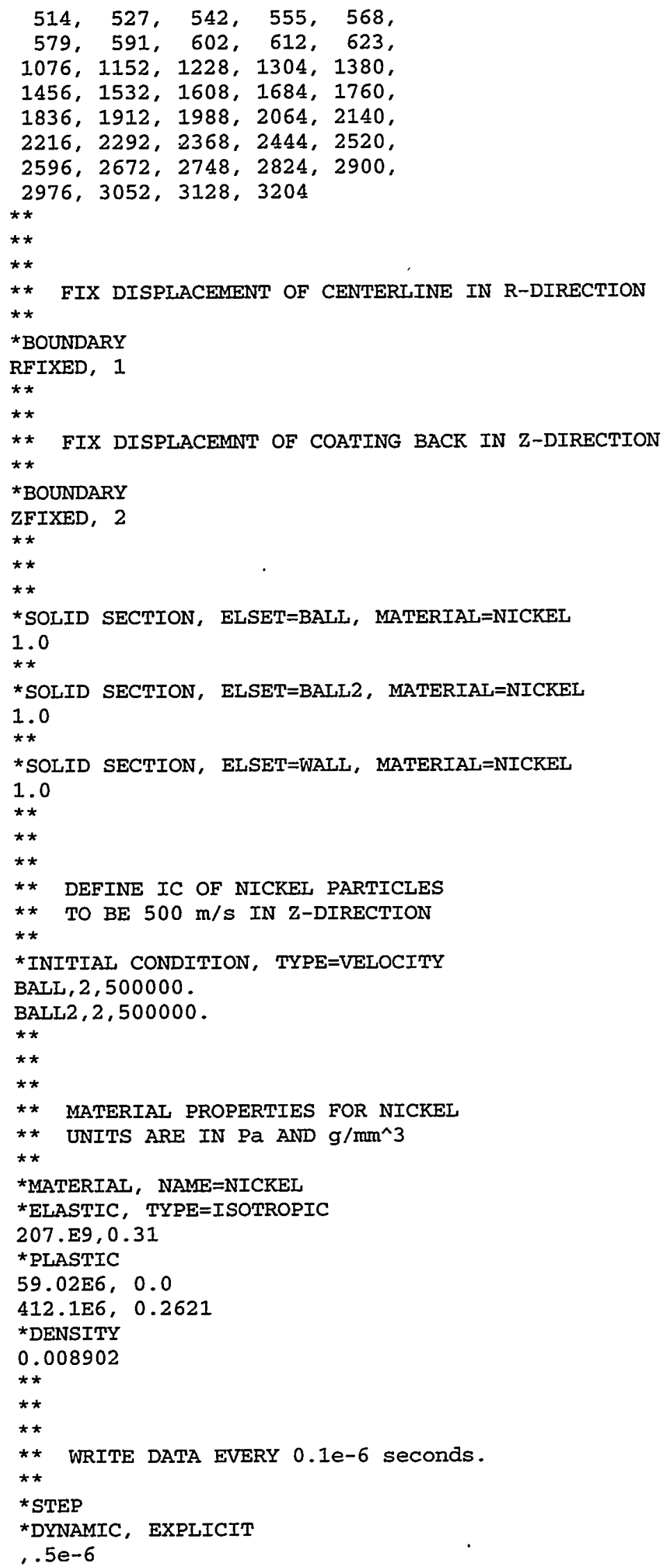


*RESTART, WRITE， NUMBER INTERVAI $=5$

*FILE OUTPUT, NUMBER INTERVAL $=5$

$\star \star$

$\star \star$

* DEFINE CONTACT BETWEEN BALL AND WALL

$\star \star$

* SURFACE DEFINITION, NAME=WAIL

WALL

*SURFACE DEFINITION, NAME=BALL

BAILL

*SURFACE DEFINITION, NAME=BALI2

BALL2

*CONTACT PAIR, INTERACTION=IMPACT, WEIGHT=1.0

WALL, BAIL

*CONTACT PAIR, INTERACTION=IMPACT2, WEIGHT $=1.0$

BALI, BAIL2

* SURFACE INTERACTION, NAME=IMPACT

*FRICTION

0.4

*SURFACE INTERACTION, NAME=IMPACT2

*FRICTION

0.4

**

* NODE FILE

U

*EL FILE

*END STEP

$\star \star$

$\star \star$

** END OF INPUT FILE

$\star \star$ 


\subsection{Appendix E, ABAQUS Status Files}

Some of the following information can be determined from the ABAQUS status files. A partial list includes stable time increment, critical element, actual CPU time, and kinetic energy in the model. Convergence was determined from the kinetic energy listed in these status files.

\subsection{One Particle}

ABAQUS/EXPLICIT is running on a Category B machine.

ABAQUS Iicense Server checked out 5 Network Tokens

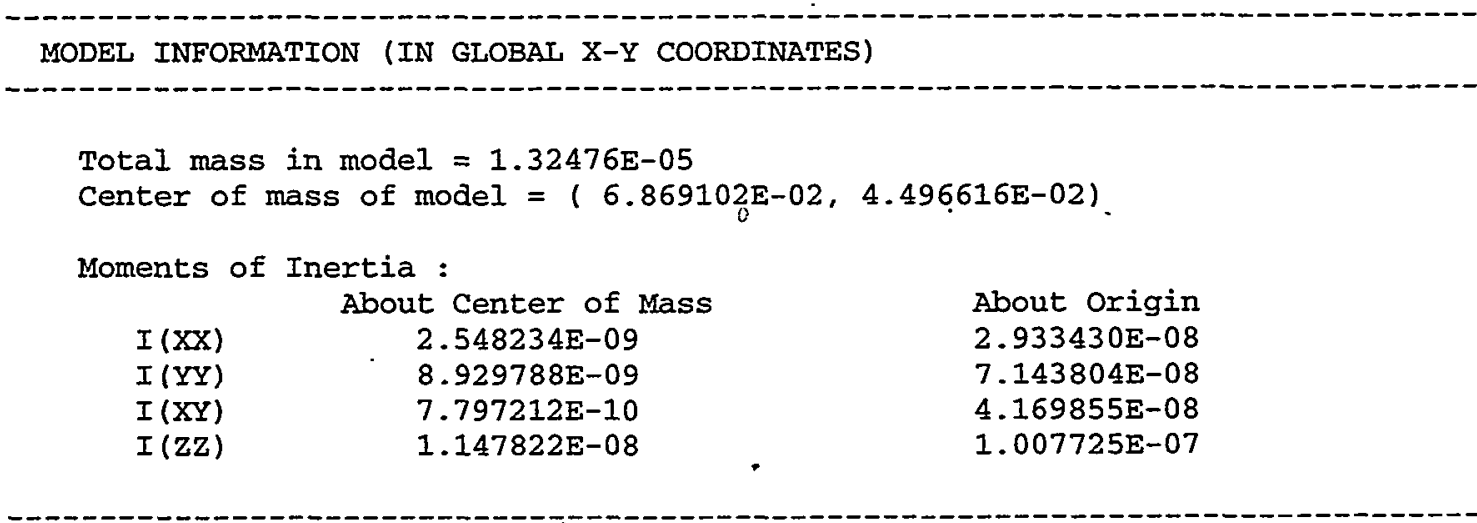

STABLE TIME INCREMENT INFORMATION

The stable time increment estimate for each element is based on linearization about the initial state.

Initial time increment $=1.05633 \mathrm{E}-10$

Statistics for all elements :

Mean $=1.69479 \mathrm{E}-10$

standard deviation $=7.49923 \mathrm{E}-12$

Most critical elements : (rank) (element number) (time increment) (increment ratio)

$\begin{array}{rrcr}1 & 55 & 1.056327 \mathrm{E}-10 & 1.000000 \mathrm{E}+00 \\ 2 & 190 & 1.056327 \mathrm{E}-10 & 1.000000 \mathrm{E}+00 \\ 3 & 45 & 1.108443 \mathrm{E}-10 & 9.529823 \mathrm{E}-01 \\ 4 & 180 & 1.108444 \mathrm{E}-10 & 9.529818 \mathrm{E}-01 \\ 5 & 46 & 1.123877 \mathrm{E}-10 & 9.398950 \mathrm{E}-01 \\ 6 & 181 & 1.123877 \mathrm{E}-10 & 9.398948 \mathrm{E}-01 \\ 7 & 64 & 1.340578 \mathrm{E}-10 & 7.879634 \mathrm{E}-01 \\ 8 & 199 & 1.340578 \mathrm{E}-10 & 7.879634 \mathrm{E}-01 \\ 9 & 3025 & 1.348101 \mathrm{E}-10 & 7.835665 \mathrm{E}-01 \\ 10 & 1075 & 1.348102 \mathrm{E}-10 & 7.835658 \mathrm{E}-01\end{array}$

ABAQUS/EXPLICIT is running on a Category B machine. ABAQUS License Server checked out 5 Network Tokens 
STEP 1 ORIGIN 0.

Total memory used for step 1 is approximately 704.9 kilowords Global time estimation algorithm will be used.

scaling factor : 1.0000

$\begin{array}{clllc} & \text { STEP } & \text { TOTAL } & \text { CPU } & \text { STABLE } \\ \text { INCREMENT } & \text { TIME } & \text { TIME } & \text { TIME } & \text { INCREMENT } \\ 0 & 0.000 \mathrm{E}+00 & 0.000 \mathrm{E}+00 & 00: 00: 00 & 1.056 \mathrm{E}-10\end{array}$

Results number 0 at increment zero.

$$
\begin{array}{lllll}
36 & 5.128 \mathrm{E}-09 & 5.128 \mathrm{E}-09 & 00: 00: 01 & 1.755 \mathrm{E}-10 \\
64 & 1.004 \mathrm{E}-08 & 1.004 \mathrm{E}-08 & 00: 00: 02 & 1.748 \mathrm{E}-10
\end{array}
$$

Results Number 1 at $1.00410 \mathrm{E}-08$

Restart Number 1 at $1.00410 \mathrm{E}-08$

$$
\begin{array}{rrr}
94 & 1.516 \mathrm{E}-08 & 1.516 \mathrm{E}-08 \\
124 & 2.008 \mathrm{E}-08 & 2.008 \mathrm{E}-08
\end{array}
$$

$00: 00: 03 \quad 1.706 \mathrm{E}-10$

$00: 00: 041.688 \mathrm{E}-10$

Results Number 2 at 2.00760E-08

Restart Number 2 at 2.00760E-08 $157 \quad 2.517 \mathrm{E}-08 \quad 2.517 \mathrm{E}-08$ $204 \quad 3.009 \mathrm{E}-08 \quad 3.009 \mathrm{E}-08$

Results Number 3 at 3.00863E-08 Restart Number 3 at 3.00863E-08 $2733.510 \mathrm{E}-08 \quad 3.510 \mathrm{E}-08$ 363 4.005E-08 4.005E-08

Results Number 4 at $4.00455 \mathrm{E}-08$ Restart Number 4 at $4.00455 \mathrm{E}-08$ $4824.506 \mathrm{E}-08 \quad 4.506 \mathrm{E}-08$ $617 \quad 5.002 \mathrm{E}-08 \quad 5.002 \mathrm{E}-08$

Results Number 5 at 5.00199E-08 Restart Number 5 at 5.00199E-08 $\begin{array}{lll}768 & 5.503 \mathrm{E}-08 & 5.503 \mathrm{E}-08\end{array}$ $9306.000 \mathrm{E}-08 \quad 6.000 \mathrm{E}-08$

Results Number 6 at $6.00005 \mathrm{E}-08$ Restart Number 6 at $6.00005 \mathrm{E}-08$ $\begin{array}{lll}1103 & 6.502 \mathrm{E}-08 & 6.502 \mathrm{E}-08\end{array}$ $1283 \quad 7.002 \mathrm{E}-08 \quad 7.002 \mathrm{E}-08$

Results Number 7 at $7.00185 \mathrm{E}-08$

Restart Number 7 at $7.00185 \mathrm{E}-08$ $14677.502 \mathrm{E}-08 \quad 7.502 \mathrm{E}-08$ $16548.003 \mathrm{E}-08 \quad 8.003 \mathrm{E}-08$

Results Number 8 at $8.00263 \mathrm{E}-08$

Restart Number 8 at $8.00263 E-08$ $18448.505 \mathrm{E}-08 \quad 8.505 \mathrm{E}-08$ $20439.001 \mathrm{E}-08 \quad 9.001 \mathrm{E}-08$

$00: 00: 051.307 \mathrm{E}-10$

$00: 00: 07 \quad 8.624 E-11$

$00: 00: 09 \quad 6.237 E-11$ $00: 00: 12 \quad 4.666 \mathrm{E}-11$

$00: 00: 16 \quad 3.905 \mathrm{E}-11$ $00: 00: 20 \quad 3.473 \mathrm{E}-11$

\section{$00: 00: 25 \quad 3.179 \mathrm{E}-11$} $00: 00: 30 \quad 2.977 \mathrm{E}-11$

$00: 00: 36 \quad 2.840 E-11$ $00: 00: 41 \quad 2.725 \mathrm{E}-11$

\section{$00: 00: 47 \quad 2.698 \mathrm{E}-11$} $00: 00: 53 \quad 2.660 \mathrm{E}-11$

$00: 00: 592.632 E-11$ $00: 01: 05 \quad 2.445 \mathrm{E}-11$

Results Number 9 at $9.00075 E-08$

Restart Number 9 at $9.00075 E-08$

\begin{tabular}{|c|c|}
\hline CRITICAI & KINETIC \\
\hline ELEMMENT & ENERGY \\
\hline 55 & $3.722 \mathrm{E}+04$ \\
\hline 55 & $3.722 \mathrm{E}+04$ \\
\hline 55 & $3.721 E+04$ \\
\hline 55 & 3. $613 \mathrm{E}+04$ \\
\hline 55 & $3.443 E+04$ \\
\hline 1064 & $3.262 \mathrm{E}+04$ \\
\hline 1064 & $3.054 E+04$ \\
\hline 1064 & $2.820 \mathrm{E}+04$ \\
\hline 1064 & $2.572 \mathrm{E}+04$ \\
\hline 1064 & $2.315 E+04$ \\
\hline 1064 & $2.065 E+04$ \\
\hline 1064 & $1.818 \mathrm{E}+04$ \\
\hline 1064 & 1. $585 E+04$ \\
\hline 1064 & $1.367 \mathrm{E}+04$ \\
\hline 1064 & $1.170 \mathrm{E}+04$ \\
\hline 1064 & $9.911 E+03$ \\
\hline 1064 & $8.295 E+03$ \\
\hline 1064 & $6.854 \mathrm{E}+03$ \\
\hline 145 & $5.604 E+03$ \\
\hline 1064 & $4.516 \mathrm{E}+03$ \\
\hline 144 & $3.587 \mathrm{E}+03$ \\
\hline
\end{tabular}
$\begin{array}{lll}2279 & 9.501 \mathrm{E}-08 & 9.501 \mathrm{E}-08 \\ 2549 & 1.000 \mathrm{E}-07 & 1.000 \mathrm{E}-07\end{array}$

Results Number 10 at 1.00000 E-07

\begin{tabular}{|c|c|c|c|c|c|c|}
\hline & STEP & TOTAL & CPU & STABLE & CRITICAI & KINETIC \\
\hline INCREMENT & TIME & TIME & TIME & INCREMENT & ELEMENT & ENERGY \\
\hline 0 & $0.000 \mathrm{E}+00$ & $1.000 E-07$ & $00: 01: 20$ & $1.890 \mathrm{E}-11$ & 144 & $3.587 \mathrm{E}+03$ \\
\hline ults nu & aber 0 at & increment & zero. & & & \\
\hline 1001 & 2.000E-08 & $1.200 \mathrm{E}-07$ & $00: 01: 51$ & $1.926 \mathrm{E}-11$ & 1064 & $1.169 \mathrm{E}+03$ \\
\hline 2040 & $4.002 E-08$ & $1.400 \mathrm{E}-07$ & $00: 02: 24$ & $41.924 \mathrm{E}-11$ & 1064 & $2.503 E+02$ \\
\hline
\end{tabular}
Restart Number 10 at 1.00000 E-07

STEP 2 ORIGIN 1.00000E-07 


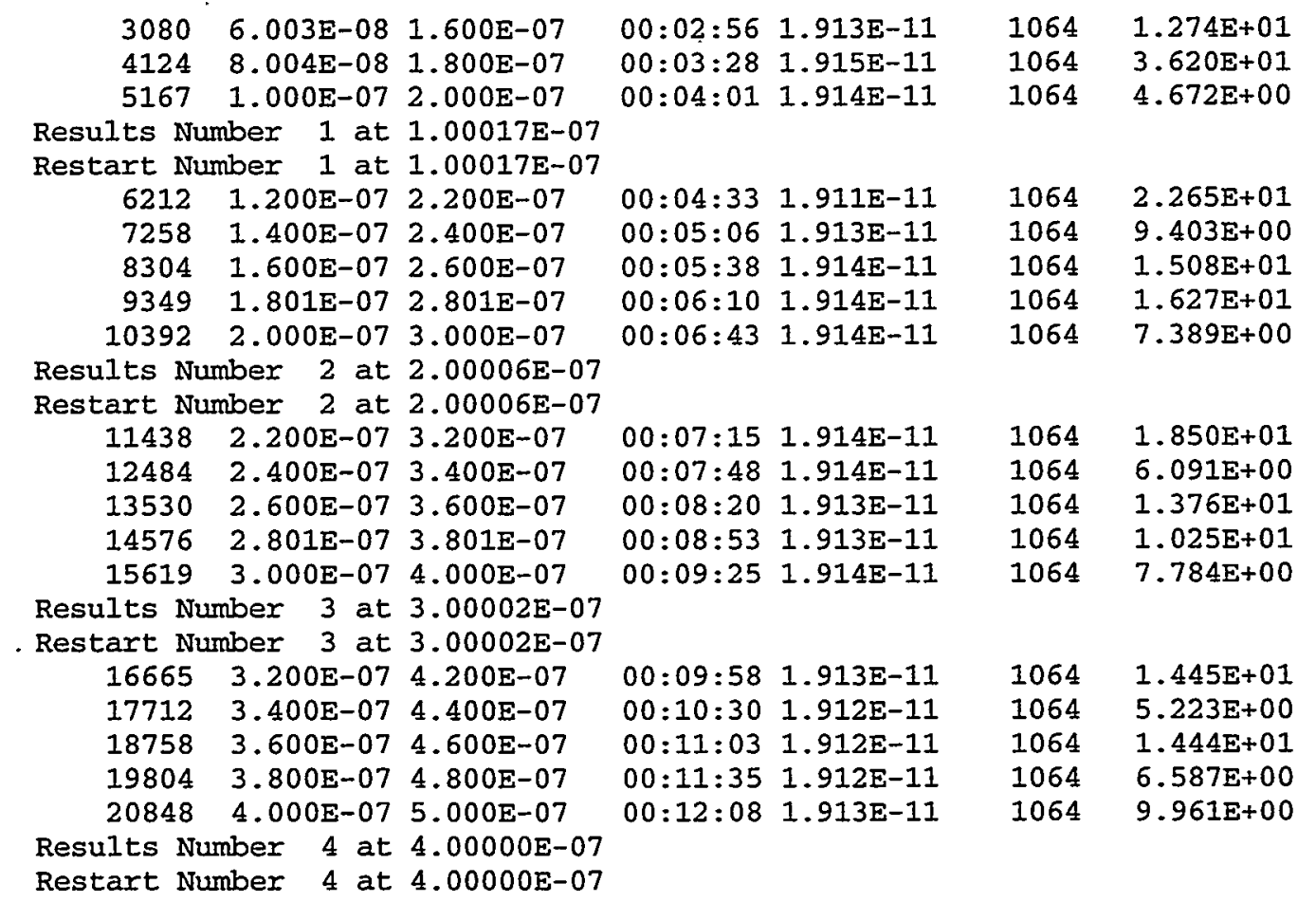

CONVERTING THE RESTART FILE

Translating specified steps and increments...

\begin{tabular}{ccrrrc} 
& Analysis & POST & & Accumulated \\
Step Index & Restart Index & Restart No. & Increment & Step Time & Time \\
\hline 1 & - & 0 & 0 & $0.00000 \mathrm{E}+00$ & $0.00000 \mathrm{E}+00$ \\
& 1 & 1 & 64 & $1.00410 \mathrm{E}-08$ & $1.00410 \mathrm{E}-08$ \\
& 2 & 2 & 124 & $2.00760 \mathrm{E}-08$ & $2.00760 \mathrm{E}-08$ \\
& 3 & 3 & 204 & $3.00863 \mathrm{E}-08$ & $3.00863 \mathrm{E}-08$ \\
4 & 4 & 363 & $4.00455 \mathrm{E}-08$ & $4.00455 \mathrm{E}-08$ \\
& 5 & 5 & 617 & $5.00199 \mathrm{E}-08$ & $5.00199 \mathrm{E}-08$ \\
& 6 & 6 & 930 & $6.00005 \mathrm{E}-08$ & $6.00005 \mathrm{E}-08$ \\
& 7 & 7 & 1283 & $7.00185 \mathrm{E}-08$ & $7.00185 \mathrm{E}-08$ \\
& 8 & 1654 & $8.00263 \mathrm{E}-08$ & $8.00263 \mathrm{E}-08$ \\
& 9 & 10 & 2043 & $9.00075 \mathrm{E}-08$ & $9.00075 \mathrm{E}-08$ \\
& 10 & 0 & 2549 & $1.00000 \mathrm{E}-07$ & $1.00000 \mathrm{E}-07$ \\
& - & 1 & 0 & $0.00000 \mathrm{E}+00$ & $1.00000 \mathrm{E}-07$ \\
& 1 & 2 & 5167 & $1.00017 \mathrm{E}-07$ & $2.00017 \mathrm{E}-07$ \\
& 2 & 3 & 10392 & $2.00006 \mathrm{E}-07$ & $3.00006 \mathrm{E}-07$ \\
& 3 & 4 & 15619 & $3.00002 \mathrm{E}-07$ & $4.00002 \mathrm{E}-07$ \\
& 4 & 20848 & $4.00000 \mathrm{E}-07$ & $5.00000 \mathrm{E}-07$
\end{tabular}




\subsection{Two Particles}

ABAQUS/EXPLICIT is running on a Category $B$ machine. ABAQUS License Server checked out 5 Network Tokens

MODEL INFORMATION (IN GLOBAL X-Y COORDINATES)

Total mass in model $=1.35453 \mathrm{E}-05$

Center of mass of model $=(6.743991 \mathrm{E}-02,4.287872 \mathrm{E}-02)$

Moments of Inertia :

$\begin{array}{lcc} & \text { About Center of Mass } & \text { About Origin } \\ I(X X) & 5.198292 \mathrm{E}-09 & 3.010256 \mathrm{E}-08 \\ I(\mathrm{YY}) & 9.879571 \mathrm{E}-09 & 7.148574 \mathrm{E}-08 \\ I(X Y) & 2.353687 \mathrm{E}-09 & 4.152327 \mathrm{E}-08 \\ I(\mathrm{ZZ}) & 1.507807 \mathrm{E}-08 & 1.015885 \mathrm{E}-07\end{array}$

STABLE TIME INCREMENT INFORMATION

The stable time increment estimate for each element is based on linearization about the initial state.

Initial time increment $=1.05633 \mathrm{E}-10$

Statistics for all elements:

Mean $=1.69726 \mathrm{E}-10$

Standard deviation $=9.37657 \mathrm{E}-12$

Most critical elements :

(rank) (element number) (time increment) (increment ratio)

$\begin{array}{rrrr}1 & 55 & 1.056327 \mathrm{E}-10 & 1.000000 \mathrm{E}+00 \\ 2 & 190 & 1.056327 \mathrm{E}-10 & 1.000000 \mathrm{E}+00 \\ 3 & 515 & 1.056328 \mathrm{E}-10 & 9.999987 \mathrm{E}-01 \\ 4 & 380 & 1.056328 \mathrm{E}-10 & 9.999986 \mathrm{E}-01 \\ 5 & 180 & 1.108444 \mathrm{E}-10 & 9.529818 \mathrm{E}-01 \\ 6 & 45 & 1.108444 \mathrm{E}-10 & 9.529814 \mathrm{E}-01 \\ 7 & 370 & 1.108445 \mathrm{E}-10 & 9.529809 \mathrm{E}-01 \\ 8 & 505 & 1.108445 \mathrm{E}-10 & 9.529809 \mathrm{E}-01 \\ 9 & 371 & 1.123876 \mathrm{E}-10 & 9.398956 \mathrm{E}-01 \\ 10 & 506 & 1.123876 \mathrm{E}-10 & 9.398956 \mathrm{E}-01\end{array}$

ABAQUS/EXPLICIT is running on a Category B machine. ABAQUS License Server checked out 5 Network Tokens

SOLUTION PROGRESS

STEP 1 ORIGIN 0.

Total memory used for step 1 is approximately 784.7 kilowords

Global time estimation algorithm will be used.

Scaling factor : 1.0000

$\begin{array}{cllcccc} & \text { STEP } & \text { TOTAL } & \text { CPU } & \text { STABLE } & \text { CRITICAL } & \text { RINETIC } \\ \text { INCREMENT } & \text { TIME } & \text { TIME } & \text { TIME } & \text { INCREMENT } & \text { ELEMENT } & \text { ENERGY } \\ 0 & 0.000 \mathrm{E}+00 & 0.000 \mathrm{E}+00 & 00: 00: 00 & 1.056 \mathrm{E}-10 & 55 & 7.444 \mathrm{E}+04\end{array}$

Results number 0 at increment zero. 


\begin{tabular}{|c|c|c|c|c|c|c|}
\hline 154 & $2.511 \mathrm{E}-08$ & $2.511 E-08$ & $00: 00: 05$ & $1.014 \mathrm{E}-10$ & 1064 & $6.993 \mathrm{E}+04$ \\
\hline 570 & $5.011 \mathrm{E}-08$ & $5.011 E-08$ & $00: 00: 20$ & $4.044 E-11$ & 1064 & $5.780 E+04$ \\
\hline 1310 & $7.512 \mathrm{E}-08$ & $7.512 \mathrm{E}-08$ & $00: 00: 45$ & $3.002 \mathrm{E}-11$ & 1064 & $4.711 E+04$ \\
\hline 2351 & $1.000 \mathrm{E}-07$ & $1.000 \mathrm{E}-07$ & $00: 01: 19$ & $2.087 E-11$ & 144 & $4.076 \mathrm{E}+04$ \\
\hline esults $\mathrm{Nu}$ & mber 1 at & $1.00007 \mathrm{E}-07$ & & & & \\
\hline estart $\mathrm{N}$ & mber 1 at & $1.00007 \mathrm{E}-07$ & & & & \\
\hline 3556 & $1.250 \mathrm{E}-07$ & $1.250 \mathrm{E}-07$ & $00: 01: 55$ & $1.983 E-11$ & 1064 & $3.205 E+04$ \\
\hline 4773 & $1.500 \mathrm{E}-07$ & $1.500 E-07$ & $00: 02: 32$ & 1.99 & 144 & $1.782 \mathrm{E}+04$ \\
\hline 6156 & $1.750 \mathrm{E}-07$ & $1.750 \mathrm{E}-07$ & $00: 03: 14$ & $1.627 \mathrm{E}-11$ & 1064 & $7.097 \mathrm{E}+03$ \\
\hline 7830 & $2.000 \mathrm{E}-07$ & $2.000 \mathrm{E}-07$ & $00: 04: 06$ & $1.404 \mathrm{E}-11$ & 144 & $2.066 \mathrm{E}+03$ \\
\hline Results Nu & mber 2 at & $2.00008 \mathrm{E}-07$ & & & & \\
\hline Restart Nu & mber 2 at & $2.00008 \mathrm{E}-07$ & & & & \\
\hline 9580 & $2.250 \mathrm{E}-07$ & $2.250 \mathrm{E}-07$ & $00: 04: 58$ & $1.384 \mathrm{E}-11$ & 144 & $3.429 \mathrm{E}+02$ \\
\hline 11386 & $2.500 E-07$ & 2.50 & $: 52$ & 1.3 & 144 & $2.821 E+01$ \\
\hline 13187 & $2.750 \mathrm{E}-07$ & 2.7 & $: 46$ & -11 & 144 & $4.826 \mathrm{E}+0 \mathrm{I}$ \\
\hline 14982 & $3.000 \mathrm{E}-07$ & $3.000 \mathrm{E}-07$ & $00: 07: 39$ & $1.392 \mathrm{E}-11$ & 144 & $6.672 \mathrm{E}+01$ \\
\hline esults $\mathrm{Nu}$ & mber 3 at & $3.00000 \mathrm{E}-07$ & & & & \\
\hline Restart $\mathrm{Nu}$ & mber 3 at & $3.00000 \mathrm{E}-07$ & & & & \\
\hline 16777 & $3.250 \mathrm{E}-07$ & $3.250 \mathrm{E}-07$ & $00: 08: 33$ & 1.4 & 144 & 3.2 \\
\hline 18569 & $3.500 E-07$ & 3.50 & 00 & & 144 & $2 E+01$ \\
\hline 20359 & $3.750 E-07$ & $3.750 \mathrm{E}-07$ & $00: 10: 19$ & $1.397 \mathrm{E}-11$ & 144 & $5.858 \mathrm{E}+01$ \\
\hline 22143 & $4.000 \mathrm{E}-07$ & 4.00 & $00: 11: 13$ & $1.400 \mathrm{E}-11$ & 144 & $4.154 E+01$ \\
\hline Results $\mathrm{Nu}$ & mber 4 at & $4.00003 E-07$ & & & & \\
\hline Restart $\mathrm{Nu}$ & mber 4 at & $4.00003 \mathrm{E}-07$ & & & & \\
\hline 23927 & $4.250 \mathrm{E}-07$ & $4.250 E-07$ & 00 & 1. & 144 & $1.991 E+01$ \\
\hline 25711 & $4.500 \mathrm{E}-07$ & $4.500 \mathrm{E}-07$ & $00: 12: 59$ & $1.403 \mathrm{E}-11$ & 144 & $4.774 E+01$ \\
\hline 27491 & $4.750 \mathrm{E}-07$ & $4.750 \mathrm{E}-07$ & & & 144 & $5.056 \mathrm{E}+01$ \\
\hline 29269 & $5.000 \mathrm{E}-$ & -07 & $00: 14: 45$ & $1.405 \mathrm{E}-11$ & 144 & $2.145 E+01$ \\
\hline
\end{tabular}

Results Number 5 at 5.00000E-07

Restart Number 5 at $5.00000 \mathrm{E}-07$

CONVERTING THE RESTART FILE

Translating specified steps and increments...

\begin{tabular}{|c|c|c|c|c|c|}
\hline Step Index & $\begin{array}{l}\text { Analysis } \\
\text { Restart Index }\end{array}$ & $\begin{array}{l}\text { POST } \\
\text { Restart No. }\end{array}$ & Increment & Step Time & $\begin{array}{l}\text { Accumulated } \\
\text { Time }\end{array}$ \\
\hline-- & $----0------$ & ----------- & --------- & -ーーーーーーーーーー & ----- \\
\hline \multirow[t]{6}{*}{1} & - & 0 & 0 & $0.00000 \mathrm{E}+00$ & $0.00000 \mathrm{E}+00$ \\
\hline & 1 & 1 & 2351 & $1.00007 \mathrm{E}-07$ & $1.00007 \mathrm{E}-07$ \\
\hline & 2 & 2 & 7830 & $2.00008 \mathrm{E}-07$ & $2.00008 \mathrm{E}-07$ \\
\hline & 3 & 3 & 14982 & $3.00000 \mathrm{E}-07$ & $3.00000 \mathrm{E}-07$ \\
\hline & 4 & 4 & 22143 & $4.00003 E-07$ & $4.00003 \mathrm{E}-07$ \\
\hline & 5 & 5 & 29269 & $5.00000 E-07$ & $5.00000 \mathrm{E}-07$ \\
\hline
\end{tabular}




\subsection{Appendix F, ABAQUS Stress Plots}

This appendix contains forty-two ABAQUS plots. At various simulation times, six stress plots were created (S11, S22, S12, S33, PRESS, and MISES). Simulation times for the single nickel particle are at 0.02e-6, 0.05e-6, 0.1e-6, and 0.5e-6 seconds. Simulation times for the two particle plots are at $0.1 \mathrm{e}-6,0.2 \mathrm{e}-6$, and $0.5 \mathrm{e}-6$ seconds.

A single particle impacting an existing surface is shown in pages $85-108$. Pages $85-90$ are the stress plots at a simulation time of $0.02 \mathrm{e}-6$ seconds. Pages $91-96$ are stress plots at a simulation time of $0.05 \mathrm{e}-6$ seconds. Pages $97-102$ are stress plots at a simulation time of $0.1 \mathrm{e}-6$ seconds. Pages $103-108$ are stress plots at a simulation time of $0.5 \mathrm{e}-6$ seconds. Two particles impacting an existing surface are shown in pages $109-126$. Pages $109-114$ are the stress plots at a simulation time of $0.1 \mathrm{e}-6$ seconds. Pages $115-120$ are stress plots at a simulation time of $0.2 e-6$ seconds. Pages $121-126$ are stress plots at a simulation time of $0.5 \mathrm{e}-6$ seconds. 


\begin{tabular}{rr|} 
S11 \\
VALUE \\
$-3.90 \mathrm{E}+09$ \\
$-3.42 \mathrm{E}+09$ \\
$-2.93 \mathrm{E}+09$ \\
$-2.45 \mathrm{E}+09$ \\
$-1.96 \mathrm{E}+09$ \\
$-1.47 \mathrm{E}+09$ \\
$-9.89 \mathrm{E}+08$ \\
-5 \\
$-5.04 \mathrm{E}+08$ \\
$-1.85 \mathrm{E}+07$ \\
$+4.67 \mathrm{E}+08$ \\
$+9.52 \mathrm{E}+08$ \\
$-1.44 \mathrm{E}+09$ \\
$+1.92 \mathrm{E}+09$ \\
$+2.41 \mathrm{E}+09$ \\
\hline
\end{tabular}

$\stackrel{\infty}{\leftrightarrow}$

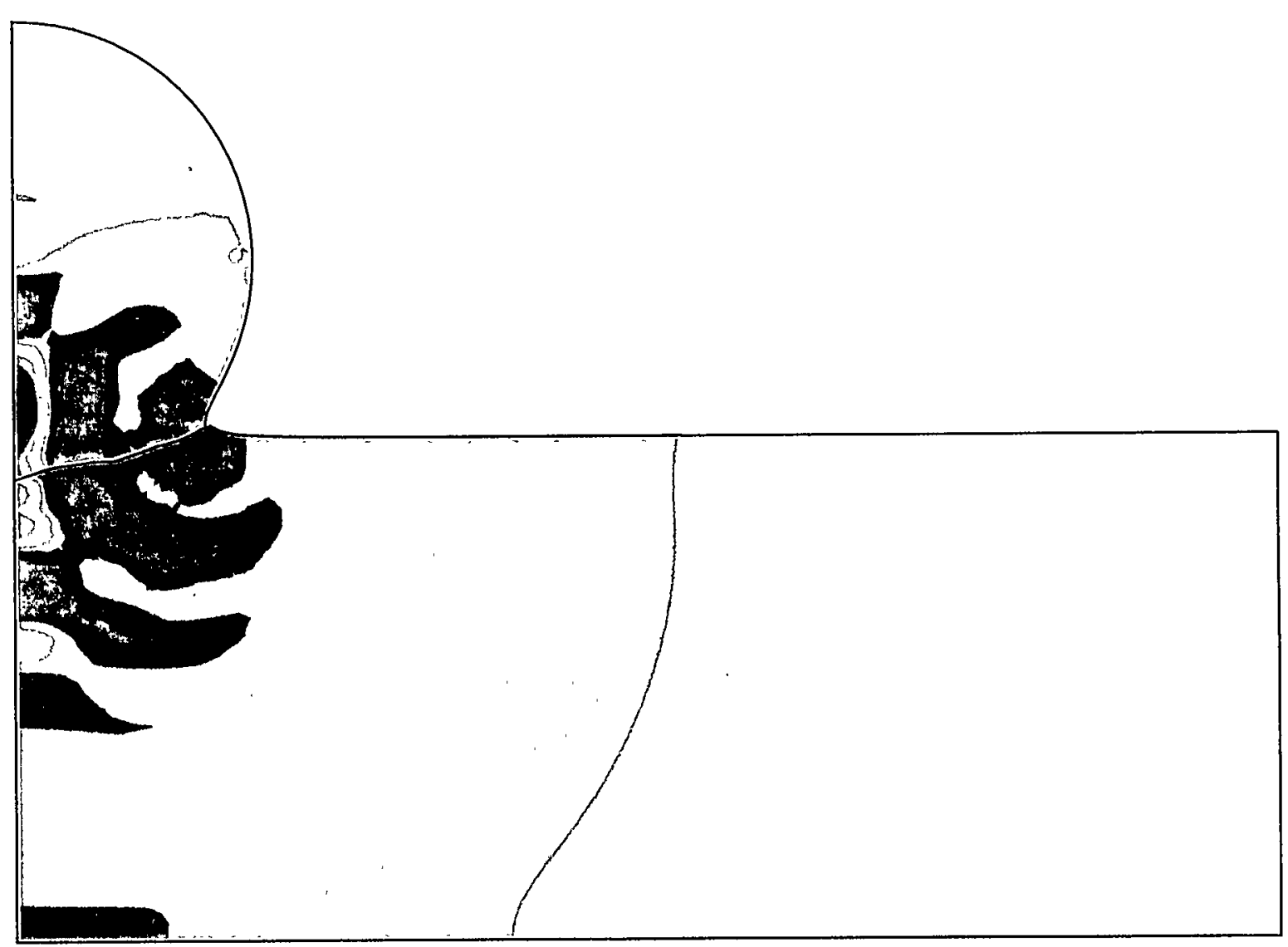

DISPLACEMENT MAGNIFICATION FACTOR $=1.00$

RESTART FILE = 1particle STEP 1 INCREMENT 124

TIME COMPLETED IN THIS STEP 2.008E-08 TOTAL ACCUMULATED TIME 2.008E-08

ABAQUS VERSION: $5.8-1$ DATE: 13 -OCT-2000 TIME: $10: 42: 24$ 


\begin{tabular}{|r|r|} 
VALUE \\
\\
1 \\
$1.99 \mathrm{E}+09$ \\
$-3.52 \mathrm{E}+09$ \\
$-3.04 \mathrm{E}+09$ \\
$-2.57 \mathrm{E}+09$ \\
$-2.09 \mathrm{E}+09$ \\
$-1.62 \mathrm{E}+09$ \\
$-1.14 \mathrm{E}+09$ \\
$-6.65 \mathrm{E}+08$ \\
$-1.89 \mathrm{E}+08$ \\
$+2.86 \mathrm{E}+08$ \\
$+7.62 \mathrm{E}+08$ \\
$+1.24 \mathrm{E}+09$ \\
$+1.71 \mathrm{E}+09$ \\
$+2.19 \mathrm{E}+09$
\end{tabular}

$\stackrel{\infty}{\circ}$

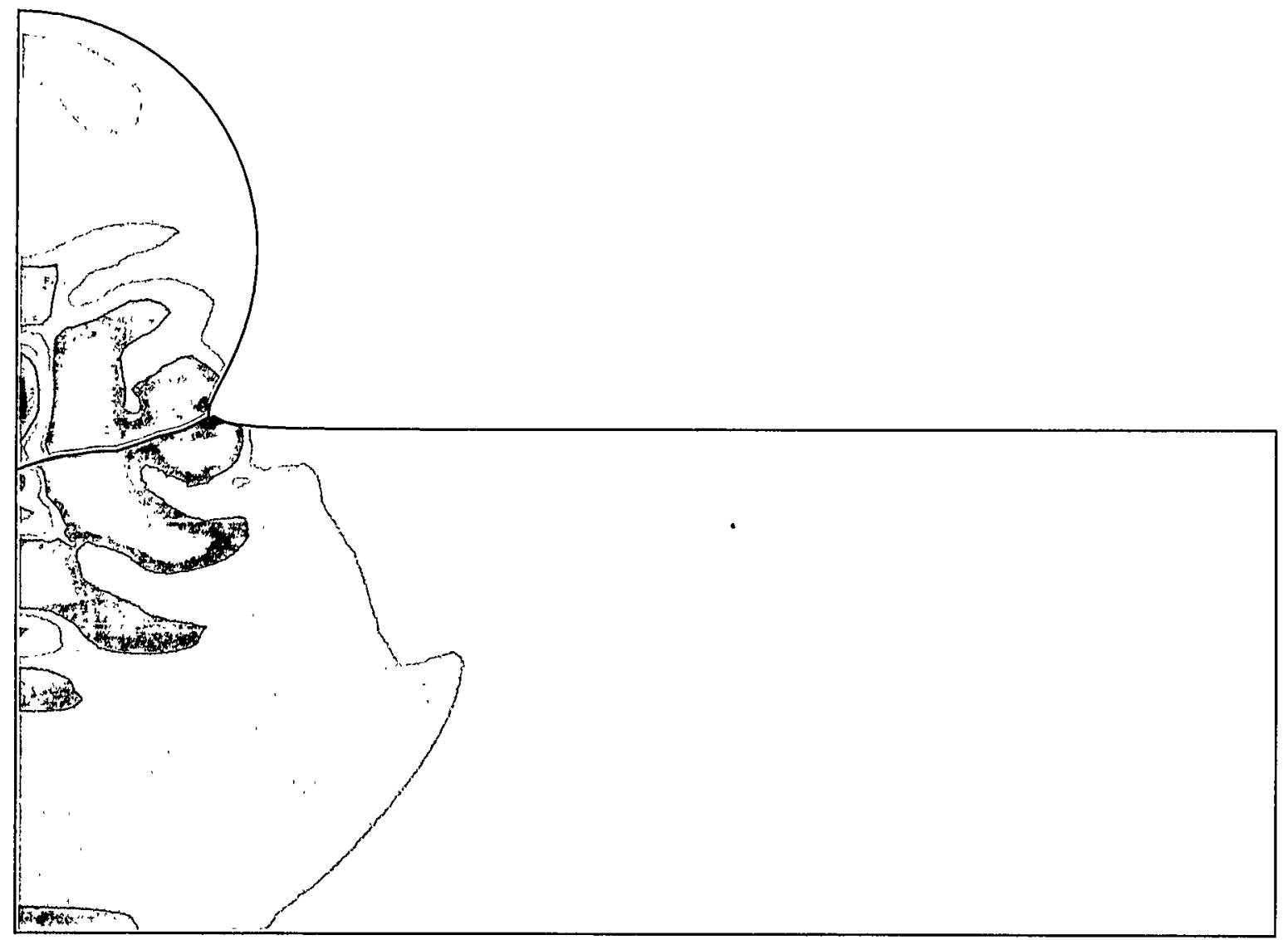

DISPLACEMENT MAGNIFICATION FACTOR $=1.00$

RESTART FILE = 1particle STEP 1 INCREMENT 124

TIME COMPLETED IN THIS STEP 2.008E-08 TOTAL ACCUMULATED TIME 2.008E-08

ABAQUS VERSION: $5.8-1$ DATE: $13-O C T-2000$ TIME: $10: 42: 24$ 


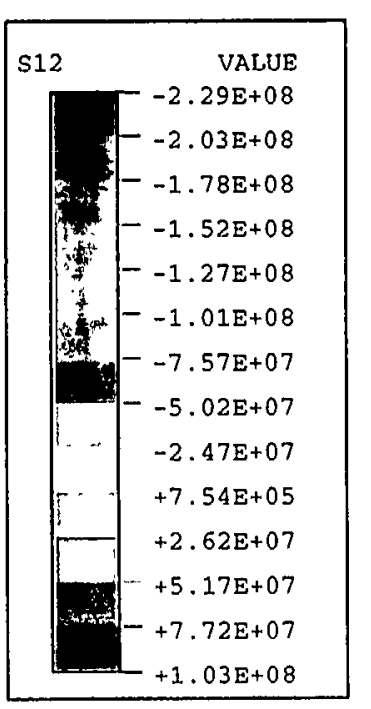

$\stackrel{\infty}{9}$

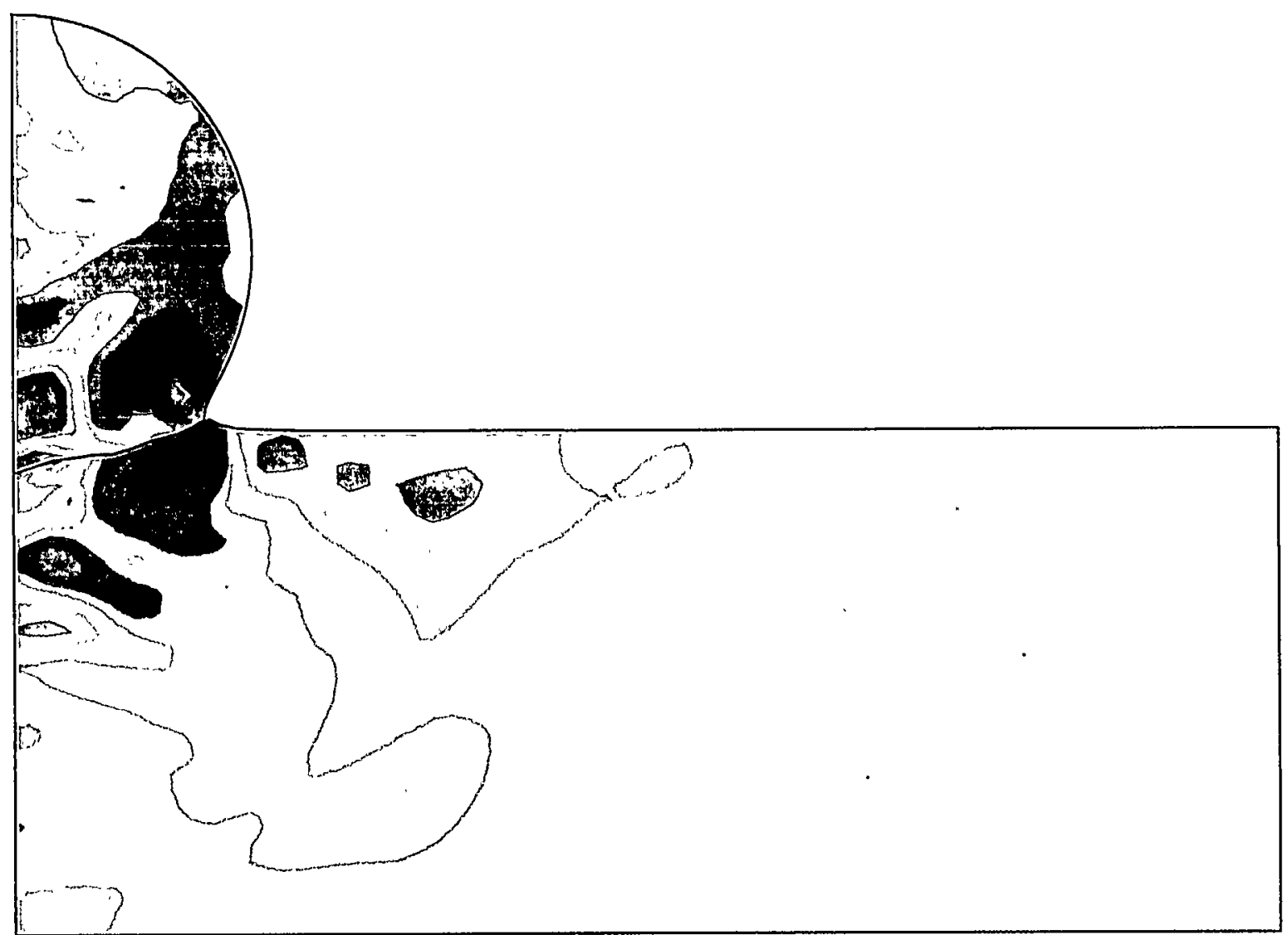

DISPLACEMENT MAGNIFICATION FACTOR $=1.00$

1 RESTART FILE = 1particle STEP 1 INCREMENT 124

TIME COMPLETED IN THIS STEP 2.008E-08 TOTAL ACCUMULATED TIME 2.008E-08

ABAQUS VERSION: $5.8-1$ DATE: 13-OCT-2000 TIME: 10:42:24 


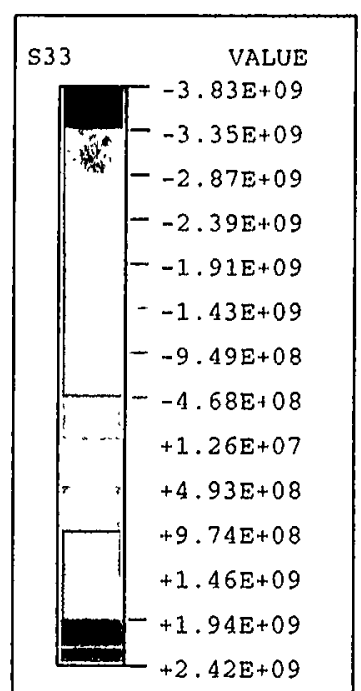

$\infty$

DISPLACEMENT MAGNIFICATION FACTOR $=1.00$

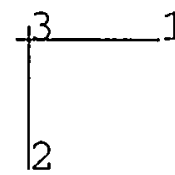

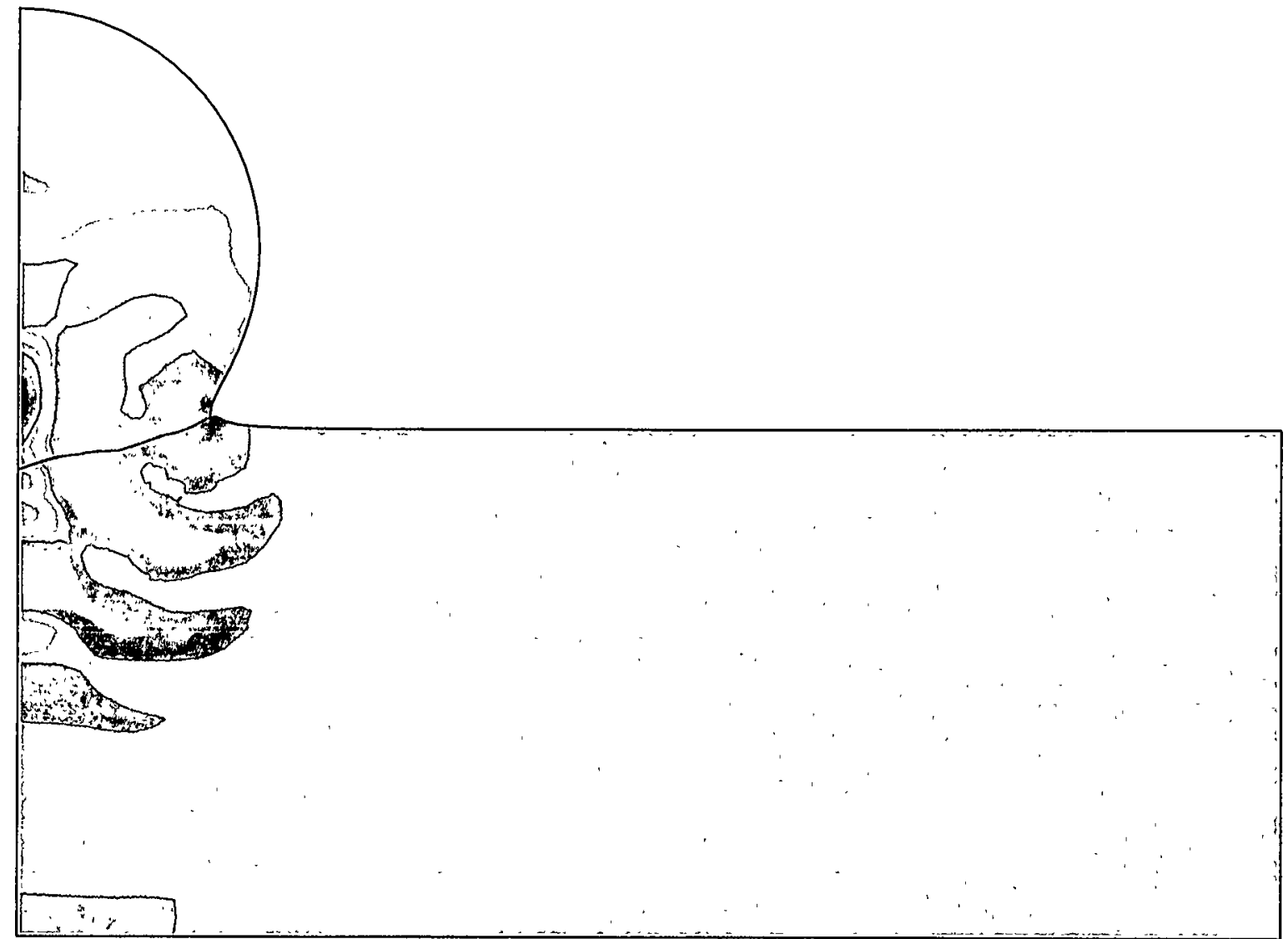

RESTART FILE = 1particle STEP 1 INCREMENT 124

TIME COMPLETED IN THIS STEP 2.008E-08 TOTAL ACCUMULATED TIME 2.008E-08

ABAQUS VERSION: 5.8-1 DATE: 13-OCT-2000 TIME: $10: 42: 24$ 


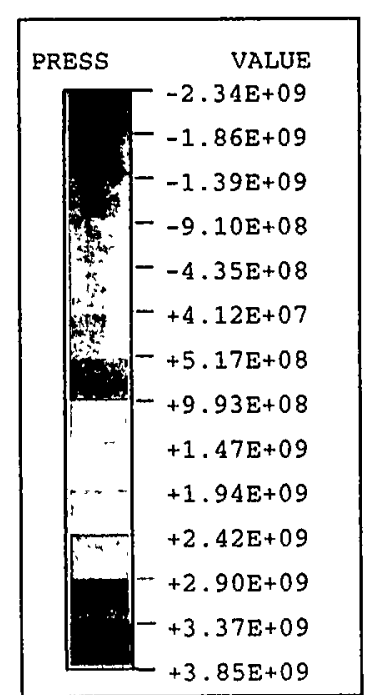

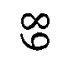

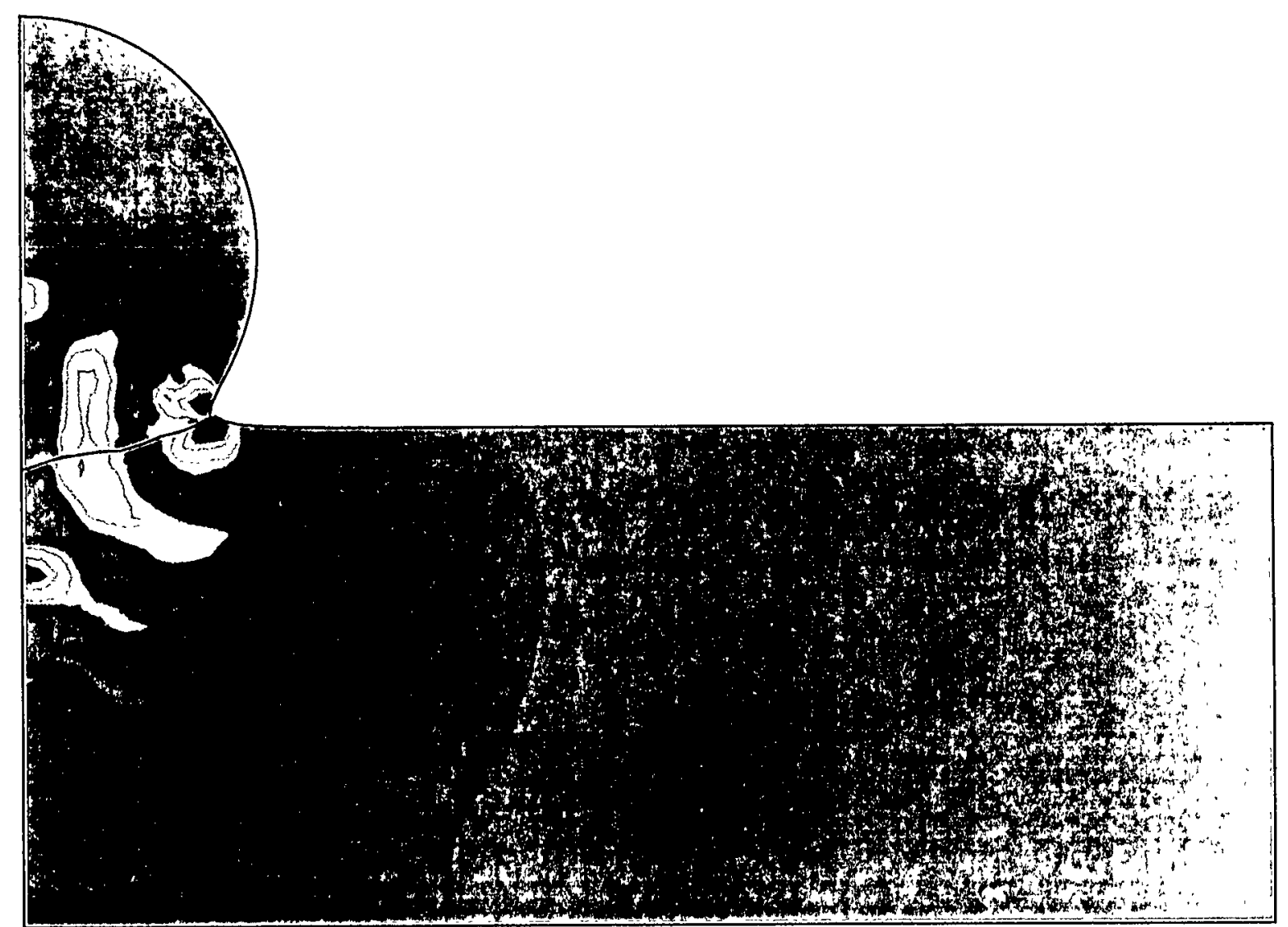

DISPLACEMENT MAGNIFICATION FACTOR $=1.00$

1 RESTART FILE = 1particle STEP 1 INCREMENT 124

TIME COMPLETED IN THIS STEP 2.008E-08 TOTAL ACCUMULATED TIME 2.008E-08

ABAQUS VERSION: 5.8-1 DATE: $13-O C T-2000$ TIME: $10: 42: 24$ 


\begin{tabular}{|r|r|}
\hline MISES & VALUE \\
\hdashline & $+0.00 \mathrm{E} 100$ \\
$+3.17 \mathrm{E}+07$ \\
$-6.34 \mathrm{E}+07$ \\
$-19.51 \mathrm{E}+07$ \\
$+1.27 \mathrm{E}+08$ \\
$-1.59 \mathrm{E}+08$ \\
$+1.90 \mathrm{E}+08$ \\
$+2.22 \mathrm{E}+08$ \\
$+2.54 \mathrm{E}+08$ \\
$+2.85 \mathrm{E}+08$ \\
$+3.17 \mathrm{E}+08$ \\
$-3.49 \mathrm{E}+08$ \\
$+3.80 \mathrm{E}+08$ \\
$+4.12 \mathrm{E}+08$
\end{tabular}

8

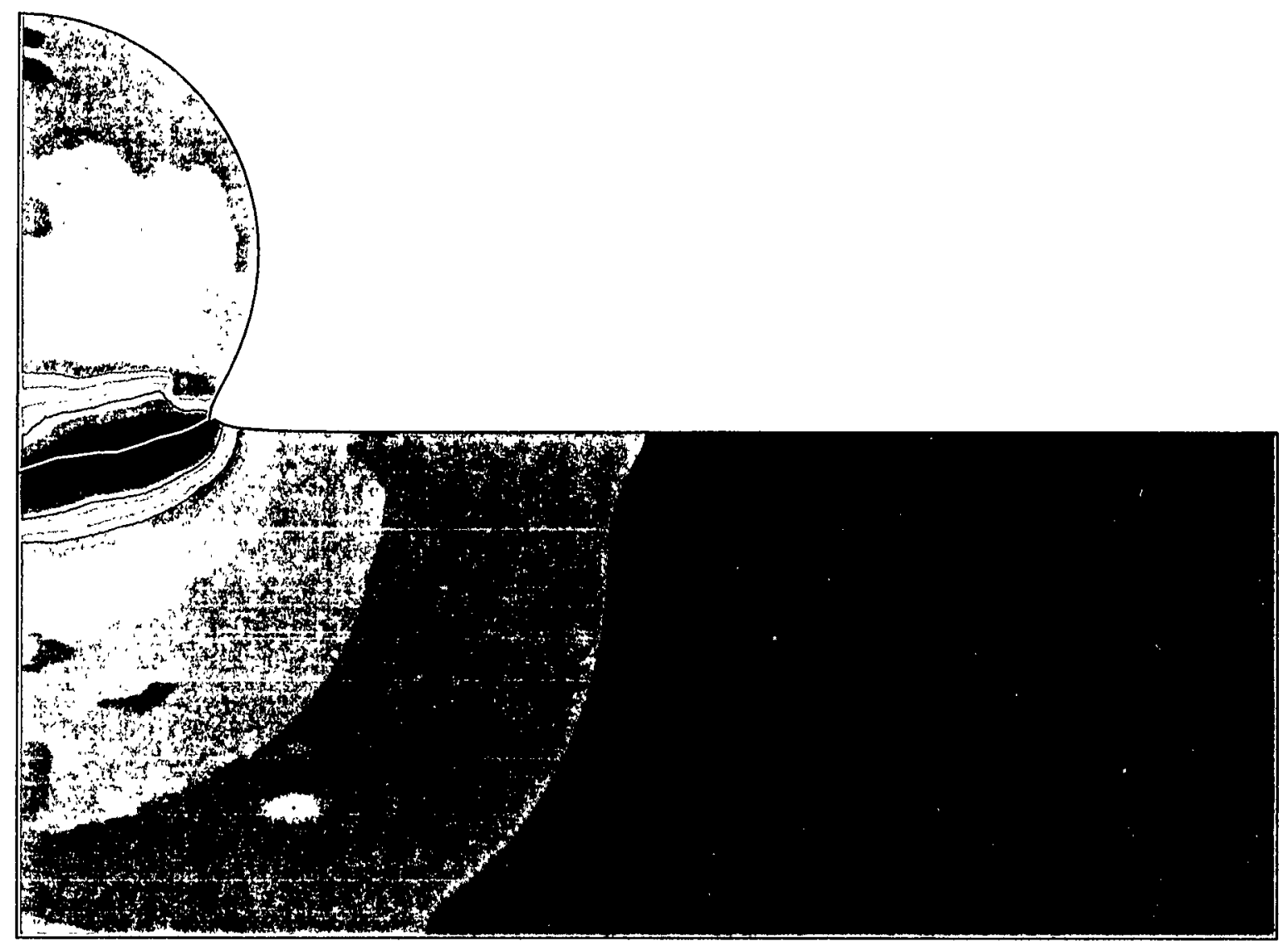

DISPLACEMENT MAGNIFICATION FACTOR $=1.00$

RESTART FILE = 1particle STEP 1 INCREMENT 124

TIME COMPLETED IN THIS STEP 2.008E-08 TOTAL ACCUMULATED TIME 2.008E-08

ABAQUS VERSION: 5.8-1 DATE: 13 -OCT-2000 TIME: $10: 42: 24$ 

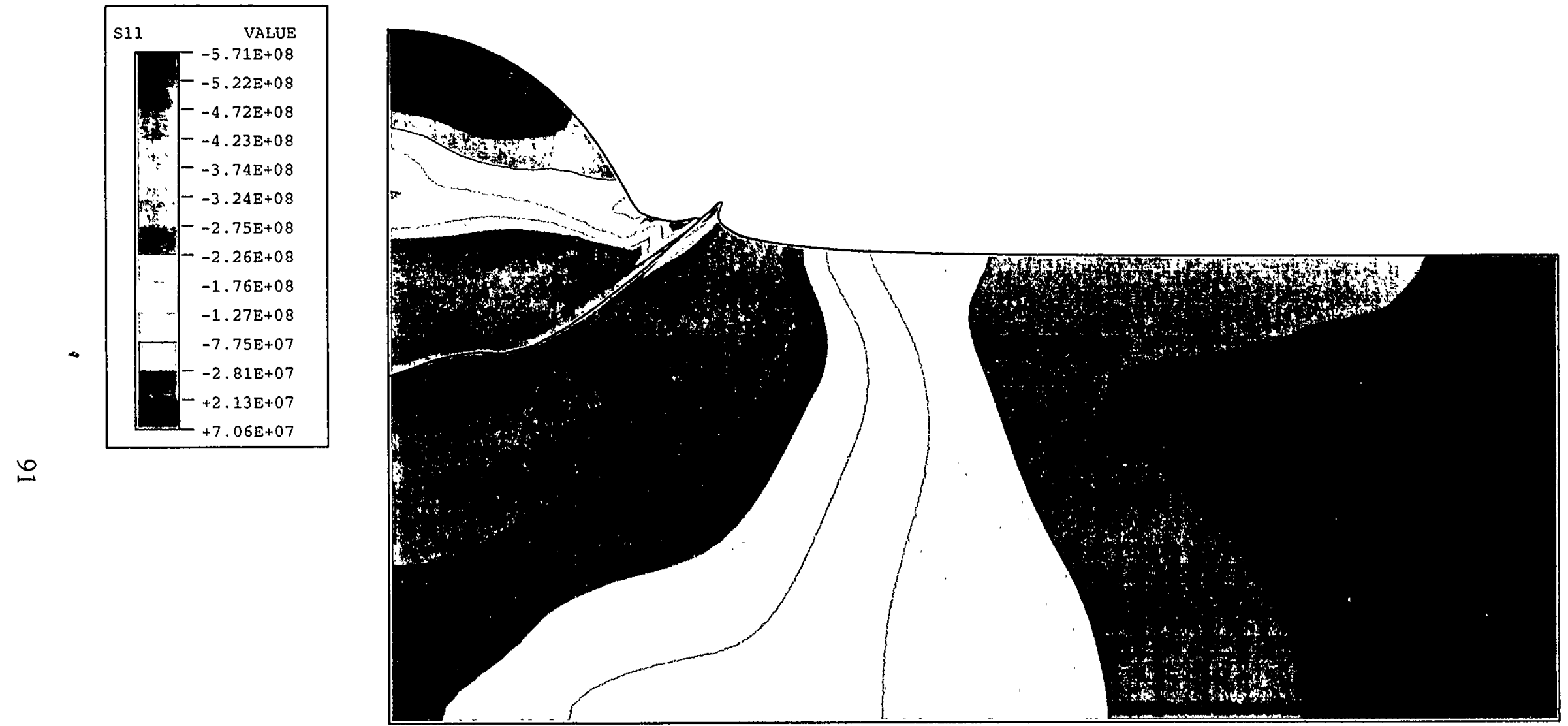

DISPLACEMENT MAGNIFICATION FACTOR $=1.00$

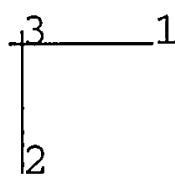

RESTART FILE = 1particle STEP 1 INCREMENT 617

TIME COMPLETED IN THIS STEP 5.002E-08 TOTAL ACCUMULATED TIME 5.002E-08

ABAQUS VERSION: $5.8-1$ DATE: $13-$ OCT-2000 TIME: $10: 42: 24$ 


\begin{tabular}{|r|r|} 
VALUE \\
\hline \\
1 \\
$-9.91 \mathrm{E}+08$ \\
$-9.11 \mathrm{E}+08$ \\
$-8.32 \mathrm{E}+08$ \\
$-7.52 \mathrm{E}+08$ \\
$-6.73 \mathrm{E}+08$ \\
$-5.93 \mathrm{E}+08$ \\
$-5.14 \mathrm{E}+08$ \\
$-4.34 \mathrm{E}+08$ \\
$-3.55 \mathrm{E}+08$ \\
$-2.75 \mathrm{E}+08$ \\
$-1.96 \mathrm{E}+08$ \\
$-1.16 \mathrm{E}+08$ \\
$-3.70 \mathrm{E}+07$ \\
$+4.25 \mathrm{E}+07$
\end{tabular}

is

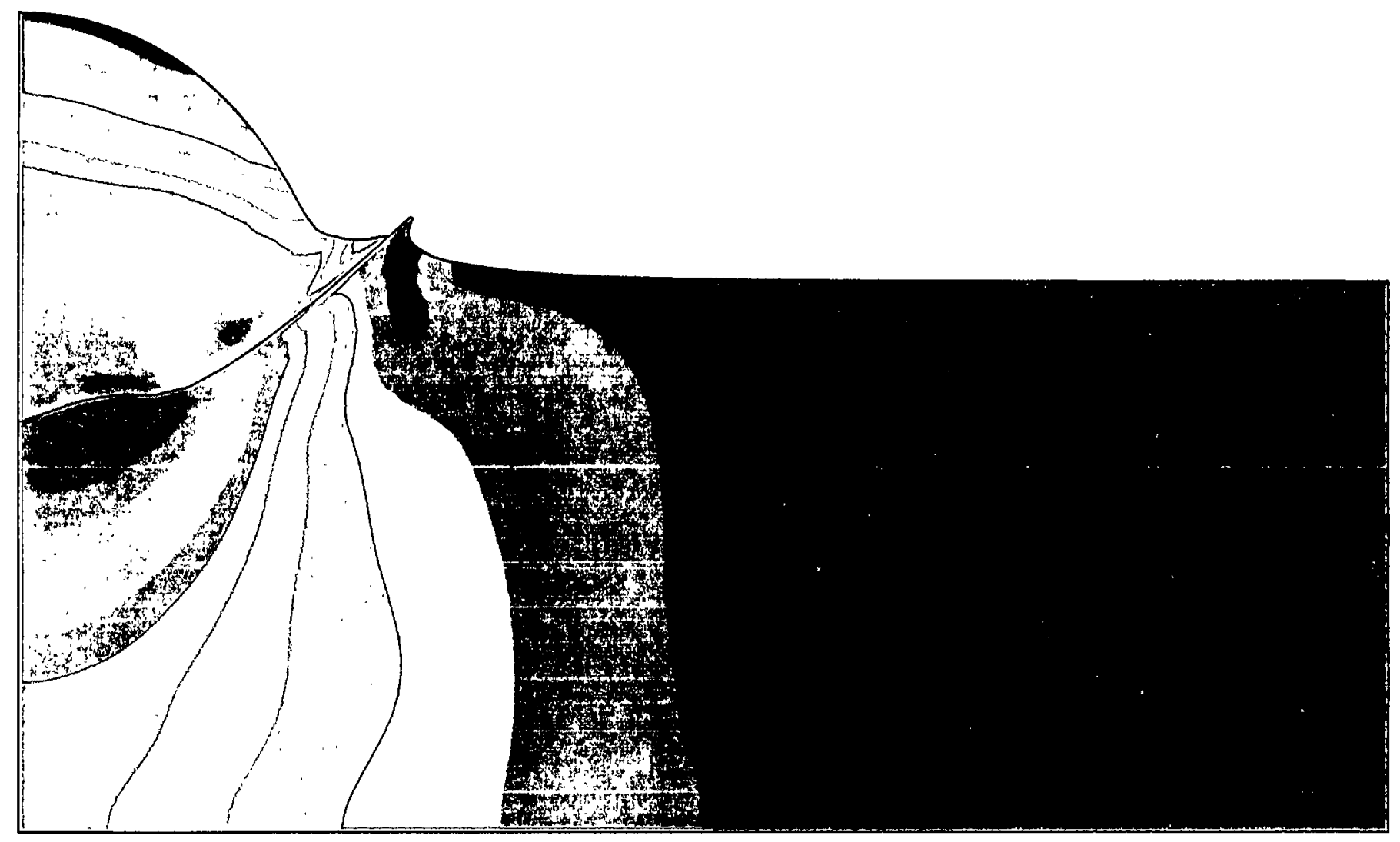

DISPLACEMENT MAGNIFICATION FACTOR $=1.00$

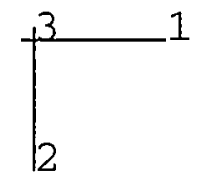

RESTART FILE = 1paxticle STEP 1 INCREMENT 617

TIME COMPLETED IN THIS STEP 5.002E-08 TOTAL ACCUMULATED TIME 5.002E-08

ABAQUS VERSION: 5.8-1 DATE: 13-OCT-2000 TIME: $10: 42: 24$ 


\begin{tabular}{|r|r|}
\hline VALUE \\
512 \\
$-2.23 \mathrm{E}+08$ \\
$-2.03 \mathrm{E}+08$ \\
$-1.84 \mathrm{E}+08$ \\
$-1.64 \mathrm{E}+08$ \\
$-1.44 \mathrm{E}+08$ \\
$-1.24 \mathrm{E}+08$ \\
$-1.04 \mathrm{E}+08$ \\
\hdashline$-8.46 \mathrm{E}+07$ \\
$-6.49 \mathrm{E}+07$ \\
$-4.51 \mathrm{E}+07$ \\
$-2.53 \mathrm{E}+07$ \\
$-5.53 \mathrm{E}+06$ \\
$-1.43 \mathrm{E}+07$ \\
$+3.40 \mathrm{E}+07$ \\
\hline
\end{tabular}

卢

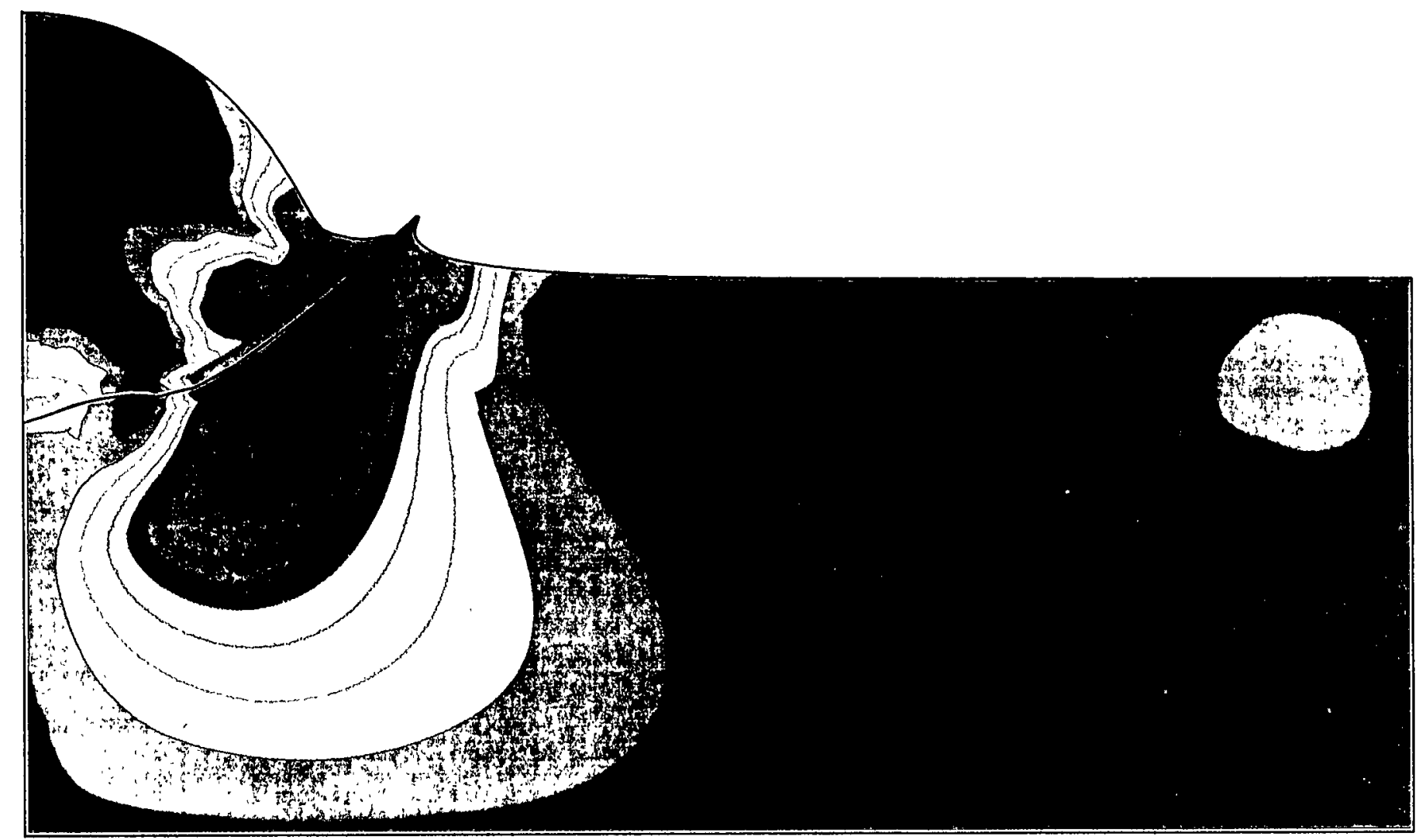

DISPLACEMENT MAGNIFICATION FACTOR $=1.00$

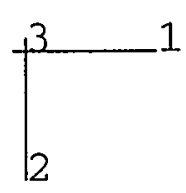

RESTART FILE = 1particle STEP 1 INCREMENT 617

TIME COMPLETED IN THIS STEP $5.002 \mathrm{E}-08$ TOTAL ACCUMULATED TIME $5.002 \mathrm{E}-08$

ABAQUS VERSION: $5.8-1$ DATE: $13-$ OCT-2000 TIME: $10: 42: 24$ 

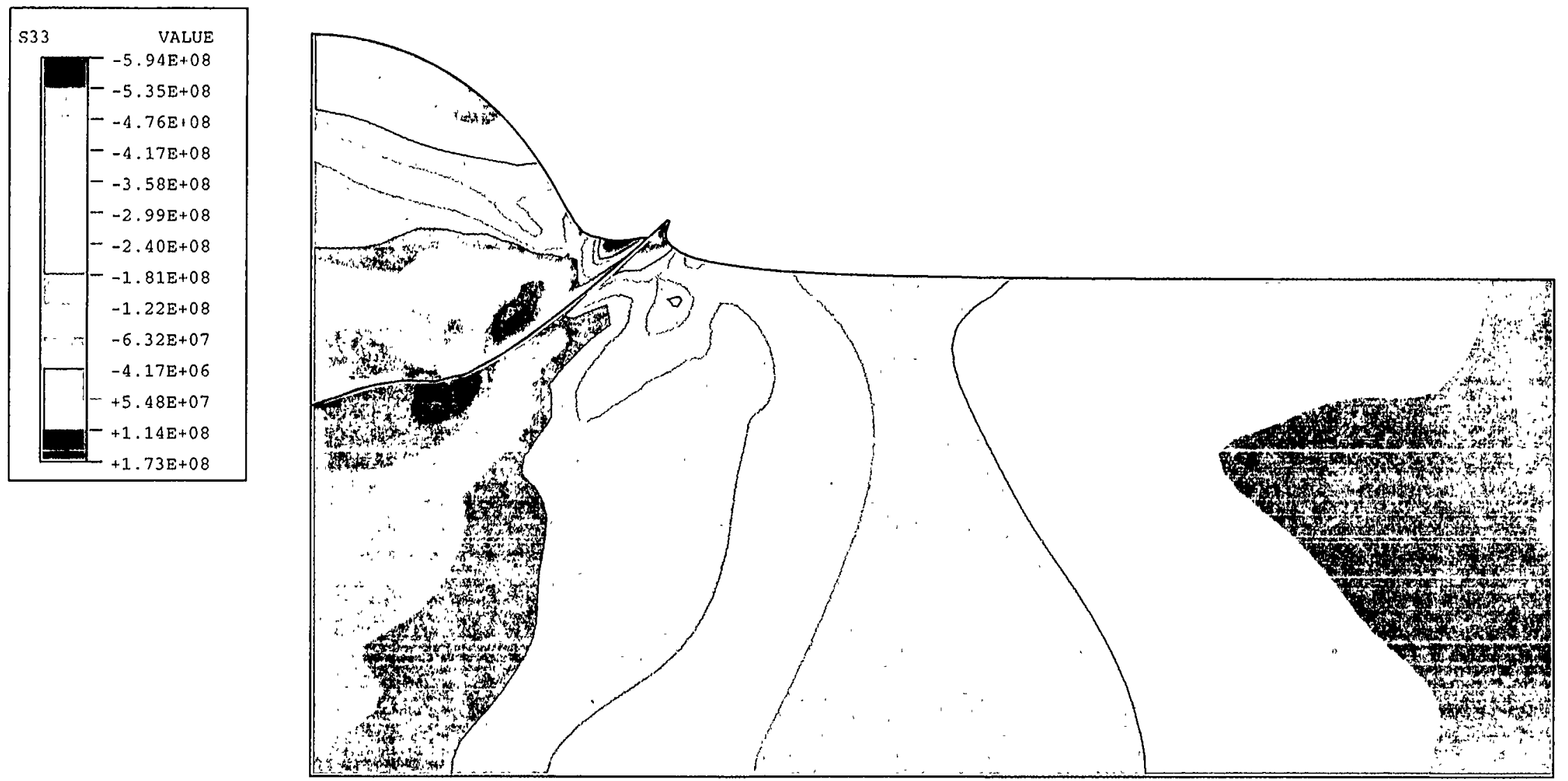

DISPLACEMENT MAGNIFICATION FACTOR $=1.00$

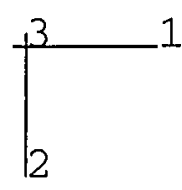

RESTART FILE = 1particle STEP 1 INCREMENT 617

TIME COMPLETED IN THIS STEP 5.002E-08 TOTAL ACCUMULATED TIME 5.002E-08

ABAQUS VERSION: $5.8-1$ DATE: 13 -OCT-2000 TIME: $10: 42: 24$ 


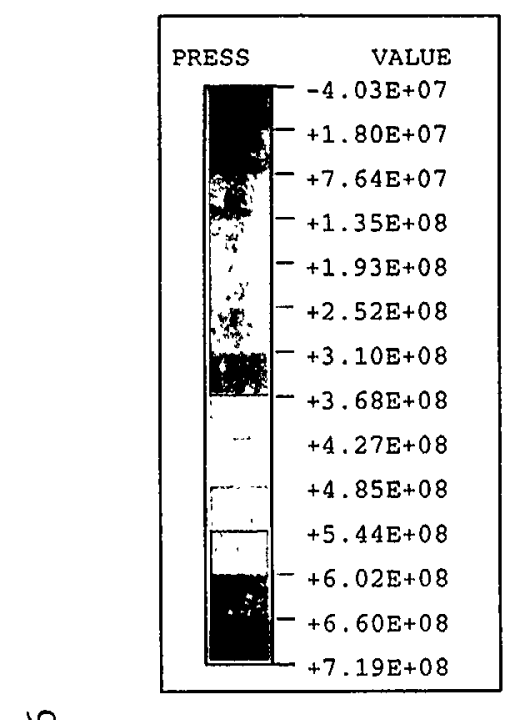

in

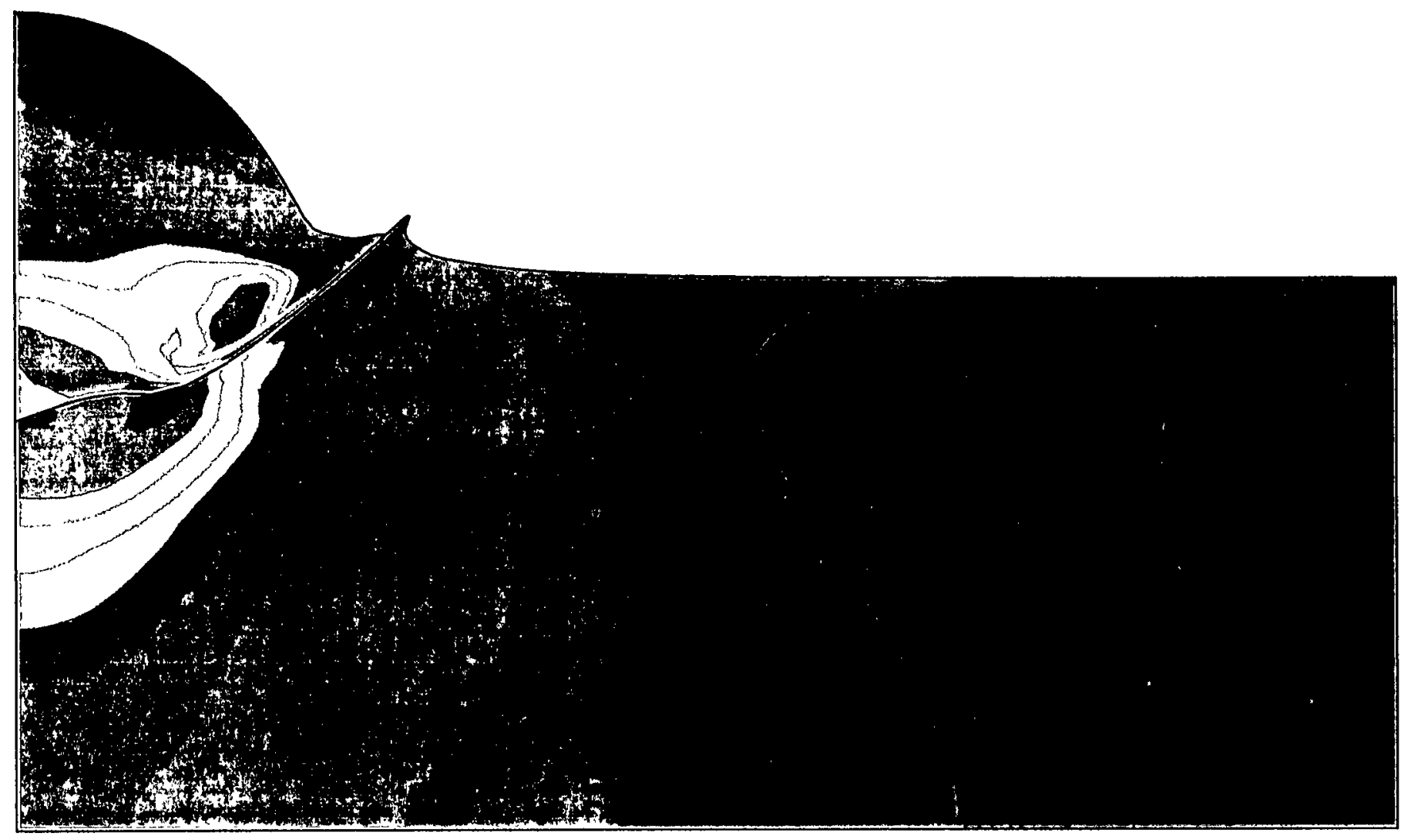

DISPLACEMENT MAGNIFICATION FACTOR $=1.00$

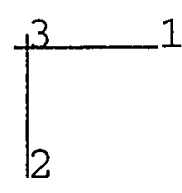

RESTART FILE = 1particle STEP 1 INCREMENT 617

TIME COMPLETED IN THIS STEP 5.002E-08 TOTAL ACCUMULATED TIME 5.002E-08

ABAQUS VERSION: $5.8-1$ DATE: 13 -OCT-2000 TIME: $10: 42: 24$ 


\begin{tabular}{|c|c|}
\hline \multirow{2}{*}{ MISES } & VALUE \\
\hline & $\Gamma+5.41 \mathrm{E}+07$ \\
\hline & $-+8.17 E+07$ \\
\hline & $-+1.09 E+08$ \\
\hline & $-+1.37 E+08$ \\
\hline & $-+1.64 E+08$ \\
\hline & $-+1.92 \mathrm{E}+08$ \\
\hline & $-+2.19 \mathrm{E}+08$ \\
\hline & $-+2.47 \mathrm{E}+08$ \\
\hline & $+2.74 E+08$ \\
\hline & $+3.02 E+08$ \\
\hline & $+3.29 E+08$ \\
\hline & $-+3.57 \mathrm{E}+08$ \\
\hline & $\begin{array}{l}+3.85 \mathrm{E}+08 \\
+4.12 \mathrm{E}+08\end{array}$ \\
\hline
\end{tabular}

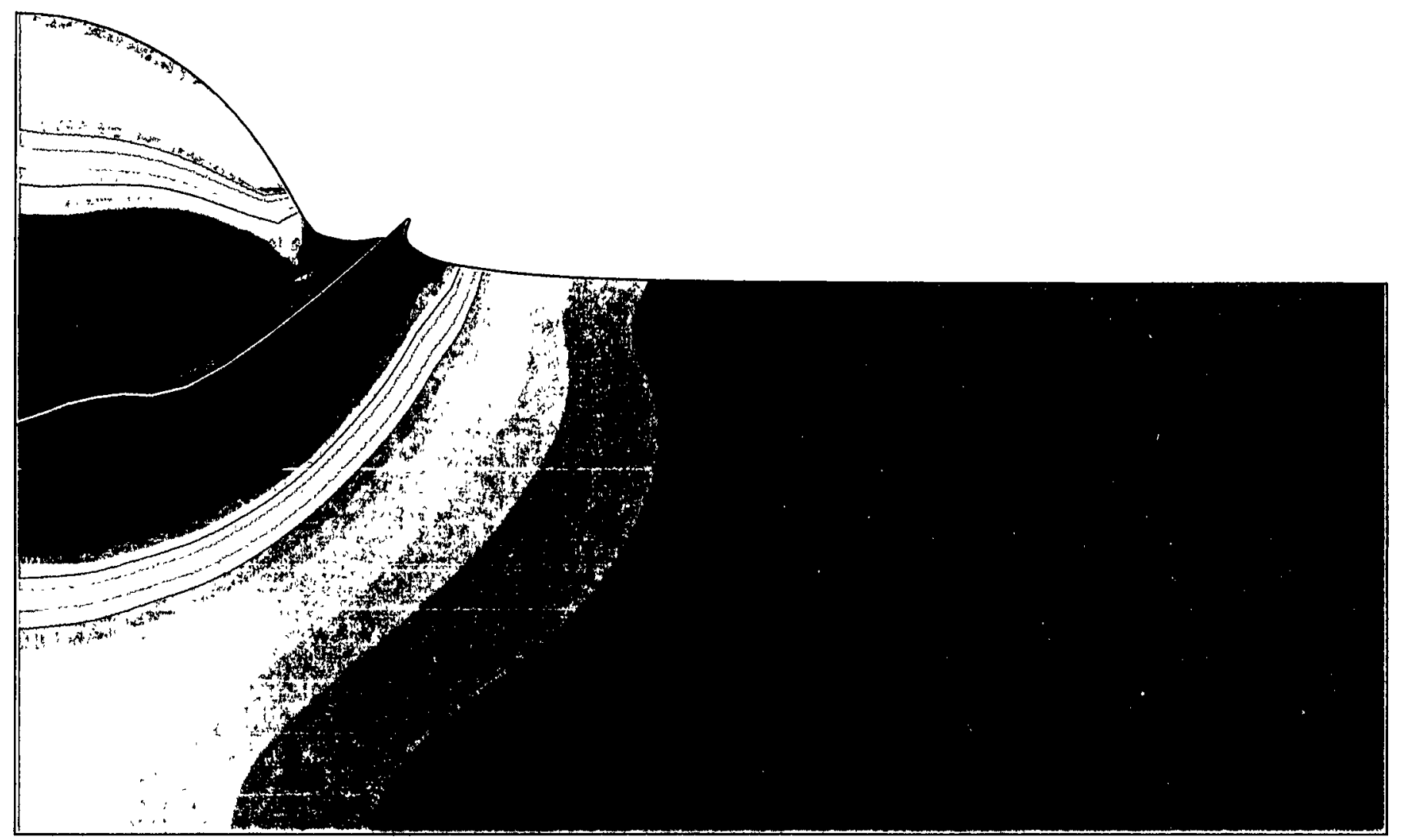

DISPLACEMENT MAGNIFICATION FACTOR $=1.00$

RESTART FILE = 1particle STEP 1 INCREMENT 617

TIME COMPLETED IN THIS STEP 5.002E-08 TOTAL ACCUMULATED TIME 5.002E-08 ABAQUS VERSION: $5.8-1$ DATE: 13 -OCT-2000 TIME: $10: 42: 24$ 

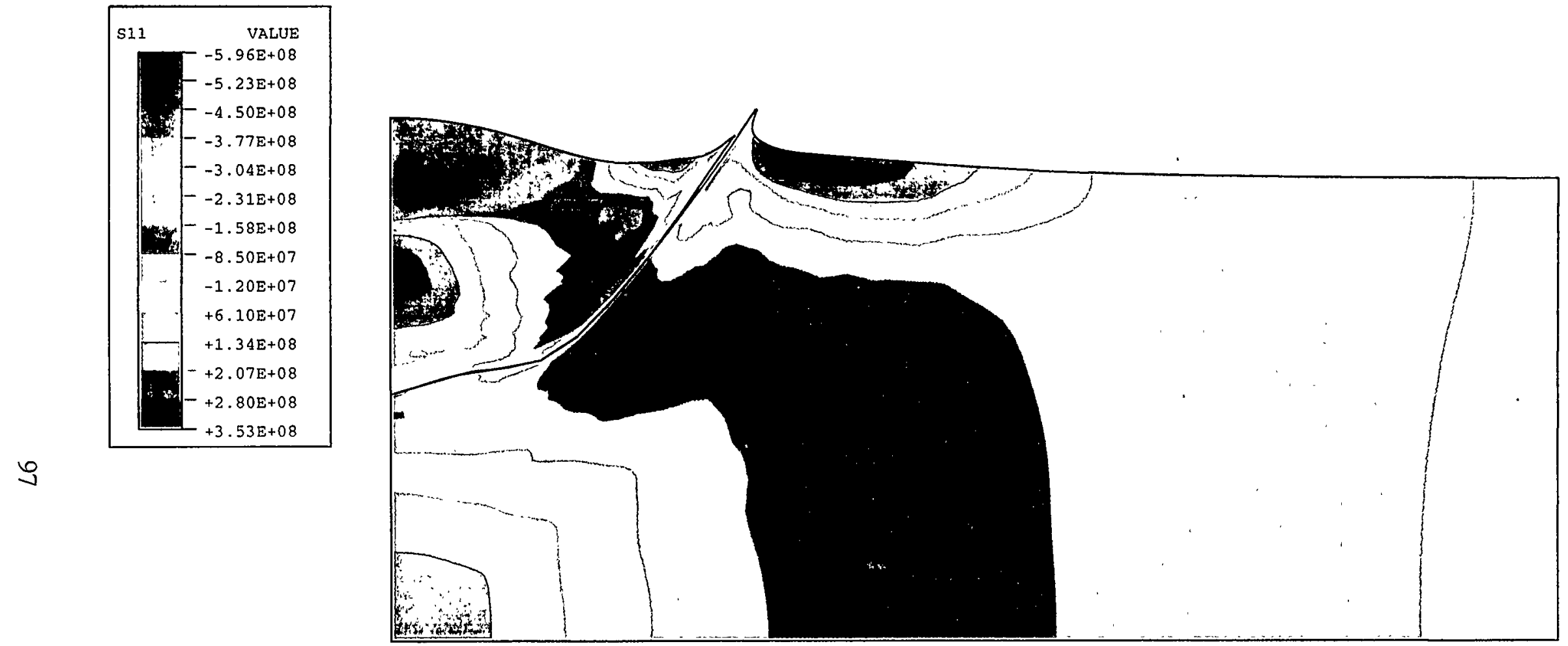

DISPLACEMENT MAGNIFICATION FACTOR $=1.00$

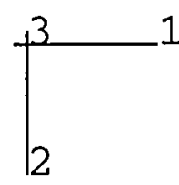

RESTART FILE = 1particle STEP 2 INCREMENT 0

TIME COMPLETED IN THIS STEP $\quad 0.0$ TOTAL ACCUMULATED TIME 1.000E-07

ABAQUS VERSION: $5.8-1$ DATE: 13 -OCT-2000 TIME: $10: 42: 24$ 


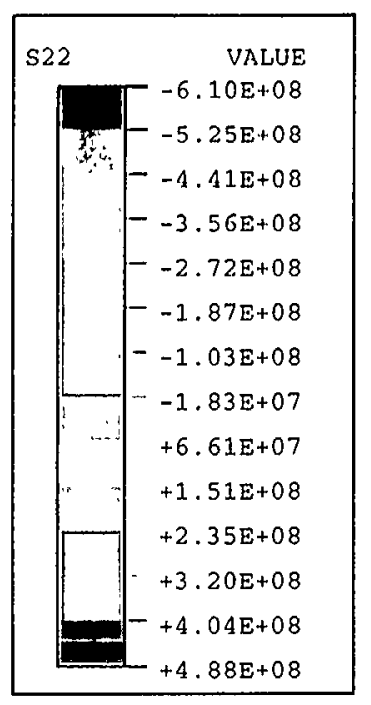

$\infty$

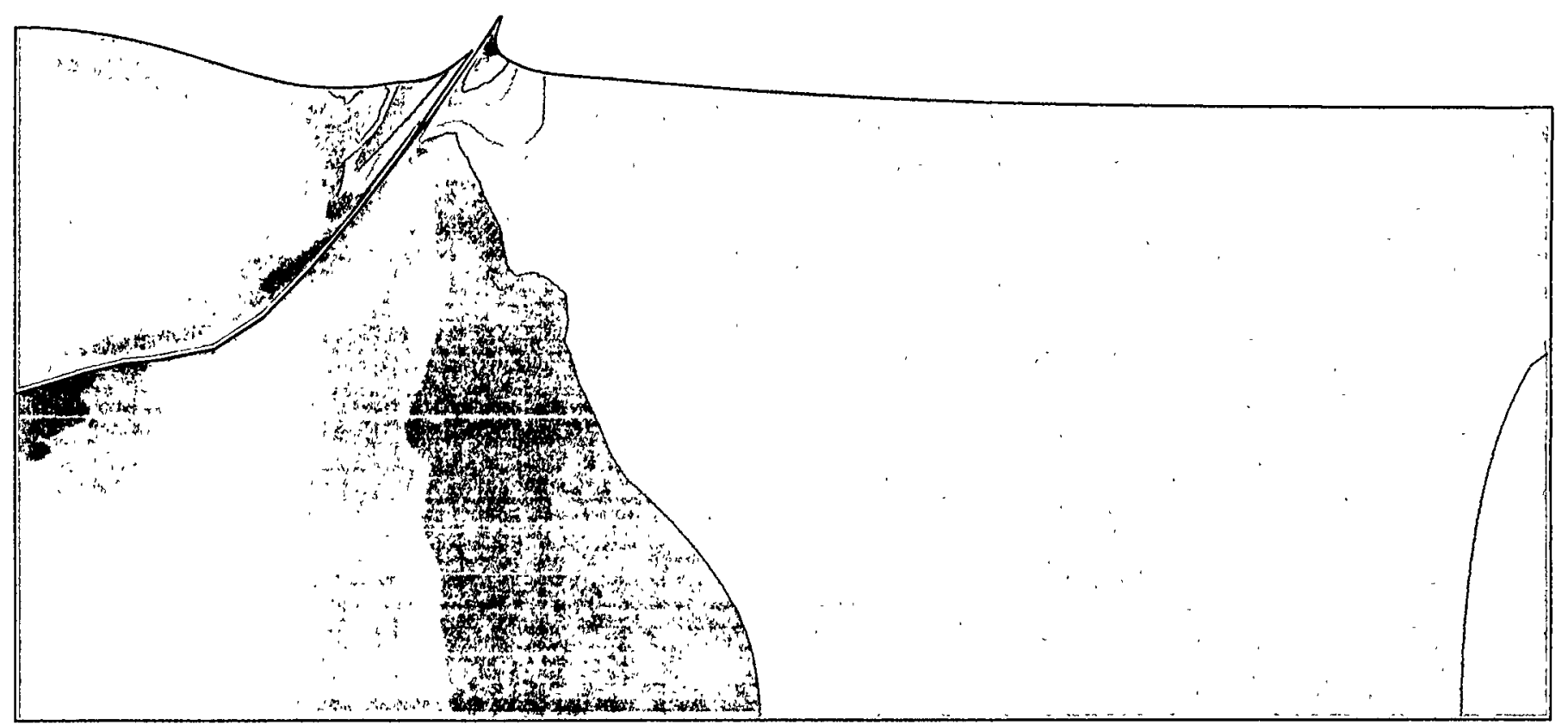

DISPLACEMENT MAGNIFICATION FACTOR $=1.00$

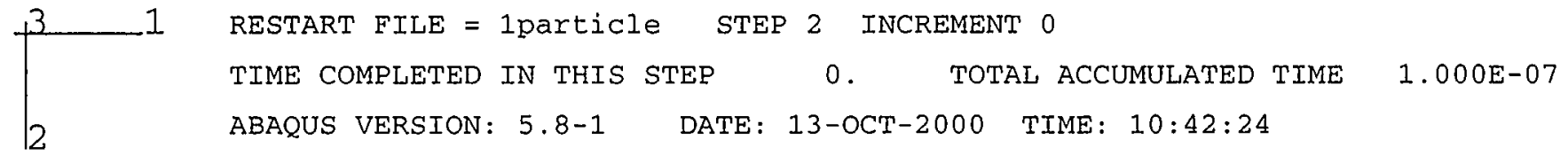




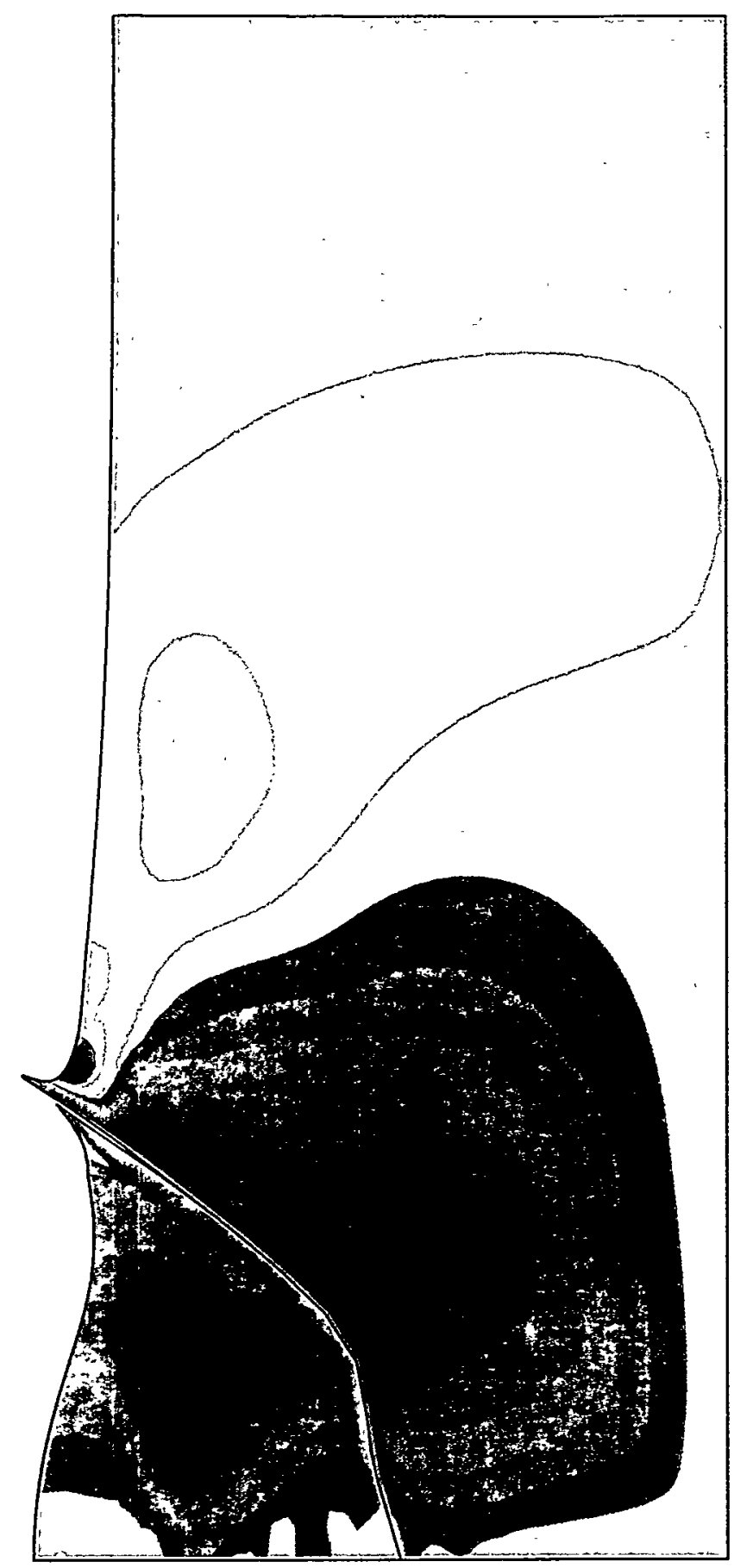

5
0
1
1
0
0
0
-1
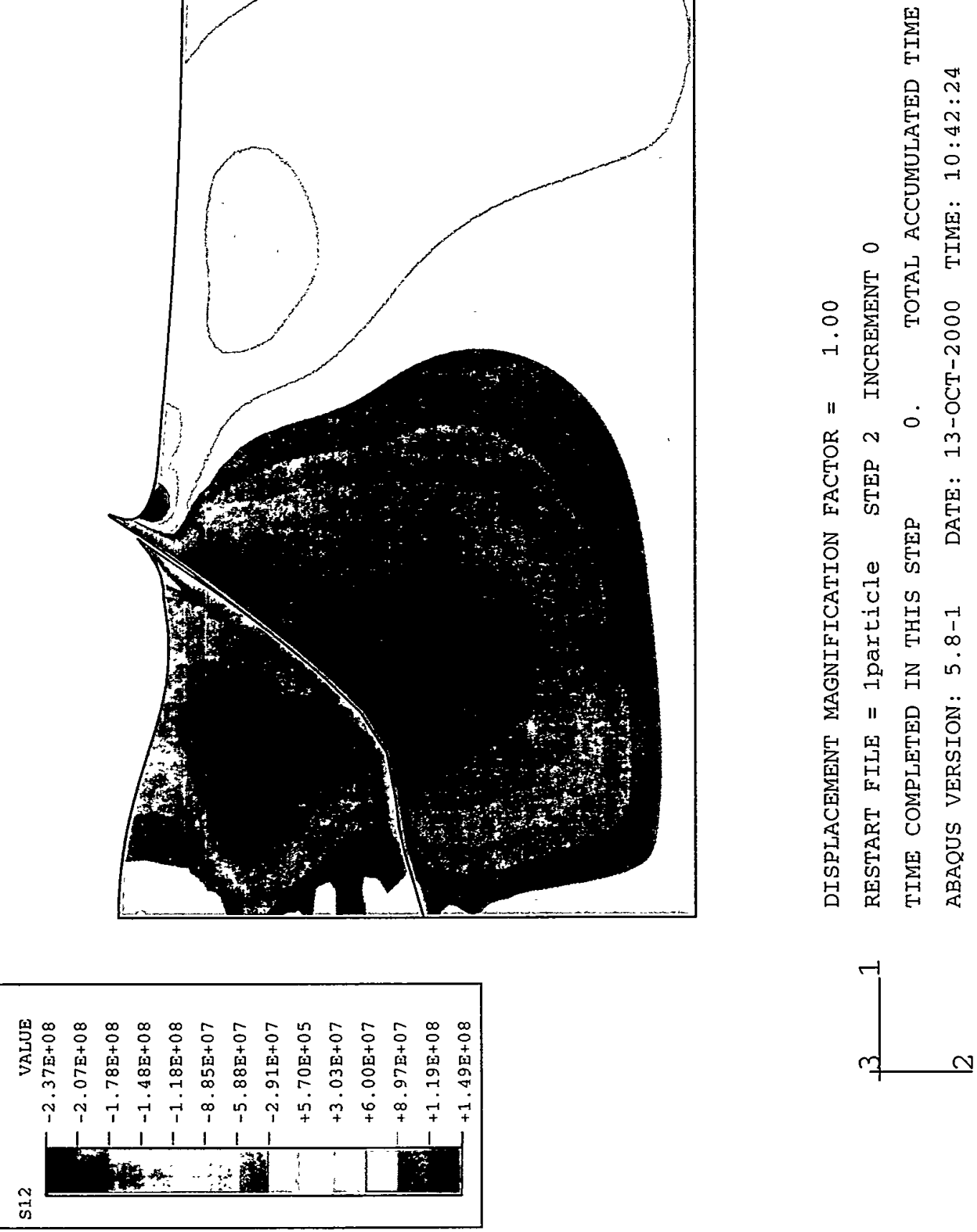


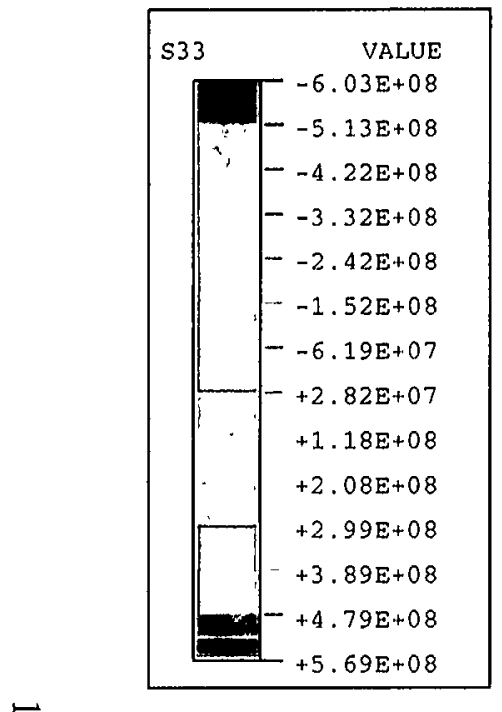

8

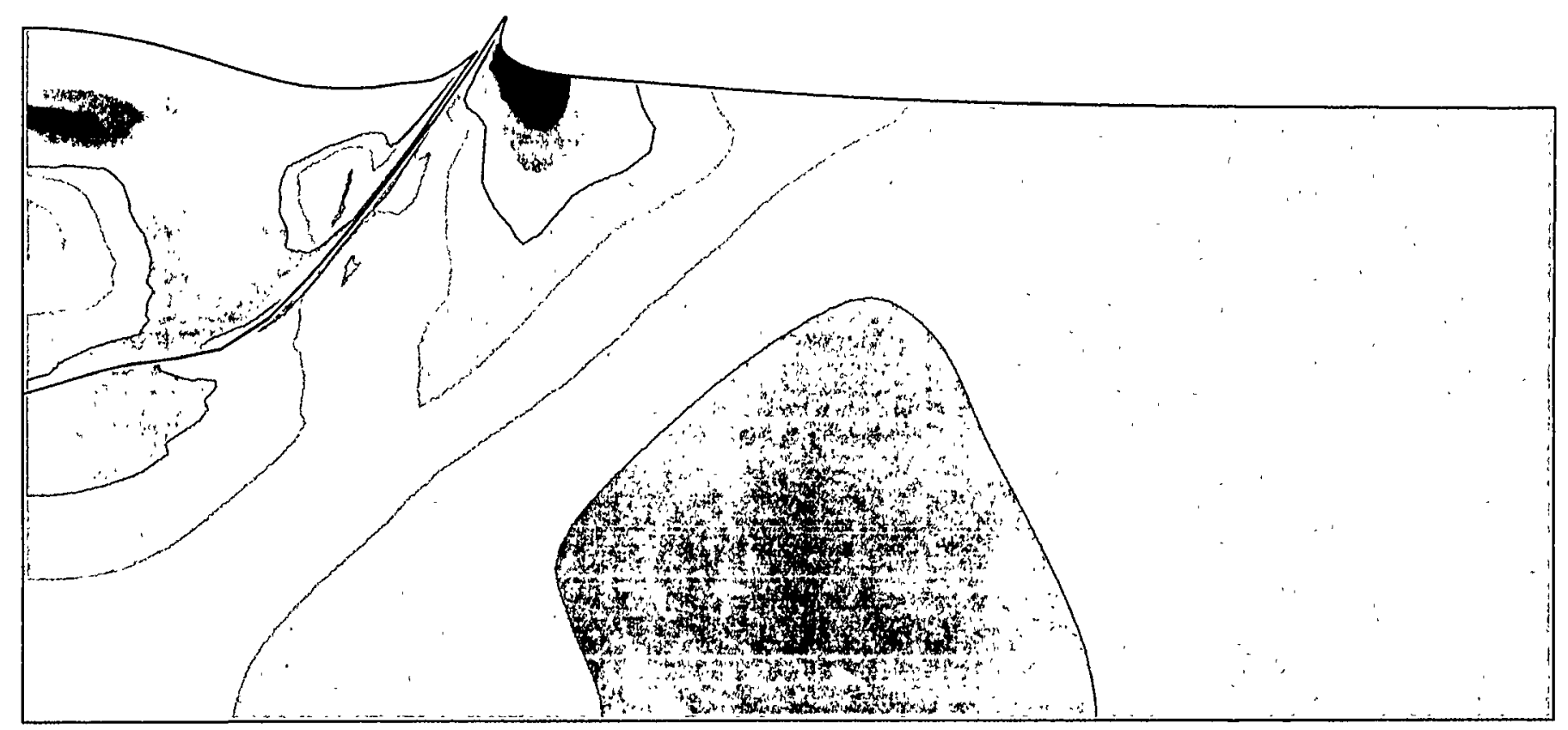

DISPLACEMENT MAGNIFICATION FACTOR $=1.00$

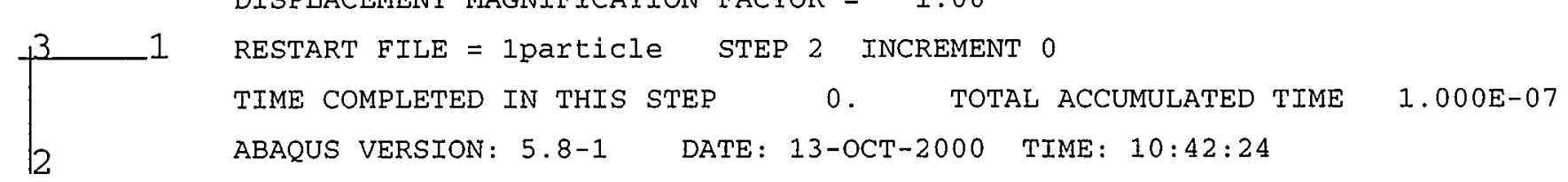



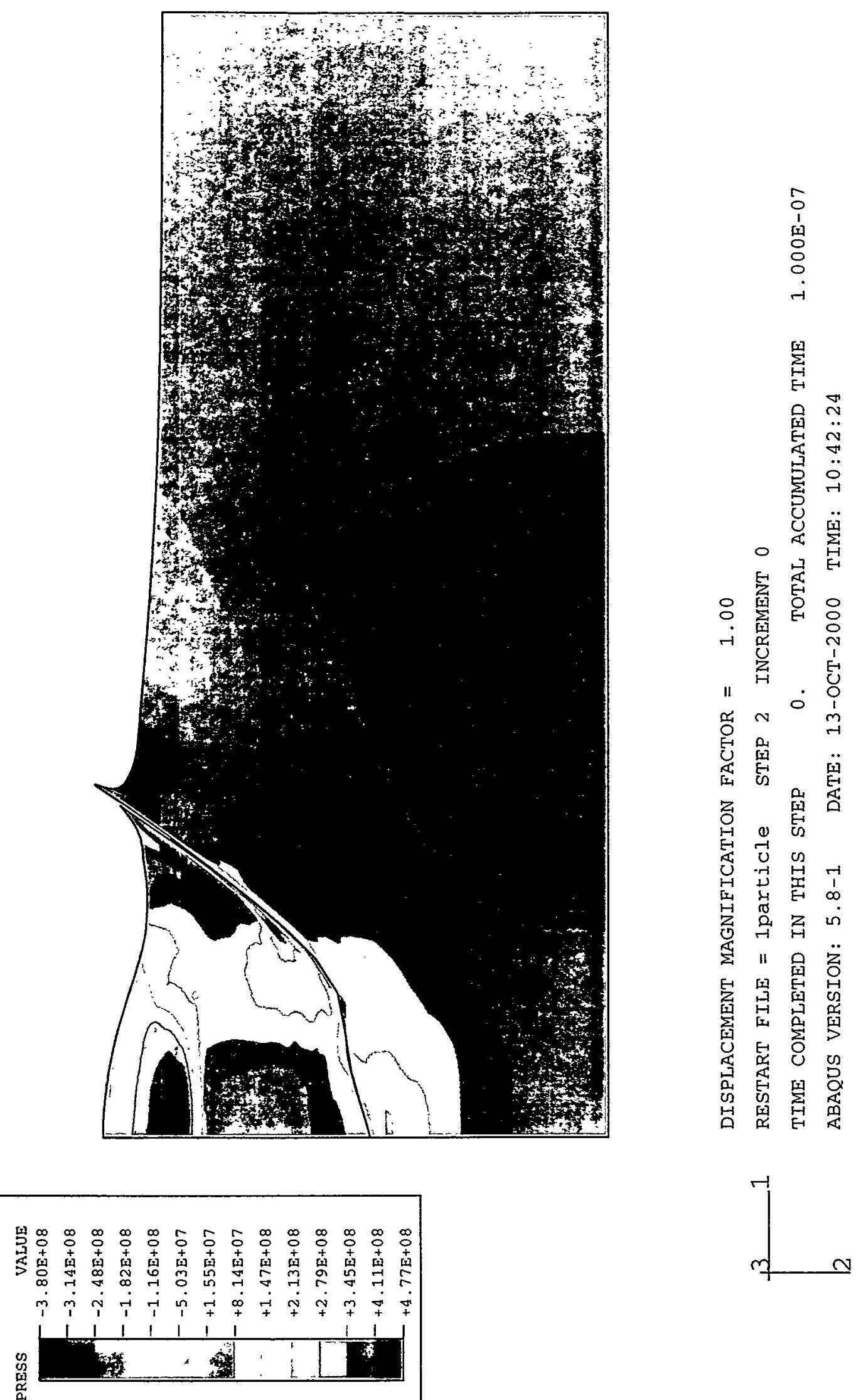


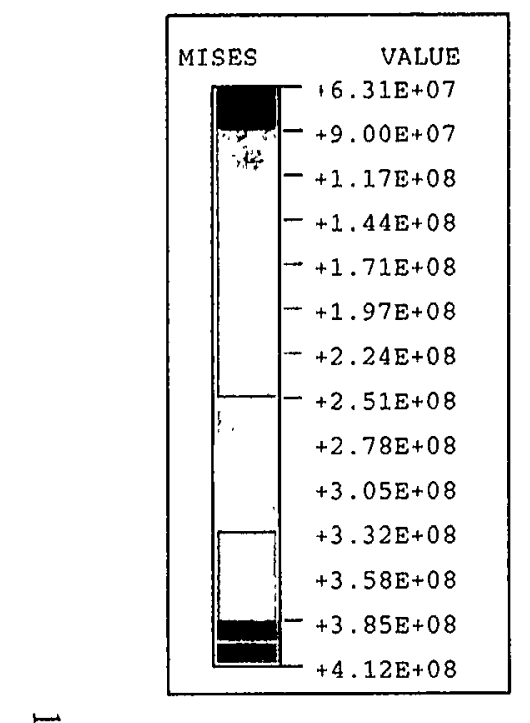

芩

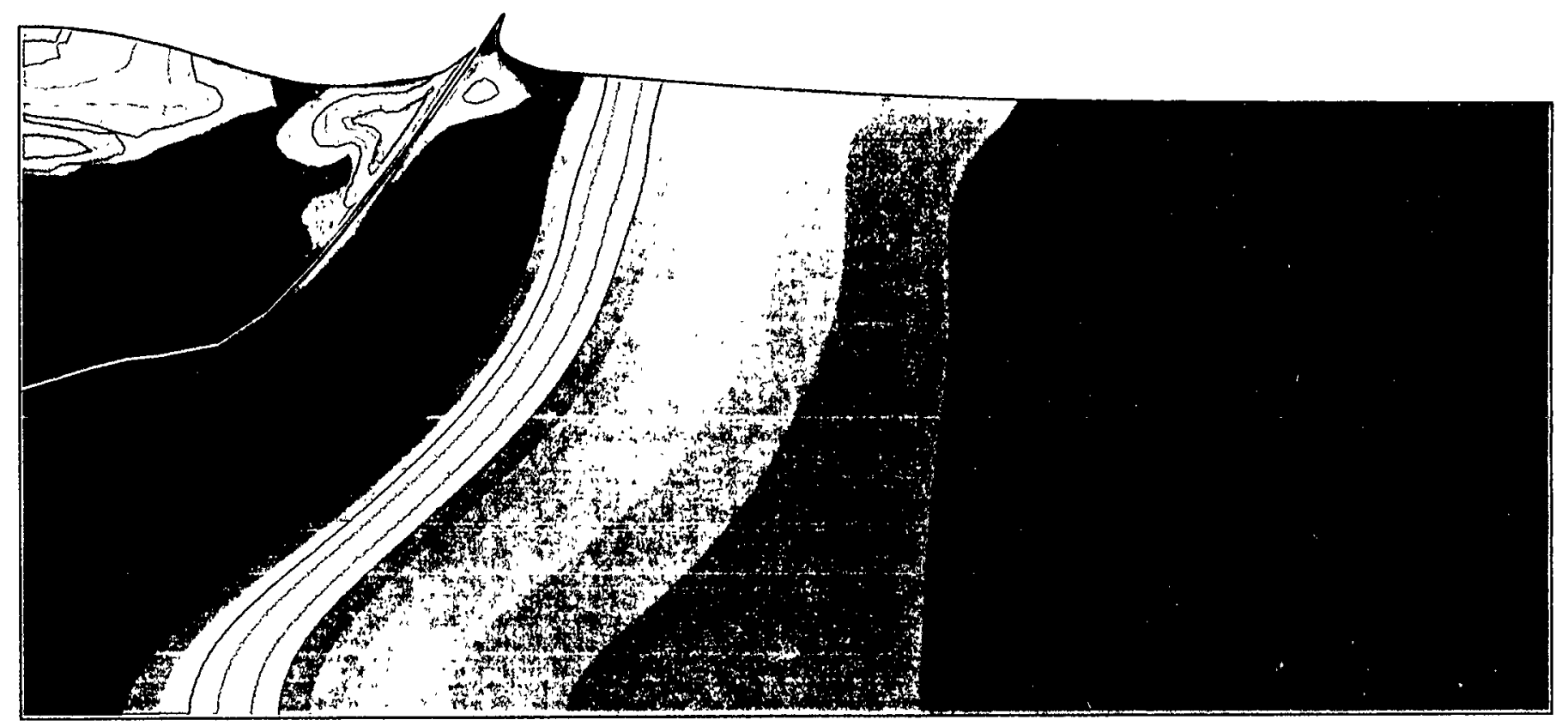

DISPLACEMENT MAGNIFICATION FACTOR $=1.00$

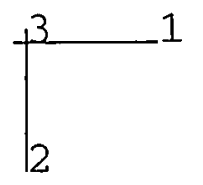

RESTART FILE = 1particle STEP 2 INCREMENT 0

TIME COMPLETED IN THIS STEP 0 . TOTAL ACCUMULATED TIME 1.000E-07

ABAQUS VERSION: $5.8-1$ DATE: $13-$ OCT-2000 TIME: $10: 42: 24$ 

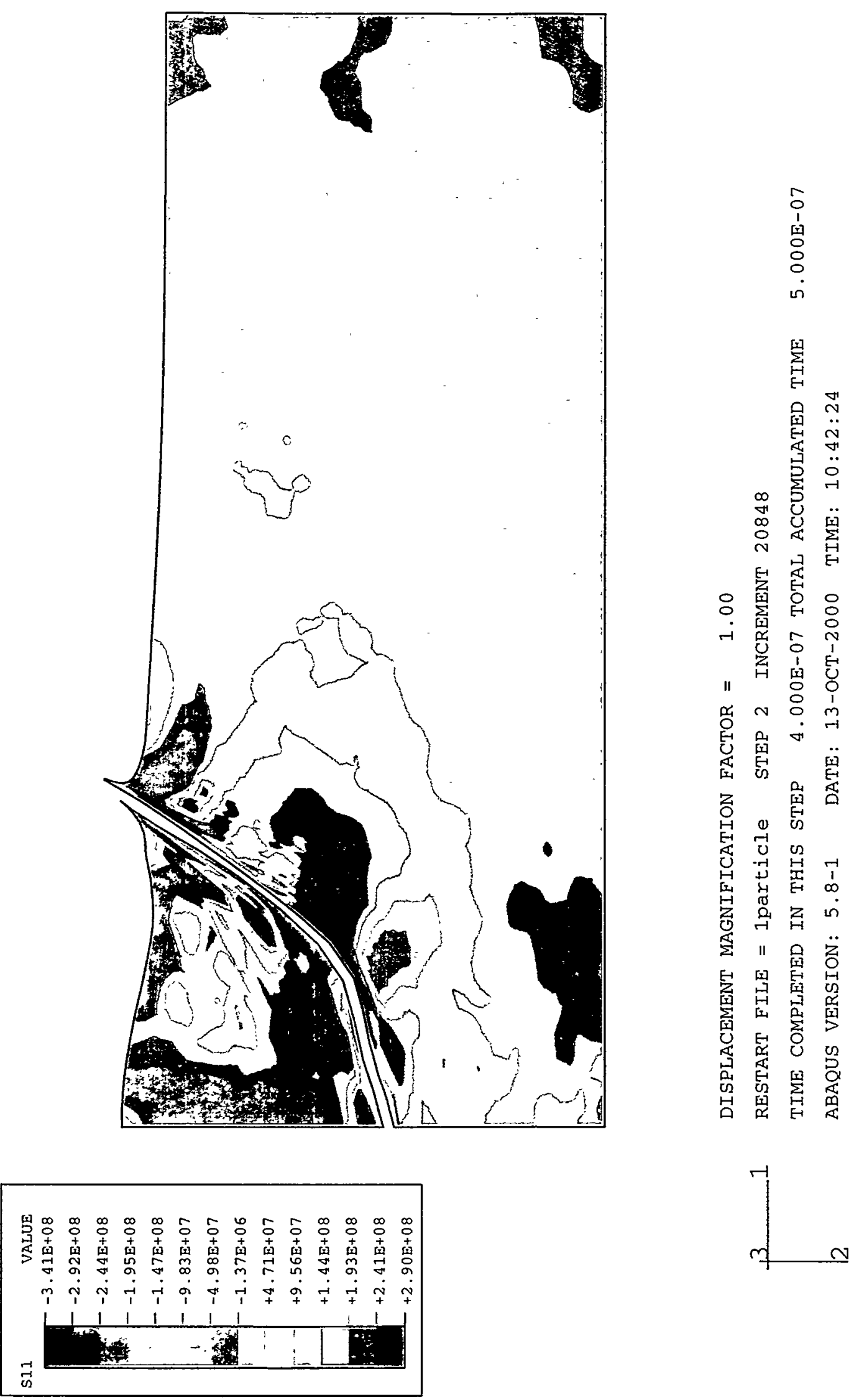


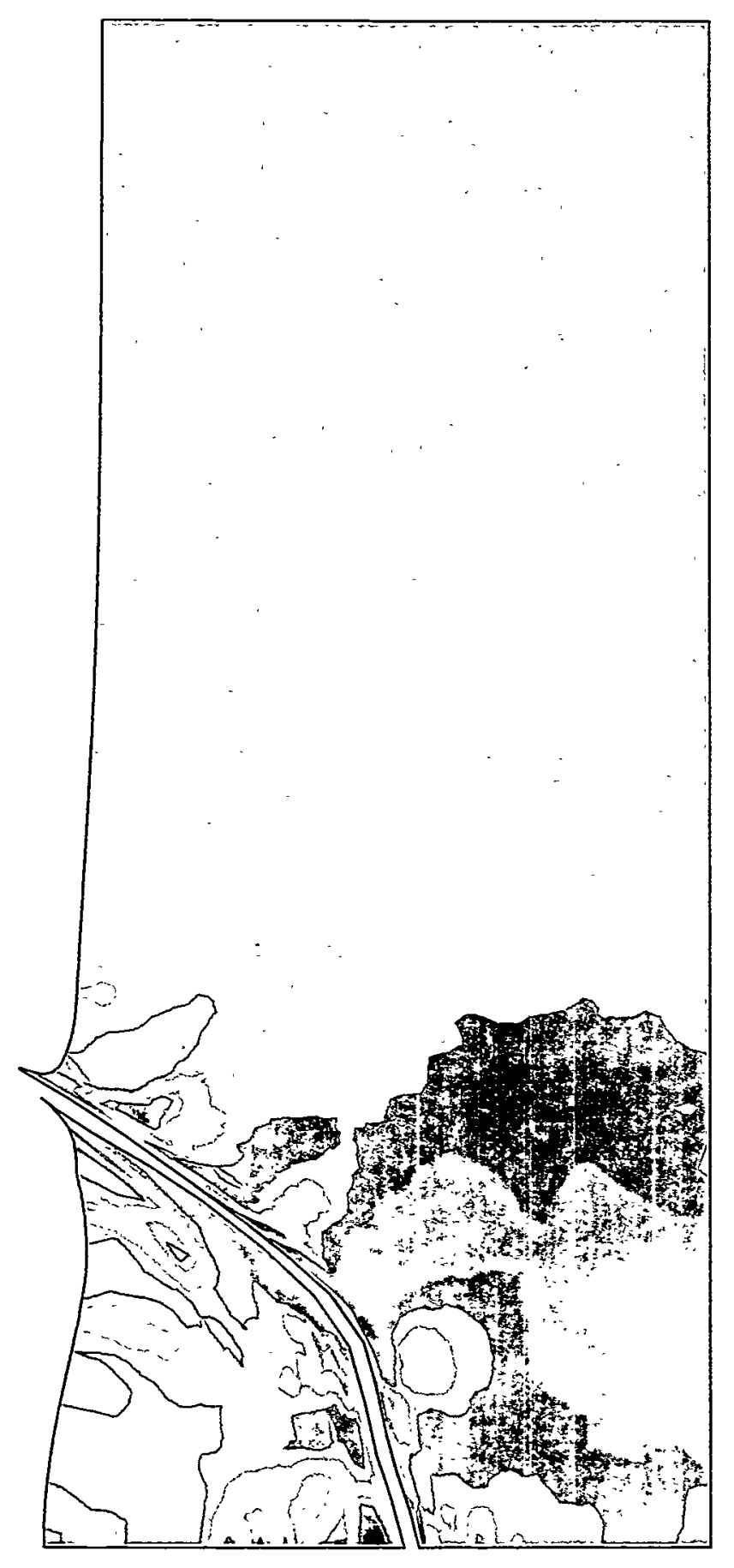

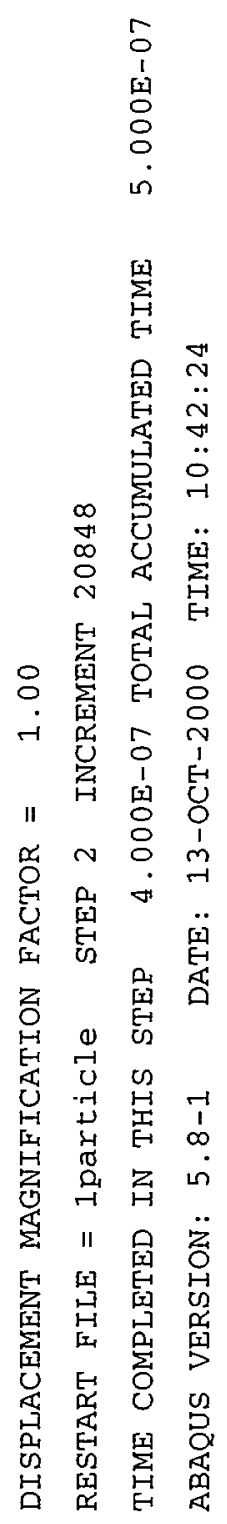
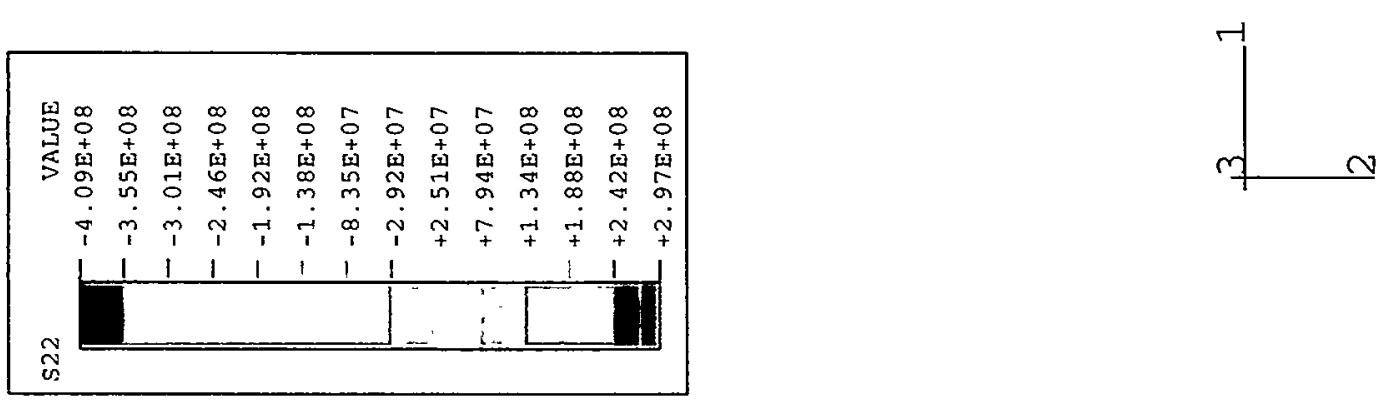


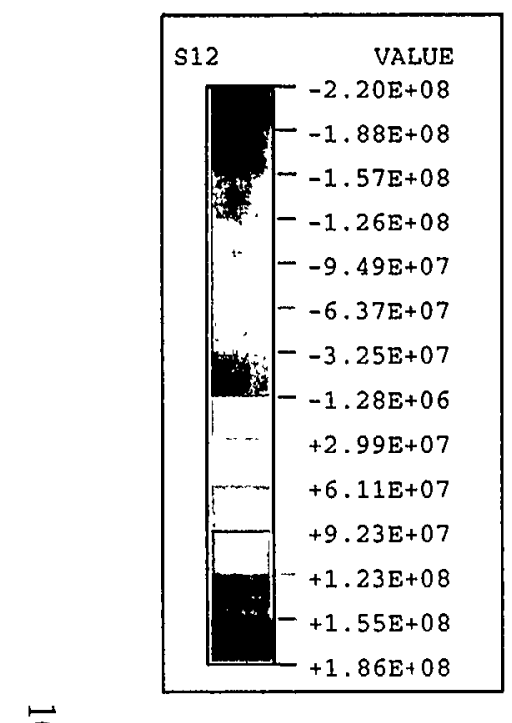

운

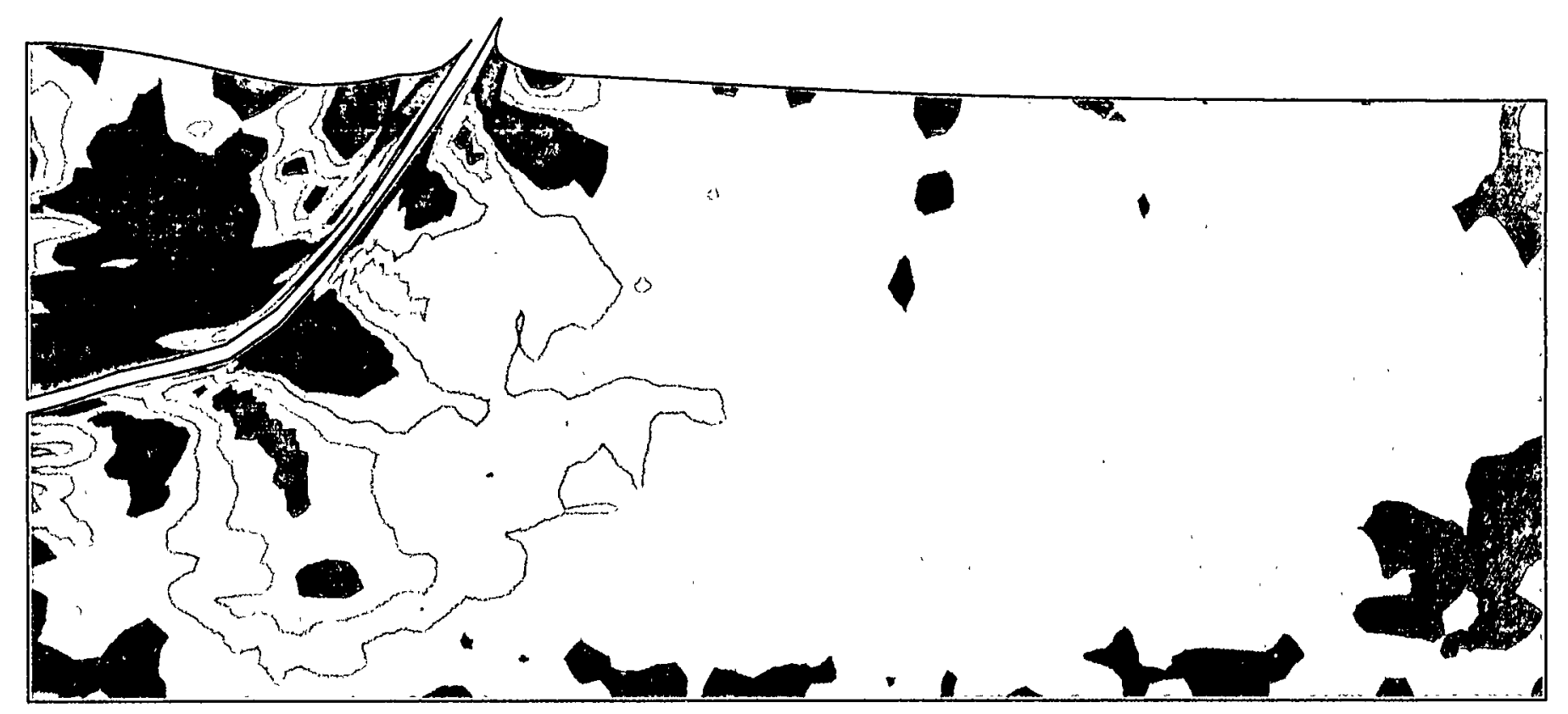

DISPLACEMENT MAGNIFICATION FACTOR $=1.00$

RESTART FILE = 1particle STEP 2 INCREMENT 20848

TIME COMPLETED IN THIS STEP 4.000E-07 TOTAL ACCUMULATED TIME 5.000E-07

ABAQUS VERSION: $5.8-1$ DATE: $13-$ OCT-2000 TIME: $10: 42: 24$ 


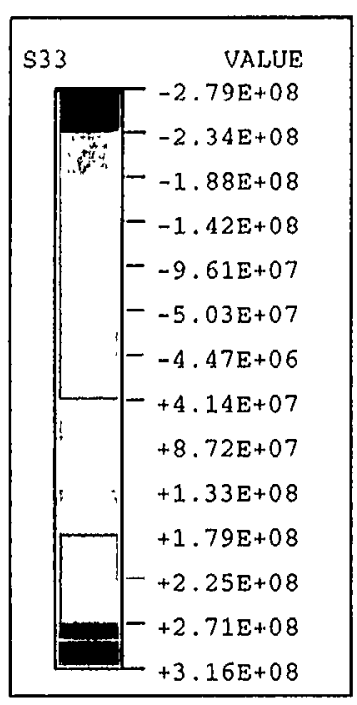

8

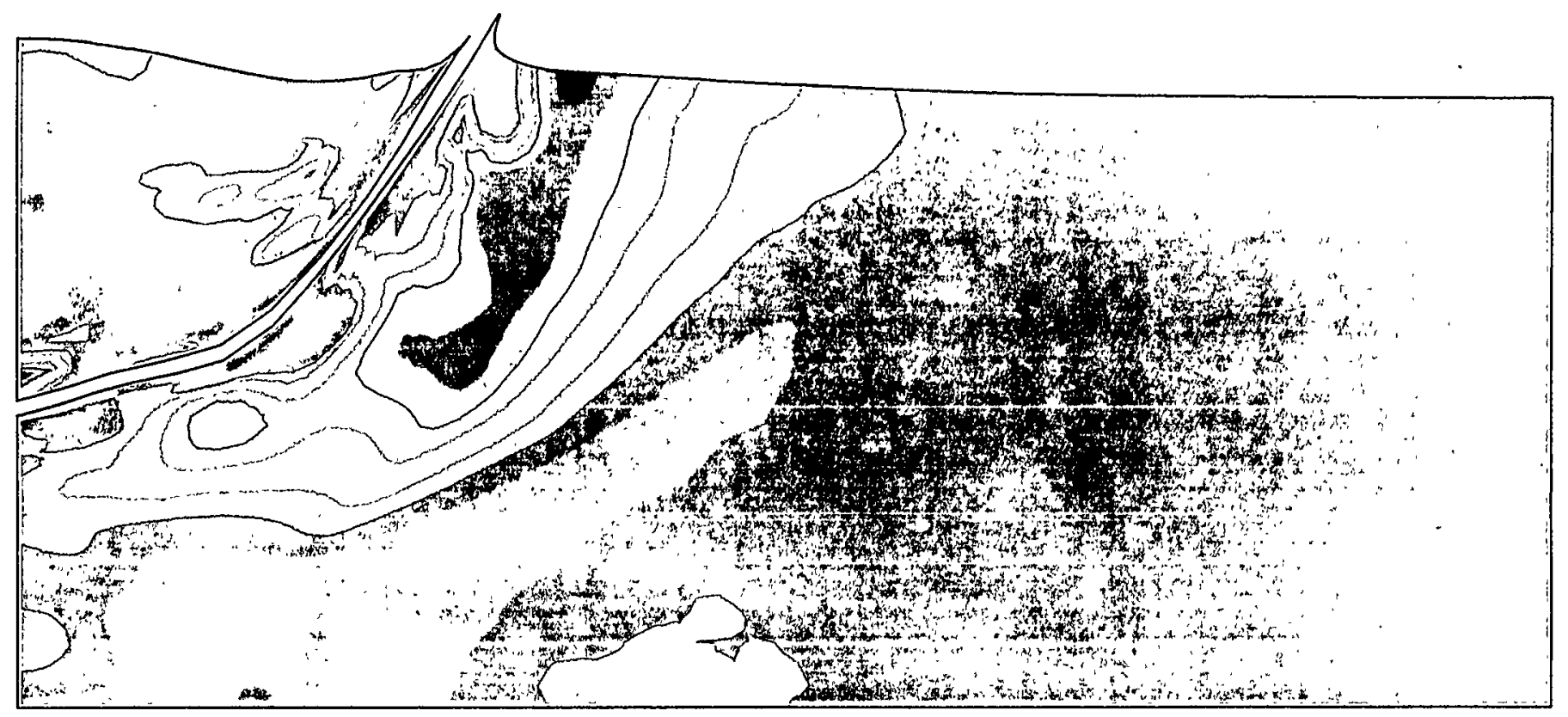

DISPLACEMENT MAGNIFICATION FACTOR $=1.00$

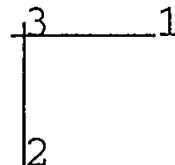

RESTART FILE = 1particle STEP 2 INCREMENT 20848

TIME COMPLETED IN THIS STEP 4.000E-07 TOTAL ACCUMULATED TIME 5.000E-07

ABAQUS VERSION: $5.8-1$ DATE: $13-O C T-2000$ TIME: $10: 42: 24$ 


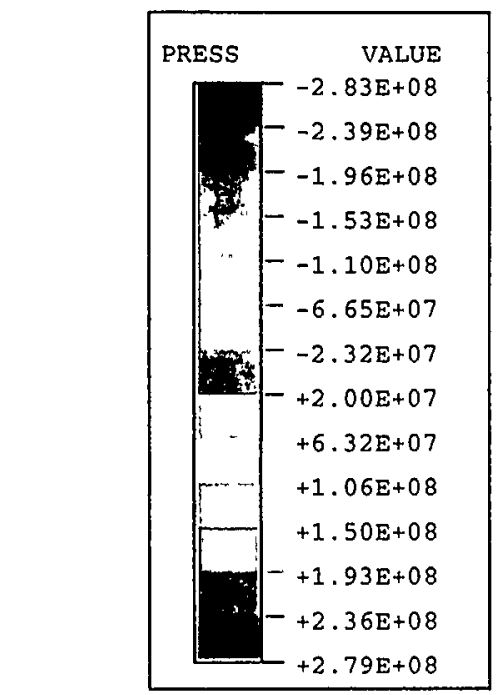

s

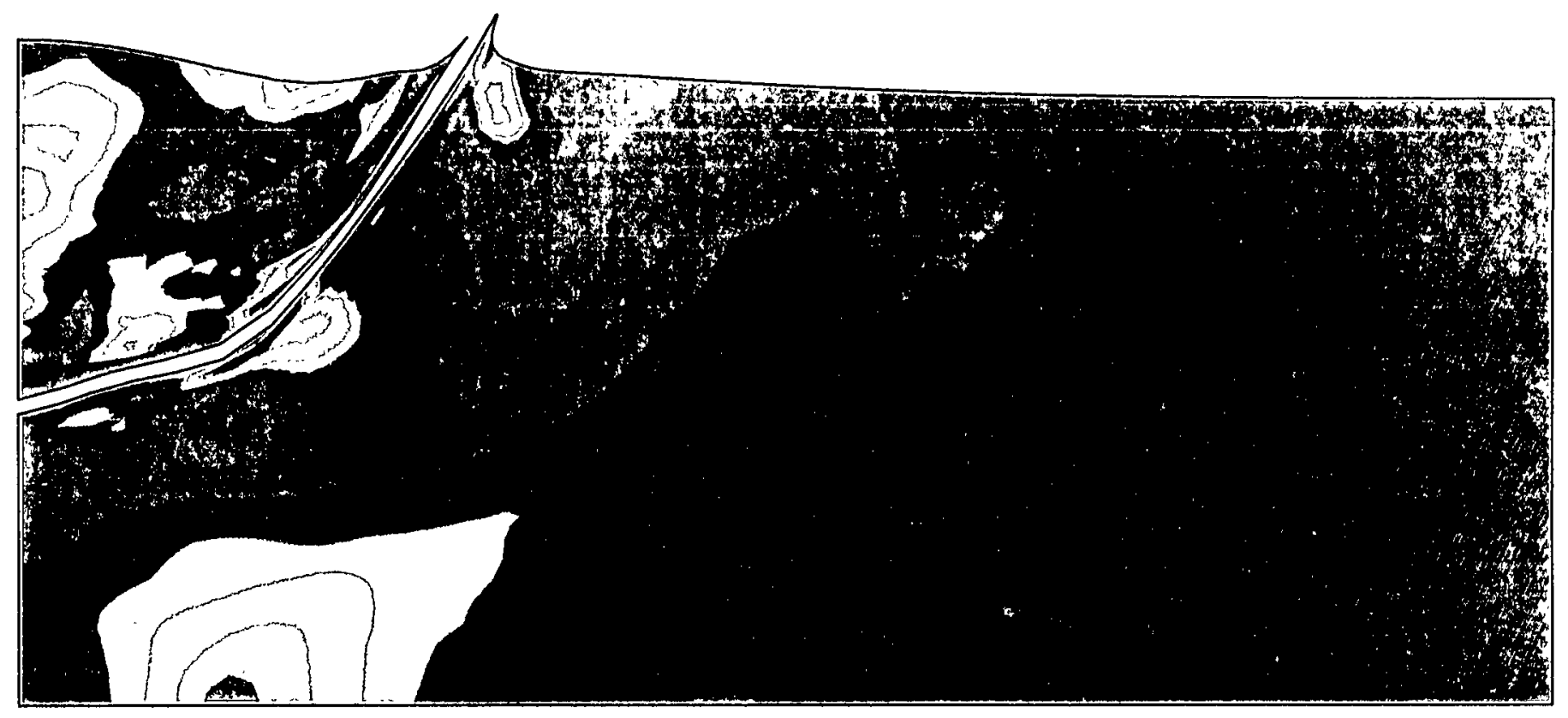

DISPLACEMENT MAGNIFICATION FACTOR $=1.00$

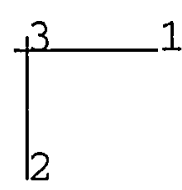

RESTART FILE = 1particle STEP 2 INCREMENT 20848

TIME COMPLETED IN THIS STEP 4.000E-07 TOTAL ACCUMULATED TIME 5.000E-07

ABAQUS VERSION: $5.8-1$ DATE: $13-$ OCT-2000 TIME: $10: 42: 24$ 

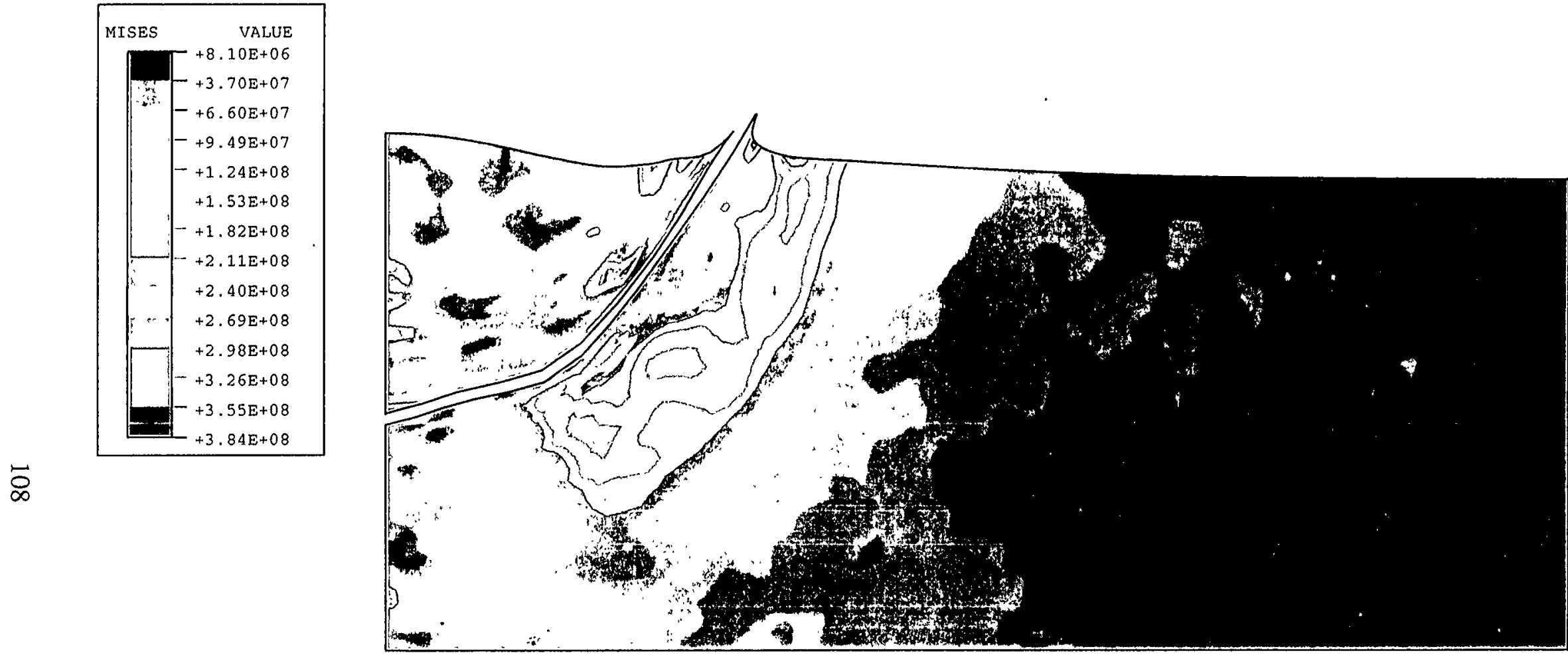

DISPLACEMENT MAGNIFICATION FACTOR $=1.00$

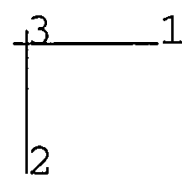

RESTART FILE = 1particle STEP 2 INCREMENT 20848

TIME COMPLETED IN THIS STEP 4.000E-07 TOTAL ACCUMULATED TIME 5.000E-07

ABAQUS VERSION: 5.8-1 DATE: 13-OCT-2000 TIME: $10: 42: 24$ 


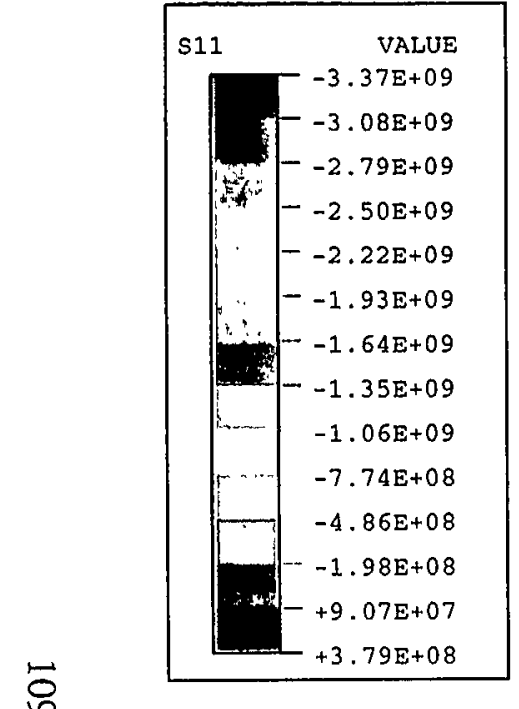

8

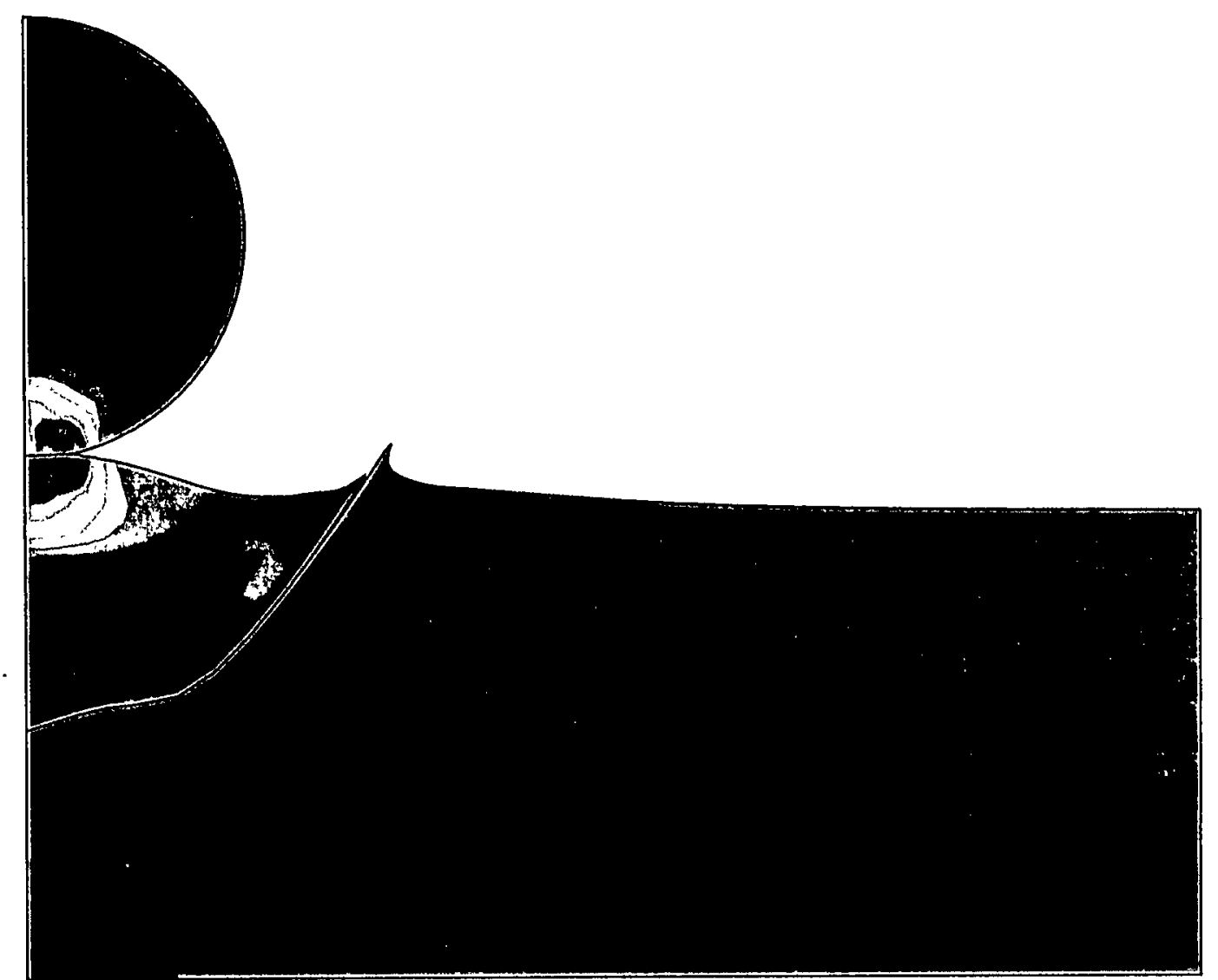

DISPLACEMENT MAGNIFICATION FACTOR $=1.00$

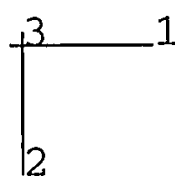

1 RESTART FILE = 2particle STEP 1 INCREMENT 2351

TIME COMPLETED IN THIS STEP 1.000E-07 TOTAL ACCUMULATED TIME 1.000E-07 ABAQUS VERSION: 5.8-1 DATE: 13 -OCT-2000 TIME: 11:00:47 


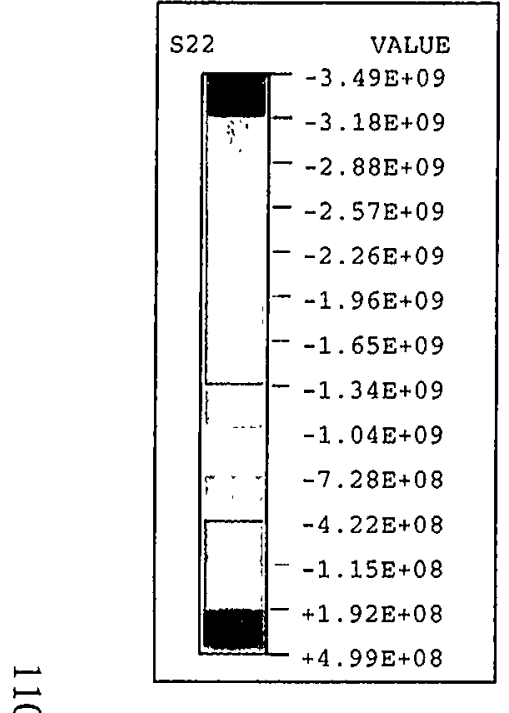

5

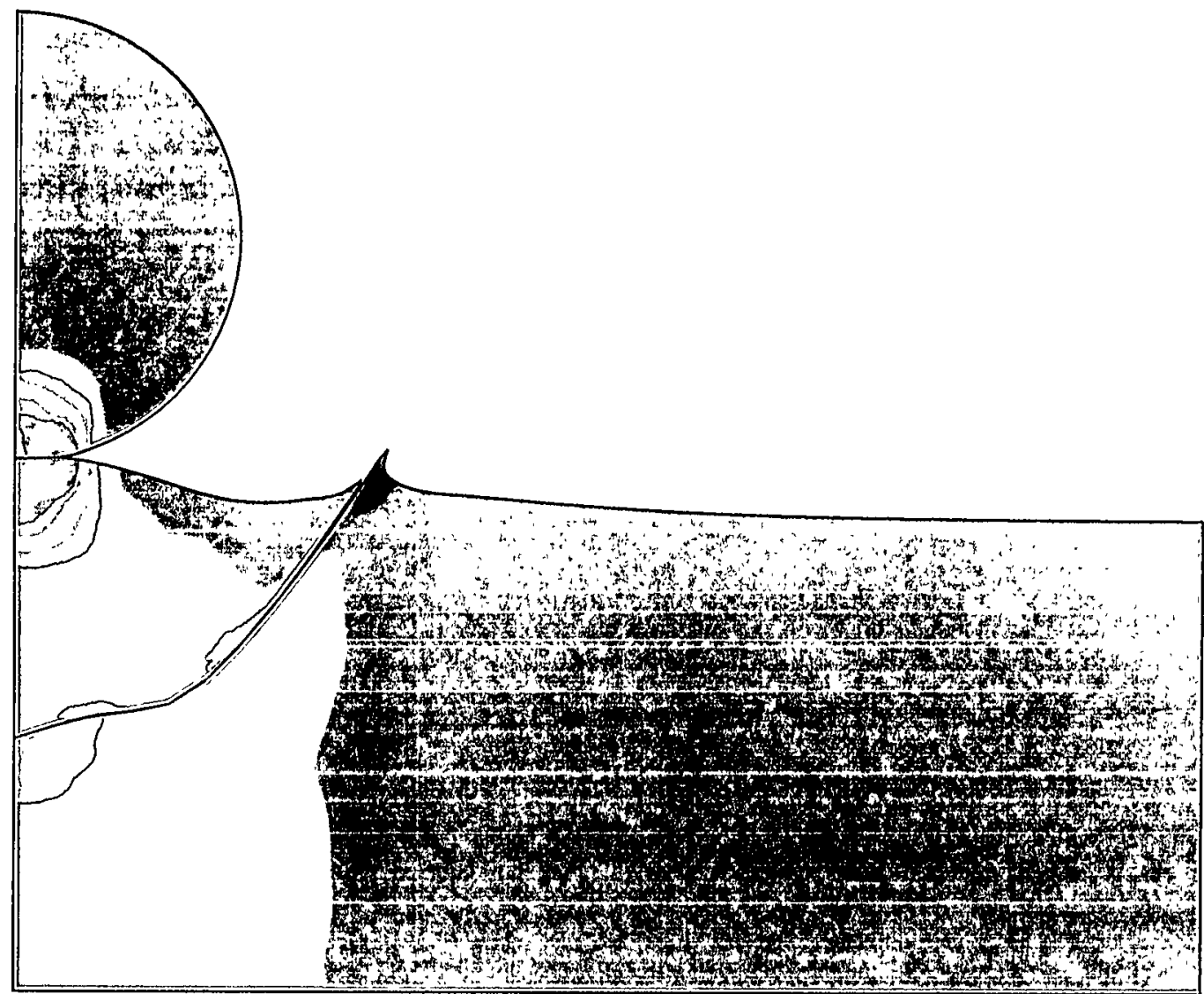

DISPLACEMENT MAGNIFICATION FACTOR $=1.00$

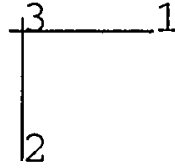

RESTART FILE = 2particle STEP 1 INCREMENT 2351

TIME COMPLETED IN THIS STEP 1.000E-07 TOTAL ACCUMULATED TIME 1.000E-07 ABAQUS VERSION: 5.8-1 DATE: 13-OCT-2000 TIME: 11:00:47 


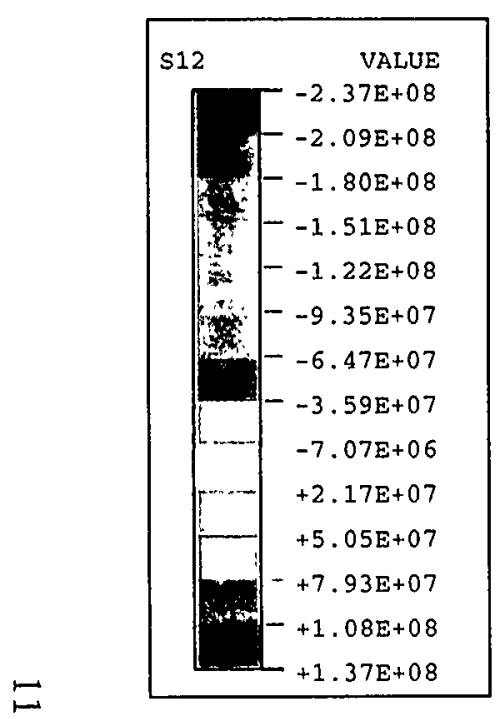

ほ

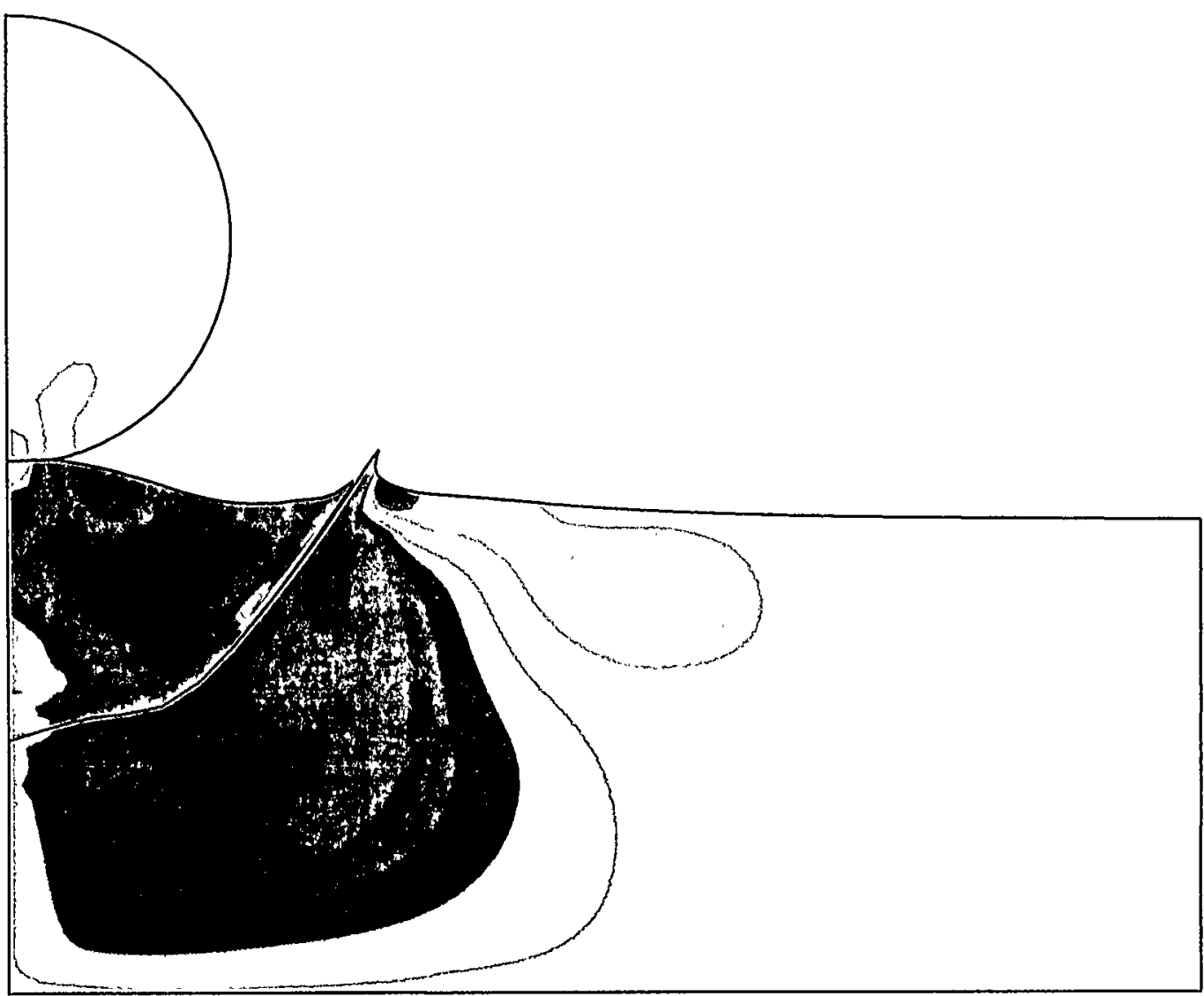

DISPLACEMENT MAGNIFICATION FACTOR $=1.00$

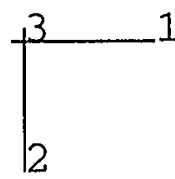

RESTART FILE = 2particle STEP 1 INCREMENT 2351

TIME COMPLETED IN THIS STEP 1.000E-07 TOTAL ACCUMULATED TIME 1.000E-07 ABAQUS VERSION: $5.8-1$ DATE: $13-$ OCT-2000 TIME: $11: 00: 47$ 


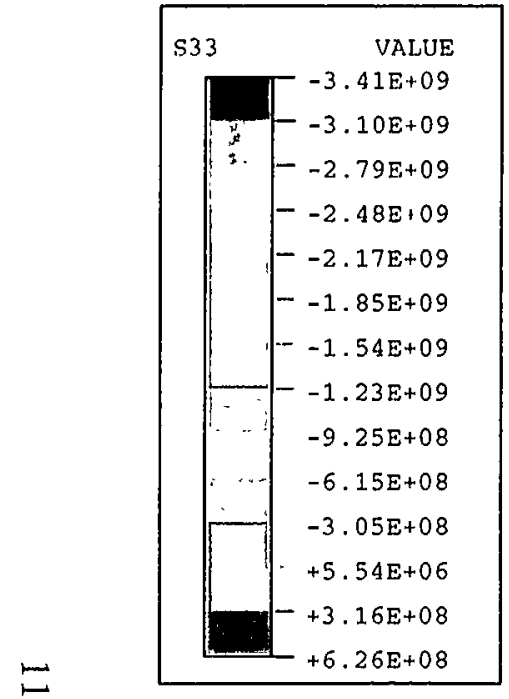

卡

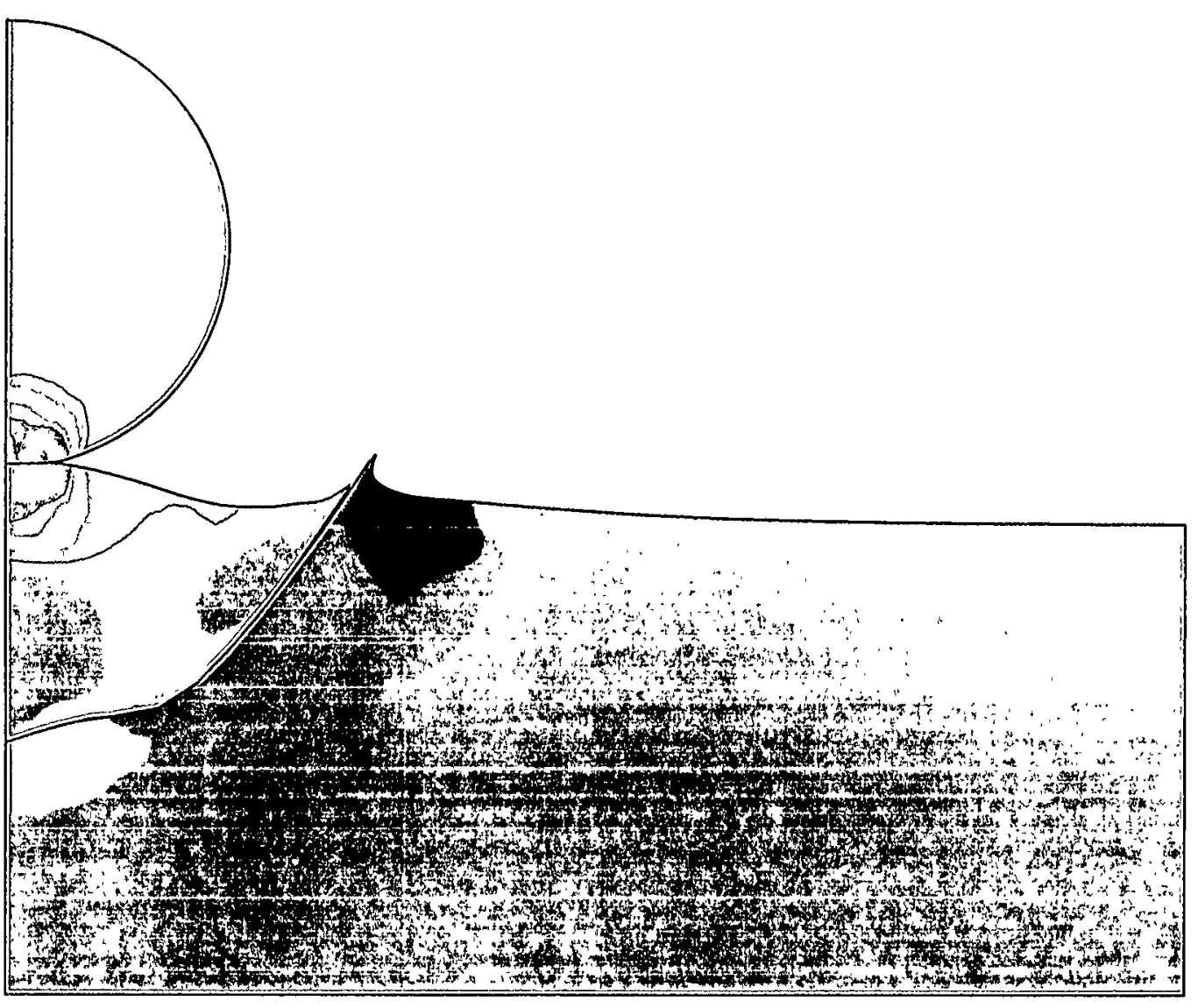

DISPLACEMENT MAGNIFICATION FACTOR $=1.00$

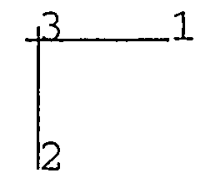

RESTART FILE = 2particle

STEP 1 INCREMENT 2351

TIME COMPLETED IN THIS STEP 1.000E-07 TOTAL ACCUMULATED TIME

$1.000 E-07$

DATE: $13-O C T-2000$ TIME: $11: 00: 47$ 


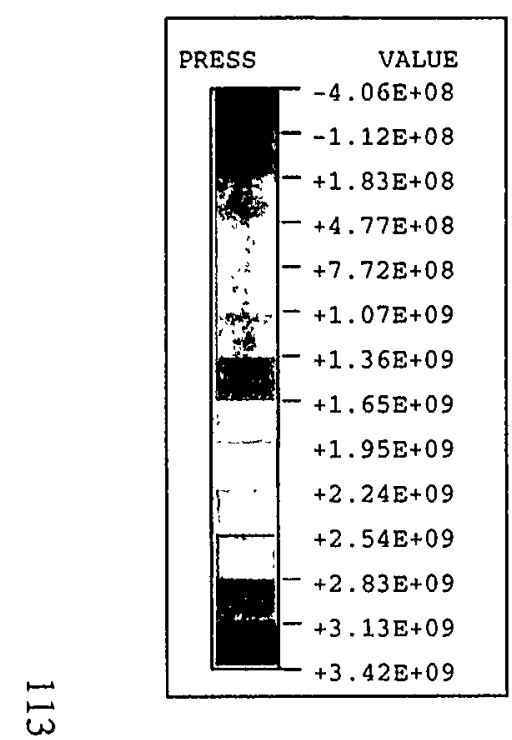

RESTART FILE = 2particle STEP 1 INCREMENT 2351

TIME COMPLETED IN THIS STEP 1.000E-07 TOTAL ACCUMULATED TIME $1.000 \mathrm{E}-07$ ABAQUS VERSION: 5.8-1 DATE: 13-OCT-2000 TIME: $11: 00: 47$ 

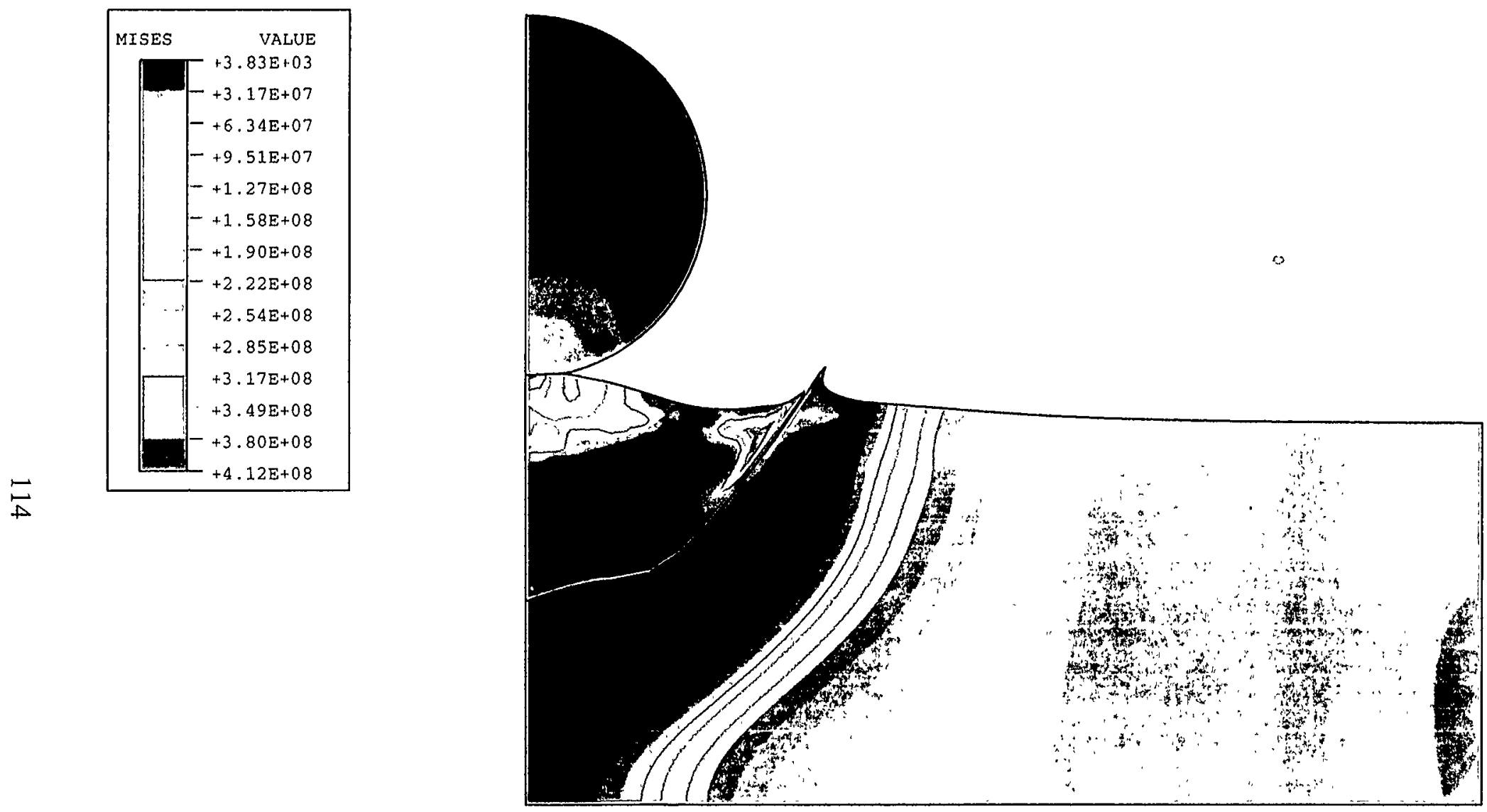

DISPLACEMENT MAGNIFICATION FACTOR $=1.00$

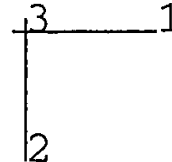

RESTART FILE = 2particle STEP 1 INCREMENT 2351

TIME COMPLETED IN THIS STEP 1.000E-07 TOTAL ACCUMULATED TIME 1.000E-07 ABAQUS VERSION: 5.8-1 DATE: 13-OCT-2000 TIME: 11:00:47 


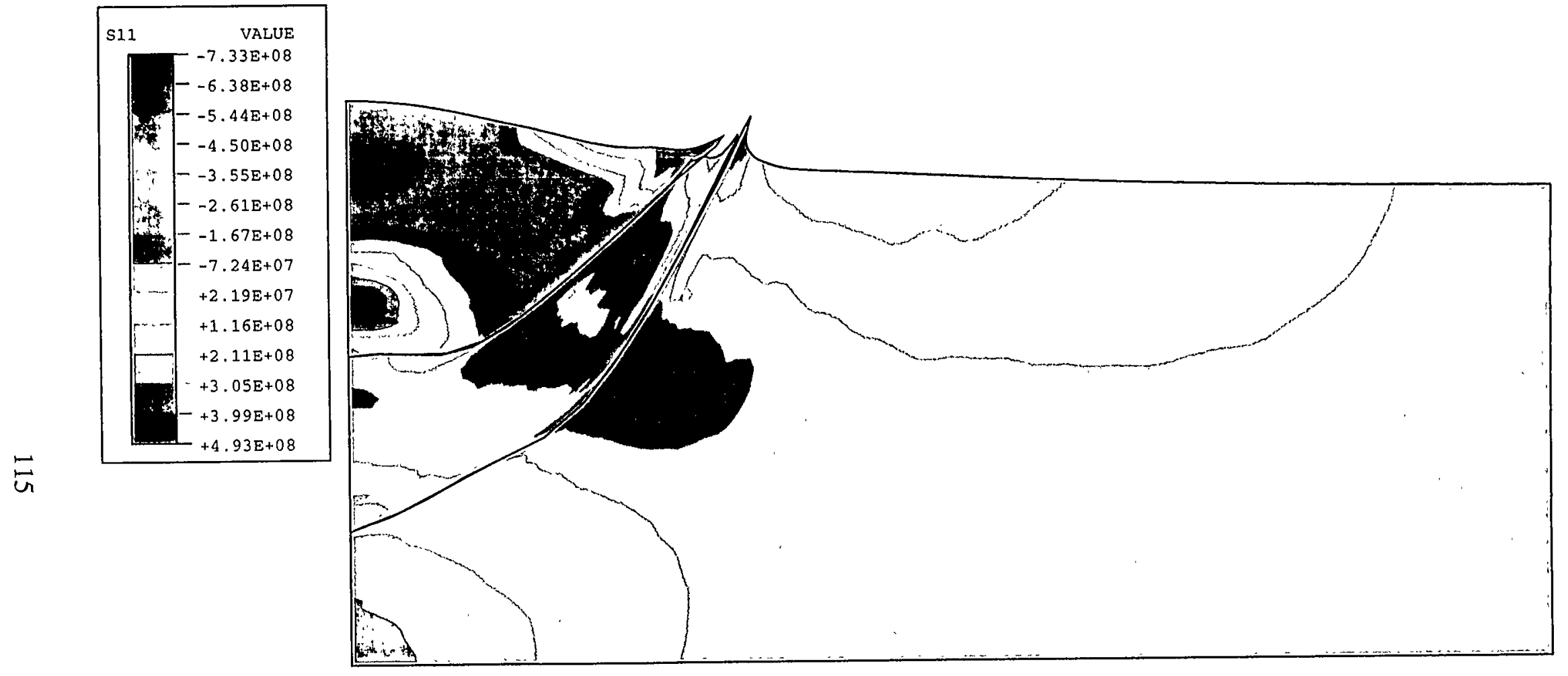

DISPLACEMENT MAGNIFICATION FACTOR $=1.00$

311 RESTART FILE $=2$ particle STEP 1 INCREMENT 7830
TIME COMPLETED IN THIS STEP $2.000 E-07$ TOTAL ACCUMULATED TIME $2.000 E-07$
ABAQUS VERSION: $5.8-1 \quad$ DATE: $13-$ OCT-2000 TIME: $11: 00: 47$




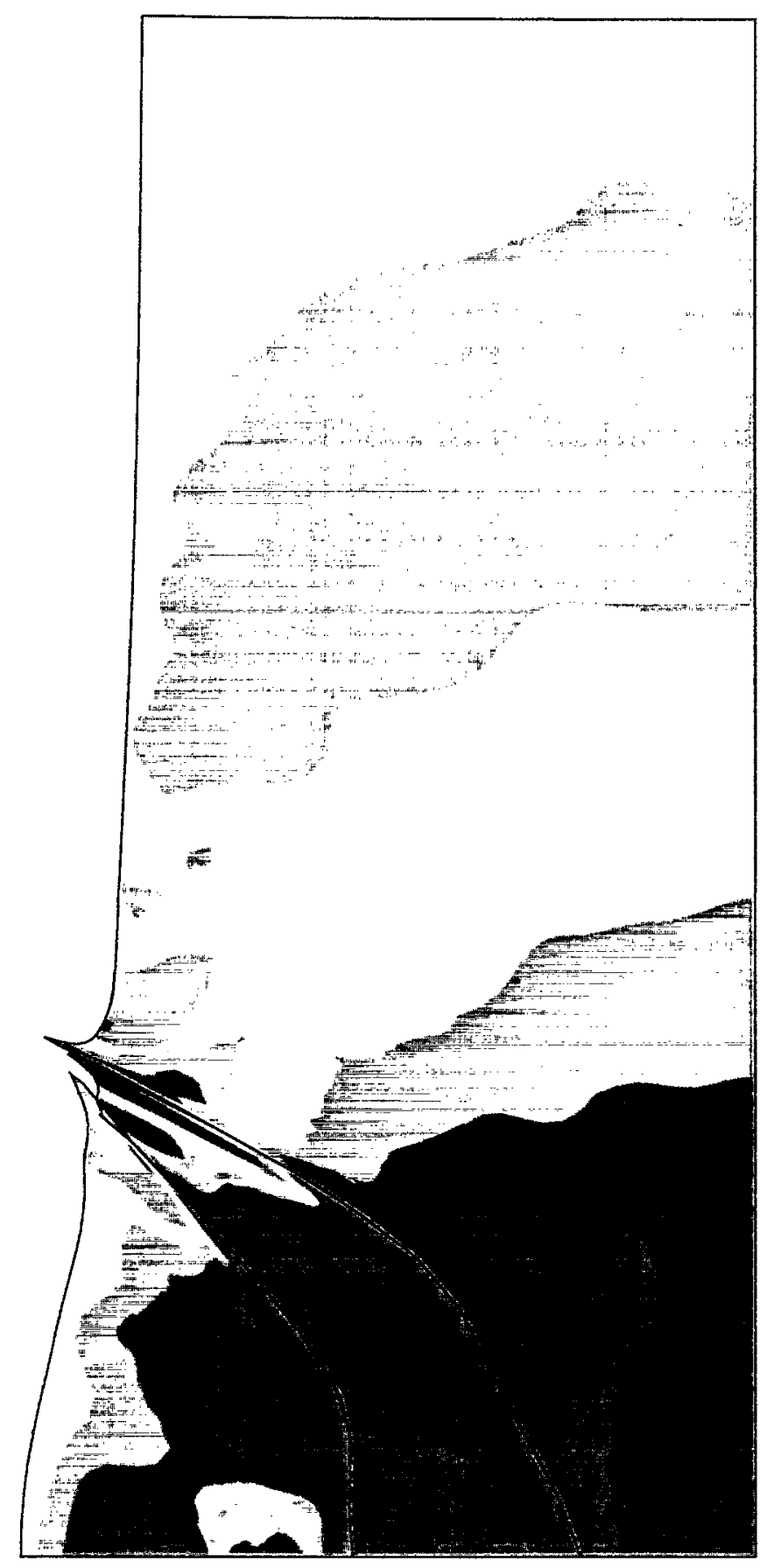

$r$
0
1
1
0
0
0
$\dot{0}$
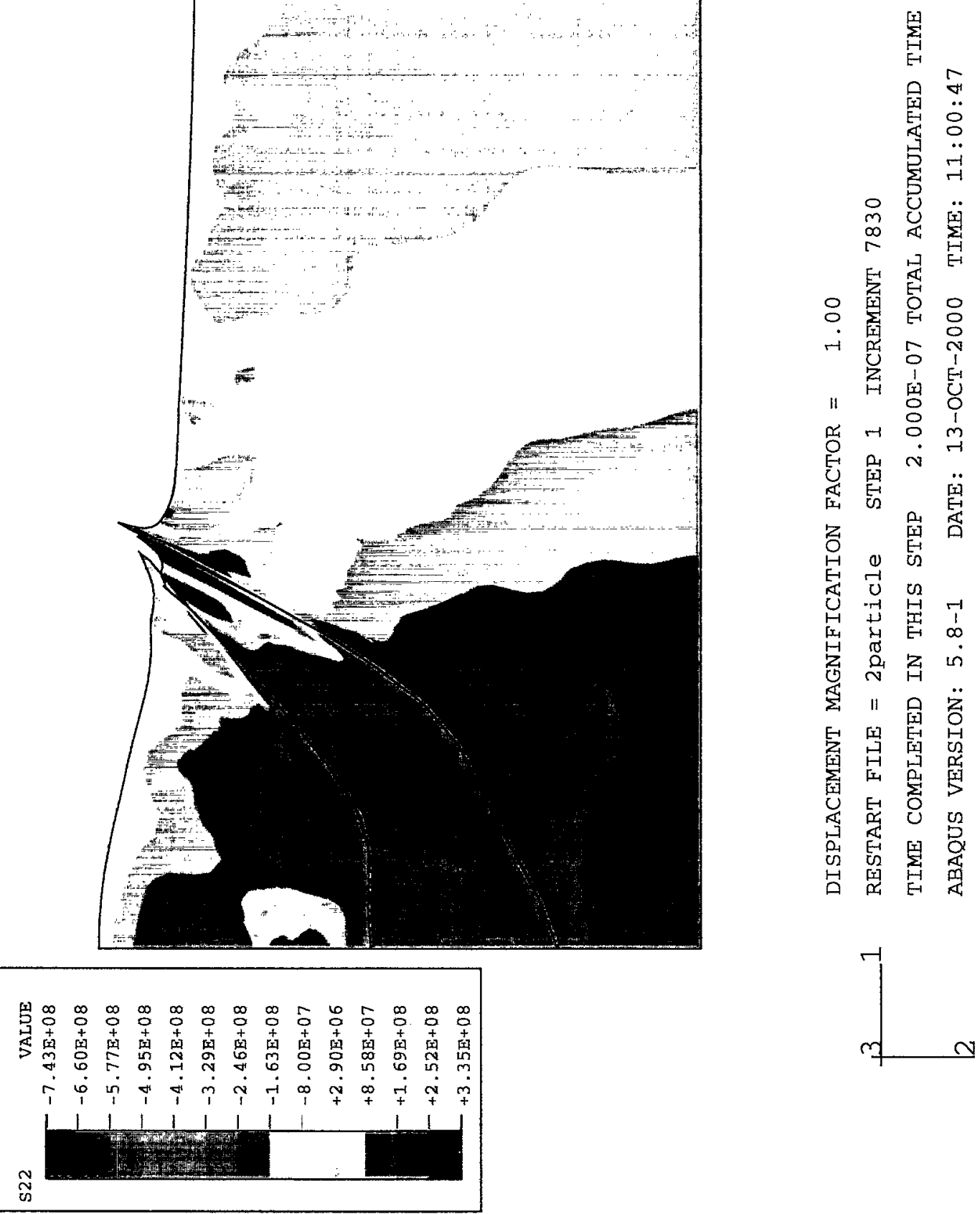

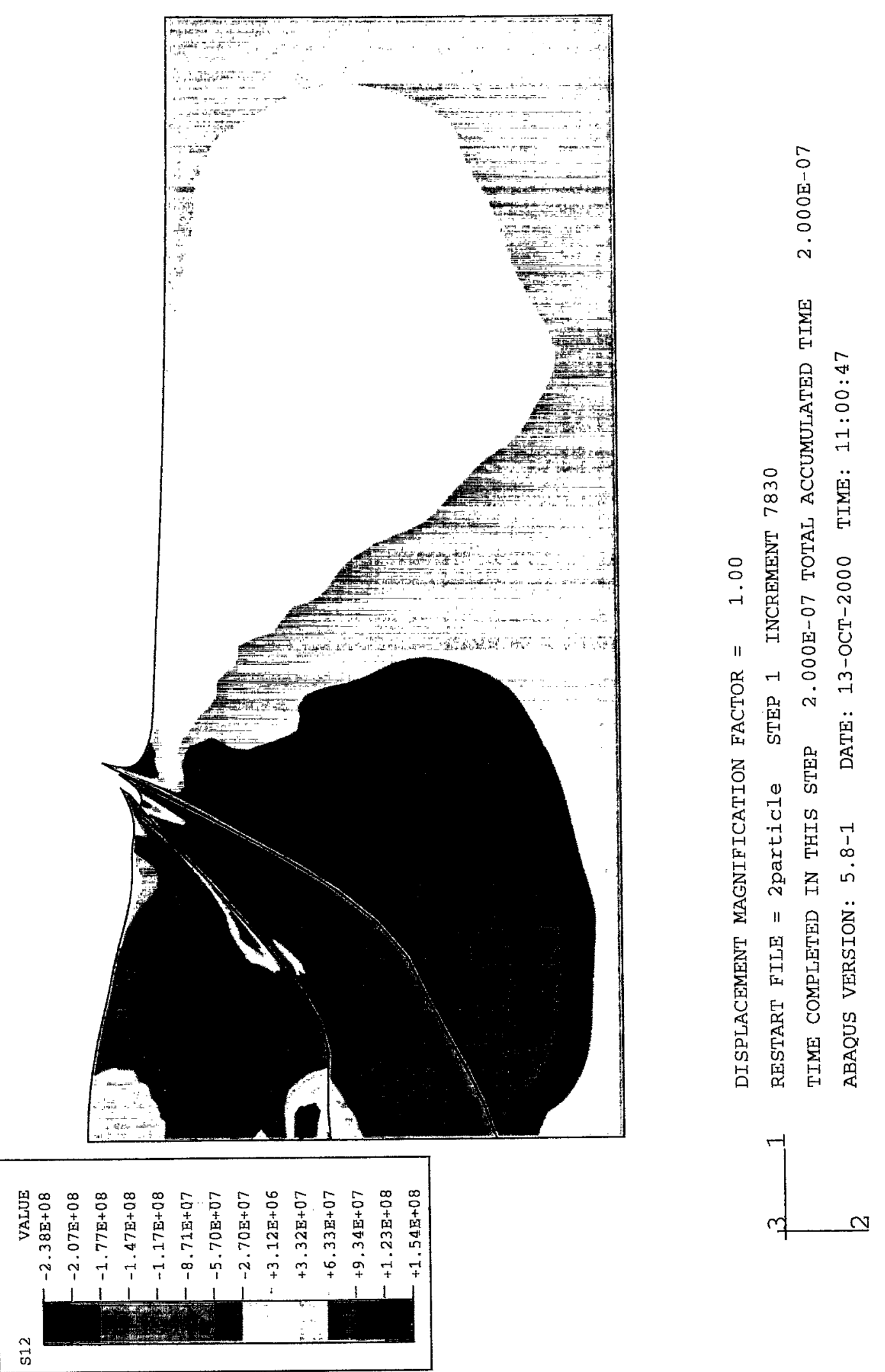


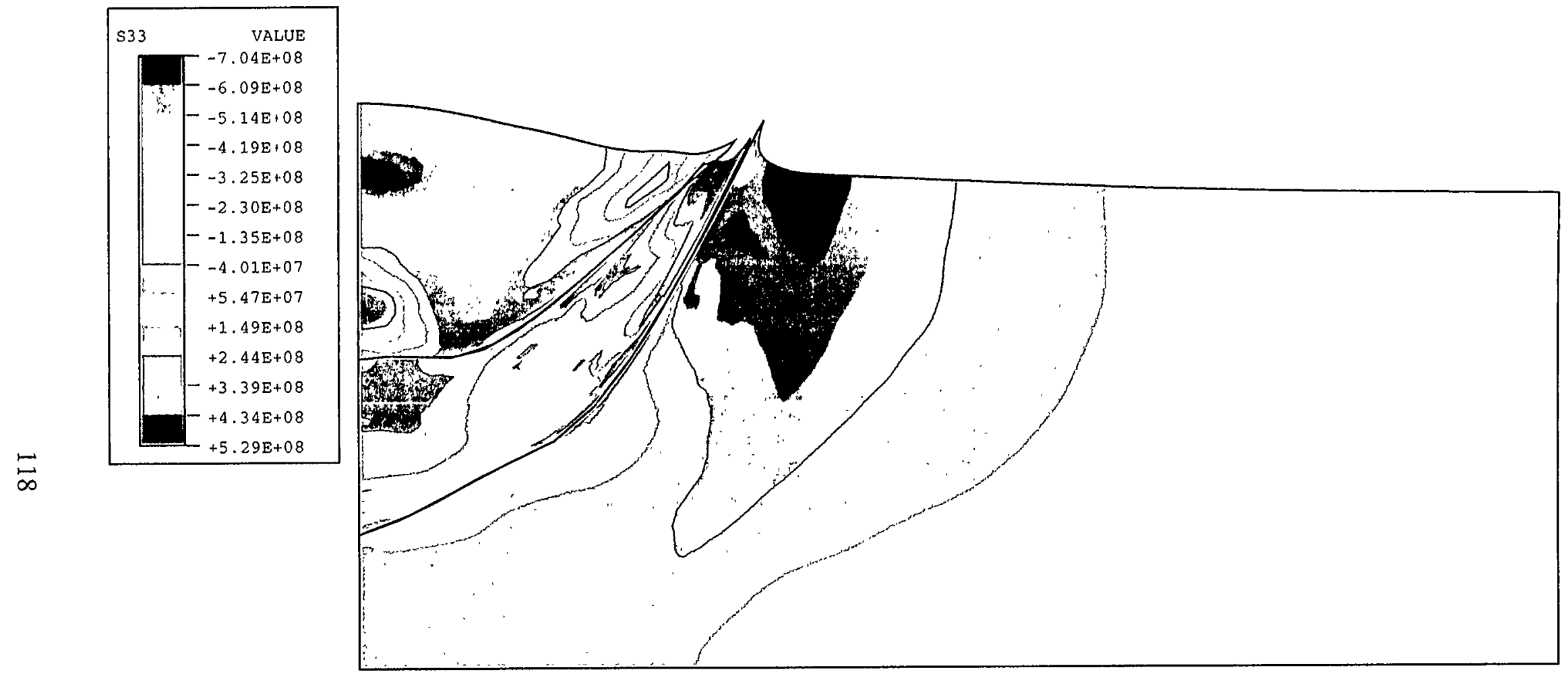

DISPLACEMENT MAGNIFICATION FACTOR $=1.00$

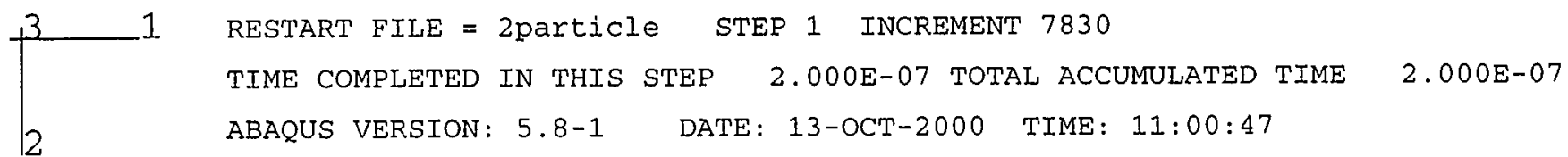



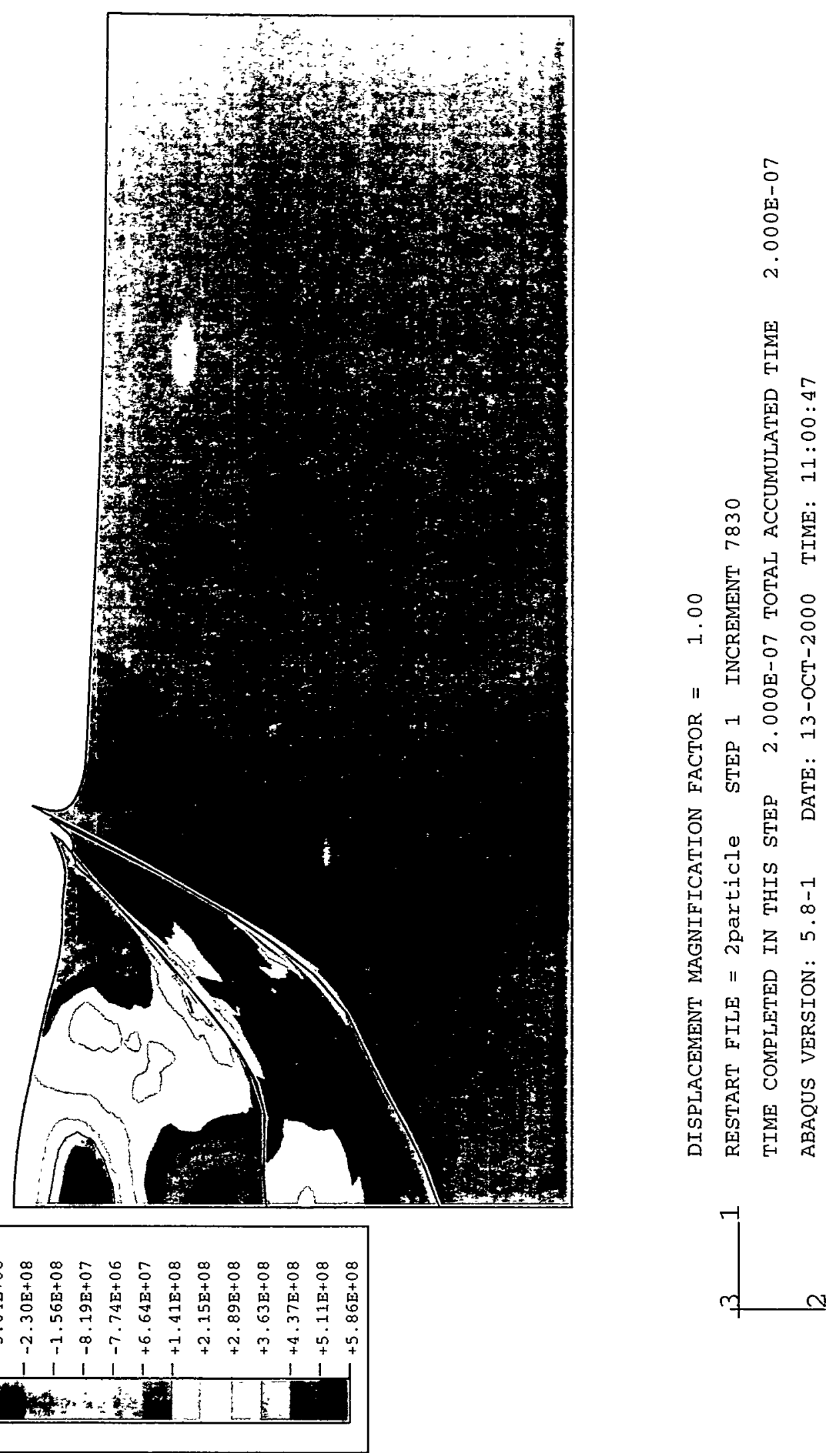


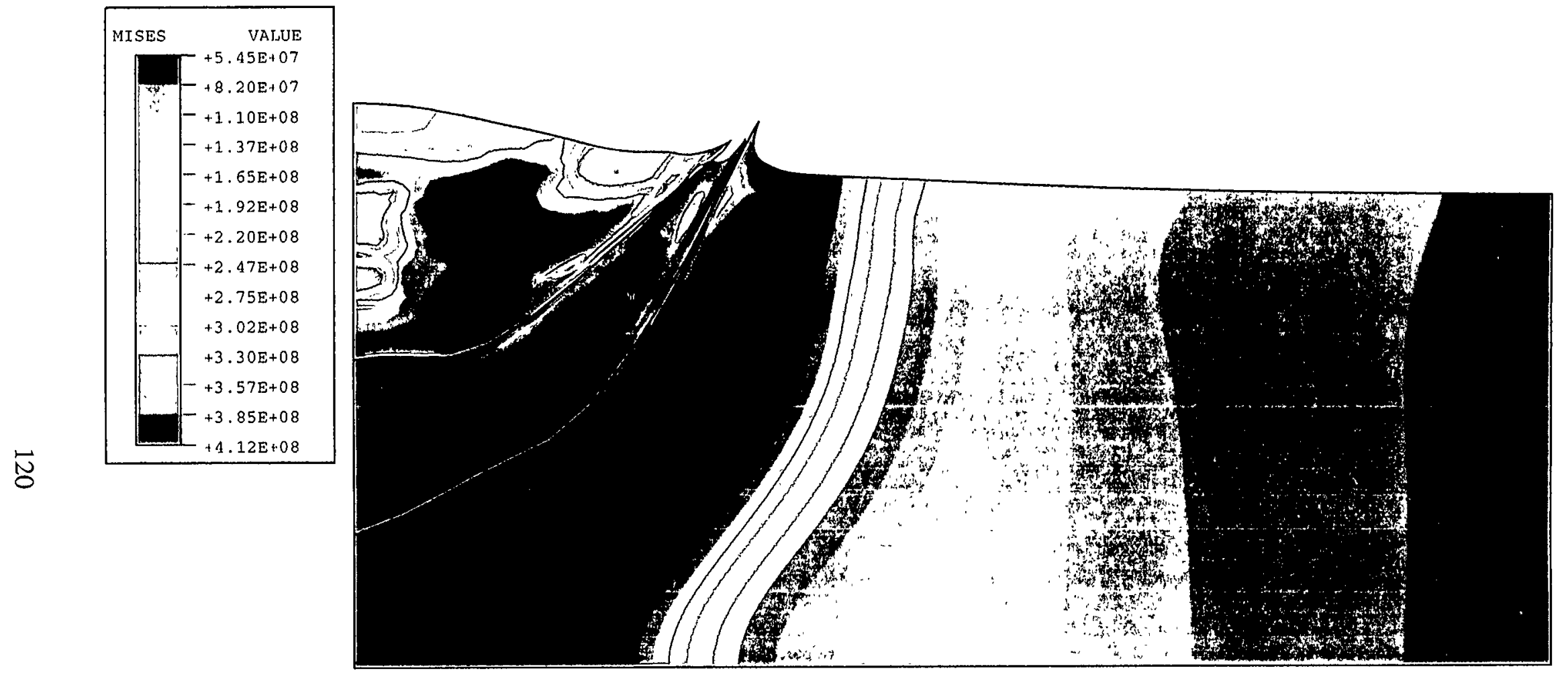

DISPLACEMENT MAGNIFICATION FACTOR $=1.00$

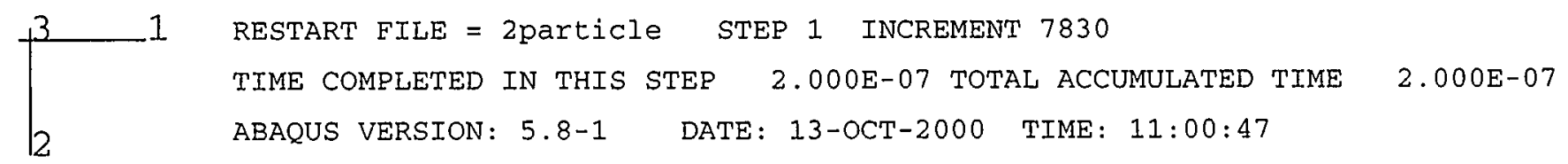




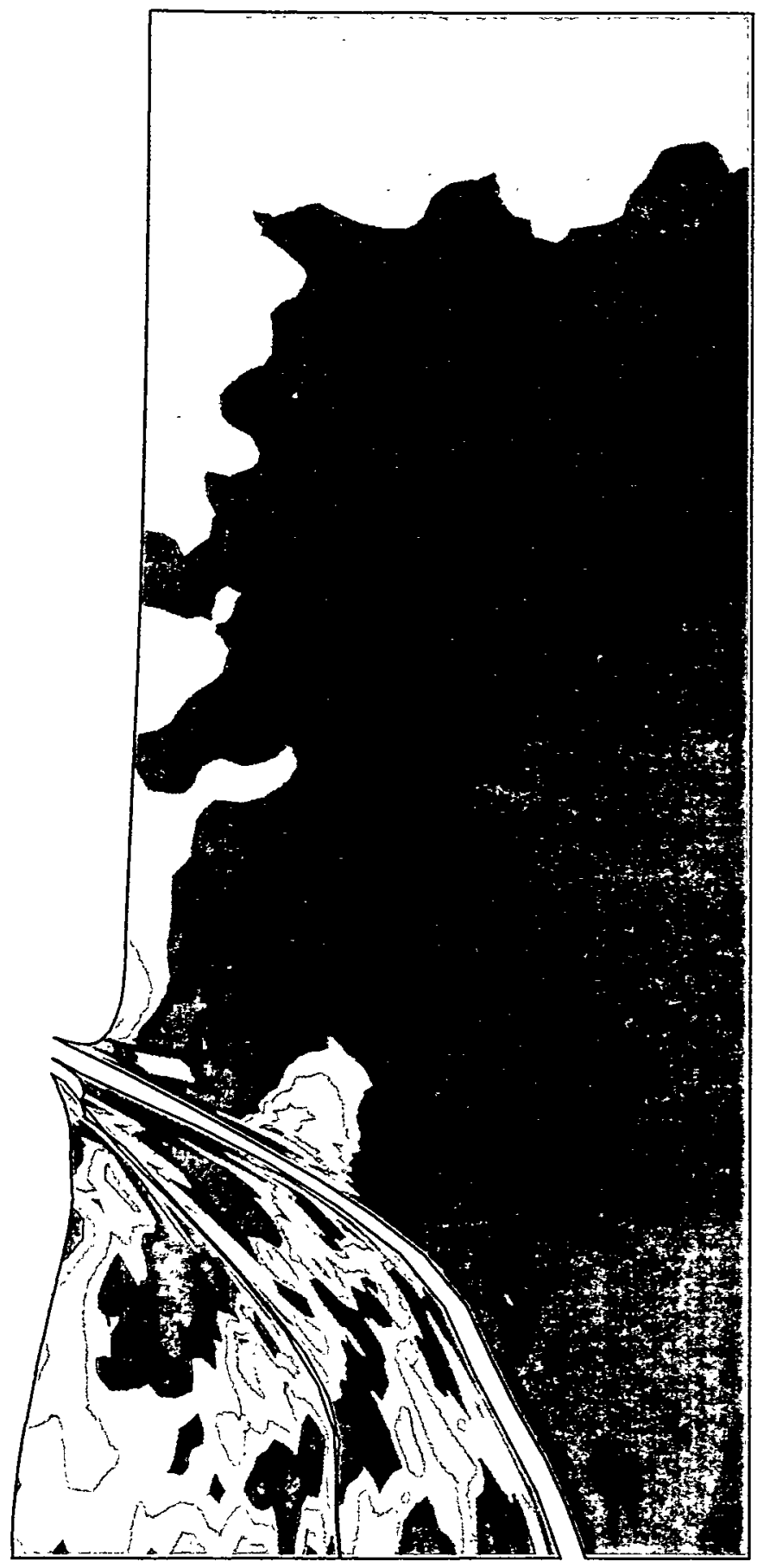

5
0
1
1
0
0
0
0
10

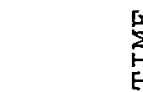

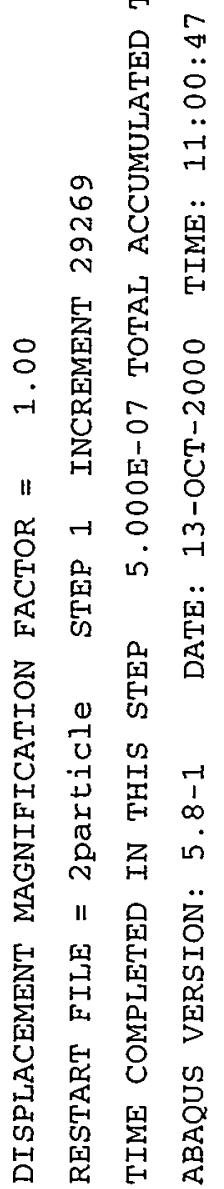
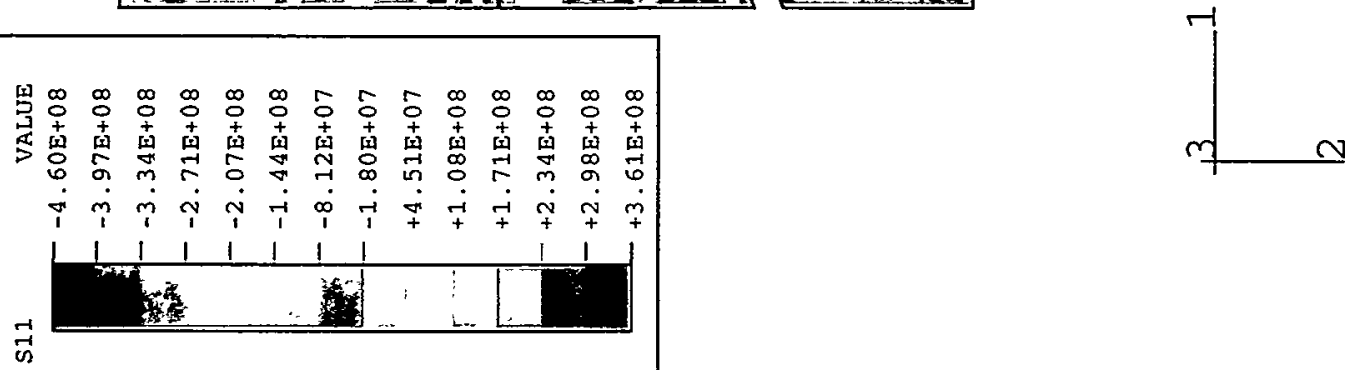


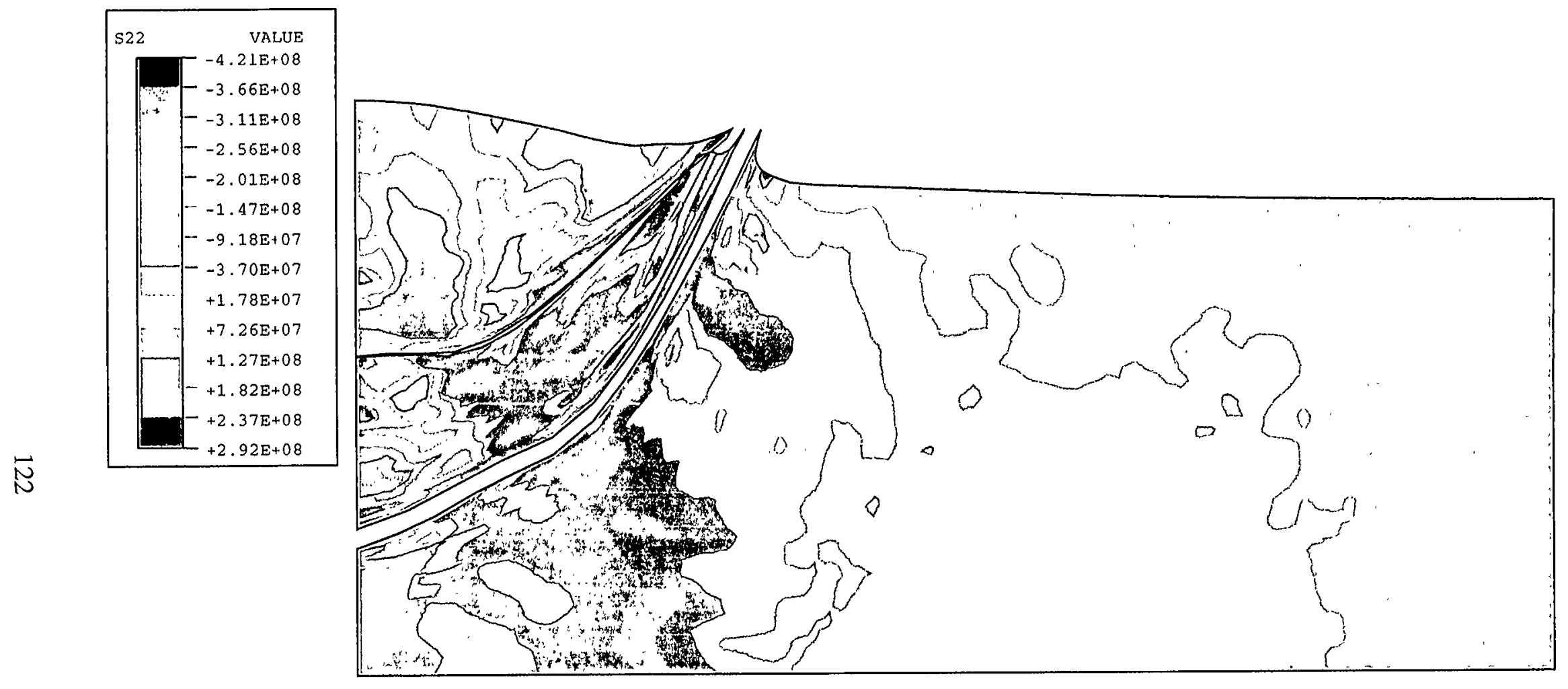

DISPLACEMENT MAGNIFICATION FACTOR $=1.00$

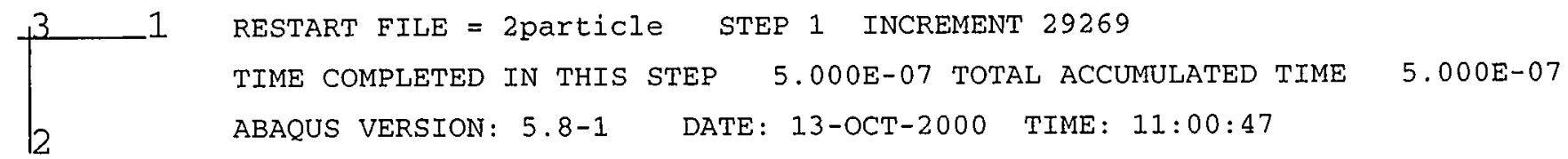



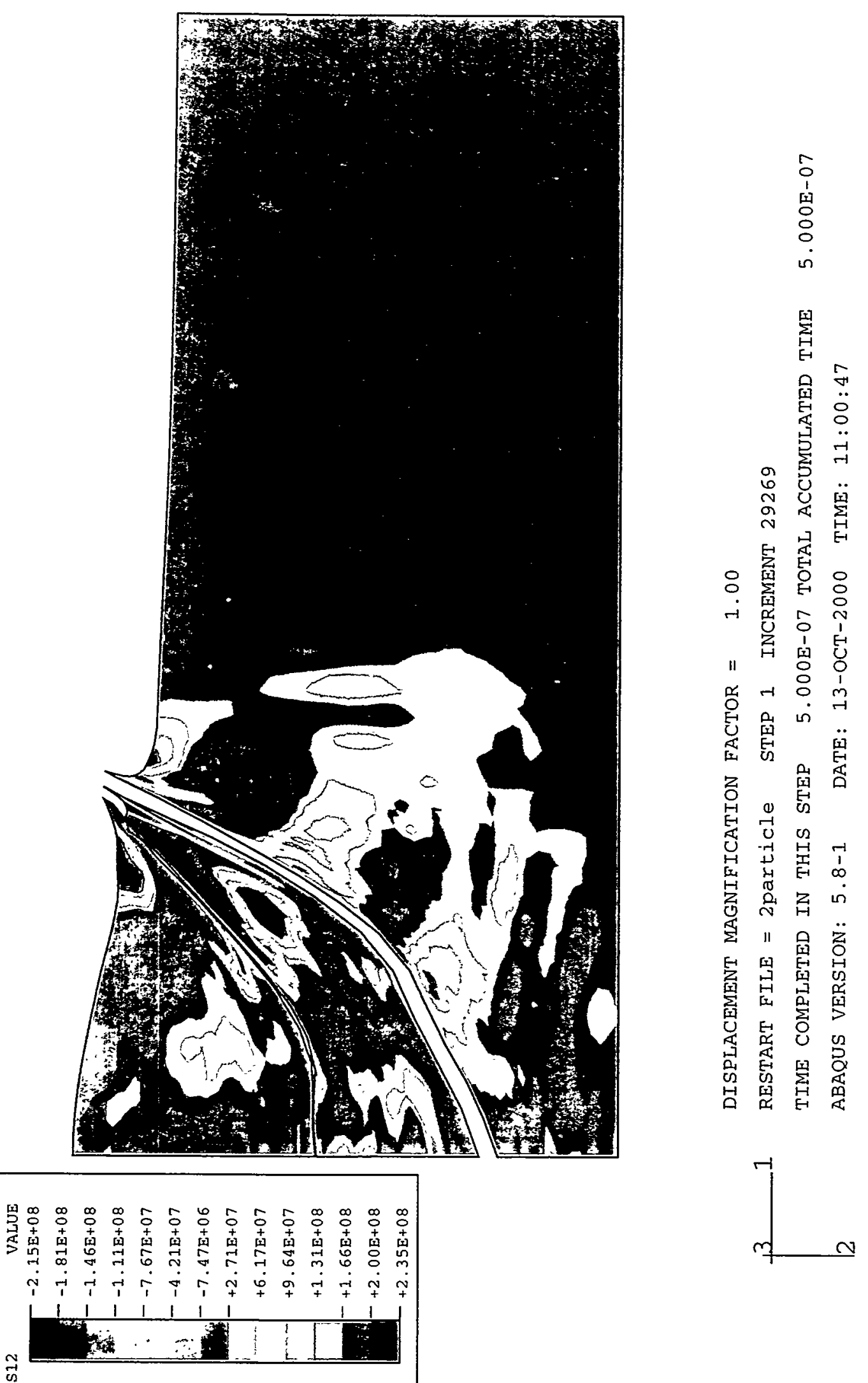

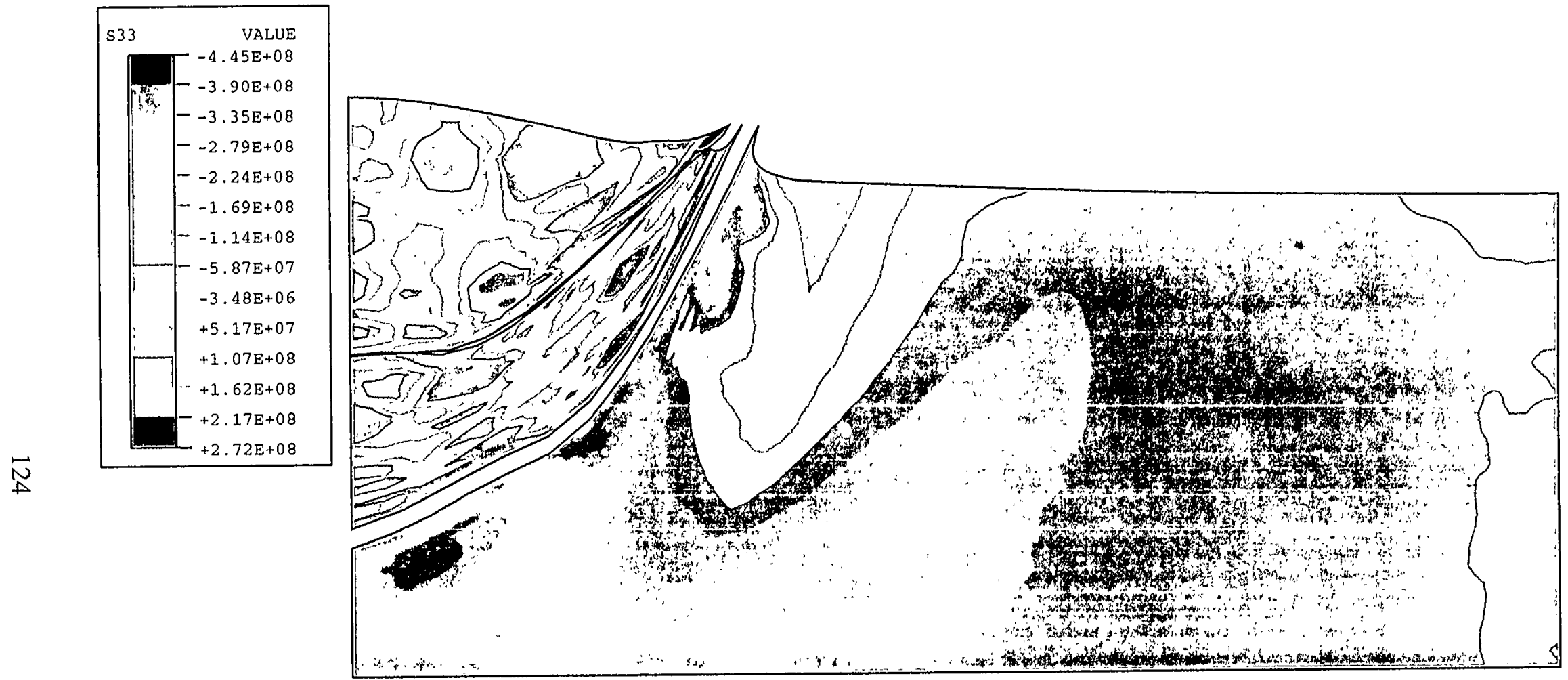

DISPLACEMENT MAGNIFICATION FACTOR $=1.00$

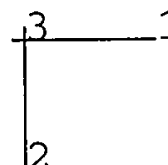

RESTART FILE = 2particle STEP 1 INCREMENT 29269

TIME COMPLETED IN THIS STEP 5.000E-07 TOTAL ACCUMULATED TIME 5.000E-07

ABAQUS VERSION: $5.8-1$ DATE: 13 -OCT-2000 TIME: $11: 00: 47$ 


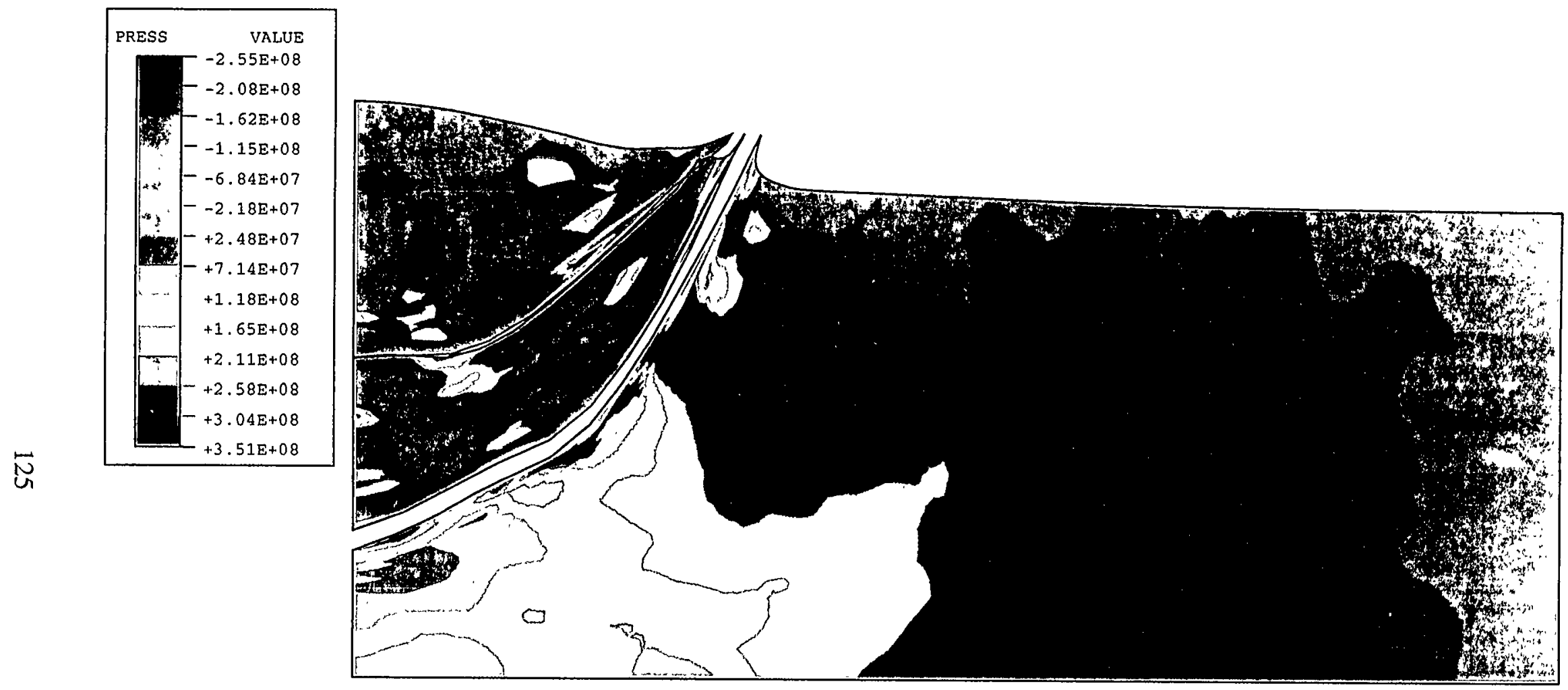

DISPLACEMENT MAGNIFICATION FACTOR $=1.00$

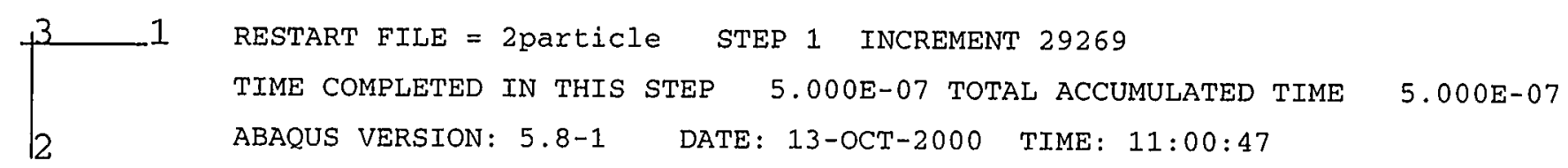




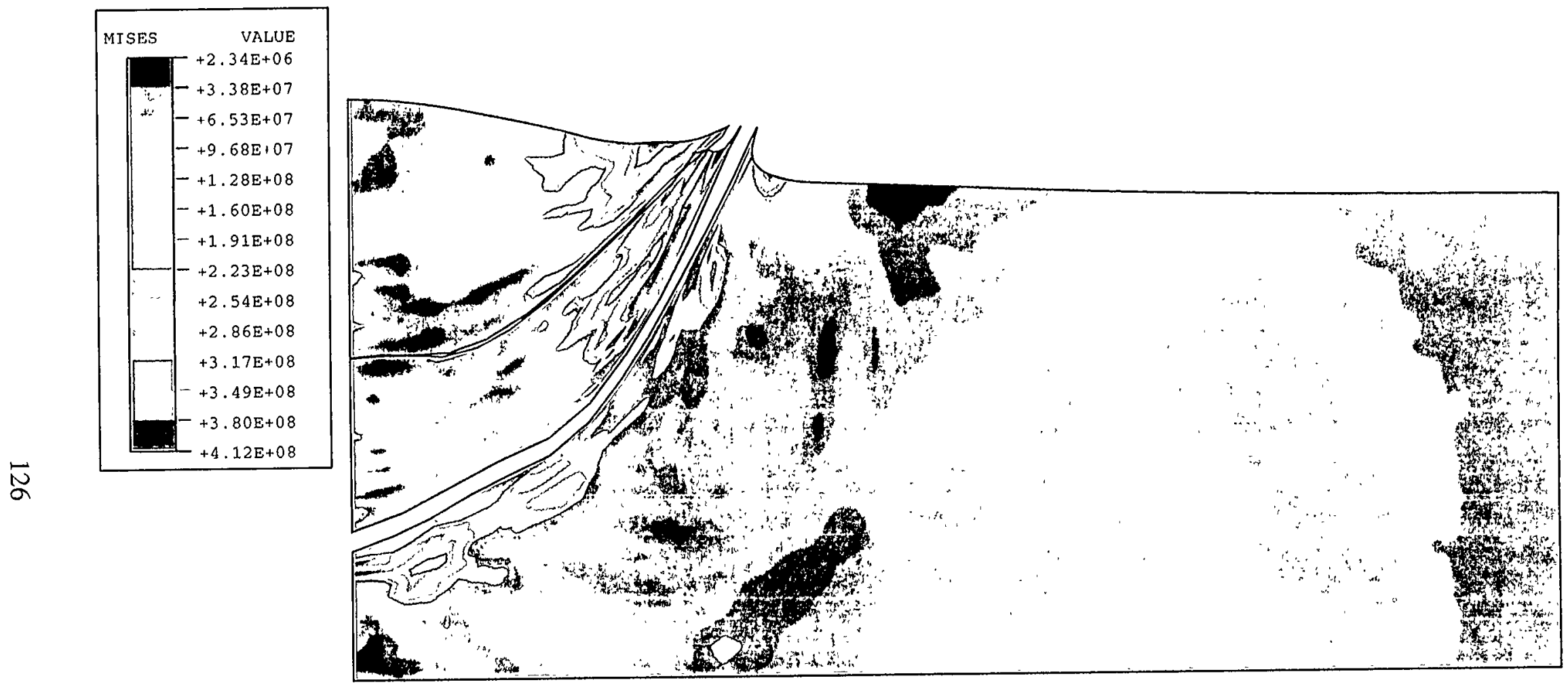

DISPLACEMENT MAGNIFICATION FACTOR $=1.00$

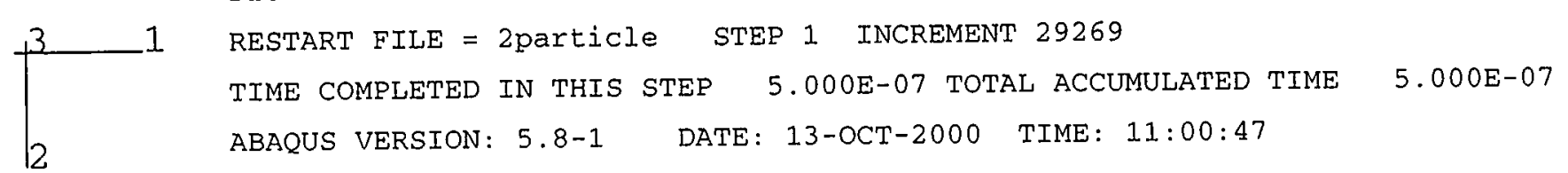




\subsection{Distribution}

$\begin{array}{lll}1 & \text { MS 0319 } & \text { C.W. Vanecek, 2613 } \\ 1 & \text { MS 0328 } & \text { W.C. Curtis II, 2612 } \\ 1 & \text { MS 0329 } & \text { E.J. Garcia, 2614 } \\ 1 & \text { MS 0329 } & \text { L.L. Lukens, 2614 } \\ 1 & \text { MS 0329 } & \text { M.A. Polosky, 2614 } \\ 5 & \text { MS 0481 } & \text { M.D. Decker, 2131 } \\ 1 & \text { MS 0481 } & \text { K.D. Meeks, 2131 } \\ 1 & \text { MS 0603 } & \text { T.R. Christenson, 1743 } \\ 1 & \text { MS 0835 } & \text { S.N. Kempka, 9111 } \\ 1 & \text { MS 0819 } & \text { M.A. Christon, 9231 } \\ 1 & \text { MS 0889 } & \text { T.E. Buchheit, 1835 } \\ 1 & \text { MS 0889 } & \text { M.F. Hosking, 1833 } \\ 1 & \text { MS 0889 } & \text { D.T. Schmale, 1835 } \\ 10 & \text { MS 0889 } & \text { M.F. Smith, 1833 } \\ 1 & \text { MS 1078 } & \text { D.W. Plummer, 1703 } \\ 1 & \text { MS 1130 } & \text { R.A. Neiser, Jr., 1833 } \\ 1 & \text { MS 1130 } & \text { J.D. Puskar, 1833 } \\ 1 & \text { MS 1130 } & \text { T.J. Roemer, 1833 } \\ 1 & \text { MS 9401 } & \text { C.C. Henderson, 8729 } \\ 1 & \text { MS 9401 } & \text { J.M. Hruby, 8702 } \\ & & \\ 1 & \text { MS 9018 } & \text { Central Technical Files, 8945-1 } \\ 2 & \text { MS 0899 } & \text { Technical Library, 9616 } \\ 1 & \text { MS 0612 } & \text { Review \& Approval Desk, 9612, for DOE/OSTI } \\ 1 & \text { UNM } & \text { H.D. Tran, ME } \\ 1 & \text { UNM } & \text { Y.L. Shen, ME } \\ 1 & \text { UNM } & \text { J.E. Wood, ME }\end{array}$

